


\section{GIFT OF}

Thos. H. Mieans
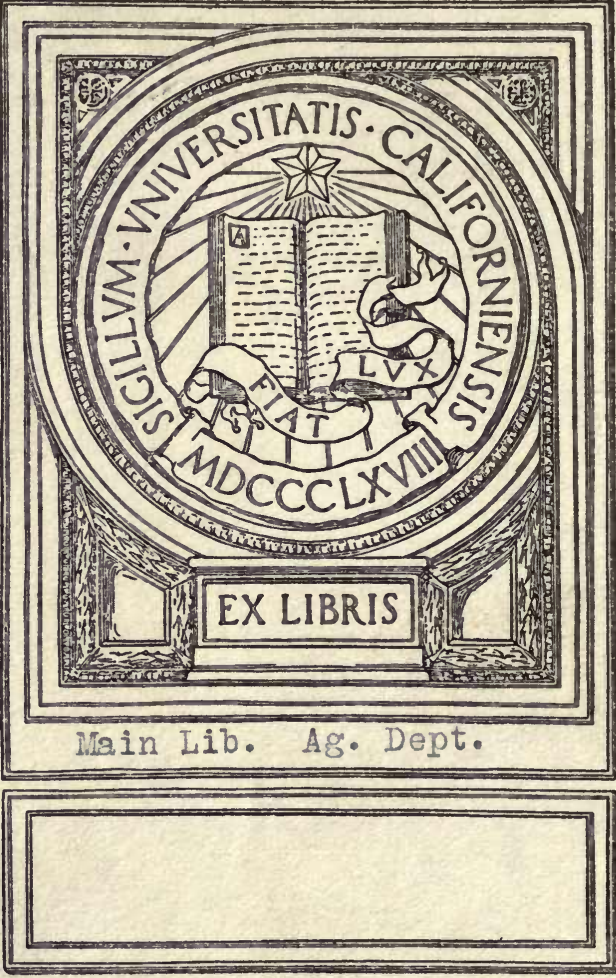


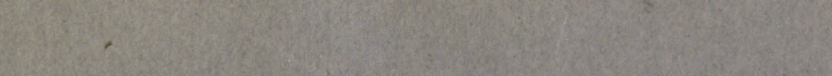
6. (2) 


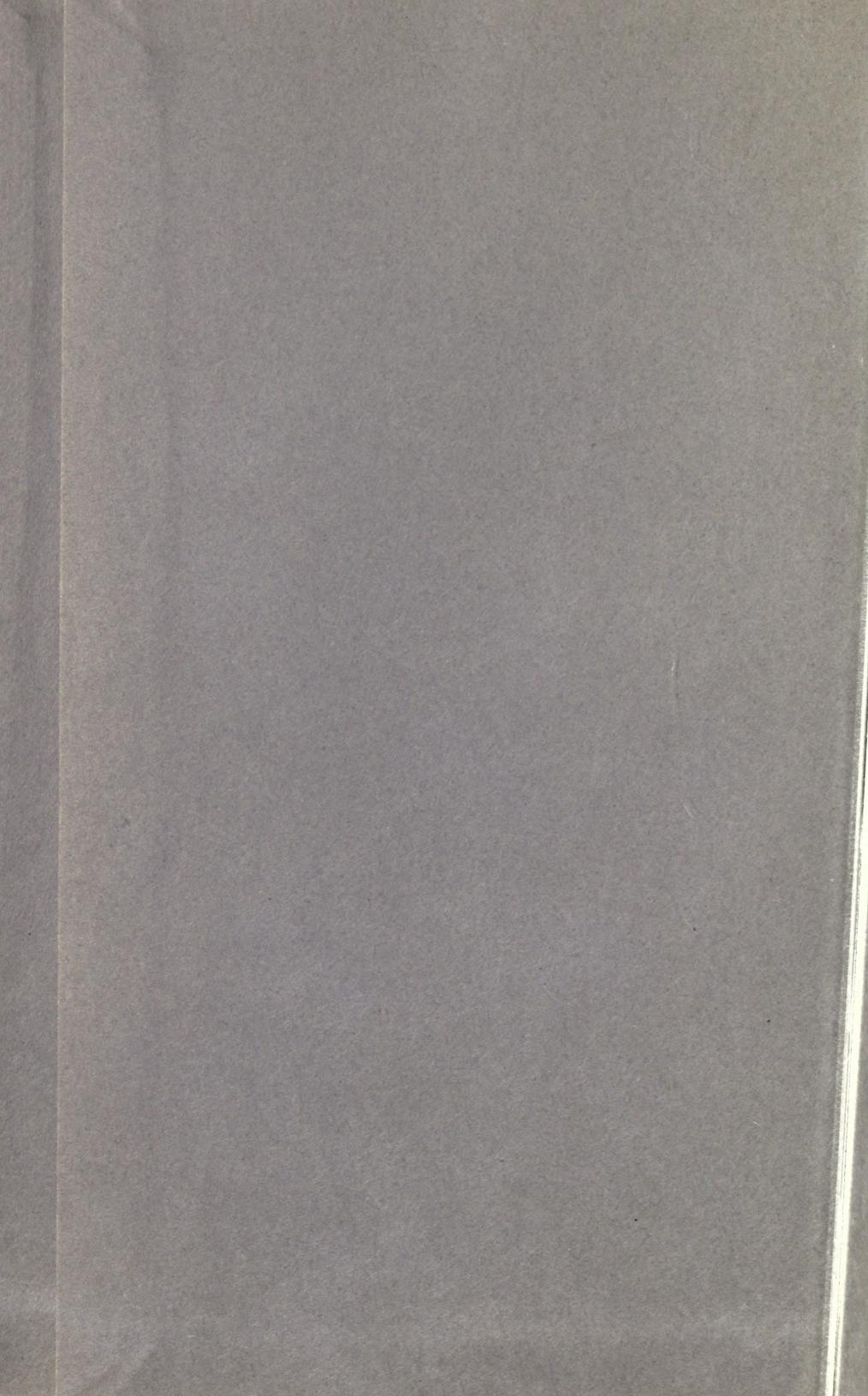





\section{A TEXT-BOOK}

OF

TROPICAL AGRICULTURE 



\section{- A T.EXT-BOOK}

OF

\section{.TROPICAL AGRICULTURE.}

BY

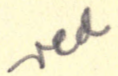

H. A. ALFORD NICHOLLS, M.D., F.L.S., C.M.Z.S.

CORRESPONDING MEMBER OF THE NEW YORK ACADEMY OF SCIENCES, AND OF THE CHAMBER OF AGRICULTURE OF BASSETERRE, GUADELOUPE; HONORARY MEMBER OF THE ROYAL AGRICULTURAL AND COMMERCIAL SOCIETY OF BRITISH GUIANA, AND OF THE CENTRAI. AGRICULTURAL BOARD OF TRINIDAD

W I TH ILLUSTRATIONS

RESPICE FINEM

\section{Loñon}

MACM ILLA N AND CO., Limited

NEW YORK : THE MACMILLAN COMPANY

I 906 

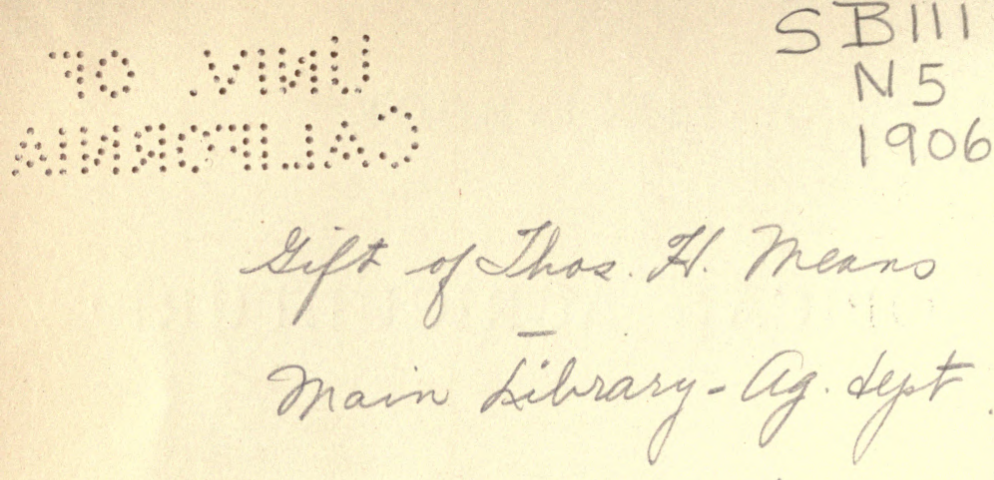

"IF you wish success, make perseverance your bosom friend, experience your wise counsellor, caution your elder brother, and hope your guardian genius."-ADDISON.

"It is both the duty and interest of every Owner and Cultivator of the Soil to study the best means of rendering that soil subservient to his own and the general wants of the community; and he who introduces, beneficially, a new and useful Seed, Plant, or Shrub into his district, is a blessing and an honour to his country."Sir J. Sinclair. 


\section{TO SIR JOSEPH DALTON HOOKER, \\ M.D., K.C.S.I., C.B., F.R.S., F.L.S., Eтc., Erc.}

Dear Sir Joseph,一

As a mark of my appreciation of the kind help and encouragement you gave me, when-during the last few years of your Directorate at the Royal Botanic Gardens-I acted as the Kew correspondent for Dominica, permit me to dedicate the London edition of my Text Book of Tropical Agriculture to you.

Had you not, on the death of our mutual friend, Dr. Imray, in 1880 , urged me to endeavour to supply his place, or what may be described as an honorary Kew official on colonial service, I should probably not have directed any attention to economic botany. The most kind letter you then wrote to me has influenced me up to now ; and, if there be anything useful in the following pages, the credit is due in a great measure to you.

In dedicating, then, this book to you, I am afforded the sincere pleasure of showing you that, in the quiet of your retirement, the influence of your work as the Director of Kew lives on and bears fruit even in this faraway field.

Believe me, always,

Yours faithfully and most sincerely,

H. A. ALFORD NICHOLLS.

St. Aroment, Dominica.

30 May', 1892. 


\section{PREFACE.}

THE Jamaica Government having offered a premium for the best Text-Book of Tropical Agriculture specially adapted for the use of the colleges and higher schools in that colony, the author sent in the manuscript of a portion of this book-under the motto Respice finemto compete for the premium. The committee appointed to decide the question adjudged the premium to the author's manuscript, on the condition that he carried out a promise to extend the book by adding several chapters treating of most of the cultivated tropical plants not noticed in the original work. This was done, and the book was published by the Government of Jamaica last year.

In the preface to the Jamaica edition the author expressed the hope that the work would prove serviceable to peasant proprietors, to owners of small estates, and to intending settlers in tropical countries. This hope appears likely to be realised; whilst the commendations 
of the West Indian press, and the adoption of the textbook by the governments of other colonies than Jamaica, indicate that it has supplied a distinct want.

The success that has attended the book so far is due probably to the fact that it is not a mere compilation, but the record of experience that has been gained by study, observation, and experimental cultivations.

Twelve years ago, when the author had to direct his attention to tropical agriculture, there was no practical book that he could turn to for help in all the difficulties that were constantly cropping up in his path. Knowing, therefore, the obstacles that usually beset the inexperienced planter, who is not content to follow the old grooves of unscientific agriculture, the author has so written the second part of this book as to afford the information he needed greatly in his own planting novitiate. This has rendered it necessary to enter into details which to the experienced tropical agriculturist may appear superfluous, but the book is really intended as a guide for the young and the unlearned, to whom such details are likely to be of essential service.

Mr. D. Morris, M.A., F.L.S., the Assistant Director of the Royal Gardens, Kew, and for many years the Director of the Botanical Department in Jamaica, has very kindly undertaken to revise the work and to pilot it through the press. The author has, therefore, not only to express to Mr. Morris sincere acknowledgments 
for his help and for the interest he has taken in the matter, but also to thank him for the greatly enhanced value that the book receives by going forth to the public with the imprimatur of so high an authority on economic botany.

The author has also to express his acknowledgments to Professor Oliver and the authorities of the Kew Gardens for the advantage of being able to illustrate the book with some scientifically accurate figures. The engravings of the coffee, the cacao, the tea, the orange, the nutmeg, the cinchona, the rice and the tania plants are copied from the guide to the Royal Gardens. The illustration of the coca plant and the diagram of the vanilla flower are from the Kew Bulletins; it is proper, however, to remark in regard to the last-mentioned, that Fig. 4 is an improvement on the original, as it shows the lamellum pushed up under the anther. The other illustrations are from the author's drawings.

H. A. A. N.

St. Aroment, Dominica.

3oth May, I892. 



\title{
CONTENTS
}

\author{
PART I \\ ELEMENTS OF AGRICULTURE
}

CHAPTER I

INTRODUCTION

CHAPTER II

\section{Solls}

How soils are formed

Glacial action

The atmosphere .

Variations of temperature

Vegetation

Wind, sea and rivers

Distribution of soils

Local and transported soils

Surface soil and subsoil.

Earth worms

Constituents of soil

Sand

Clay

Lime

Vegetable matter

Stones 
CHAPTER III

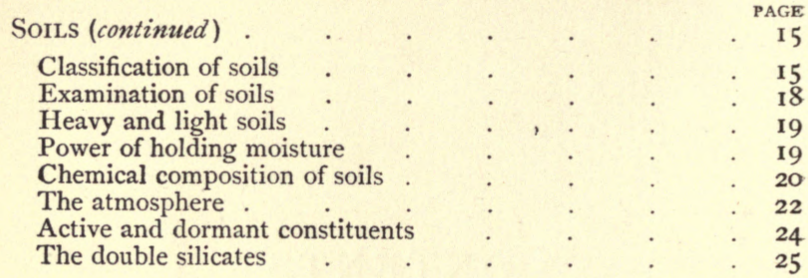

CHAPTER IV

Plant Life

The root

The stem .

The leaves

The flowers

Fertilisation by winds

Fertilisation by insects

The seed

The embryo

Germination

Nutrition of plants

Composition of plants

\section{CHAPTER V}

Plant Life (continued).

Propagation of plants

Seeds

Bulbs and tubers .

Runners

Suckers

Layers

Division

Cuttings

4I

$4 \mathrm{I}$

4I

42

43

43

43

44

44

CHAPTER VI

Climate 


\section{CHAPTER VII}

\begin{tabular}{|c|c|c|c|c|c|}
\hline ManURES & . & . & & ${ }^{\circ}$ & . \\
\hline Exhaustion of the soil & . & . & . & & . \\
\hline Action of manures & . & & . & & . \\
\hline General and special man & nures & . & . & & \\
\hline General manures & . & & . & & \\
\hline Farm-yard manures & . & . & . & & \\
\hline Compost & . & . & . & & \\
\hline Waste products & . & . & . & & \\
\hline Green crop manures & . & & . & & \\
\hline Special manures & . & & . & & \\
\hline Nitrogenous manures & . & . & . & & \\
\hline Phosphatic manures & . & . & . & & \\
\hline Bones & . & . & $0^{\circ}$ & & \\
\hline Mineral phosphates & . & . & . & & \\
\hline Super phosphates & . & & . & & \\
\hline Reduced phosphates & . & & . & & \\
\hline Thomas-Gilchrist Slag & . & & . & & \\
\hline Calcareous manures & . & . & . & & \\
\hline Gypsum . & . & & & & \\
\hline Potash manures . & . & & & & \\
\hline Kainit . & . & & & & \\
\hline Common salt & & & 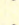 & & \\
\hline
\end{tabular}

CHAPTER VIII

Rotation of Crops

CHAPTER IX

Drainage . 66

CHAPTER $\mathrm{X}$

IRRIGATION .

\section{CHAPTER XI}

Tillage Operations

The Cutlass

The Rake .

The Hoe .

The Spade

The Fork .

The Dung Fork 
Tillage Operations (continued)-

The Pickaxe

The Digger or earth chisel

The Plough

The Cultivator or grubber

The Harrow

75

The Roller

CHAPTER XII

Pruning

78

CHAPTER XIII

Budding AND GRAFting

8 I

Budding .

Grafting

Whip or tongue grafting

Wedge grafting

Saddle grafting

Crown grafting

Inarching .

PART II

AGRICULTURAL PRODUCTS

CHAPTER I

INTRODUCTION

\section{CHAPTER II}

\begin{tabular}{|c|c|c|c|c|c|c|}
\hline Coffee & . & . & . & t & . & . \\
\hline Soil & . & $\therefore$ & . & . & . & . \\
\hline Climate & . & . & ( & & . & • \\
\hline Propagatio & & . & . & & . & $\cdot$ \\
\hline Seed beds & and nurseries & . & . & & & . \\
\hline Bamboo p & & . & . & & $\cdot$ & \\
\hline Preparation & n of the land & . & . & & . & . \\
\hline Lining & . & . & $\cdot$ & & . & \\
\hline Holing & . & . & 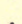 & & & \\
\hline
\end{tabular}


CoffeE (continued) -

Planting out

Shade

Weeding

Topping

Pruning

Manuring .

Catch crops

Enemies of the coffee tree

Crops

Pulping

Fermentation and washing

Hulling or peeling

Winnowing

Dry berry .

CHAPTER III

CacaO

Varieties

Soil

Climate

Propagation

Preparation of the land

Lining

Holing

Planting out

Shade

Weeding

Pruning

Manuring .

Catch crops

Enemies of the cacao tree

Crops

Sweating

Curing

Claying

\begin{tabular}{|c|c|c|c|c|}
\hline • & - & - & - & - IIO \\
\hline - & - & . & . & . $\quad$ IIO \\
\hline - & - & - & - & . 112 \\
\hline • & - & - & - & - II3 \\
\hline - & - & - & - & . $\quad$ II 3 \\
\hline - & - & - & - & . $\quad 114$ \\
\hline - & - & - & - & - II 4 \\
\hline - & - & - & - & - II5 \\
\hline - & - & - & - & . $\quad 115$ \\
\hline - & - & - & - & - II 5 \\
\hline • & - & - & - & - 116 \\
\hline • & - & - & - & - II 6 \\
\hline • & - & - & - & - II7 \\
\hline & - & - & - & - 118 \\
\hline & - & - & - & - II 8 \\
\hline & - & - & . & - II 8 \\
\hline & - & - & - & . 120 \\
\hline & - & - & - & - $12 \mathrm{I}$ \\
\hline & . & . & . & . 122 \\
\hline
\end{tabular}

CHAPTER IV

TrA .

Soil

Climate

Propagation

Planting.

Cultivation

Pruning 
TEA (continued)-

Crops

Manufacture of the tea

Withering

Rolling

Fermenting

Firing

Bulking

Sorting

Packing

CHAPTER V.

Sugar Cane

Soil

Climate

Propagation

Planting

Cultivation

Crops

Manuring

Manufacture of Sugar

CHAPTER VI.

Fruits

The Orange

Soil

Climate

Propagation

Planting

Cultivation

Manuring

Catch Crops

Pruning

Crops

Enemies of the orange tree

Packing for the markets

Soil

Propagation

Planting

Cultivation

Crops

Preparation of the juice

Concentration of the juice 


\section{CHAPTER VII.}

$\begin{array}{lllll}\text { FRUITS (continued) } & & & & \\ \text { PAGE } \\ \text { The Banana and the Plantain } \\ \text { Soil }\end{array}$

CHAPTER VIII.

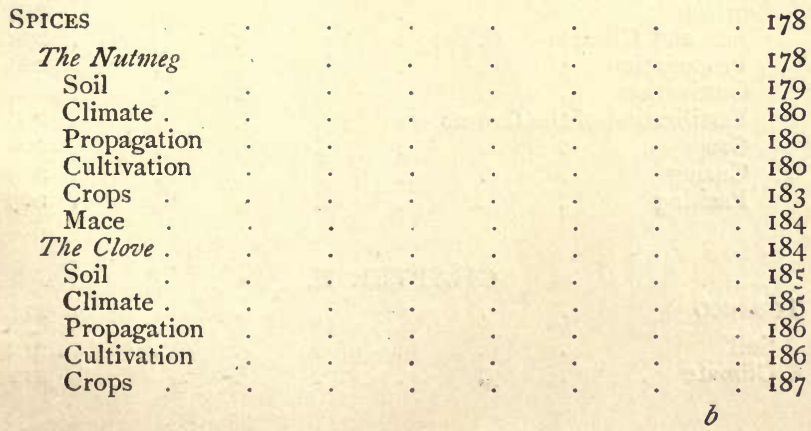




SPICES (continued)-
Pimento
Soil and Climate

CHAPTER IX.

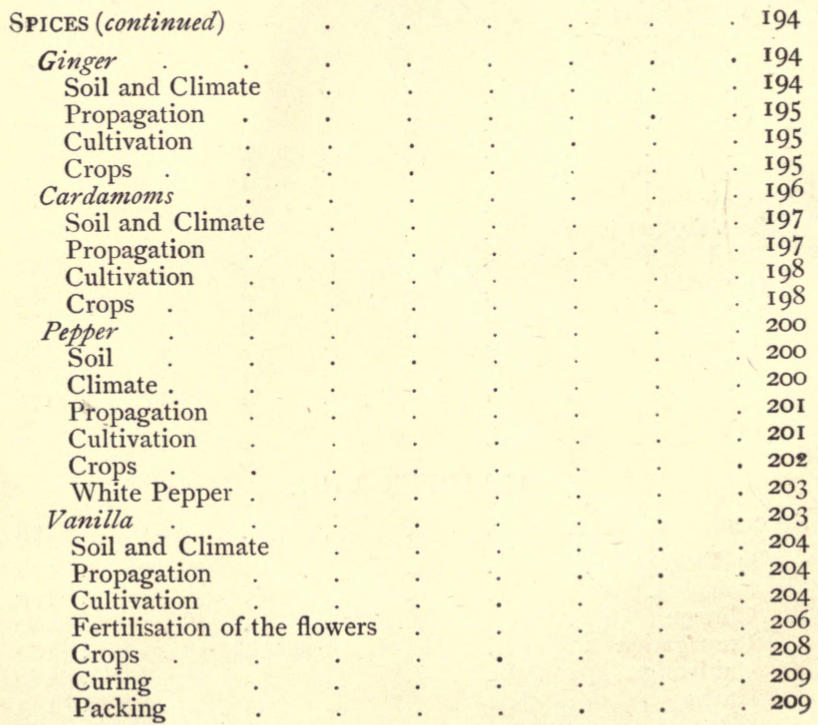

Tobacco

CHAPTER $\mathrm{X}$.

Soil

Climate 
Nurseries

Preparation of the land

Planting out

Cultivation

Topping .

Suckering .

Enemies of the tobacco plant

Harvesting

Tobacco house

Curing

CHAPTER XI.

DRUGS

Cinchona .

Soil

Climate .

Propagation

Cultivation

Harvesting

Lopping

Coppicing .

Shaving

Mossing

Drying and Packing

Castor Seeds

Soil and Climate

Cultivation

Crops

Castor oil

CHAPTER XII.

DRUGS (continued)

\section{Coca}

Soil and Climate

Propagation

Cultivation

Crops

Falap

Soil and Climate

Propagation

Cultivation

Crops 
DRUGS (continued) -

Soil and Climate $\quad . \quad . \quad . \quad . \quad . \quad . \quad .24 I$

Propagation . . . . . . . 24I

Cultivation $\quad . \quad$. $\quad . \quad . \quad . \quad . \quad 242$

Crops .242

CHAPTER XIII.

DYes

Anatto

Soil and Climate

Propagation

Cultivation

Crops

Preparation of anatto.

Turmeric

Logrwood

Soil and Climate

Propagation

Cultivation

Cutting the logs

Indigo

Soil and Climate

Cultivation

Manufacture of the dye

CHAPTER XIV.

The Tropical Cereals

260

Maize 260

Soil

Climate

Cultivation

Crops

Rice

Common Rice .

Soil and Climate

Preparation of the land

Cultivation

Crops

Mountain Rice

Cultivation

Crops

Guinea Corn

Soil and Climate

Cultivation

262

263

263

264

265

266 


\section{CHAPTER XV.}

Food Plants

\section{Cassava}

Soil and Climate

Cultivation

Crops

Preparation of cassava meal

Cassava starch

Tapioca

Cassareep

Arrowroot

Soil and Climate

Cultivation

Crops

Preparation of the arrowroot .

Tous-les-mois

The Yam

White yam

Negro yam

Guinea yam

Cush-Cush

Soil and Climate

Cultivation

The Sweet Potato

Soil and Climate

Cultivation

Crops

The Tania

Soil and Climate

Cultivation

Crops 


\section{LIST OF ILLUSTRATIONS}

The Organs OF AN ORANGe

The ORgans OF AN ORANGE Flower . • • • 3 I

Stages in the Germination of a Bean . . . . 36

Methods of Budding And Grafting ․ . . 83

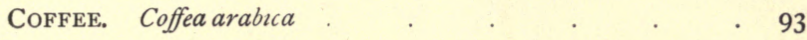

CACAO. Theobroma cacao. . . . . . III

A Pod of Criollo Cacao Grown in Dominica . . II2

TEA. Camellia theifera . . . . . . . . $\quad$ I23

Orange. Citrus Aurantium . . . . . . 145

Orange Seed, with Several Embryos . . . . 148

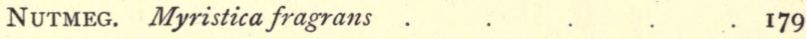

Male and Female Flowers of the Nutmeg . . 182

A Vanilla Flower to Illustrate the Method of Artificial Fertilisation . . . . . $\quad 207$

Cinchona. Cinchona officinalis . . . $\quad 222$

CocA. Erythroxylon Coca . . . . . 235

RICE. Oryza sativa $\quad$. $\quad . \quad$. $\quad . \quad 267$

TANiA. Colocasia esculenta . . . . . $29 \mathbf{I}$ 



\section{PART I}

THE ELEMENTS OF AGRICULTURE 


\section{A TEXT-BOOK}

\section{OF \\ TROPICAL AGRICULTURE}

\section{CHAPTER I}

\section{INTRODUCTION}

AGRICULTURE is a compound word, made up of two Latin What words (ager, a field, and cultura, cultivation, meaning the means. cultivation of the soil); but, like many other foreign words now forming part of the English language, it means more than its two Latin roots, taken by themselves, would lead one to suppose. By Agriculture is meant, then, the art of cultivating or tilling the soil so as to make it give the largest possible quantity of vegetable produce for the use of man and domesticated animals.

From the earliest times in the history of the world, man has tilled the soil, and Agriculture has always been considered one of the noblest and most useful occupations of Agriculture an important and noble mankind. Baron Liebig, the great Agricultural Chemist, said, "There is no profession which can be compared in importance with that of Agriculture, for to it belongs the production of food for man and for animals; on it depends the welfare and development of the whole human species, the riches of states, and all industry, manufacturing and commercial. There is no profession in which the application of correct principles is productive of more beneficial 
effects, or is of greater and more decided influence." If,

Proper

knowledge of principles necessary for success.
West Indian planters ought to be successful. then, so much depends on Agriculture, how necessary is it for people to possess a proper knowledge of its principles! Indeed, it is found that in places where cultivators are acquainted with the art, the crops are large, the people are richer, and there is more general prosperity than there is in those countries where the principles of proper cultivation are not usually known.

In the West Indies, a planter who is industrious and who has a knowledge of Agriculture, need never despair of becoming prosperous, for most of the soil is as good as can be found anywhere else in the tropics. To the West Indian Agriculturist, then, industry and knowledge promise success and prosperity, and this fact must be borne in mind by all those who intend to devote themselves to the honourable occupation of cultivating the soil.

Plants grow, All plants, whether small herbs or large trees, like animals, grow; that is to say, in their early life they are much smaller

and must have food.

Food supplied by nature not enough for plants long cultivated in the same soil.
Object of the book. than when they have grown up. Anything that grows must have food. Animals obtain their food from plants or from the animals that have lived on plants, but plants obtain their food from the soil and from the atmosphere. In a wild state, as will be explained fully later on, plants get in this way enough food, upon which to live and thrive, but when they are grown in large quantities in order that their produce may be useful to man, the ordinary supply of food furnished by the soil and the air is not enough for their continued growth; and this fact accounts for the failure of crops when one kind of plant is grown for a number of years on the same land, without any attempt being made to supply the place of the food that the plant has taken up from the soil.

The main object of this book is to show how all this takes place, and to explain how the plant-food may be given back to the soil and made ready to be taken up by the roots that are always in search of it. 


\section{CHAPTER II}

\section{SOILS}

THE Agriculturist-or planter, as he is usually called in A knowledge the West Indies and other tropical countries-has first to of soils direct his attention to the soil, and it is necessary for him to know what is its nature before he sets to work to cultivate it.

HOW SOILS ARE FORMED.-All soils, no matter what their Soils formed kind, have been formed by the gradual breaking down or away of wearing away of the hard rocks which in ages past formed rocks. the land. For countless years the wearing away of the rocks has been going on, it is going on now, and it will continue to go on as long as the world remains what it is. As the surfaces of these hard rocks slowly but surely crumbled Theparticles away, the minute flakes and particles were washed down to $\begin{gathered}\text { worn off } \\ \text { rocks carried }\end{gathered}$ the plains and the valleys, there to remain, or to be carried to far disfar distances, even to the sea, by the rivers formed by rains or by melting ice and snow. The breaking up of the rocks is brought about by various agencies, which will now be considered.

Glacial Action.-In the arctic and antarctic regions, Snow made and in mountainous countries in other parts of the world, the snow collects in the more elevated places, and, by the pressure of its own weight, is formed into ice. More snow again falling on this, it becomes too heavy and too bulky to remain on the slopes of the mountains, and so it gradu- 
ally slides down into the valleys, carrying away with it projecting masses of rock and grinding away the rocky bed over

Formation of glaciers.

Transformations of the earth's surface and changes of climates.
Rocks worn away by the atmosphere.

which it glides. The mass of ice and snow thus formed is termed a glacier, and its slow and grinding movement down the mountain slope is called glacial action. When the end of the glacier gets down to the warmer regions of the plains or valleys it melts and forms a stream of water; the larger portions of the rock it has broken off in its descent soon find resting places, but the finer particles of the hard rocks are made into mud by the water, and this is carried lower down into the valleys and deposited on the level parts or carried out to sea by the rivers.

In past ages the earth was very different from what it is now, the land was composed almost entirely of hard rocks, which, in many places, were covered with ice and snow. Indeed, in parts of the world where the climate is now warm and where the land is highly cultivated, there are evidences of glacial action still to be found, and most of the inhabitants little think that their rich soil has been, to a great extent, formed by the slow grinding action of the glaciers on the hard rocks which covered their country in past ages.

The Atmosphere is one of the principal agents in the formation of the soil. It is made up for the most part of two gases, oxygen and nitrogen, with a small quantity of carbonic acid. It is the latter, which, with the help of water in the form of rain, snow, mist and dew, acts on limestone and other rocks and causes them gradually to crumble away. The softer portions are first attacked, and this accounts for the holes and crevices that are frequently found in exposed rocks. But even the hard portions are gradually worn away, and the whole process is seen going on in stone buildings, where, after a time, the sharp corners become rounded, and the smooth surfaces are roughened, by the "weathering" effect of the atmosphere. Weathering action on rocky material 
may also be well seen in churchyards, for inscriptions on tombstones are, after a time, completely obliterated by the destructive effect of air and moisture, whereas similar inscriptions on tablets protected in churches are unaffected after a number of years.

VARIATIONS OF TEMPERATURE have also a powerful effect Rocks worn in the formation of soils. Rocks expand by heat and con- away by tract by cold. Thus in the hot tropical sunshine the sur- of temperafaces of the rocks expand and are again contracted by the cool air of the nights ; this causes them to crack, and then pieces flake off, thereby giving rise to a constant, small, but certain, addition to the soil. In colder countries, frost has a very destructive action on all rocks. Water contracts by cold until it is near to the freezing point, but as it becomes frozen it expands. In cold climates this sudden expansion Frost. at the freezing point often gives rise to great trouble by causing water pipes to burst, for the force exerted by the expansion is so great as to burst strong iron vessels. It is easily understood, therefore, why rocks are split and crumbled by frost. Rain water soaking into the holes and crevices of the rocks, suddenly expanding with great force on freezing, splits them up into fragments, and thus allows fresh surfaces to be acted on by the atmosphere-which easily finds its way into all the open spaces.

VEGETATION.-Plant life assists in the formation of soils in Soils formed two ways. When the roots of a plant reach a rock, the acid py action of sap eats into the surface dissolving out certain elements which are taken up by the plant as food, and liberating sandy particles which are added to the soil. Again, the roots enter into the crevices of the rock and by their gradual increase in bulk force the two sides apart, acting in this way like a wedge. The force thus exerted is very great, and even such delicate and soft plants as mushrooms can in their growth exert so powerful a pressure as to lift heavy weights. Some years ago, 
in a town in England, a new stone pavement was laid down, and, to every one's surprise, after a time the heavy stones were mysteriously lifted out of their places. An examination into the matter showed that the earth under the stones had been mixed with the spores of mushrooms, the spores had grown and the mushrooms by their increase in size had lifted up the pavement. In the West Indies, where vegetation is vigorous in growth, the splitting up of rocks by the entry of roots into cracks and crevices can easily be investigated by any one.

The formation of soil by the combined action of the atmosphere and vegetation is a very important factor in the production of what is known as vegetable mould. A chemical change which may be described as a slow burning (or decay) is brought about by the action of the oxygen of the atmosphere on moist organic bodies, by means of which they are gradually consumed and resolved into their various constituents. In the case of trees and plants in the tropics this decay is very rapid, and the result is the large quantities of vegetable mould met with in tropical forests. In a very small An illustra- way the same thing may be observed on rocky precipices,
tion of the formation of soils. or even on walls. Lichens, which are flat, leathery kinds of plants, first attach themselves to the rocks and eat into the surface. The lichens die and decay, and add vegetable matter to the scanty soil formed by them with the atmosphere and moisture. Mosses then grow up, and they in turn die and decay, adding to the soil by their action during life and by their remains after death. Then small hardy plants appear on the scene, to give place in time to larger plants, until at last a shrub or a tree grows up and sends its roots into the cracks and crevices of the rock, with the final result that the rock is split up and crumbled away to form the soil for more vigorous vegetation. All this, of course, takes a very long time, but then the process has been going on for ages, so that it must have exerted a very considerable influence on the formation of soils. 
WiND, SEA AND Rivers.-The Wind, in places, is a fac- Action of tor in the formation of soils, more especially in dry weather when sand and dust are sometimes carried long distances by strong breezes. The wind also carries straw, leaves and other light objects far away and in this manner often adds fertile matter to a poor soil.

The Rivers are constantly assisting in the formation of Action of soils in various ways. In mountainous regions the particles rivers. worn off the rocks are carried down to the low-lands mainly by the action of the rivers: and the running waters, especially when in flood, grind down the rocks and stones by rolling them over and against each other. It will be noticed that the stones in the bed of a river are mostly smooth and round owing to this rolling action, the rounding off of the angles being caused by the constant friction or rubbing together. The mud and gravel brought down by slow-flowing Alluvial rivers in times of floods are deposited in the plains or at the bottom of the valleys where they form alluvial soil, while in swift-flowing rivers they are carried out to sea to be spread along the bottom of the ocean.

THE SEA.-In some places the sea is gradually encroaching on the land by wearing away the shore by the incessant action of the waves, but in other places the reverse happens, for the sea becomes gradually filled up and so in time is turned into dry land. The mud and gravel brought down The sea bed by rivers and glaciers form, as it were, a submarine soil, and frry land. by volcanic and other agencies, this soil has been in places lifted up above the sea to become in time land capable of cultivation. In some parts of the West Indies, the fact that the land has been formerly under the sea is plainly shown by the beds of coral found at some distance from the shore. In Dominica, for instance, which is a volcanic A part of island, there are cliffs and beds of coral two or three Dominica island, there are cliffs and beds of coral two or three formerly hundred feet above the sea; and, as coral is built up in under the the sea by a marine animal, it is evident that parts of 
Dominica have been in past times below the surface of the ocean.

DisTRIBUTION OF SolLs.-We have seen that the soil has been formed for the most part by the gradual wasting away of hard rock, and we now know that the soil thus formed is brought down from the higher land mainly by rivers and glaciers and floods of rain-in other words by water in its ordinary or its frozen condition. Of course a

Mountain soils.

Lowland soils.

The mud.

Fossil remains. portion of the soil stops on the slopes of the mountains when they are not too steep, but the greater part is carried farther down; and, as a rule, the finer the soil the farther it is carried. The big stones and rocks broken off by the glaciers - and the various other processes we have been considering-are left behind, and the smaller stones are carried lower down to form gravels, while the fine soil in the shape of mud is carried for long distances and spread over the land as sands and clays. If some mud be taken and stirred in a glass of water and allowed to rest, it will be found after a time that the mud will settle at the bottom of the glass and the water will remain clear on top of it. And this is what occurs, and has occurred since the world was created, in regard to the fine particles of rock brought down by floods, rivers and glaciers from the high lands. The mud has settled on the land and formed the soil that we now cultivate. In order to understand all this, it must be remembered that the world has not always been what we now find it. The land has altered in shape and elevation, the sea has been over much of the land, and the land of those days is now, in places, under the sea, and the climate of different countries, as we now find it, is quite altered from what it was many years ago. This is shown by the remains of elephants and other animals that live in hot climates being found embedded in the ice of Siberia and other intensely cold regions. Unless we remember all these wonderful changes, and think of the thousands of years that have 
elapsed during which the natural forces we have been considering have been at work, we cannot understand how the soil could possibly have been made by the slow wearing away of granite and other hard rocks. But the more we The marvels study these great questions, the more marvellous does Nature of Nature. appear to us to be.

Local Solls and Transported Solls. - As we have seen, the soil may be carried long distances by the agency of water and wind, and thus the soil may be found to be very different in its character from that made from rocks in the neighbourhood. When this occurs the soil is said to be transported. And when the soil formed in a place is not carried away but remains where it was made, it is said to be local, or indigenous, or sedentary-which really means that the soil is, so to speak, home-made, and not imported from other places.

Surface Soll and Sub-soil.-If a deep hole be dug in the land, it will usually be found that at some distance below the surface the character of the soil becomes altered. On the top the soil is darker in colour and much easier to dig, Surface soil. because it is looser; this is called the surface soil, and its darker colour is caused by the decayed leaves and roots and stems of plants it contains. The lighter and closer soil at Sub-soil. the bottom of the hole is called the sub-soil, and it varies considerably in character. It may be made up of sand, or of gravel or clay, or it may be like the surface soil. The sub-soil may be a local soil, and the surface soil a transForted one, or vice versî, and when this happens they will usually be very different in their nature. The surface soil varies in thickness according to its position and surrounding influences. In forests and highly cultivated lands, it is usually deep, but on steep hill sides and in dry places, it is shallow.

Earthworms.-Darwin, the great naturalist, has shown Earthworms aid in the formation that earthworms exert a wonderful influence in the forma- of soil. 
tion of surface soil. These most useful animals feed on the leaves and other parts of plants, and they burrow into the ground in all directions, sometimes even to the depth of five

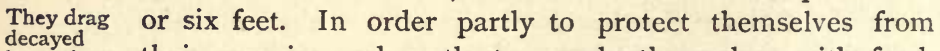
leaves into their holes. their enemies and partly to supply themselves with food, they drag half-decayed leaves and stalks into their burrows, and so block them up to a depth of two or three inches. Thus worms fertilize the soil by adding organic matter to it. The little heaps of earth often seen at the mouths of the.burrows, more especially in wet weather, are called castings, and they consist of very fine particles of mould mixed with decayed vegetable matter. The worms make their burrows by swallowing the soil and then bringing it to the surface where it is got rid of in the form of these castings. In this They turn way they continually turn over the soil, and besides, their
over and mix the soil. burrows allow air and water to get easily into the earth, and also form channels for the roots of plants to grow along without difficulty. It is seen, therefore, that the humble earthworms are really working for the benefit of the planter; and so, on that account alone, none of them should be purposely injured or killed.

Constituents of Soils.-All sorts of soils are composed of five substances, namely (I) Sand, (2) Clay, (3) Lime, (4) Vegetable Matter, (5) Stones.

Sand.-This substance is well known to every one. It consists of fine particles of hard stone, which do not cohere when wet, and which fall quickly to the bottom when they are thrown into a vessel containing water. If sand be mag-

Nature of sand. nified it will be found to be made up of minute smooth stones with rounded edges, or, in other words, of very small water-worn pebbles. There are several kinds of sand commonly met with. Calcareous sands consist of grains of limestone, or of broken shells, as is often seen on the sea shore; hence we have coral-sands and shell-sands. Micaceous sands are largely composed of a hard substance known 
as mica. Sand, however, is principally composed of a Quartz sand. glassy substance known by the names of quartz, flint, silica or rock-crystal. It has a gritty feel and it easily scratches such hard substances as glass. This property is sometimes made use of in the "sand-paper" sold in the shops. Sand makes the soil loose, and thus it assists the air and water in finding their way through the land, and aids the roots of plants in their efforts to penetrate in all directions.

Clay is composed of two chemical bodies known as silica Nature of and alumina in combination with water. When dry it may be made into a powder, and when wet it becomes sticky and is then capable of being moulded into various shapes-and this property is known as plasticity. But when clay is burnt it loses its plastic property, for it then becomes hard and brittle. There are various kinds of clay, some quite white, Varieties of from which china ware is made, others yellow, from which bricks are made, others again are red and are used to make pots, goglets and other earthen-ware articles. Clay is colder, and it retains much more moisture than sand.

Lime usually occurs in soils combined with carbonic acid as a carbonate of lime. It came originally from the old hard rocks, but now it occurs in various forms, as chalk, Varieties of lime-stone and coral. It is contained in large quantities in the shells of land snails and of some marine animals besides coral, and many of the lime-stones of the earth are composed entirely of these shells and deposits which accumulated at the bottom of the sea in past ages.

Vegetable matter exists in all soils upon which plants have grown. The leaves, roots and stems decay as already shown and form a dark brown substance called humus or vegetable mould. This occurs abundantly on the surface of the ground in forests and in less quantities in all cultivated lands. In some damp, hollow places where mosses and similar vegetable plants grow abundantly, the soil is composed almost entirely soils. of humus, for the mosses grow up and die and decay, and 
other mosses grow up on the dead ones, until, after numbers of years, the humus fills up the hollows and forms what is known as peaty land.

Stones useful in soils.

Stones are simply particles of the original rock from which the soil was formed. They vary greatly in size and shape. Some are rounded, others are sharp and irregular. If they do not exist in too great a number they serve a useful purpose in the soil, as they render the land lighter in character, while they assist in retaining moisture in the soil, and by their gradual wasting away slowly add material to the earth. For the stones are weathered by the atmosphere and other agencies in the same way as the rocks from which the soil was made. 


\section{CHAPTER II I}

\section{SOILS (continued)}

Classification of SoILS.-Soils have been divided into classes, sub-classes, orders and species, somewhat analogous to what has been done in regard to the various members of the animal and vegetable kingdoms, but it is not necessary Eight classes to do more here than to consider the eight principal classes, of soils. with their chief sub-divisions, into which the different soils are usually placed.

The first class comprises the clay, or, as they are some- Clay soils. times called, the argillaceous soils, which contain over 50 per cent. of clay. They are cold and difficult to work on account of their stiffness. Water does not run through them easily, and so they must be well drained in order to be properly cultivated. As clay loses its plastic or sticky property by being subjected to heat, it does good to a clay soil to pass fire over it or to burn it in heaps and then spread it over the land. Clay soils may or may not contain lime up to the proportion of 5 per cent., and thus they are divided into two sub-classes.

The second class comprises the loamy soils which contain Loams. from 30 to 50 per cent. of clay. These soils may also be with or without lime.

The third class is the sandy loams, containing from 20 to Sandy 30 per cent. of clay, and they are also sub-divided according loams. to the presence or absence of lime in them.

The fourth class is the loamy sands, and contains from Io sands. 
CHAP.

to 20 per cent. of clay; and like the other three classes, lime may be present in or absent from them.

Sandy soils. The fifth class comprises the sandy soils, which contain over 70 per cent. of sand, and they may also be with or without lime.

Marls. The sixth class or the marly soils, contain from 5 to 20 per cent. of lime, and they may partake of the characters of the first four classes, or of the eighth. Thus there are five subdivisions of the marly soils.

Calcareous soils.

The seventh class, or calcareous soils, contain more than 20 per cent. of lime, and they may partake of the characters of the first, second, third, fourth, fifth and eighth classes. Thus a loamy calcareous soil would contain from 30 to 50 per cent. of clay, and more than 20 per cent. of lime. . And a sandy calcareous soil would have over 70 per cent. of sand, and more than 20 per cent. of lime.

Vegetable soils.

The eighth class contains the various vegetable soils, in which humus or vegetable matter occurs in not less a quantity than 5 per cent. The vegetable soils may in their turn partake of the character of clayey, loamy or sandy soils, or be composed almost entirely of vegetable matter as in the case of bog and peat earth.

In each of the sub-divisions of the first seven classes the soil may be referred to three groups, namely poor, intermediate and rich, according to the quantity of vegetable matter contained in them. If we take, as an example, the first class which includes the clay soils, the presence of vegetable matter (or humus), if not more than a half per cent. would cause it to be classed as a poor clay. If there were above a half and not more than one and a half per cent. of humus it would be an intermediate clay, and where there is from one and a half to five per cent. of humus it would be a rich clay. Above five per cent. of humus would cause the soil to partake of the character of the eighth class and it would become a vegetable soil. 
Classification of Soils (after Schübler and Wrightson).

Classes.

I. Clay or Argillaceous Soils. (Over 50 per cent. of clay.)

II. Loamy Soils. ( 30 to 50 per cent. of clay.)

III. Sandy Loams. ( 20 to 30 per cent. of clay.)

IV. Loamy Sands.

( 10 to 20 per cent. of clay.)

V. Sandy Soils.

- (Over zo per cent. of sand.)

VI. Marly Soils. ( 5 to 20 per cent. of lime.)

VII. Calcareous Soils.

(More than 20 per cent, of lime.)

VIII. Vegetable Soils.

(More than 5 per cent. of humus.)
Sub-Classes.

I. With lime.

2. Without lime.

I. With lime.

2. Without lime.

I. With lime.

2. Without lime.

I. With lime.

2. Without lime.

I. With lime.

2. Without lime.

I. Clayey Marl.

2. Loamy Marl.

3. Sandy loam Marl.

4. Loamy sand Marl.

5. Vegetable Marl.

I. Clayey calcareous soil.

2. Loamy calcareous soil.

3. Sandy loam calcareous soil.

4. Loamy sand calcareous soil.

5. Vegetable calcareous soil.

6. Pure calcareous soil (without clay or sand).

I. Clayey humus.

2. Loamy humus.

3. Sandy humus.

4. Bog or peat.

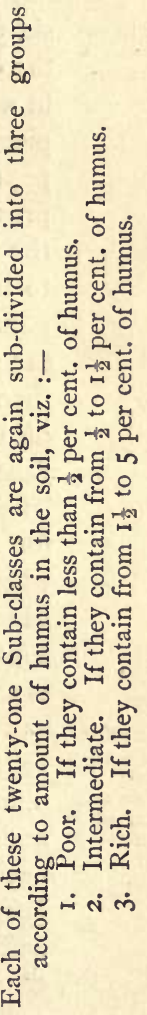


How to examine soils mechanically.

Lime effervesces when hydrochloric acid is poured on it.
Examination of SolLs.-We have seen that soils are classified according to the proportion of clay, sand, lime and humus they contain, and the presence of these substances in the soil may be very readily ascertained by the following simple experiments :-Weigh out a quarter of a pound of the earth after it has been well dried, boil it for a short time in a pint of water and then pour it into a glass vessel. A piece of blue litmus paper should then be put in, and if the paper turn to a red colour, it shows that acid humus is present in the soil, and that lime is necessary to counteract the acidity. More water is then to be added, the whole is to be well stirred, and the muddy water is to be carefully poured off into a large vessel, care being taken that none of the sand which settles to the bottom is lost. The sand is then to be stirred up with fresh water, which is again poured off into the larger vessel. And this is to be done several times until the sand becomes quite clean and free from mud. The contents of the larger vessel are to be allowed to remain for several hou's until the fine mud settles to the bottom, when the clear water is to be carefully poured off. The sand and the mud should then be dried and weighed separately ; when, by comparing their weights with a quarter of a pound, the proportion of sand and earthy matter in the soil can be ascertained. To discover the presence of lime in a soil, it is only necessary to pour a little hydrochloric acid upon it; this will cause effervescence if there be any lime, and the degree of the effervescence will give to an experienced observer a rough indication of the quantity of lime. To ascertain the exact quantity of lime, however, the acid must be allowed to remain some time on the soil, and then a solution of ammonia must be added. All the lime will, by this means, be dissolved out of the soil and it will remain in the liquid, from whence it can be thrown down by a solution of carbonate of potash or oxalate of ammonia. But this process can only be attempted by a person having some knowledge of chemistry. The proportion of vegetable 
matter or humus, in the soil, is ascertained in a rough Organic manner, by heating for an hour to a red heat, a given matter dequantity of thoroughly dry earth in an iron or clay vessel, when the vegetable matter will be burnt off. The earth is then to be cooled and weighed, and the loss in weight will give the proportion of humus in the soil.

HeAvy AND Light SoILs.-It has been shown in the mechanical examination of soils that the sand, which is the heaviest part, falls to the bottom of the vessel when stirred up with water, and that the clay being lighter is suspended in the water for a time and can be poured off so as to leave the sand by itself. This shows that sandy soils are heavier than clay ones--indeed, a cubic foot of sand will weigh from 30 to 35 pounds more than the same quantity of clay. But agriculturists call a clay soil a heavy one, and a sandy soil a light one. These terms, however, refer,-not to the relative weights, but to the facility with which the soils are worked. The clay being tenacious or sticky, it is much more difficult to plough or to dig than a sandy soil, in which Clay soil difficult to the particles of sand move more easily one on the other and allow the implements to pass freely through the land. Sometimes these soils are called stiff and free, instead of heavy and light, and these are perhaps better names, for the reason that they are not likely to confuse any one. Clay soils retain much more moisture than sandy soils, as is well Clay soils known, and this causes a great difference in regard to their $\underset{\text { moisture. }}{\text { retain }}$ temperature. Clay soils are therefore spoken of as cold, and sandy ones as warm, but a well-drained clay soil may be warmer than an undrained, low-lying, sandy soil, and this indicates the necessity for proper drainage of land; for, as will be shown later on, a certain degree of warmth is requisite for the propagation of plant life.

The Power of Holding MoIsture is possessed in a Retention greater or less degree by all soils. If the end of a strip of of water blotting paper be dipped into water, the water will run up 
the paper for some distance. The same things occurs when the end of a wick of a lamp is dipped into oil. This action is known as capillary attraction, and all soils are capable of exerting such an action, which is one of the greatest importance from an agricultural point of view. Sand possesses this power to the least extent and clay to the greatest, and this accounts for the well-known fact that a clay soil is always wetter than a sandy one placed under the same

Power of soils to hold water.

Chemistry of soils.

Chemical elements. influences. In order to find out the power of any soil to hold water, it is only necessary to place a known quantity of the earth, well pounded and dried, into a glass vessel and to pour water upon it until it is more than covered. It is to be allowed to soak for a day and then the water above the earth is to be carefully poured off. The weight of the remainder compared with the weight of the dry earth will give an idea of the capability of the soil for holding moisture. Another ready way is to take a flower pot, to fill it nearly to the top with dry soil, and then to weigh it. (The weight of the pot, both wet and dry, must, of course, be known.) Then gradually pour water on the soil until it begins to drop from the bottom. As soon as the dropping has ceased weigh the whole, and in this manner the proportion of water held by the soil is approximately arrived at.

Chemical Composition of Solls.-It has been shown that the greater part of all soils has been formed by the wasting or decomposition of hard rocks, and naturally the same substances that occur in the rocks, will be found in the soils also. Chemists have found out that every thing in the world is composed of elementary substances by themselves, or so combined together as to make up compound or complex bodies. These elementary or simple substances are termed elements, and they are of two kinds, namely, metals and non-metals. There are a good many elements, but it is unnecessary to enumerate them all here, as some of themwhilst useful in the arts and manufactures-are not at all 
concerned in agriculture. Some of the elements are termed Organic organic, because they were supposed, formerly, always to be elements. found in organised beings - that is, in plants and animals; and the rest are called inorganic, as they are not necessarily Inorganic present in living things. But organic elements occur in elements. enormous quantities in inorganic substances, and inorganic elements are found in organised bodies, so that the terms organic and inorganic elements are now used simply as convenient expressions.

The organic elements are oxygen, hydrogen, nitrogen and carbon, which disappear as vapour or smoke when an orgaElements nised body is burnt in the air. The first three are gases, and the last is a substance, one form of which, charcoal, is familiar to every one. Besides these, there are two other substances, namely, sulphur and phosphorus, which are sometimes called secondary organic elements, because they are frequently found in organised bodies. In all, then, there Eleven are six non-metals, as they are termed, ever present in fertile $\begin{gathered}\text { necessary } \\ \text { elements. }\end{gathered}$ soils, and, in addition to them, there are five metals which are always to be found in combination with other elements, in lands suitable for cultivation. These are potassium, sodium, magnesium, calcium and iron.

Oxygen is an invisible gas which enters largely into the Compounds composition of the atmosphere; and in combination with another gas, hydrogen, it forms water. It combines readily with other elements to form different compounds called oxides. If iron be exposed to air and moisture its surface rusts, and this rust is simply a combination of iron and the gas oxygen; it is in fact an oxide of iron. Oxygen also oxides. combines with carbon to form carbon dioxide, usually called carbonic acid, a compound gas that plays a very important part in plant life. In combination with the element silicon, oxygen forms the oxide silica, which is the basis of all sands; with potassium it forms potash; with sodium it forms soda; with magnesium it forms magnesia; with calcium it forms lime, and with aluminium it forms alumina, which is the basis of all clays. 
Compounds of hydrogen.

Hydrogen is the lightest of all the elements. It combines with eight parts of oxygen to form water ; and in combination with nitrogen it forms ammonia. Hydrogen is also an important part of nitric, hydrochloric, sulphuric and phosphoric acids.

Nitrogen, like oxygen and hydrogen, is an invisible gas, and like them also it plays an important part in all life. The air we breathe is composed of one-fifth of oxygen and four-fifths of nitrogen. The two gases are not combined, like oxygen and hydrogen in water, but are both free in the atmosphere - in other words they are mixed together mechanically and not combined chemically.

Carbon is not a gas, but in chemical combination with oxygen it forms the important gas, carbonic acid, which has

Carbon forms the bulk of plants.

Respiration of animals. been already alluded to. Carbon makes up the greater part of the bulk of all plants, and it is taken up by them, not in its pure state, but in the condition of carbonic acid. The plant under the influence of sunlight then decomposes, or breaks up the carbonic acid into its two elements, and whilst it keeps the solid carbon to build up its tissues, it gives back the oxygen to the atmosphere. This is just the reverse of what occurs in the case of animals, for they take in oxygen and breathe out carbonic acid ; and thus, by a wonderfully wise provision of Nature, the poisonous carbonic acid breathed into the air by animals, is taken up by plants in order that they may keep the carbon and restore the healthgiving oxygen to the air.

The Atmosphere.-A good deal has been said about the atmosphere and it is so much concerned in the growth of plants, in the formation of soils, and in the processes whereby they may be kept fertile, that it is necessary for the agriculturist to have a correct knowledge of its nature. We have Composition seen that the atmosphere, or the air we breathe, is composed of the atmosphere. of a mechanical mixture of the two important gases, oxygen and nitrogen, in the proportion of about one-fifth of oxygen and four-fifths of nitrogen. The oxygen, although in much less quantity, is the more active element, and the nitrogen 
really only serves to dilute it and prevent it having too active an effect. Besides these two gases, the air contains carbonic acid, ammonia, nitric acid, chlorine, sulphuric acid and water in the form of vapour. The quantities of these substances, in comparison with the oxygen and nitrogen, are so small as to be scarcely perceptible, but then the atmosphere is so vast in its extent that even an extremely minute proportion in a given quantity is really an enormous mass in the whole.

Carbonic Acid, as we have seen, is taken up by the plants in order to build up their tissues, for the roots, stem, leaves, flowers and fruit are, for the most part, composed of the carbon supplied by the carbonic acid of the air.

The Ammonia in the atmosphere comes from the decay of Formation of animal and vegetable bodies, from active volcanoes, and from ammonia. the combustion of substances by heat, as when wood or coal is burnt in a fire. It would naturally appear, therefore, that ammonia would be more abundant in the air of large cities than in country districts, and careful experiments have shown that this is really the case.

Nitric Acid is formed principally by the electricity, which Formation of is so often manifested to all by means of lightning. After a thunder storm, the air always contains a much larger quantity of nitric acid than it did before.

Chlorine, in the form of chloride-commonly called chlo- Salt in the ride of sodium or salt-is found in the atmosphere, and its atmosphere. presence is due almost wholly to the influence of the sea. Small quantities of salt, as fine spray, are carried by winds and currents of air for wonderful distances inland.

The Sulphuric Acid in the air is due to the same cause as nitric acid, and it is also given off in large quantities from active volcanoes.

The Watery Vapour of the atmosphere is often precipi- Sources of. tated in the form of rain and dew in hot and temperate vapour in countries, and as snow or hail in colder regions. It is con- sphere. stantly given off by the leaves of plants and in the breath of 
animals, but its principal sources are rivers, lakes and seas, from whence it is obtained by evaporation during the heat of the day.

The ammonia, nitric acid, chlorine and sulphuric acid of the atmosphere are carried to the earth by the rains, and so made available for the use of plants.

How plants obtain nitrogen.

Nitrogen is a very important constituent of plants. It is contained, as we have seen, in the atmosphere in a free condition, as well as in combination with other elements in the form of ammonia and nitric acid-which are carried down to the earth by rains. It also exists in the soil in chemical union with other substances, as nitrates. Ammonia, too, is formed in the soil by the decomposition of dead plants and animals ; it does not remain free, however, for when it comes in contact with the potassium salts, it acts on them and forms compounds of nitric acid which are readily taken up by the delicate hairs on the roots of plants, and it is in this way that the nitrogen used by plants is obtained.

Food taken up by the roots of plants must be soluble.

Acid sap of the rootnairs.
ACTive and DoRmant Constituents of Soils.--All the substances taken up by the plant from the soil, must be capable of being dissolved in water aided by carbonic acid and some organic acid. If a portion of dry soil be soaked in pure water for a time, the water that is poured off will be found to be altered in character and taste, for the reason that it has taken up from the soil some of the active or soluble substances used as plant food. Perhaps, in a fertile soil, this will not be more than two parts in every thousand, so that nine hundred and ninety-eight parts are insoluble in water. But, if acids be added to the water with which the soil is soaked, a very much larger quantity of plant food will be dissolved out, and this is what occurs in the case of plants, for the delicate root-hairs dissolve out from the soil the active constituents by means of an acid fluid which always permeates the walls of these finest divisions of the roots. If the'soil, however, from which all the plant food 
soluble in acids has been removed, be spread out in the air and sun for some weeks and then be again soaked in pure water in an acid solution, it will be found that a small portion of it has become soluble and thus available for plant food. This part was, therefore, in the first instance, in a dormant condition. The alteration brought about by the exposure of The partithe the soil to the air is easily understood if the way in which soil merely rocks are weathered be remembered. For the small particles pieces of the earth are merely minute fragments of rock upon which the same wasting influences act in the same way as in the case of the great masses of hard rock from which the soil was originally formed. These facts then, explain why tillage Why the soil operations, which expose the under layers of the soil to the by tillage. air and the sun, render the earth more fertile, and why the resting or fallowing of land restores fertility by allowing time for the air to permeate the soil and so to increase the soluble constituents.

The Double Silicates.-All soils contain silica and alumina, and a considerable portion of these elements are combined together with other elements to form what are called double silicates. These are four in number, namely: I-Importance Silicate of alumina double Silicate of alumina and ammonia ; 2 -Silicate of alumina silicates. and potash; 3-Silicate of alumina and lime; 4-Silicate of alumina and soda. Now all these substances are used by the plant with the exception of alumina-which is the basis of clay. But, although not a plant food, alumina, in its form of a silicate, is an important agent in the preparation of the food, for it combines with ammonia, potash, lime and soda in such a way as to give up these elements readily to the roots of plants in a soluble condition. It has been found that silicate of alumina combines most readily with ammonia, and then, in point of order, with potash, lime and soda. Thus, if silicate of alumina and potash be placed where it can get ammonia, it will part with the potash for ammonia and become a silicate of alumina and ammonia. 
And, in the same way, the soda, in a soda double silicate, will be given up for lime or potash or ammonia; and the lime, in a lime double silicate, will be given up for potash or ammonia, if these substances be brought near to it. This property of the double silicates is most important to the agriculturist, and it has been made of much use in the system of applying artificial manure to land. 


\section{CHAPTER IV}

\section{PLANT LIFE}

As agriculture is the art of cultivating the soil so as to pro- A knowledge duce crops from the various plants of use to man, it is neces- of plant life sary for the agriculturist to have a knowledge of all that concerns the life of a plant.

Most plants usually consist of five parts, namely, the root, the stem, the leaves, the flowers and the fruit. There are some plants, it is true, that have one or more of these parts wanting, but it is unnecessary to consider them in this work, for the tropical agriculturist is concerned mostly with the ordinary flowering plants.

THE RoOT, which is called the descending axis of the plant, varies very much in its character. In the grasses and other plants, the roots consist of many fibres spreading out in the soil in all directions; some of them, indeed, are much longer than the stem, as in the case of the maize-the roots of which have been traced to the length of fourteen feet. Other roots, called tap-roots, send a thick prolongation of the main axis straight down into the soil, and give off small fibres at intervals ; the best example of this is the carrot, but Functions of coffee and cacao also possess tap-roots. Roots have two imroots. portant functions : firstly, they fix the plant into the soil, or to the substance on which it grows; and, secondly, they take up nourishment for the plant to live and thrive on. At their ends all roots become very small and tender, and give 
Root hairs, off minute, hair-like prolongations, called appropriately roothairs. The extremity of a root is covered by a cap of stronger tissue so as to protect the growing point, and to enable it to make its way into the soil. The root-hairs apply themselves to the particles of the soil, and by means of the

$?$ acid fluid permeating their very thin walls, they dissolve take up plint out the active constituents, and then take up and pass them food,

and then perish, on to the sap, which is used for the growth and nourishment of the plant. The root-hairs perish as soon as they have extracted the soluble portions of the soil they are applied to, when fresh ones take their place. but fresh ones are put out from more advanced parts of the roots, so as to seek for the nutritive substances from other particles of the soil, and thus this process goes on continually, and the earth is searched in all directions for the food necessary for the well-being of the plant.

THE STEM is sometimes called the ascending axis of the plant, because, when the seed begins to develop, the minute stem always strikes up towards the air and light, whilst the roots strike downwards into the soil, avoiding light and air. In certain instances, however, the stem runs along the ground as in some grasses and other plants, or it may even run underneath the surface, thereby resembling the root.

Importance of leaves.

THE LEAvES are flattened expansions of the stem, in which some of the most important functions of the plant take place. They are composed of a thin layer of vegetable tissue called parenchyma, held together by ribs or framework of wood-like substance wrongly called veins, and covered on both surfaces by a thin skin of much finer material known as the epidermis. In the epidermis there are pores or openings called stomata, through which carbonic acid, oxygen and watery vapour are taken in or given

Their functions. out by the leaf. The functions of leaves have been described as a combination of those of the lungs and stomach of animals, for the leaves not only take in gases and after- 
wards give them out in a different form, but they digest the food drawn up by the roots and elaborate it so as to render it fit for the nourishment and the building up of all the tissues of the plants.

THE FLOWERS are those parts of the plant concerned in the formation of fruit, and they are often remarkable for their beauty and their fragrance, or their peculiar construction. A typical flower consists of four distinct series of or- Four organs gans, arranged in a circle round the axis of the flower stalk. This arrangement may easily be seen in the flowers of the orange or the lime.

On examining one of these flowers carefully, five thick, small green organs, like stunted leaves, will be noticed on the outside and at the lowest part of the flower. This outer series of organs is called the calyx, and the separate parts are called sepals. In the case of the orange flower, then, the calyx consists of five sepals. Inside the calyx, and similarly arranged, is the corolla-composed of five leaf-like organs, white in colour and possessed of a delicious perfume. These are called petals, and so the corolla is described as being composed of five petals. Within the corolla comes a series of peculiarly shaped organs, called stamens and bearing at their summits yellow, hollow bodies, the anthers, filled with a fine dust-like substance. The fourth and last series of organs are called carpels, and collectively, the carpels form the pistil. Each carpel consists of a hollow lower part called the ovary, in which are found one or more minute bodies called ovules. The carpels are separate in many flowers, but in the orange they are joined together and become one body, which consists of the small round undeveloped orange, terminating in a club-shaped prolongation called the style. At the end of the style there is a sticky body, the stigma, and very frequently some of the dust from the anthers may be found adhering to it.

This dust, which is called pollen, acts when applied to the 
Fertilisation stigma in such a way as to fertilize the flower, that is, to of the flowers. cause the pistils to develop into fruit with seeds in them. Without this fertilising process taking place, no fruit can be formed, and the flowers would wither, die, and drop off the tree. As soon as the ovules become fertilized by the pollen, the compound pistil of the orange begins to grow into fruit. The sepals remain permanently attached to the stalk at the base of the fruit; the petals wither and drop off, as do also the stamens; the ovary grows rapidly to form the fruit or seed envelopes, and the ovules become in time the seeds from which new plants may be raised.

Numbers of flowers possess an arrangement of their parts similar to that of the orange; and from the description already given, it will not be difficult to determine which are the floral envelopes, as the sepals and the petals are collectively called, and which are the stamens and pistils. But very many flowers differ greatly from the type of which the orange may be taken as an example. Thus, for instance, instead of the floral envelopes being composed of two series of organs, there may be only one, as in the case of the lilies, and this single envelope is called the perianth, and it is made up of perianth leaves, which are usually highly coloured. The parts of the calyx, corolla and perianth may be separate leaf-like organs, or they may be joined together, making envelopes of an infinite variety of forms. The floral

The floral envelopes may be wanting. envelopes, too, may be inconspicuous or entirely wanting. In the case of the cocoe or tania, the inflorescence-which is the name given to the collection of flowers on the flowering stem-consists of a central axis on which are set numbers of stamens above and pistils below; each stamen is a staminate flower and each pistil is a pistillate flower; there is no calyx or corolla or perianth, but the inflorescence is protected by a large, yellowish, leaf-like envelope called a spathe.

In some plants the stamens and pistils are in different 

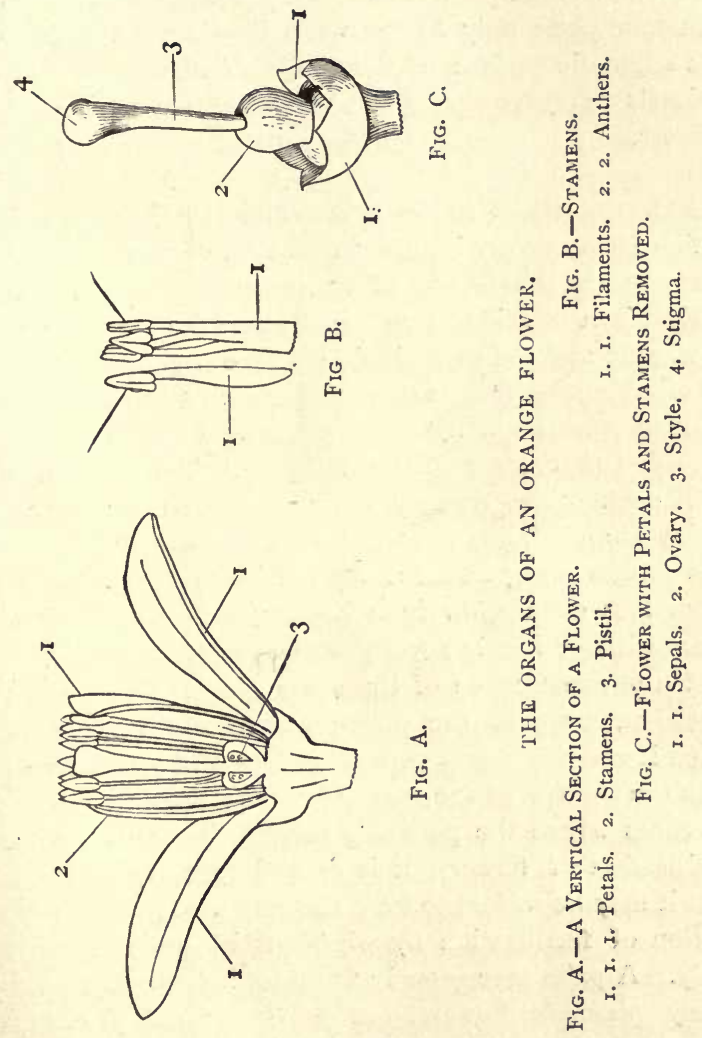
The arrange- flowers, or even in different trees, some trees, as in the case ment of the
stamens and the nutmeg, producing staminate or male flowers, and pistils. others producing only pistillate or female flowers. When this happens the plants are called dicecious, and fertilisation can take place only by the wind blowing the pollen on to the stigmatic surface of the pistils, or by insects and other animals carrying the pollen from the male to the female flowers.

Fertilisation of the date palm.

FERTILISATION BY Winds.-The date palm, the fruit of which forms a very important portion of the food supply of many of the inhabitants of western tropical Asia and north Africa, is a diœcious tree usually fertilized by the agency of winds : and the people often secure a good crop of dates by climbing the female trees and shaking the pollen of the male flowers upon the female ones. Indeed, it has been recorded that some of the nations of Africa, when at war with each other, destroy their enemies' male date trees, which are much less numerous than the female ones, and by this means bring about a famine in the land. A female palm tree once grew in a hot-house in Berlin for eighty years without bearing fruit, when, on it becoming known that a staminate tree of the same species was flowering in Dresden, some of the pollen was sent for by post, and when it arrived it was sprinkled over the pistillate flowers with the result that the tree became fruitful and bore a crop.

Wind-blown In cases where the pollen is carried by the wind for the
pollen. fertilisation of flowers, it is exceedingly dry and light so that it may be wafted to long distances. A wonderful illustration of fertilisation by wind-carried pollen occurred in Italy. A palm tree grew in Otranto, it bore year after year many pistillate flowers, but no fruit was produced, although the tree was healthy and vigorous. After many seasons, a male tree of the same species blossomed at Brindisi, and soon afterwards the tree at Otranto was laden with fruit. The wind had carried the pollen a distance of 
twenty-four miles: and, year after year, although the trees were so far separated, the one was able to fertilize the other.

FERTILISATION BY InsECTS.- There are innumerable plants the flowers of which are unable to fertilize themselves, and are incapable of being fertilized by the agency of winds. In some instances, too, although perfect stamens and pistils occur in the same flowers, they do not develop at the same time, and thus the pistils of one flower must be fertilised by the pollen of another. This provision, which is called cross fertilisation, is very common, and it is a wise provision of nature to enable the plants to produce better seed. In other instances, as in many orchids, aristolochias, \&c., the stamens are so situated as to be quite unable to cast their pollen on to their own stigmas, or on to the stigmas of other flowers; and, therefore, the pistils could not be fertilised, and the plants could not produce fruit and propagate their species without the agency of insects or birds.

Most persons in the West Indies have noticed, at some time or other, butterflies, bees and humming birds flitting from flower to flower in the bright sunlight. The butterflies dart their long probosces right into the corollas; the bees creep into the flowers; and the humming birds, ap- Humming parently motionless, but really beating their wings with birds and wonderful rapidity, remain poised in front of a flower whilst they probe it to the bottom with their long and slender beaks. The humming birds, the bees, the butterflies, the The nectar beetles and the moths all go to the flowers to rob the nectar and acts bird -a juice containing sugar secreted at the time of pollination - that is, when the stigma is ready to receive the pollen. This nectar is industriously collected by bees, and it is stored up by them in the form of honey. The nectar is secreted by glands on the axis or stalk to which the various parts of the flower are attached, and in some cases it is secreted 
by similar glands or cushions on the petals or the stamens themselves. On examination, these organs may be seen as a small swelling or as special receptacles or spurs, from which the-nectar exudes. All the various glands, cushions and receptacles exuding sweet juices, as mentioned above, are generally called nectaries.

Birds and insects ferti lise the flowers, whilst they feed on the nectar.
A wonderful example of the arrangements of Nature to ensure fertilisation by insects.

We have seen how insects and birds go to flowers to rob the nectar, but nature has wisely provided that they shall, at the same time, render a service to the plant by assisting in the important process of fertilisation. Flowers are of an infinite variety of form; but, no matter how the several parts are arranged, insects cannot get at the nectar without coming in contact with the anthers, so that the pollen escapes and clings to them. And thus, when another flower is visited, the pollen is brushed against the sticky stigma and so remains to effect its important work. This is the commonest way in which flowers are fertilised by insects, but in other instances the arrangement of the flower to effect pollination is simply marvellous. Aristolochia trilobata is a curious climbing plant that grows wild in Jamaica, Dominica, and other islands of the West Indies. Its flower is very pretty; there is no corolla, but the coloured calyx is formed like a pitcher with a curved swan neck. This neck has a lid-like covering prolonged into a tail which freely waves in the wind and thus serves to arrest the attention of insects. The lid prevents rain entering the pitcher, but it allows free access to flies and other small animals. The inner side of the neck forms a tube leading down to the inflated bottom of the flower; and it is set with hairs all sloping away from the entrance, and with their points directed towards the interior; so that, although they offer no obstacle to an insect entering the cavity of the flower, they effectually prevent its exit. A fly, then, entering the pitcher in search of nectar, is kept imprisoned until it has, by its movements, caused the pollen to be applied to the stigma; and when this occurs, the hairs gradually collapse, 
and the fly is free to get out, carrying with it, however, some pollen grains that may be useful to effect cross-fertilisation in another flower. The bright colours of flowers, and their The colour odours, seem to attract insects and other animals concerned odours of in fertilization, and it is generally seen that those flowers flowers. dependent on animals for pollination, have some characteristic-whether of colour, form, or odour, which serves to attract the attention and invite the visits of their welcome guests. Thus we see that Nature has wisely arranged that, whilst the flowers are feeding the insects, the insects are fertilising the flowers, to the end that the species may be propagated, and that man and the lower animals may reap a fuller harvest from the soil.

The SEED, or as it is sometimes called, the plant egg, is The seed composed of a very small body, the embryo or young plant, and the emand a store of nourishment-made up usually of starch or oil-for the infant plant to feed on until it is able to take up food for itself. The embryo and the food are contained within two hard envelopes which protect them from injury.

The EMBryo is the miniature plant, and it is composed The seed of the radicle, or root ; the caulicle, or stem; one or two contains food leaves, the cotyledons; and the bud, or plumule-which is plant until usually packed away in a little pit at the base of the cotyle- formed. dons. Of course all these parts, which correspond to similar parts of the developed plant, are very simple. They are in fact the rudiments or the unshaped beginnings of the perfect plant. The nourishment stored up in the seed for the first food of the young plant may be contained in the cotyledons-which are then thick and fleshy as in beans; or it may be apart from the cotyledons, as in the maize and the cocoa-nut ; but all seeds contain a supply of it, for otherwise they would not be able to become developed into plants, as the radicle cannot take up food from the soil until it grows into a regular root. 

The requi- GERMINATION.- When placed under favourable condi-
sites of germination. tions, the embryo begins to grow into the plant, and this vital action is called germination.

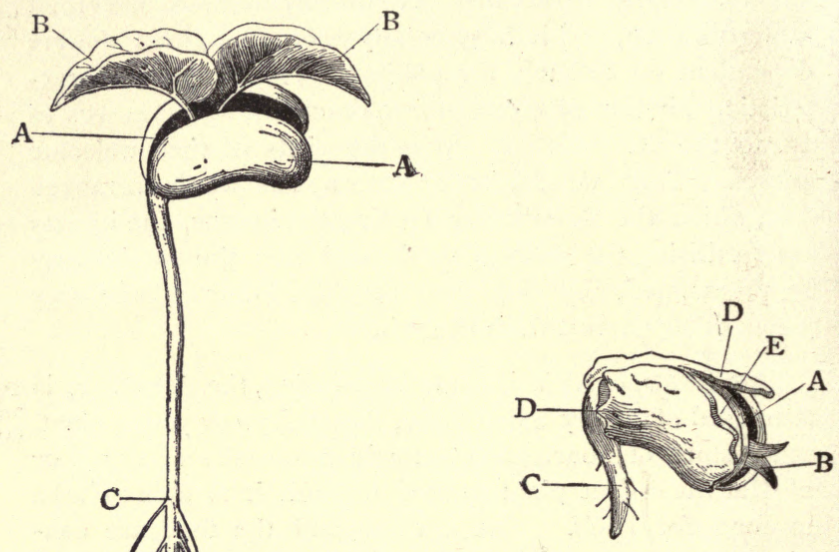

FIG. 2.

FIG. I.

STAGES IN THE GERMINATION OF A BEAN.

Fig. 1.-A. Cotyledons. B. Plumule developing leaves. C. Radicle developing roots.

Fig. 2-A. A. Cotyledons. B. B. Leaves developed from the Plumule.

C. Roots developed from the Radicle. D. D. Outer envelope of seed.

E. Inner envelope of seed.

The necessary conditions for germination are three, namely, the presence of moisture, warmth and air, and 
when these three requisites are present in proper proportions the following process takes place:-The seed absorbs moisture which causes all the parts to soften and swell so as to burst the coverings and allow the embryo to grow; at the same time certain chemical changes are taking place, for The process the insoluble starch or oil present in the seed is converted of germiinto a soluble substance like sugar upon which the miniature plant feeds. The carbon let loose by this chemical change Chemical ac. combines with the oxygen of the air to form carbonic acid. During all these changes heat is given off, and thus the seed Heat is supplied with warmth, to a certain extent, by its own vital evolved. action, but outside heat is necessary in the first instance; for, without its presence, the life that is in the seed could not be, as it were, wakened from its sleeping condition.

The embryo having burst out of the coverings of the seed, The growth the radicle pushes downwards into the soil to form the root, ${ }_{\text {embryo. }}^{\text {of the }}$ and the plumule grows upwards to form the stem and leaves. Nature has endowed the embryo with this property, and nothing whatever can prevent the radicle from going downwards into the soil, and the plumule from growing upwards into the air. If a seed be so planted as to have the radicle directed upwards, it will turn downwards as soon as it commences to grow, and the plumule will also turn round and strike upwards - this may often be seen in the case of cacao and other seeds which have been planted with the wrong end upwards.

The Nutrition of Plants. - It has been already seen that the infant plant is suplied with food from the store of nourishment kept for that purpose in the seed. But by the time the roots and leaves are formed, this supply has been eaten up, and the plant must now look to the soil and the air for its food. The leaves absorb the nourishment from How plants the air, and the roots take it up from the soil by reason of feed. the delicate hairs on their smallest fibres. In order that this process may go on, however, the nourishment must be dis- 
solved in water, for neither the root nor any other part of the plant can take up solid food. Sugar, salt and other such solid bodies, are easily dissolved in water; that is to say, the substances disappear in the water, but they still exist in a different form, as may be known by the taste. Now the water in the soil aided by carbonic acid and the acid fluid of the root-hairs, dissolves the various soluble substances in exactly the same way as water dissolves sugar. Ammonia, carbonic acid and compounds of lime, potash, \&c., are always present in a soluble form in a fertile soil, and thus they can be taken up by the roots and used for the nutrition and growth of plants. The carbonic acid and ammonia in the soil comes from the rain (which brought them down from the atmosphere) and from the decomposition or putrefaction of the animal and vegetable matter in the earth, but the inorganic compounds are derived from the soil itself; which, as we have seen, has been formed out of the hard rocks.

The Composition of Plants.-The whole process of the nutrition of plants will be better understood after a knowledge of their composition is gained. If a plant be The ashes of taken with its roots, stem and leaves, and destroyed by fire, plants. nothing will be left but a small quantity of ashes. About 95 parts have been burnt off, and only about 5 parts remain. The 95 parts have disappeared in the form of gas or vapour ; they are styled the organic or volatile portions, and they have come principally from the atmosphere. The ashes which are left are called the inorganic or mineral portions, and they have come from the soil. Sometimes the ashes are in larger or smaller proportions than 5 per cent., the limits being from I to 11 per cent., but 5 per cent. may be taken as the average quantity.

The organic The volatile portions of the plant are of two kinds, one portions are volatile.

containing all the organic elements except nitrogen-and called, therefore, non-nitrogenous, and the other containing 
all the four organic elements - and known as nitrogenous. In the former class are included cellulose or woody material, starch, sugar, gums, \&c.: and in the latter class are included protoplasm and chlorophyll. Protoplasm is that Importance part of the plant in which the principal vital functions are plasm. centred, and chlorophyll is the colouring matter of the leaves, and it is the agent specially concerned in decomposing carbonic acid so that the carbon is retained by the plant, and the oxygen is returned to the atmosphere. The inorganic portions of plants are silica, chlorinc, potash, soda, magnesia, lime, oxide of iron, phosphoric acid, and sulphuric acid; sometimes, manganese and other mineral substances may be found in minute proportions. These organic elements do not occur by themselves or in a free condition, but they unite with each other to form compounds, as for instance in the superphosphate of lime which is composed of phosphorus, calcium, hydrogen and oxygen. A knowledge The imof the composition of the ashes of plants is of the greatest of chemical use to planters, for they are then able to determine whether analysis of a particular plant can be grown with success on certain portions of their lands. Thus, if the land be deficient in lime, and the planter wishes to grow plants that take up much lime, he knows that the plants will not grow properly unless he gives lime to the soil in some way or other. The inorganic parts of the plants, as shown by the quantity of ash, are very small, but they are as necessary to the wellbeing of the plant as is the water which is contained in the tissues in such abundance. A soil in which all but one of Soils should contain all the necessary inorganic elements are found will not grow the inorganic the plant, for the absence of the element occurring in the found in ashes in the smallest quantity renders the soil less able to the plants. produce luxuriant vegetation of the sort desired. This explains the wonderful help that agricultural chemistry renders to the farmer or planter. He first finds out what is Value of the composition of the plant he wishes to grow and then has his soil analysed so as to see whether it contains all the 
elements necessary for the food of the plants, and whether these elements exist in an active condition. If not, he knows what to add to the soil, in the form of manure, to make it fertile; or, as we shall see later on, he finds out that tillage or rest will develop in the soil all the necessary substances in sufficient quantity and in a soluble form ready to be taken up by the roots of the plants. 


\section{CHAPTER V}

\section{PROPAGATION OF PLANTS}

IN a natural condition, plants are propagated either by seeds, by bulbs and tubers, by runners, by suckers or by buds. Man has, by his knowledge, increased the means of propagation by dividing the plants, by making cuttings of the stem and roots and by employing the process known as layering. There are, then, two principal means of propagation, namely, Two kinds of natural and artificial. Both methods are made use of in propagation, cultivation. artificial.

- Propagation bY Seeds.-In most instances plants reproduce themselves by their seeds and many of the crops grown by men are propagated in this manner. The production of seeds is the aim, and often the end, of the life of the plant. The seed falls to the ground and germinates, the plant grows, it becomes mature, and then it flowers and seeds-and often the seeding is the expiring effort of the organism. This is the circle of plant life, and it has been going on for countless ages in the same way as it goes on now. It will be noticed that many plants of the same Variation kind vary greatly in regard to their size, their vigour of often due to growth, their appearance of health, and the quality and conditions. quantity of their seed or fruit. Whilst one plant, growing in a good soil and under favourable conditions, will be luxuriant in appearance and prolific in its return of fruitor seed or leaves or root as the case may be-another plant 
of the same kind growing in a bad situation, and under disadvantageous surroundings, will be poor, sickly, stunted and nearly or altogether barren. Now the aim of the agriculturist is to produce healthy and vigorous plants which of good seed. will give him good crops, and one of the first things necessary to ensure that end, after he is satisfied that the soil and climate are suitable, is to select good seeds. In setting a fowl, no one would select the smallest and worst looking eggs, and then expect to get a fine brood of big chickens, and, in the same way, no sensible planter ought to expect to get strong and prolific plants from bad seed. In selecting the Seeds to be seed, it must be obtained from the healthiest plants, because got from the a robust parent is likely to have a progeny with similar
healthiest plants, characteristics, for the same laws of nature operate as well and largest in the Vegetable as in the Animal Kingdom. The seed, and best seed then, must be chosen from the best plants, and the largest
selected.

Improvement of fruit.

and best seed should be selected from these plants. In this way, the planter will ensure a large proportion of fine seedlings; and if the same process of selection be carried on for a series of years, there is every chance that our West India fruits, \&c., will be greatly improved. Too little attention has hitherto been directed to these important matters, and this fact accounts for the comparatively inferior fruits that are found in these countries.

Propagation by Bulbs and Tubers. - Bulbs and tubers may appear on plants either above or below the ground. In Yam tubers. some yams both kinds are found in the same plant. If yams were left in the ground they would give off tubers and then the parent plant would die. Afterwards the tubers would grow up and form a collection of plants in the same place. But as these plants would be too crowded to thrive, some would die, and thus the plants would be propagated by nature to a certain extent only. Man steps in, however, and separates the tubers, and by placing them all under favourable conditions he is able by artificial methods to 
increase the number of plants from the parent yam-and, consequently, to obtain a much greater yield. This is a case in which natural methods of propagation are made use of by man for his own advantage.

Propagation bY RUnNers.-This mode of propagation is well seen in the strawberry plant and in some running grasses. A slender branch is sent off from the base of the stem, it runs along the ground, and at its end produces a new plant. The branch withers and dies as soon as the new plant is rooted. Some plants also have creeping stems rooting all along their under surfaces, and developing new plants from buds on the upper ones.

Propagation BY SUCKERS.-Suckers are merely modifications of runners; they are branches, or more properly speaking underground stems, which may be very long or short, given off below the ground, and then, after rooting, they grow up into the air and eventually become independent plants by the decay and separation of the underground stem which connected them with their parent. The plantain and banana are familiar examples of this process of proBanana pagation, for they very rarely bear seed, and man is dependent on the suckers for the plant to supply the important food borne by them. Botanists make several divisions of suckers and runners, giving them different names according to their characteristics, but for all practical purposes the young agriculturist may consider runners and suckers as the two necessary divisions.

PROPAGATION BY LAYERS.-In certain instances this pro- Layering cess, which is much used by gardeners to propagate plants, natural is a natural one. If branches of some plants by their own process. weight or by some accidental circumstances, bend down to the ground and remain still on damp earth, roots will be given off from the underside of the branch, and in time the branch may become an independent plant. This process 
has been copied by man, who now propagates plants by it at will. The branch to be layered is bent down to the earth, or to the soil placed in a pot or a box, and kept immovable by a peg or by some other contrivance, and in order to stimulate the branch to give off roots, the connection with the present stem may be partly cut through, or be twisted or even broken. After a time roots will be formed and then the connection may be severed altogether.

Propagation By Division.-This is a very simple and sure way of multiplying those plants that have many roots and stems-such for instance as guinea grass, cardamoms, ginger, arrowroot, \&c. The whole plant is dug up, the earth shaken from the roots, and then it is divided into as many

One bud at least to be left.

Seedlings often vary from parent plant.

Cuttings to be taken from the best plants. plants as it can safely give. Care must be taken that, at least, one growing bud is left on each divided plant, otherwise the new plant will not grow properly.

PROPAGATION BY CUTTINGS.-This is a very important way of propagation, for by it the individual peculiarities of the plant are maintained. In the case of seeds there is often a variation between the parent plant and the seedling, but this is obviated by multiplying the individual by cuttings. The cultivation of the sugar cane is carried on by cuttings, and bamboos, sweet potatoes, cassava, \&c., are propagated in the same way. Cuttings should always be cut across as smoothly as possible, just below an eye or bud on the stem or branch of the plant, and in this way there is more chance of the cutting striking root. In the propagation of plants by cuttings on a large scale, as is done in the West Indies, sufficient care is not taken to secure good parent plants. The writer of this work has often seen sugar cane "plants," as the cuttings are sometimes called, taken from the worst and smallest canes in the field, and then the planters have been surprised afterwards to find their canes puny and backward. But a cutting will always reproduce the peculiarities of the parent plant, and vigorous sugar canes 
cannot be expected to grow from cuttings of inferior plants. In the temperate and cold regions of Europe and America, where tropical plants can be kept alive only in hot-houses, their propagation is carried on chiefly by cuttings, and the gardeners have become very skilful in raising plants in this way. In fact many plants can now be raised Plants raised from simple buds, or even from leaves or portions of leaves, and leaves. but these processes do not much concern the tropical planter. It may, however, be pointed out that the principle of the process may easily be made out in the case of the common begonia, a leaf of which placed or pinned down on damp earth will eventually produce several perfect plants. 


\section{CHAPTER VI}

\section{CLIMATE}

Climate controls the growth of plants more than anything else, and one of the first questions the planter has to consider is whether the climate is suitable to the cultivation he intends

Plants must be grown in suitable climates. to take up. The soil of parts of Holland may be suitable in every way to the growth of the sugar cane, and the soil of Jamaica to the growth of beet-roots for sugar, but the climate, in both instances, prevents the possibility of success, if even any one were foolish enough to try it. And yet the Jamaican succeeds with the sugar cane, and the Dutchman makes sugar from his large crops of beet-roots, for the reason, simply, that the climate of Jamaica is adapted to the cane, and the climate of Holland to the beet.

What

climate is.

Climate implies the greater or less degree of heat and light and moisture - that is to say, the principal conditions that affect vegetation and render a country fit for the abode

Latitude. of man and animals. Climate is generally determined by latitude ; it is hottest at the equator, and it becomes colder the nearer we approach the poles. This general rule, however, is subject to exceptions, the chief one being eleva-

Elevation. tion above the level of the sea. Near the equator there are mountains over $16,000 \mathrm{ft}$. high, the summits of which are covered with snow all the year round. Humboldt, the great German explorer, discovered that the thermometer fell one degree for every 343 feet of elevation, and thus in mountainous countries the climate really depends on the height 
above the sea. This is very noticeable in small mountainous Mountain islands like Jamaica and Dominica, for whilst at the sea level climates. the climate is hot and tropical, in the higher mountains it becomes cool and temperate. On the sea coast the mango and the sugar cane and the cocoa-nut flourish, whilst European fruits and vegetables cannot be cultivated; but in the heights of the mountains, the mango and cocoa-nut will not thrive, and yet European plants live and fruit and may even run wild, as in the case of the strawberry on the Jamaica cinchona plantations.

Forests exert a very marked effect on climate, especially Forests. in the tropics, the dense foliage preventing the rays of the sun from reaching the earth, and thus the atmosphere is affected by cool vapours. When the forest is cleared away, Cultivated however, and the land is brought into cultivation, the air and warmer. becomes drier and warmer, and so does the soil also. A similar effect takes place when swampy and marshy land is drained and brought into cultivation.

When the atmosphere is loaded with clouds and vapours as is the case in all maritime countries, the climate is much more equable than in the interior of the continents. But lakes and marshes have a bad effect on climate; they give rise to fogs, especially at night, which chill the ground and render the place unhealthy.

Aspect has also an effect on climate, a northern and an Aspect. eastern aspect being, as a rule, colder and moister than southerly and westerly ones; but, as aspect depends on the sun, in a mountainous country it is often affected by the lay of the land; ridges, alternating with valleys or ravines, causing a wide difference in the climate of places near to each other. In a narrow valley, one side, being mostly in Valleys. the shade, may be cool and damp whilst the other side is warm and dry, and thus plant life would differ materially on either slope.

Exposed and windy situations have a different climate from Exposure. sheltered places, although the soil and rainfall and aspect 
may be about the same ; but this, happily, in most instances the agriculturist may control, for shelter belts of trees will often convert an exposed and barren place into a thriving plantation.

Soil. The soil has a great influence on climate, the temperature for instance of countries, whose surface is covered with sand, being much higher than the temperature of those in

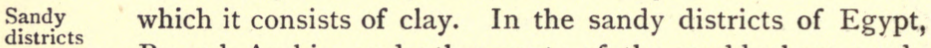
usually hot. Bengal, Arabia, and other parts of the world where sandy deserts exist, the heat is intolerable in certain seasons of the year 


\section{CHAPTER VII}

\section{MANURES}

Exhaustion OF THE SOIL.-It has been shown that growing plants take up certain substances from the soil in a soluble condition, and these substances-which are called Active active constituents-exist in the soil in a small proportion constituents only. If land be continually cropped, therefore, and no means be taken to restore the substances removed away in the crops, the soil becomes gradually exhausted, and the land loses its fruitfulness. In nature this does not happen, Uncultifor, in forests, the constituents of the soil are returned by vated land the decay of the leaves and branches and trunks which fall become to the ground; and, on prairies and savannahs where wild exhausted. animals roam, the return to the earth of the substances eaten as food, is continually going on, for the animals manure the land with their excrements in life, and with their bodies when they die.

The land must be regarded by the planter as a bank in Theland the which he has opened an account. If he continually draw planter's cheques on the bank, and make no fresh deposit to meet the drain, he will sooner or later come to the end of his capital, and the same argument applies to the soil. In cacao and Bad culticoffee cultivation in the West Indies, particularly on lands vation. of peasant proprietors, one often sees the planter take away crops year after year, whilst he does next to nothing to make up for the heavy drain on the land; and, then, after a time, he finds he gets.very small crops, and he thinks the 
fault lies with the trees, or that the soil is not adapted to the cultivation, whereas the fault is entirely his own, as he has gone on taking away from the soil without putting anything back.

Fertility to be restored by rest, as well as by good cultivation.
Chemical action of manures.

Mechanical action.
General manures the most valuable.
Exhaustion may, in certain instances, be partly prevented by rest and by propercultivation. As, for instance, when the land is dug or ploughed up in order that the dormant constituents may be made active; or when the cropping is stopped by allowing the field to remain fallow. But this can be done only in those cases where cultivation such as sugar cane or corn is carried on; for cacao and coffee, and other such plants, are practically permanent, and so the land cannot be fallowed, and the crops cannot be stopped. It is in these cases, then, that manure and tillage operations are so useful and necessary.

THE ACtion of MANURES.-The principal action of manures is to restore the fertility of an exhausted soil ; to enrich a naturally poor soil ; or to prevent exhaustion by giving back to the soil, in a suitable form, the various elements taken away in the valuable crops. Besides the action of adding plant food to the land, manures act chemically on the organic and inorganic constituents of the soil ; they render some of the dormant substances active, and in this way they liberate plant food that was, as it were, locked up in the land. A third, and an important action, is a mechanical one, for manures improve the physical condition of the soil by making tenacious and heavy clay land lighter and more porous, and by binding together sandy soils and making them more capable of retaining moisture.

General and Special Manures.-Manures are usually divided into these two classes. A general manure is one that supplies to the soil all the consituents removed by growing plants, not only from the soil but from the air. It contains, therefore, all the organic and inorganic elements found in the plant; and it is the most valuable kind of 
manure that can be used by the planter. Special manures, which are sometimes called artificial, on the other hand, contain one or more of the necessary constituents of plant food, and they are used when it is found that these constituents have been removed from the soil by heavy cropping, or do not originally exist in the soil in sufficient quantity. Baron Liebig laid down what he styled the "Law of Mini- Liebig's law mums," by which he meant that the crops are governed by of manures. the minimum of one, or several, of the inorganic elements of plant food. A soil may contain in excess all the necessary constituents for plant growth except one, and if that one be supplied artificially the fertility of the soil is ensured. The application of a manure containing a plentiful supply of the one deficient substance, shows the principle of special or artificial manures; but it shows, also, the necessity of accurate knowledge of the soil and of plant life, in order to determine what ought to be the exact composition of the artificial manure the planter proposes to make use of. The indiscriminate and ignorant use of these manures frequently Indiscrimidoes permanent harm to the soil, without increasing the mate use of crops; and then they entail an outlay in money that brings often does no profit, and that often causes loss.

General Manures may be divided into three classes, namely-1. Farm yard manure. 2. Green crop manure. 3 . Waste products.

Farm yard manure consists of litter (straw, cane trash, Sc.) which has been trodden down by horses, cattle, pigs or sheep in stables, cowsheds, pigsties and pens, and mixed with the solid and fluid excrements of the animals. It is the most valuable manure that can be put on the land, Value of for it enriches the soil more than any other substance can $\begin{gathered}\text { farm yard } \\ \text { manures. }\end{gathered}$ do, it exerts a beneficial chemical, as well as mechanical effect on the land, and no other manure is so lasting in its action. Its quality, and therefore its effect on the soil, varies greatly according to the animals producing it and the kind 
of food that is given to them. Young animals use most of their food to build up their bodies; and, consequently, the manure from them is not so valuable as that from fully grown ones. And animals that get rich food produce much richer manure than poorly fed ones. For instance, horses Well-fed fed partly on corn or oats, or seed cake, give a more valuable animals give the best manure. manure than animals merely fed on grass; and, in England and elsewhere, cattle are often fed highly in order simply to enhance the value of their manure, and it is frequently found cheaper, in the end, to expend money in this way than in the purchase of artificial manures. Fermenta- When farm yard manure is put in a heap it commences to
tion. ferment, and this is caused by the rapid growth of myriads of low vegetable organisms of the nature of moulds. This fermentation produces heat and causes important changes to take place in the manure, whereby it is rendered more fit for the formation of plant food. Sometimes an odour of ammonia is easily discovered, and this shows that the heap is too dry and that water should be thrown upon it. And when the heap is exposed and heavy rain falls on it, a stream of black liquid stuff will run out. This is very valuable and should not be lost. It ought to be collected and poured back on the heap or on to the soil, where its high fertilising action may be useful. This liquid manure contains ammonia and other organic substances, and hence its value as Dung heap plant food. If possible, the dung heap should be kept under under cover. cover, and then there will be no chance of heavy rains washing away its valuable substance.

Compost is a kind of farm yard manure composed of all the animal and vegetable refuse the planter can lay his hands on. Weeds, dead leaves, road and gutter scrapings, dead animals, kitchen waste, and any other thing of the kind, are heaped up together and allowed to rot, when a compost. valuable manure will be formed. Its value may be increased by pouring some of the liquid manure over it, and by turning it sometimes, so as to assist the fermentation by allowing 
air to enter. The addition of a small quantity of lime stirred into a compost heap improves the quality of the manure immensely, as it assists in forming nitre (or nitrate of Nitre. potash), a very important fertilizing substance-which is too expensive, however, to be much used as an artificial manure. It must be remembered in regard to dung and compost heaps that they must not be kept too long, for otherwise the exposure to the weather, and the excessive fermentation, zause a deterioration in the value of the manure as a plant food.

Waste products of towns and villages form excellent manure, and a good planter will be very glad to obtain them to put on his land. Blood and bones, and other refuse from slaughter houses, decayed fish, hair, wool, rags, saw-dust, sweepings, night soil, \&c., \&c., are all useful to increase the fruitfulness of the soil. They should be put on the land Nothing capable of forming manure to be lost. and dug or ploughed into it and they will well repay all the trouble and slight expense the planter has incurred in obtaining them.

Green Crop Mamuring.-By this term is understood the digging or ploughing into the land of growing crops in order that the roots, stems and leaves may decay in the soil and so add to its food constituents. In England and other countries, clover, grass, turnips, rye, mustard, vetches and such plants are raised on lands simply for the purpose of being afterwards ploughed in as green crop manures. This system has been found to answer admirably for restoring the fertility of exhausted soils. It does this by giving to it nitrogen taken from the atmosphere. Recent scientific research has shown that leguminous plants, especially such as clover, peas and beans, have the property of absorbing nitrogen and yielding a large crop of nitrogenous fodder, while the soil by reason of the tillage is often richer and better able to produce other crops. This system is extremely well suited to light fertile soils. It is not advisable to use it where the soil is heavy and retentive. In a modified way it 
Leguminous has been tried with success in the West Indies in cane plants as green crop manure.

cultivation; pigeon peas and what are called Bengal beans in St. Kitts have been raised and then cut down and ploughed into the land; but the system is not followed so widely as it deserves. Another way in which the plan could be employed would be by burying in the ground the heavy crops of weeds that the abundant rains of the West Indies do not fail to make the land produce. The weeds should be Weeds not to hoed up before they seed, for " one year's seeding makes be allowed to seed.

seven years' weeding," as the old proverb says, and to bury the seeds in the soil is to preserve them for future germination.

Sea-weed, fern foliage and all other similar vegetable materials that may be obtainable, make excellent green crop manures, and those West Indian planters whose lands lie near to forests, or to a shore strewn with sea-weed, should not neglect the opportunities thereby offered, of a plentiful and cheap supply of manure that contains many if not most of the elements necessary for the food of cultivated plants.

Cheap

SPECIAL MANURES are often called artificial, not because manures. they are all made artificially, but in order to distinguish them from farm yard or natural manure. There are many kinds of special manures, but they may be all referred to Four classes four principal classes, namely :- I. Nitrogenous manures. of special manures.

2. Phosphatic manures. 3. Calcareous manures. 4. Potash manures. If farm yard manures could be obtained by all planters in sufficient quantity for their lands, there would be no necessity at all for special manures; but it is very rarely the case that enough general manure can be obtained on an estate, and the successful agriculturist is forced to fall back on the various special manures that chemical science has shown to contain the elements of fertility wanting in his soil.

Nitrogenous Manures, as their name implies, are rich in nitrogen, which, as we have seen, is an important plant food 
carried to the earth in the form of the ammonia and nitric acid of the atmosphere. As nitrogenous matters exist but Nitrogenous sparingly in most soils, they are easily exhausted when crops matters in are continually reaped off the land; and hence the exhausted. necessity for restoring them in the form of special manure, if the soil is to be kept fertile. The most important and the best known of the nitrogenous manures is Guano, which, as a fertiliser of the soil, ranks next to farm yard manure. It is the dry dung of sea-birds, found principally on the coast Composition and the adjacent islands of Peru, and it contains from 8 to ${ }^{\text {of guano. }}$ 20 per cent. of ammonia. As rain rarely or never falls in these places, the dung has retained its soluble nitrogenous constituents and these give value to the manure. Some of the best guano deposits have become exhausted, and so the manure now supplied under that name is very often of an inferior quality, hence the necessity of particular care in purchasing the article ; some buyers, indeed, exercise so much caution in the matter as to require a chemical analysis of the manure they are about to purchase. Guanos contain phosphates of lime and magnesia, and sometimes these substances are in such large proportions as to render the manure partly a phosphatic one. Rain and sea-water dissolve out the nitrogenous substance, and when guano is taken from places subject to these influences it is found that the nitrogenous matters are low in quantity and that the phosphates Two kinds are abundant. Consequently there are two kinds of guano of guano. one remarkable for its nitrogenous substances which is called nitrogenous guano, and the other called phosphatic guano on account of the abundance of phosphates in it.

The principal other nitrogenous manures are sulphate of ammonia, and nitrate of soda. They are richer in ammonia than even guano; and, as they are very soluble, they are used to stimulate, or to whip, as it were, the soil into doing Soil stimumore work; they are on this account sometimes called lants. "stimulants" or "whips." Their effect is immediate and marked. In a few days after application of the manure, 
the foliage becomes greener, abundance of fresh leaves are thrown out, and the succeeding crop is large. Sulphate of ammonia was formerly one of the "waste products" of the gas manufactories. Nitrate of soda, or "Chili saltpetre" is a white salt-like substance found in enormous beds, sometimes eight feet thick, in the rainless parts of Peru and Chili.

Phosphates in the soil liable to exhaustion.

Worn-out pastures.

"Boning " land.

Fermentation of bones.
Phosphatic Manures.- Phosphorus, in the form of Phosphoric acid, is an important plant food, and it is classed as one of the secondary organic elements. It cannot be obtained from the air ; and, as it exists in the soil usually in very small quantities, it is one of those substances that are liable to be exhausted by continuous cropping, and thus it must be supplied in the form of a manure. It is present in all general manures, and some of the special manures contain it in large quantities and hence they are called phosphatic manures. Phosphorus is a very important constituent of the bones of animals and the milk of cows, and when cattle are grazed on pasture land for any length of time they exhaust the phosphoric acid in the soil by taking it up in the grass, and by "fixing" it in their own bodies. This is the principal reason that pastures become " poor" or "worn out" or " used up," and it has been found by experience that the application of phosphatic manures to a worn-out pasture will soon restore it to a luxuriant condition. The principal phosphatic manures are bones, superphosphates, and reduced phosphates.

Bones contain about half their own weight of phosphate of lime, all of which has been taken by animals from the soil in their food. For a long time past bones have been used as manure. They were broken into small pieces with hammers and spread over the land, and this was called "boning" the soil. But bones do not readily crumble away, and so they were ground to powder, and in this way they acted quickly. It was found afterwards that they would ferment if moistened with water and kept in a heap exposed to the air ; and, as the fermentation causes the bone to decompose, or break 
down into its various constituents, this system was a marked improvement. Baron Liebig, however, to whom agricultural science owes so much, found out a cheap and rapid way to prepare the bones for manure. He acted on them by sulphuric acid, producing a dissolved bone manure, and in this condition the phosphate of lime becomes quite soluble and ready to be used as a plant food.

Mineral Phosphates. - The demand for phosphatic manures becomes so great, owing to their important action on the soil, that the supply of bones could not keep up with the demand, and other sources of phosphates had to be looked for. Fortunately, large quantities of fossils of ex - Phosphatic tinct organisms, and petrified excrements containing phosfossils. phates, known as coprolites, were found in the Eastern counties of England, and in various parts of the continent of Europe, and they were soon utilized for phosphatic manures. Besides coprolites, deposits of mineral matters rich in phosphates have been discovered in practically inexhaustible quantities in various parts of Europe and America. In the West Indies, mineral phosphates are mined in West Indian the Islands of Sombrero, Redonda, St. Martin, Aruba and phosphates. Navassa. Except in the case of the Redonda deposits, the phosphoric acid in the mineral phosphates is combined in various proportions with the metal calcium, and in the $\mathrm{Re}$ donda mineral the acid is combined with alumina, forming phosphate of alumina. The mineral phosphates are usually of a very hard rock-like character, and before being used they are ground to powder; but, as the phosphates in them are, for the most part, in an insoluble condition, and, therefore, not easily taken up by the plants, it has been found necessary to dissolve them in sulphuric acid so as to improve their manurial value.

Superphosphates.-The discovery of the way to convert the insoluble phosphate of lime, or calcium, of bones and minerals into the soluble form has been of immense service to scientific agriculture. The insoluble phosphate is com- 
Chemistry posed of three equivalents of lime in combination with of the
phosphates. phosphoric acid, and it is called tribasic, or tricalcic phosphate because the base of the compound--the lime, is treble. It may be thus expressed:-

$$
\text { Phosphoric acid }\left\{\begin{array}{l}
\text { Lime. } \\
\text { Lime. } \\
\text { Lime. }
\end{array}\right.
$$

If bones be simply broken up and put into the soil, after a time the tribasic phosphate becomes converted in a sparingly soluble dibasic phosphate by the action of carbonic acid and water. Thus-

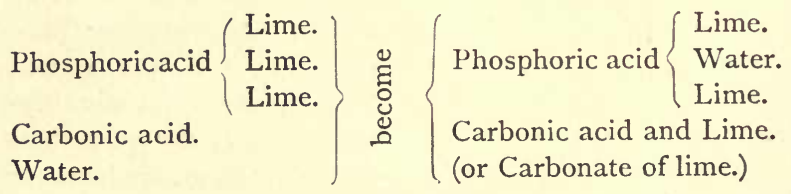

But when sulphuric acid is poured on tribasic phosphate, a perfectly soluble monobasic phosphate, and sulphate of calcium (or gypsum), are formed. The chemical reaction is easily understood from the following equation.

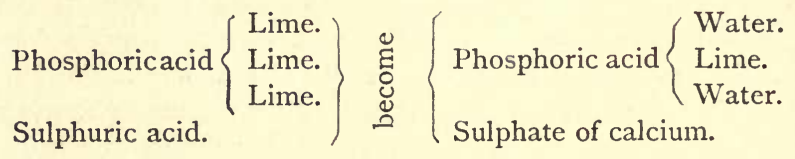

This soluble monobasic phosphate is called a Superphosphate because the proportion of phosphoric acid to the lime is above what it is in the other phosphates.

Objection to superphosphates.
Reduced Phosphates.-Superphosphates are very soluble, and it has been found, for this reason, that they are unsuitable for some soils, as they are too easily washed out by rains, and it has been discovered also that they are too acid for plant food, and, therefore, useless until they have been so acted on by other substances in the soils as to be available for the use of the plant. In calcareous soils the super- 
phosphates are at once acted on by the lime, and their acidity is reduced, and they become dibasic phosphates- Dibasic which is the best form for plant life; but in soils where phosphates there is not much lime this process cannot take place, and the soil. agricultural chemists have made reduced phosphates, which are simply these dibasic phosphates of lime.

Thomas-Gilchrist Slag.-Within the last few years a valuable phosphatic manure has been made from slag-a substance which was formerly a waste product given off in Formerly a the process of purifying pio the process of purifying pig iron. This slag is a black duct.

blistered material that collects in quantities on the surface of the molten iron. It contains a large proportion of phos- Its compophate of lime, as well as metallic iron and its oxides, silica, magnesia, and oxide of manganese. The manure called usually "Thomas Phosphate Powder" is made by separating the metallic iron from the slag, and then reducing the remaining mass to a fine powder - in which form it is applied to the soils as other manures. It has been used with success A valuable on sugar plantations in British Guiana and elsewhere in the manure for tropics, and it is employed extensively in Europe : but, as it much iron. contains a large proportion of iron, it is not considered to be suitable for ferruginous soils.

Calcareous Manures.-Lime is an important constituent of all plants; and, although it is present in abundance in most soils, it is deficient in some. There are soils Lime acts also, such as stiff, heavy clays, where the application of lime and mehas a beneficial effect by its chemical and mechanical action. chanically It renders insoluble substances soluble, and it causes the cold, heavy clay to become warmer, and more friable and porous. Lime is applied to the soil in its ordinary state, and it is then called by the planter "raw lime," or in a crude state as chalk, marl, shells-which are composed mainly of carbonate of lime, and as gypsum or sulphate of lime.

When coral, or shells, or limestone, are heated in a kiln, the carbonic acid is driven off and pure lime or "quick- 
lime" is left. Cold water poured on quick-lime causes it to swell up, with the evolution of much heat, and then it falls down into a white powdery stuff which is much more bulky Slaked-lime. than the quick-lime was. This powder is called slaked-lime, and it has not such a burning effect as quick- or unslakedlime. Both forms are used as manure, the unslaked-lime being applied to vegetable soils containing deleterious vegetable acids. It neutralises the acids, and it forms useful compounds in the soil. Chalk, broken shells and limestone, and also marly and calcareous earths, are applied to soils in which there is a deficiency of lime. All these manures-for if one soil be added to another to increase the fertility it is

Lime to be applied to surface $\mathrm{cf}$ soils.

Uses of gypsum. still called a manure-should be kept near the surface, and not be ploughed deeply in, as lime sinks into the soil, and has a tendency, therefore, to run away from the roots of the plants.

Gypsum, or sulphate of lime, is often used as a manure. It is an ingredient of all superphosphates, and the phosphatic manures are to a certain extent calcareous ones. Gypsum, which consists of lime, sulphuric acid and water, is found in a native state in various parts of the world. Deprived of the water it forms the well-known "plaster-of-Paris." Formerly gypsum was added to dung-heaps, and spread on the floors of stables, \&c., as it was believed to have the power of "fixing the ammonia," that is, preventing it from passing away in the form of vapour; but now it is applied at once to the land, and it is found to be espectally useful as a manure for potato crops.

Potash MANURES.-Potash enters largely into the inorganic constituents of plants, as is shown by its being one of the chief of the substances found in the ashes. It is usually abundant in the soil, and it is only after heavy cropping that it becomes necessary to make up for its loss by the application of a potash manure. As it is contained in quantity in all plants, it is returned to the soil by the decay of weeds 
and the leaves of trees and bushes. One of the chief Importance reasons of the value of a general manure is the fact that of potash potash is an important constituent of it. When a potash manure was required it used to be supplied as wood-ashes; but, in parts of Germany, large beds of potash salts, known as liainit, have been discovered, and they have been dug out and used as manure. Kainit contains salts of magne- Composition sium and sodium besides those of potassium. In most parts of kainit. of the West Indies, however, potash manures are unnecessary, as the potash can be obtained from the abundance of refuse vegetable matters found everywhere. Ashes of plants, decayed weeds, and green crop manures will supply all the potash necessary for the growth of West Indian crops, except in cases-as on some sugar-cane estates-where the same crops have been raised for many years from the same soil, and where vegetable manures are obtained with difficulty.

Common Salt is sometimes used as a manure, but it does not come within any of the above four classes of special manures. It is a compound of the two elements sodium and chlorine, both of which are found in the ashes of plants. It is always present in the atmosphere of maritime countries, and it is carried down to the soil by the rains. It must not Salt, how be directly applied to tender plants as it would probably kill applied. them, but to canes and cocoa-nut trees it may be sparingly applied directly either as crude salt or as sea water. In sugar cane lands, far away from the coast, it is stated that it has been found advantageous to put some sea water into the cane holes at the time of planting, and when cocoa-nut palms are cultivated inland, and they do not thrive, an application of salt or sea water has often been found to make them grow vigorously and bear fruit. 


\section{CHAPTER VIII \\ ROTATION OF CROPS}

Active and dormant constituents of soils.

Fertility sometimes restored to soils by fallowing.

Different plants require food in different proportions.
It has been shown in the preceding pages that only a small portion of the soil can be dissolved out in water, and that this soluble portion is the only available one for plant food. Other and much larger portions are, however, in a dormant condition, and are, therefore, after a time, by the action of water and air, capable of being eaten up by the plant. But, when successive crops from one kind of plant are taken off the soil, the alteration of the dormant constituents cannot keep pace with the drain caused by the growing plants-which then become weak, sickly and unproductive. By resting the land or allowing it to fallow for a time, some of the dormant constituents become active, and fertility is restored; but, in certain cases where not much land is available, the loss of a year's crop is a very serious matter, and means have been devised to overcome the difficulty. One of these means is the application of manure. But then manure costs money, and it may not always be possible to obtain it. So the second system, called rotation of crops, is employed with success in many cultivations.

The ashes of all plants are not the same in composition; and, therefore, plant food is not always required in the same proportions. Some plants, as shown by their ashes, require a large proportion of potash and phosphoric acid; others consume much silica and require less potash and phosphoric 
acid; and others, again, want a good deal of lime and magnesia, and less of the other inorganic elements. For instance, turnips take up from the soil five times as much potash as wheat; barley takes up twenty-six times as much silica as wheat; and clover requires eight times as much lime and magnesia as wheat, and only one-sixteenth the quantity of silica. If, therefore, turnips be grown on the land one year, and barley, clover, and wheat be grown on the same land for three succeeding years, it is found that the soil in the four years gives a much greater return, with less injury to the land than if one of the crops were raised every year for four years. This is the system usually employed in Norfolk Norfolk in England, and it is called the Norfolk course of rotation. system of In some parts of the world the soil is so deep and rich that, with proper tillage, the same crops can be grown on it for numbers of years, without the application of any manure; but, even with this extra fertile soil, the time comes when exhaustion takes place, and in certain districts of the United States of America the land which was once exceedingly fertile has been almost ruined by constantly taking off the same crops. It is a principle in rotation that two grain crops should not succeed each other, but be separated by root or fodder crops. Thus it would be a very bad system to take maize crops off the same land for two years running; A suggested but, if tanias or yams be planted the first year, maize the course of second, sweet potatoes the third, and castor oil or some such crop the fourth, a very good rotation would be established. Unfortunately, in the West Indies, very little attention has been directed to working out a proper system of rotation, as has been done in Europe and North America ; and it is impossible, therefore, to lay down any precise rules for the guidance of all planters. But every one can make experi- The importments for himself, and it is not necessary, in the way of experiments. experiment, to plant more than a small portion of land, say 50 or 100 feet square. A good planter will be always experimenting in one way or another, in order, practically, to find out 
Improvements wanted in the tropics

Resting of various layers of the soil.

Mechanical effect on soils.

Rotation prevents blights. the value of manures on his land, or the results of rotation on his crops, \&c. Indeed it is mainly by experiments, conducted by scientific men and farmers or planters, that agriculture has become what it is to-day. In the tropics there is much room for improvement and cliscovery : and every planter, no matter how humble may be his position, is capable of making such discoveries by experiment as may be of material benefit to his neighbours, and perhaps to the world at large. Some of the most wonderful scientific discoveries of all ages have been made by humble workers, without the aid of any elaborate apparatus.

An important effect of rotation is the resting of the various layers of the soil. For instance, maize sends down its roots deep into the ground, and so derives much of its sustenance from the sub-soil. Potatoes and tanias, on the other hand, are surface feeders, and they eat up the soluble constituents of the surface soils, which were, to a great extent, left alone by the roots of the maize.

Rotation also exerts a beneficial, mechanical effect on the soil in two ways. Firstly, in the.preparation of the land each year for the different crops, the turning over of the soil causes its exposure to the atmosphere, and the dormant constituents are thereby acted upon by the oxygen of the air, with the result that the active and soluble constituents are increased in quantity. Secondly, the roots of the former crops, rotting in the soil, cause channels for the entrance of water and air in all directions, and thus the soil is made more porous, and the atmosphere is able to exert its beneficial effects not only on the surface but even in the sub-soil. In addition to all these advantages, a proper system of rotation prevents blights and keeps away destructive insects that confine their depredations to particular plants. When a crop intervenes on which these insects cannot feed they die of starvation, and are in this way got rid of. The same applies to vegetable blights, which are usually in the form of extremely minute plants belonging to the order of moulds or 
mushrooms. It is generally noticed that plants cultivated on the same land for many succeeding years are prone to be injured by vegetable blights and insect pests. In nature, a Danger of diversity of plants is found on the same soil; and, when interfering natural laws are much interfered with, there is the proba- of nature. bility of disastrous consequences ensuing. 


\section{CHAPTER IX}

\section{DRAINAGE}

IT has been shown in the preceding pages, that rain, apart from its action in dissolving the soluble substances of the soil, has a markedly beneficial effect in other ways. In the The effect of first place it washes down the carbonic acid, ammonia and rain. nitric acid of the atmosphere, and brings them to the roots of the plants. In the second place, the passage of the rain through the soil causes air to follow it, so as to fill up the vacant spaces left by the water as it descends to the sub-soil. A porous soil contains little spaces and channels between The soil is the earthy particles, for the soil is not properly solid, but not solid. consists of innumerable little pieces of wasted rock which do not fit into each other, but only touch at certain parts, thereby leaving open spaces in all directions. Now, when the soil is dry, these spaces are filled with air; and, when much rain falls, they become filled with water. But, as the

Porous soil. water drains down into the lower layers of the soil, fresh air is drawn in again - for the spaces cannot exist with nothing in them. This explains what is meant by the porosity of a soil, and it shows how advantageous it is for the planter to change a heavy, compact, and sodden clay soil into a porous one.

Another physical property of soil is that known as capillarity, and which has been considered in Chapter III. Capillarity, or capillary attraction, is due to the same cause as porosity ; but, in the case of capillarity, the particles of 
the soil are finer and more closely packed together, and each Fine partiparticle is surrounded by a thin layer of water in which are dissolved substances useful for the nourishment of plants. by a thin Capillary attraction may be easily demonstrated by taking water. two small sheets of glass, and applying their faces so close together as to make them almost touch. If they be then dipped into water, it will run up for a distance on the inner surfaces of the two glasses. This action is capillary attraction, and to it is due the fact that all the water does not run out of a well-drained soil, but a portion remains to benefit vegetation.

When the rain, which falls on the earth, sinks down into the soil, and does not leave it sodden or saturated with moisture, the land is naturally drained; but in some Natural instances there is an obstacle to the water running off, it drainage. remains in the soil, it keeps the soil cold, it prevents the entry of the atmosphere, thus putting a stop to the change of the dormant into the active constituents, it becomes after a time impregnated with vegetable acids that are injurious Sour or acid to plant life, and it causes the roots to damp or rot off. The soils. reason that a damp soil is a cold one, is explained in several ways. In the first place the water is colder than the surrounding air, and the presence of the water prevents the air from entering in to warm the soil. Then again, the land Damp soils is rendered cold by the evaporation of the water. Every one always cold. knows that water left in a saucer, in the atmosphere, will gradually pass off into vapour-in fact, it will dry up. But the conversion of water into vapour carries off a good deal of heat, and this is the principle made use of in water-coolers Evaporation and goblets. These are made of porous earthenware abstracts through which the water gradually percolates and is then evaporated from the outside surface. This causes a great abstraction of heat, thereby making the water in the goblet, and the goblet itself, much cooler than the surrounding air. This is also what takes place in soils sodden with moisture, and the object of drainage is to remove the surplus water 
Drainage causes fertility.

Drainage pipes and tiles.

Outlet of drain to be kept clear.

Soil must not be overdrained. from the soil, and thus to make it warmer, to restore its porosity, to make it sweeter by the removal or alteration of the vegetable acids, and, in short, to make it more fertile.

Most of the land in the West Indian Islands being of a hilly nature, it may be easily drained by digging deep, open trenches so as to carry off the surplus water to the lowest part of the estate, or to a stream in the vicinity. The depth of the main trench or ditch will depend on the nature of the soil, the amount of water and the lay of the land, but it should not be less than three or four feet, as the roots of many cultivated plants go deep into the soil, and it does them much harm to be kept in standing water.

A more expensive way is to make covered drains, which is done in the following manner:- The trench should be dug wide at the top ; and at the bottom, which should be smooth and sloped gradually, it must not be wider than it can be made without the sides falling in. Along the bottom are placed drainage pipes or tiles. The latter are simply flat earthenware tiles curved in a semi-circular manner, and they form an arch to allow the water to run freely underneath and to support the earth with which the trench is filled up. Small stones and pebbles should first be placed over the tiles; or, if they cannot be got, brushwood or straw or cane trash may be used; surface earth, but not the clay from the trench, is then filled in over this, and the drain is complete. The outlet must be kept clear, and provided this be done there is very little chance of the drain becoming choked. Another way is to fill the trench nearly to the surface with stones, large ones being placed at the bottom and smaller ones on top.

Of course in draining land, as in all other agricultural operations, experiments will often teach useful lessons. By deepening drains, or by running cross drains into them, the fertility of the land may be much increased, but care must be taken not to overdrain a soil. The object of drainage is not 
to make the land absolutely dry, but to prevent the stagnation of water in it-that is, to make the rain water pass slowly through the soil, allowing it to leave in its passage sufficient moisture to keep the soil moderately damp below the surface. In light, porous soils, drainage operations must not be carried so far as in heavy, clay ones ; indeed the porosity of the soil and its capability of holding moisture, will always indicate to an intelligent person acquainted with the principles of agriculture, what amount of drainage is necessary for his lands. 


\section{CHAPTER X}

\section{IRRIGATION}

Drainage means the removal of water from land where it

Objects of irrigation. exists in too large a quantity. Irrigation means the reverse, namely, the application of water to land where it does not exist at all, or where its quantity in the soil may be increased so as to benefit vegetation. A good deal has been said about the necessity of water to fit the soluble part of the soil for plant food. Without water, therefore, plants cannot Arid regions. live, and in the large, rainless tracts of land in Peru, Bolivia and Chili, and other parts of the world, there is no vegetation, except in those places to which water has been carried by irrigation. Water may be conveyed to the land by canals, or pipes or spouts, from rivers, or lakes, or ponds, or it may be pumped up from wells and thence distributed over the soil.

The art of irrigation comprises two essential particulars, namely, to give a supply of water to growing plants; and, at the same time, to prevent the supply being so great as to cause the soil to remain sodden with moisture. If, thereProvision fore, canals and trenches be made to carry water, to irrigate must be made to get rid of surplus the soil, particular care must be taken to provide canals for taking away the water after it has passed through the land. In some cases, the water is simply conducted through the land by the canals, the soil obtaining its supply by the water percolating through the porous earth. Another system is to have a series of transverse trenches on the sloping land. 
The water is conducted to the upper trench or canal, and it Irrigation overflows and runs along the surface, to collect in time in trenches. the second trench. After the second trench is full, the water in it overflows and runs down to the third trench, and this goes on in a similar manner until the water from the last or lowest trench is carried away to the river or to some lower level, where it will do no harm. This is called catch-work irrigation. In some countries, where large rivers run through Overflow of low lying land, as in the case of the river Nile in Egypt, and the river Ganges in India, the river itself is allowed to run over the land when its waters are swollen and full of rich mud. The waters are allowed to remain on the land whilst the mud settles, and in this way the fertility of the soil is enormously increased. The number of feet that the waters The rising of of the Nile rise above the lowest level, is a sure index of the crops to be expected in Egypt. A low Nile means short crops and distress amongst the people, whereas a high Nile indicates large crops and prosperity. In India too, a low Ganges means, sometimes, terrible famine in the lands it is unable to irrigate; and the great works of irrigation carried The irrigaon by the government of India, have happily prevented, in in India, many instances, the occurrence of famines, and turned poor districts with their miserable and sickly inhabitants, into Their benefihighly cultivated lands peopled with a healthy and proscial effects. perous population. 


\section{CHAPTER XI}

\section{TILLAGE OPERATIONS}

IF the soil were allowed to remain without any preparation of tillage, its upper layers would become so hard and compact that the seeds sown could not germinate; and, if seedlings of coffee or cacao were planted out, the young and delicate roots would not be able to penetrate the hard soil, and

The advan. tages of tillage.

Tillage increases the soluble constituents of the soil,

renders the soil porous, and destroys lastly, it is the means employed by the planter for getting weeds.

Good and bad tillage.

the plants would die. Tillage operations, which are really the breaking up and stirring of the soil, prevent all this, for they render the soil loose and friable, so that the seeds can easily germinate, and the young roots can push themselves through the soil with facility. But, besides this important effect, tillage acts in other ways on the soil. By digging and ploughing and by the various other operations the earth is turned over and exposed to the action of the atmosphere, by which means, insoluble portions of the soil are rendered soluble and thereby become available for plant food. Another effect of tillage is to render the soil more open and porous and thus to facilitate the passage of water through it. And rid of the weeds which are ever ready to eat up the food that ought to be kept for his crops. A properly tilled soil is therefore free from weeds open and porous; and a badly tilled or untilled soil is hard on the surface, compact, and full of weeds ; and if it have any cultivation on it, the plants are poor and the crops are small. If a clean soil, after heavy rain, settle down with a hard surface, the tillage has been 
bad, but if the rain sink into the soil without forming a "crust" it is a good indication of proper tillage.

The deeper the soil is tilled, the better it is for the plants Deep tillage growing on it, as the atmosphere descends deeper, and thus acts on more soil, and prepares more plant food. This accounts for the advantages derived from sub-soil ploughing The sub-soil and from the holing of the land; which, as we shall see in to be turned the second part of this book, is the proper way to prepare the soil for cacao, coffee and other plants put in at a considerable distance from each other.

Tillage operations are of two kinds; namely, those per- Manual and formed by man himself with manual implements, and those implemtal performed with implements worked by horses or cattle, or by steam.

The implements of manual husbandry are,-(I) the cutlass, (2), the rake, (3) the hoe, (4) the spade, (5) the fork, (6) the dungfork, (7) the pickaxe, and (8) the digger or earthchisel.

The Cutlass is a long, broad, heavy knife with a short handle. It is one of the most useful implements of the West Indian labourer. By its means bushes are cut down, trees lopped and the land weeded to a certain extent. On steep hill sides, where the heavy rains would wash down the soil if the land were hoed up, the cutlass is used to clear away the weeds by cutting them off just at their roots. On an emergency, too, the cutlass may be used for digging small Utility of the holes, and for pruning off the large branches of trees. Some cutlass. men are so expert with this implement that they are able, with one swift sweep, to cut off a big branch of a tree, and the cut is as clean as, and indeed smoother than, a saw would be able to make it.

THE RAKE is a bar of iron along which iron teeth are arranged, as are the teeth of a comb. It is fixed on a long handle which is set at right angles to the teeth. Rakes are made of various sizes, and are used for raking up weeds and 
rubbish, and for breaking up the soil after it has been dug up and turned over.

THE HOE is also an implement used very extensively in the West Indies. It varies both in size and shape, but the one most in use is a plate of iron seven inches long and about six inches broad, sharpened at the cutting edge, and fixed, at somewhat less than a right angle, to a handle about Utility of the four feet long. It is used for digging, for turning over the hoe. soil, for weeding, and for drawing up earth to the roots of plants. A strong man can do a great deal of work with a hoe in the course of a day, and in places where a plough cannot be used it is simply an invaluable instrument for tillage operations.

THE SPADE is a flat blade of iron fixed to a handle about two feet nine inches long. At the upper edge of the blade, close to the insertion of the handle, a narrow piece of strong iron-called the tread-is fixed so as to allow the foot of the

The spade does better work than the plough.

The fork preferred to the spade. operator to push the spade into the ground. The spade is not much used in the West Indies, but it is a very valuable implement, and it really does better work than the ordinary plough. The soil is dug about eight or nine inches deep, and the spadeful of earth is thrown forward, being turned as it is thrown, so as to leave the under surface of the soil uppermost.

THE FORK is shaped somewhat like a spade, except that instead of a blade it has from three to five strong pointed iron prongs, called tines, at least an inch in width. It is a most useful implement, and for digging operations it is by many persons preferred to the spade, inasmuch as it is easier to use, it pulverizes the soil better, it does not so readily cut or injure the roots of cultivated plants, and in most soils the clods of earth can be turned over as easily with the fork as with the spade. It is used also for stirring up the earth around the roots of plants, and for "forking in " farm-yard manure and leaf moulds. 
THE DUNG FORK is made on the same principle as the cultivating fork, except that the tines, which are from two to six in number, are slighter in structure, more curved and of a rounder form. It is the only implement that can be used with facility in the loading, turning over, mixing and Utility of the dung fork. spreading of farm-yard manure, stable litter and such like substances. Being light, although strong in construction, it is not difficult to manage, and the sharp and thin tines easily penetrate compact farm-yard manure without the necessity of exerting much force.

THE PICKAXE is a strong, slightly curved bar of iron tipped with steel, into the middle of which a wooden handle is fixed so that the concavity of the curve is towards the operator. One end of the pickaxe is usually pointed, and the other end flattened out and sharpened like an axe. The handle must be of strong, hard wood of a pliable nature, for The handle a brittle one would soon break in use. The pickaxe is used to be careas a powerful double lever; and as an implement to break Adouble up hard soil, and to cut the roots of trees in the ground. In lever. digging holes, and in throwing down banks, the pickaxe is almost indispensable.

The Digger or EARTH Chisel is a very useful imple- The digger ment for holing the ground for planting cacao, lime, orange, useful for coffee and other young trees. It is a strong, heavy chisel, about four inches broad, fixed into a hard-wood handle about three feet long. In digging deep holes, where the pickaxe and hoe cannot be used, the digger is most serviceable.

The principal instruments worked by cattle or horses are ploughs, cultivators, harrows, and rollers. They all do the same kind of work as the manual implements; but, as they do the work much faster and cheaper, they are of course employed in cases where extensive tilling operations are to be carried out. 
The Plough is an implement used to perform the work of the spade. It consists of a curved blade of iron-the mould-board or turn furrow, terminating in a strong steel extremity-the ploughshare, and so arranged that it can be dragged through the earth by cattle, and guided by a man. In front of the ploughshare is a strong, knife-like, cutting instrument called the coulter, which cuts the earth and thus

The action of the plough. allows the free entry of the ploughshare, the mould-board then turns over the slice of earth to one side, thereby burying the weeds and exposing the under surface of the soil to the sun and air. Ploughed land is made up of alternate Ridges and ridges and furrows, and therefore a much larger extent of furrows. soil is exposed to the atmosphere, than if it were dead level. Some ploughs are made to run along the furrows made by the ordinary plough, in order to break up the subsoil, for it has been found that continual ploughing of the land to one uniform depth causes the subsoil to become so hardened and compact that the roots of plants cannot easily penetrate it. This compact layer is called a Plough pans. ploughpan, and one of the objects of the subsoil plough is to break it up.

The Cultivator or Grubber is an implement made on the type of the rake. It consists of a strong frame to which are attached many teeth, called tines, descending obliquely downwards and forwards. Its use is to break up the soil after it has been ploughed, so as to expose fresh surfaces for the atmospheric agencies to work on, and it also serves to draw out the weeds that have been torn up by the plough.

The HARRow is made in various forms; and it too is simply an extension of the type of the rake. Harrows are used for turning over and breaking up clods, so that the soil may be pulverized and the particles exposed to the air and sun. Some light harrows made of chain work are used to rake the soil over seeds that have been sown, and others are 
used to drag the weeds out of the earth when they have been loosened by the ploughs and cultivators.

THE Roller, as its name implies, is used to smooth the earth by being rolled over it. One heavy kind, called sometimes a CLOD CRUSHER, has strong projecting teeth so that it easily crushes up the clods of earth it is drawn over. The lighter kinds of rollers are used to press seeds into the earth, and to prevent too much evaporation from the soil by making the upper part more compact. 


\section{CHAPTER XII}

\section{PRUNING}

A knowledge IT is necessary for the tropical agriculturist to have a general of pruning necessary.

Effect of pruning. knowledge of the system of pruning in order that he may be able to improve his trees and to increase their fruitfulness. When a branch of a tree is cut off, much of the sap or nourishment that would have been used by it goes to the branches that remain, and more especially to those in the vicinity of the part taken away. Besides, by removing useless branches, or as it is called "thinning them out," more air and light are allowed to reach the remaining portions of the plant, and thus their assimilation of food from the atmosphere is increased. The effect of pruning does not always take place immediately, for sometimes it merely causes an increase of quantity of sap in the branches, which does not exert its influence on the fruitfulness of the plant until the next fruiting season.

Pruning causes extra developBut the removal of one portion of a plant, whether it be ment. the branches, leaves, flowers, or fruit, is always followed by extra development sooner or later. If, for instance, all the first flowers of young cacao trees be taken away, as they should be, there will be increased fruitfulness at the next season. And, if all the young fruit be taken off an orange tree, flowers will break out again and the crops will be reaped at a much later time. This is very important to West Indian planters, for oranges obtain much higher prices in Europe and North America in some seasons than in 
others; and, by removing the young fruit or pruning off the fruitful branches, the crop time might be altered somewhat at the will of the growers.

In pruning so as to increase fruitfulness, it is necessary Observation to observe, first of all, on what portion of the tree or plant the fruit is borne. In some plants it is borne by the wood of the same season's growth, in others by the wood of the second season, and in others again it is borne on the wood of the stem or the mature branches. In the first instance what it will be necessary to prune out branches that are backward portions of in growth, and that have little or no fresh wood on them. prune. In the second instance the young wood must be cut back so as to allow the strength of the plant to be put forth in pushing out flowers instead of continuing to increase the new wood. And, in the third case, the small branches and the young wood not required to increase the spread of the tree, must be taken away by the pruner. In all cases, however, Suckers to be suckers or "robber stems," as they are called, must be re- removed at moved from trees or bushes grown for their crops, as suckers rob the plant of much of the sap or food necessary for the growth of the flowers or fruit. Pruning does not Hacking mean simply chopping at a tree with a cutlass so as to $\begin{gathered}\text { trees not } \\ \text { pruning. }\end{gathered}$ decrease its bulk, but it means an important operation, that should not be undertaken without forethought, or without some knowledge of its principles. If a branch is to be re- Cut off moved entirely, it must be cut off close to the stem, with a $\begin{gathered}\text { branches } \\ \text { close to the }\end{gathered}$ clean cut, and particular care must be taken not to injure stem. the bark of the tree, for this bark will grow and in time heal up the wound; but, if it be torn away or jagged, a much longer time will be taken up in the process of repair of the wound, and the wood of the tree itself may become decayed and thus cause permanent injury. In order to pre- The wound vent decay by the action of the air and moisture, or by to be tarred. insects, a good plan is to paint over the wound with tar or some such substance, if the branch pruned off be a large one. In cutting away small shoots, a sloping cut should be 
made coming out just in front of the bud, forming a wound at half a right angle to the branch. The reason of this is that as soon as the bud develops, as it will do shortly, the increased vigour of growth will soon heal up the wound; but if any considerable portion of the stem be left beyond the bud, it will die and produce decay in the branch or cause the necessity of another pruning operation to remove it. Do not prune Care must be taken not to prune trees or shrubs when they they are full are full of sap, as they will "bleed" so much as to injure the of sap.

plants. The circulation of the sap is not the same in regard to time in all plants, or in the same plants growing in different places and in different climates. Observation Experiments and experiment are therefore necessary to determine the
necessary.

proper time for pruning, and a small cut into the stem of a plant will always show if bleeding is likely to take place. 


\section{CHAPTER XIII}

\section{BUDDING AND GRAFTING}

IN Chapter V. it has been seen that plants are sometimes propagated by bulbs - which are simply modified buds, - and by cuttings. The bulbs and the cuttings are set in the soil, and after a time they form roots and become independent plants of the same character as their parents.

Budding and grafting are practically the same processes Nature of as propagation by bulbs and cuttings, with the difference that budding and the buds and grafts are made to grow on plants already rooted. The advantages of budding and grafting are, that Theiradvanmany delicate plants, and more especially fruit trees, are tages. rendered much hardier by their branches being made to grow on strong stocks-as the plants used for the reception of the buds and grafts are called. And when they become stronger they naturally give a larger return in fruit. Besides this, some plants which are very difficult to propagate Useful for by cuttings are easily multiplied by budding and grafting, propagating and seedling fruit trees, which take a very long time to bear, varieties. can be made to fruit much earlier by these processes. In the case, too, of oranges and other fruit trees, the seeds do not always produce plants that bear fruit of the same character as that of the parent-in fact they do not "breed Seeds do not true." That is to say, if the seed of a very fine orange be always breed planted the fruit obtained from the seedling, when it has grown into a tree, may after all be of a worthless character, so that after the trouble of nursing the tree from the seed, 
and after the weary waiting for years for the produce, nothing but disappointment may be the result. But by adopting the system of budding or grafting, the fruit could be reaped in a much shorter time, with the certainty that all the characteristics of the original plant would be preserved.

BUDDING.-This is simply the removal of a bud and a portion of bark from one tree, and so placing it under the bark of another tree that it will adhere and grow into a branch in the same way as it would have done on the parent stem. By this method the parent may be rapidly multiplied. The How to bud. operation is performed in the following manner. The bud should be cut carefully from the branch of the parent with the base of the leaf stalk and about three quarters of an inch of the bark attached (Fig A.) ; a portion of wood will always come away with the bud if it be cut properly, and this must be gently dug out from the bark with the point of the penknife. The bud is then ready for insertion under the bark of the stock, which is done as follows:-The incisions, like the letter $\mathbf{T}$ with a long tail, are made beneath a growing leaf on the stock (Fig. B.). The incisions should go right through the bark, but not into the wood. The bark is to be carefully lifted up from the wood on both sides by the handle of the budding knife, and the bud is then inserted at the top and gently pushed down until it is firmly held by the flaps of the incision (Fig C.). If any of the bark of the bud remain outside, it is to be cut off so that it fits the cross cut in the stock accurately. A ligature of bast, or worsted, or narrow tape, is then to be applied so that the bud is bound down firmly but not tightly. The ligature covers up all the incision and allows the bud to expand. A leaf may now be tied over the part in order to keep off the sun and too much moisture, and the operation is complete.

GRAFTING, as we have seen, is analogous to propagation by cuttings. A cutting called a scion, is taken from the 


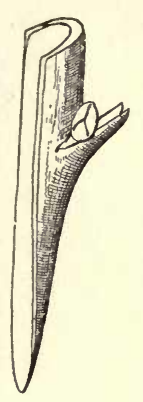

FIG. A.

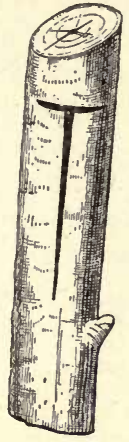

Fic. B.

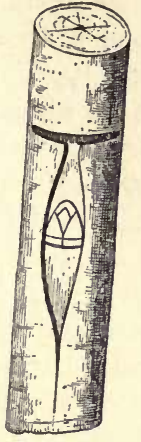

FIG. C.

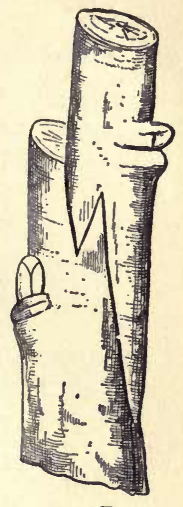

FIG. D.

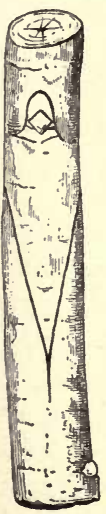

FIG. E.

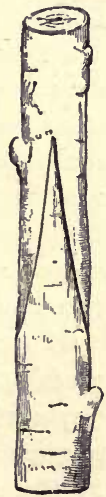

Fig. F.

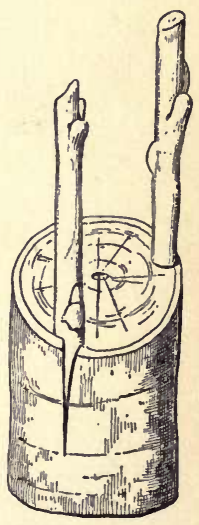

FIG. G.

METHODS OF BUDDING AND GRAFTING 
The princi- parent tree, and made to grow on the stock. There are ples of grafting.

How to graft. various ways of performing the operation, all of which have different terms applied to them, but the principle involved in all is, that the whole or a portion of the bark of the scion must be in contact with that of the stock.

Whip, or tongue grafting is the kind most often employed, and it is performed in the following manner. The stock having been cut back, or "headed down," as it is termed, one side of it is pared away in a sloping direction for an inch or an inch and a half, and a wedge-shaped portion is then to be removed from the upper part. The scion is then cut so as to fit the stock-in fact one is tongued into the other (Fig. D.). The scion and the stock are then bound firmly together with bast, and grafting wax (or prepared clay) is applied over all so as to keep in the moisture. The scion should have three or four buds in it, the lower one of which must be near the cut surface applied to the stock, and it is advisable also that the stock should be headed down close to a bud, as the vital processes are always more active in such situations. Care must also be taken that the bark of the stock and the scion are accurately applied to each other, but it is not necessary that both should be of the same size, although it is better for them to be so.

Other methods are wedge grafting (Fig. E.) and saddle grafting (Fig. F.). The way in which the scion and stock should be cut in these two methods is easily understood by looking at the figures. Of course the same precautions are necessary as in tongue grafting.

Grafting Crown grafting is very useful in orange culture, especiorange trees. ally when it is desired to graft sweet oranges on to large and old sour orange stock. The trunk of the tree is cut right through with a saw, and then smoothed off with a knife. Two or three scions are then inserted between the bark and the wood. It will be found much easier to insert the scions if a piece of hardwood, cut the exact size and shape of their 
ends, be used to force a passage between the bark and the wood of the stock (Fig. G.)

INARCHING, or grafting by approach, as it is sometimes called, is analogous to propagation by layering. It differs from grafting in that the scion is not removed from the parent until they are both firmly adherent. It is considered to be the most certain of all kinds of grafting, and it is extensively employed in the West fndies for the multiplication Inarching of plants of the better kind of mangoes. The operation is performed in the following way:-A branch of the parent having been selected about the same size as the stock, the bark and a portion of the wood of each are pared away to the extent of two or three inches, and they are then bound fast together; the bark of the wounds being accurately fitted, and grafting wax is applied over all. It is usual to make tongues in the stock and the scion, so that one may fit into the other, but this is not really necessary, although it helps to prevent movement-which is always fatal to union. 



\section{PART II}

\section{AGRICULTURAL PRODUCTS}





\section{CHAP'TER I}

\section{N TRODUCTION}

IN the first part of this book, the elementary principles of agriculture have been considered, and the student should now be well acquainted with plant life and its needs, and with the way in which Nature works to enable man to produce the fruits of the earth for his own use.

The application of the principles of agriculture to the various cultivations undertaken in tropical countries, will now be considered, and some hints on the preparation of the produce for the market will be given under each head.

The great fault hitherto committed by many tropical Mixed cultiplanters, has been the confining of their attention to one vation. kind of cultivation on their land. If several different crops were taken off alternately, as in a system of rotation, or grown in different parts of the land where the soil and climate prove suitable, the planter would be in a much better position than he is now, for he would not, as it were, "have all his eggs in one basket." There is scarcely a spot on any estate, whether large or small, in the West Indies, that is not capable of giving remunerative returns from some plant or other, and the successful planter will adapt his cultivation to his soil, and not make the futile attempt to grow crops on land and in climates quite unsuitable to them.

In all planting operations, there must be no carelessness, 
Careless planting disastrous.

Nature to be copied. for a careless planter deserves to fail, and he will probably meet with disaster. For instance, if with great care and at considerable expense a large number of seedlings of cacao or coffee have been raised, and they are planted out in the fields in a careless way, they will probably die in large quantities, and the results of all the previous work and expenditure will be liable to be swept away by inattention to what, to the inexperienced, may appear to be trifling details. Writers on agricultural subjects have always urged the necessity of care and forethought in planting ; and Mr. Morris, the distinguished Assistant Director of the Royal Gardens at Kew, whilst in charge of the Botanic Gardens of Jamaica, wrote as follows :- "All the operations connected with planting are of so important a character, that too much care and attention cannot possibly be given to them. On the mode in which the plants are put in, and the plantation started, depends the whole success of the undertaking, and to realise these conditions in their fullest sense may very fitly be termed the essential elements in the character of a good and successful planter."

A planter is simply one who copies nature and natural processes in order to get a large return from the soil. Nature, as we have seen, proceeds by slow and careful means, the smallest operation being done with exactly the same careful wisdom as the most gigantic one, and all things working together in obedience to natural laws, produce the wonderful world around us. A planter, who deserves the name, must humbly copy nature, not only in its indications for the treatment of plant life, but also in the careful and laborious way in which all things are done. 


\section{CHAPTER II}

COFFEE. Coffea arabica. Coffea liberica.

COFFEE was formerly grown very extensively in the West Decline of Indies, but owing principally to the great attention paid to $\begin{gathered}\text { coffee culti- } \\ \text { vation in the }\end{gathered}$ sugar cultivation, the exports have become comparatively West Indies. small. In Dominica, the coffee planters were ruined in the early part of this century, by a blight which killed out their trees, and it is only since Liberian coffee has been introduced that there seems a chance for the revival of the industry, as the blight does not affect this species.

The Arabian or common coffee plant came originally from Where the the mountains of Abyssinia, and it was from thence carried coffee plant to Arabia, and later on, to all parts of the tropical world. Liberian coffee was discovered, a few years ago, in the forests of the West coast of Africa, and it has been introduced into the West Indies and elsewhere from the Royal Gardens at Kew.

Soll.-As the coffee tree has a long tap root, it will thrive only on land where the soil is deep. The best soil is a well drained, loamy one, but the plant is hardy and it will grow The plant a in any soil except stiff, heavy clay and poor sands. Dr. hardy one. Browne in his "Natural History of Jamaica" says of coffee, 'The tree will grow and thrive in almost every soil about the mountains of Jamaica, and even in the driest spots has frequently produced very abundant crops." A rocky soil where the earth is deep between the rocks, is very suitable, Rocky soil and less manuring is then required for the plants, as the 
rocks are continually adding to the soil by the weathering action of the air and rain and other natural forces. They are also said to retain the heat received from the sun and keep the coffee plants warm during cold nights.

Climate.-The most suitable climate for coffee cultivation is that found in the mountainous regions of the tropics with a range of temperature from $55^{\circ} \mathrm{F}$. to $80^{\circ} \mathrm{F}$. The best Elevation. coffee is grown at elevations varying from 2,500 to 5,000 feet above the sea. The plant is, however, cultivated at much lower levels, and even close to the seashore. But the AraNot less than bian coffee does not do well under 1,500 feet, and it is ex-
$\mathbf{x} 500$ feet above the sea. tremely liable to blights and insect pests when grown in these low situations. As nearly all the coffee estates in Dominica were below I,500 feet, the disastrous blight which ruined the coffee industry of that Island, was probably due, in a measure, to the fact that the climate was not suitable to

Liberian coffee a lowland plant. the cultivation. Liberian coffee, on the other hand, thrives best under I, 500 feet : it is indeed a lowland plant, and it may be grown with success in sheltered situations almost as far down as the seashore. An extremely wet climate is not favourable to the coffee plant, and it will not thrive in very Exposure to exposed situations. But the exposure can nearly always be be avoided. modified by shelter-belts of trees; and, in those countries Shelter-belts liable to hurricanes, they are a necessary protection. They of trees. must not be allowed to grow unrestrained, however, or they will shade the coffee too much. An annual trimming with the cutlass will not only keep the shelter-belts in proper form, but the small branches and leaves cut off, if buried in the ground between the coffee plants, will rot and form a capital manure for the soil.

Propagation.-Coffee plants are propagated by seed, and the seedlings may either be raised in seed beds or Seeds germi- taken up from under cultivated trees, for the seeds readily
nate readily. germinate if placed on damp soil in a shady place, and 
numbers of plants grow up under the trees on coffee plantations.

SEed Beds or Nurseries.-A sheltered piece of land in Nurseries a moist situation, or within easy reach of a good supply of sheltered water, having been chosen, it should be laid out in beds for situations. the reception of the seed. If possible, the nurseries should

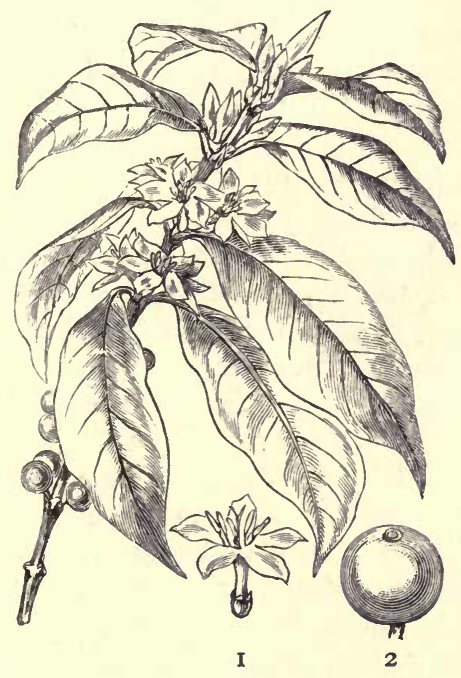

COFFEE (Coffea arabica).

I. Flower. 2. Fruit.

be made near the planter's house so as to be frequently over- They require looked, for they require constant attention, and it may be constant necessary to visit them at nights, to kill any nocturnal insects that are fond of cutting the stems of the seedlings. When it is not intended to plant the coffee on a very large scale, Plants raised the seeds may be grown in boxes or pots nearly filled with in boxes 
loose earth and raised some distance above the ground, for in this way the young plants can be better attended to, and there is not so much danger of the ravages of caterpillars and other voracious insects that sometimes destroy the leaves and young plants.

Seed beds to be manured.

Loose soil necessary.

Fresh seeds to be sown. weeding.

Reserve plants. nate in six weeks.
The seed beds must not be too wide, they ought to be well manured if the soil be poor, and the earth should be dug up and pulverised-every root and stone being carefully removed. If the land be stiff clay, some sand or charcoal dust should be mixed with it, as the delicate rootlets of the young plants require a loose soil for them to penetrate easily.

Seeds germi- weather the seeds will germinate in about six weeks, and the seedlings will be ready to transplant in from eight to ten months. Should dry weather come on after the seeds are planted, the nurseries ought to be well and frequently watered. The beds must be constantly weeded, and the weeds be pulled up before they grow to a large size, otherwise there will be the danger of pulling up the coffee plants with them. A reserve of plants should be kept to supply vacancies occurring in the plantation by reason of some of the plants dying after they are put out in the fields. Other beds are to be made, the soil being prepared in the same manner as for the nurseries, and the seedlings are then planted in them about 8 or 12 inches from each other. In this way, they will grow and keep pace with the plants in the field ; and, when vacancies occur, they can be supplied with well-grown plants. An excellent way, when planting on a small scale, is to transfer the seedlings into bamboo pots, and to keep them at first in a shady and moist place, and 
afterwards to harden off the plants by placing the pots in Hardening more exposed situations.

off the

plants.

BAMBOo Pots.-As a good many plants cultivated by the tropical agriculturist are raised to great advantage in bamboo pots, it is as well for particulars to be given of the way of planting seeds and seedlings in these useful receptacles. A bamboo stem is a hollow cylinder divided into many com- How bampartments by cross partitions of thin, hard, woody tissue. At boo pots are each joint, or node, or knot, where the stem is swollen, there is one of these partitions, and thus a bamboo stem has as many compartments as it has nodes. If the stem be sawn through, an inch or so below each node, there will be made a number of hollow cylinders from Io to 14 inches long, and from 3 to 4 inches in diameter, open at one end and closed at the other. These are the bamboo pots, and there is nothing Utility of the else so admirably adapted for raising plants, and so cheap pots. and plentiful in most tropical countries. The pots being deep accommodate the tap roots better than the ordinary flower pots. Their sides are glazed with a hard siliceous material which does not allow evaporation, and thus prevents the roots from being chilled and the soil from drying up, as is the case in porous earthenware pots. The bamboos, too, are strong and hard, and not broken by falls or knocks, and they are so inexpensive as to allow a pot to be destroyed for each plant. On estates where there are no bamboos, or where none can be easily got, the planter should grow several clumps, if only for the sake of making the stems into pots.

A plant is set in a bamboo pot in the following way :- How to place The pot having been pierced below with a large hole for the plant in the purpose of allowing exit to the water, some small stones should be put in so as to prevent the earth from choking the hole, and so as to favour drainage. On the stones some moss or rotten leaves should be put in order to keep the earth from getting in amongst the stones, and thus choking the channels for the passage of the surplus water. The earth 
must now be filled in to within an inch of the top, and the pot knocked several times to settle the soil. When the pot is used for raising a seedling, the seed may now be sown; but if plants from the nurseries are to be potted off, the earth must be filled in only to the level of where the end of the longest root will touch, and then the plant is put inbeing held in the centre of the pot-and the soil is packed round the roots; a few sharp taps on the bottom or at the sides of the bamboo will cause the earth to settle nicely amongst the roots and prevent any of them from being turned up or doubled on themselves. The seedling being now planted in the pot, the earth should be pressed down rather tightly about the stem, so as to prevent too much evaporation from the surface, and the operation is complete. The reason

Watering the plants.

Forest land best for coffee cultivation.

Cutting down the forest. that a space of an inch is to be left between the surface of the earth and the top of the pot is because, in watering the plant, there is a better chance for it to get a sufficient quantity of moisture. The best way in watering, is to use a can with a spout, and gently to pour in the water until it runs over the sides of the bamboo.

Preparation OF THE LAND.-Having finished the nurseries, the attention of the planter must now be directed to the preparation of the land. Forest land rich in humus is, of course, best suited for a new plantation, inasmuch as the plants will grow better in virgin soil, and the land will not require any manure for a long time. The forest having been cut down, the branches must be lopped and strewn evenly over the ground before the fire is set. Of course the felled forest trees must be allowed to remain for a time exposed to the sun, otherwise the smaller branches will not catch fire properly. Where possible, it is better not to burn the bush but to pack it in lines between the young coffee trees, in order that, by its rotting, it may add to the richness of the soil-otherwise the nitrogenous compounds so beneficial to plant life are sent off into the atmosphere by the burning. 
LINING.-The land having been cleared, the next thing is to line it out, pickets or stakes being placed at each spot that is to be occupied by a coffee tree. Care should be taken Straight to get the lines symmetrical, for a badly lined estate is an advisable. offence to the eye, and it causes much trouble in giving tasks and in picking the crops. On the small properties of peasant proprietors where coffee is cultivated, the trees are sometimes so overcrowded as to injure each other and to diminish the crops. It is a mistake to imagine that the Overcrowdgreater the number of trees on a given piece of land, the $\begin{gathered}\text { ing of the } \\ \text { trees to be }\end{gathered}$ greater will be the return in crops. As we have seen in the avoided. first part of this book, the atmosphere and sun and rain have a great deal to do with plant growth : and, in order for these important agencies to work properly, there must be sufficient space around a tree for the air to circulate freely and for the sunlight to enter. Crowding of plants prevents this and does much harm in other ways. The roots intertwine and rob one another of the available plant food, which as we know now exists in the soil in a soluble condition. This plant food is abstracted from the land in order to build up the many woody stems and sterile branches of the crowded trees, whereas, if the plants were put in at proper distances, the food in the soil would be taken up to produce, not a number of useless stems, but a quantity of fruitful branches on well-formed trees. It so happens that larger crops are obtained from the fewer trees, and the known facts concerning plant life fully explain why this takes place.

A good way to line out the land is to get a number of long How to line. stout cords, and to stretch them over the field at regular distances. A similar cord held by a person at each end is then stretched across all the other cords; and, where the single cord touches all the others, pickets are put in. In this way the lines will be perfectly straight, and the distance of the pickets from each other can be made to suit the desire of the planter.

The distances at which coffee trees should be planted will Distances. 
vary according to the soil and to the lay of the land. In Ceylon, the usual distance is six feet by six feet, which gives $\mathbf{I}, 2$ Io trees to the acre. On the rich land in the West Indies, however, the plants may be put in farther apart, and on poor soil and also on steep hillsides, shorter distances may be adopted, but the trees should never be closer than five feet Not closer by five feet, which would give 1,740 trees to the acre. than five feet. Liberian coffee being larger and more vigorous than Arabian coffee, the distances of planting may be wider, and in Dominica the trees are usually planted at ten feet by ten feet which gives 435 trees to the acre.

HolinG.-The land having been lined out, the next thing is to put in the plants ; but, except where the forest has been cleared, and where the virgin soil is rich and friable, it is Size of holes. necessary to hole the land. That is to say, holes must be dug where every picket stands, and these holes should be from one foot to two feet square and from a foot and a half to two feet deep. In clays and poor soils the larger size is preferable, and on a good, rich, loamy soil the smaller size

Holes left open for a few weeks.

Filling the holes. will be sufficient. The holes must be left open for a few weeks so as to allow the air to get into the sub-soil and to act on the dormant constituents, and the earth dug out should be placed below the hole if the land be hilly and anywhere on one side if it be level. In filling the holes, none of the earth taken out must be put back, but surface soil from the vicinity and weeds must be put in, care being taken to keep out stones and large roots. The more weeds buried the better, as they answer the purpose of a green crop manure. After a week or two, the weeds will rot and add richness to the soil, which will sink down and leave a shallow hole that must be again filled up with surface earth; and, if the land be poor, some farm yard manure or compost The earth to may with advantage be added. It is advisable to raise the be raised in a mound. earth somewhat, leaving a small mound where the hole was, and in the top of the mound the young tree is to be planted. 
The object of the system is to allow for the subsidence of the earth, as it is found, no matter how well the holes are filled, that sinking always occurs; and thus, after a time, the young plants will be left in a depression unless the soil be heaped up as described.

Planting Out.-The trees should be planted out, if possible, at the commencement of the rainy season, and on no account should the seedlings be put in the fields during dry weather ; for, until the plants are firmly rooted in their $\begin{aligned} & \text { Seedlings to } \\ & \text { be planted in }\end{aligned}$ new situations, a few days' sun and dry weather will be wetweather. almost certain to kill them. Temporary shade may, how- Temporary ever, be afforded by fixing small branches of trees in the ground around the plants, or a few sticks, pushed into the earth, may be made to support plantain or fern leaves in such a way as to give light shade to the young coffee trees. In The roots removing the plants from the nurseries, care must be taken injured. not to injure the roots; and, where it can be done, a ball of earth should be removed with the plants. If the roots be much injured, it is as well to take off a few of the lower leaves so as to restore the balance between those parts above and those below the ground. When plants are raised in bamboos, on no account should the pot be split and then put in the ground with the plant inside it, for the rotting wood, remaining at the root of the young tree, wiil be liable to injure it. The proper way is to have the soil in the pot How to well wetted before taking them into the fields; and when $\begin{gathered}\text { remove the } \\ \text { plants from }\end{gathered}$ the hole is ready for planting, each pot is to be split by a the bamboo sharp blow of the cutlass on either side, and then by using a pots. little force the sides will separate, and the plant with its roots undisturbed and covered with soil, can be at once set in the ground, and failure will be scarcely possible. Of course when stones have been put in the pot for the purpose of drainage, they must be gently turned out of the soil with the fingers before the plant is set in the earth. After the young tree is planted, the soil should be pressed down firmly 
round the stem to prevent too much evaporation from the Staking the plants. roots, and in very windy places it will be as well to put in a short stake close to the tree, and to tie the plant when large enough to it so as to prevent too much shaking. In all planting operations extreme care must be taken to prevent the sun from burning the roots, and whilst the plants from the nurseries are being removed to the fields they should be well covered up with plantain or other leaves.

Watering the plants.

If dry weather come on suddenly after planting, the seedlings ought to be watered at least once a day until they become well rooted, for unless this be done a large proportion will die. When the young plants are rooted they require careful nursing until they throw out several pairs of branches. Planting at Another way of planting is to dispense with the nurseries
stake. and to sow the seeds in the open field in the place where the coffee tree is to be grown. Holing the land must, however, be adopted except in rich, friable, virgin soil. Three seeds are sown in each hole at a distance of six inches from each other, and should all the seeds grow up well, the largest and strongest and best formed tree is allowed to remain, the others being taken up to be used when necessary for supplies or for planting fresh land. This system is called planting at stake and each hole requires much careful attention,-it must, indeed, be regarded as a miniature nursery.

Shade necessary in the lowlands.

SHADE.-Much shade is not required by full-grown coffee trees, except when the Arabian species is planted in the lowlands, and then shade becomes necessary. The shelter belts may be allowed to grow up in this case, until the high branches of the trees overshadow the cultivation, for a portion Shelter belts of the day. Pois doux (Inga laurina) or the rose apple of trees.

(Eugenia Jambos) may be used for these belts, but any native tree that does not exhaust the soil will answer very well. Liberian coffee growing in the lowlands, and the Arabian coffee growing in the mountains over 2,000 feet from winds. elevation, do not need shade, and the belts of trees will be 
required only for protection from high winds. But when the coffee trees are young some shade is almost a necessity, except in very sheltered and damp places. Plantains and bananas may be used for this purpose, but they must not be planted too close to the coffee. The pigeon, or congo pea Pigeon peas (Cajanus indicus) makes an excellent shade plant for the soil. $_{\text {enrich }}$ young trees. This plant has the reputation of enriching the soil by throwing down large quantities of leaves rich in nitrogen, besides which its roots penetrate to a considerable distance, and thus when the tree is cut down-as it should be as soon as the coffee is well grown-the soil is improved by the decaying roots, and by the free entry of the atmosphere into the channels formed in the ground by such decay. When the coffee trees commence to bear, the shade plants growing amongst them had better be taken away altogether, for otherwise the coffee will become "leggy," that is to say Leggy trees. their stems will run up quickly with long intervals between the branches, the leaves will be larger and few in number, the stem will be weak, and the crops will be small. A fully Sun benegrown coffee tree, in a good situation as regards soil and ficial to ma climate, delights in the sun, and it is only in the case of the young and delicate plants that such shade is useful.

WEEDING.-After the young plants are established in the Constant fields, they will require constant weeding and this necessity weeding in the cultivation of coffee was recognized by the early planters in the West Indies. Laborie, who wrote in 1797, Laborie. a first book on coffee cultivation, entitled The Coffee Planter of San Domingo, says,- "There is not perhaps any plant which requires more purity of soil than the coffec tree. Weeds keep it back, cause it to grow yellow, fade, wither, and even perish." The weeds may be put in heaps to rot, and then they can be used to cover the roots of the coffee trees, but they must be rotted before this is done, and unless the earth be shaken out of the roots, and the heaps turned once or twice, many of the weeds will live and grow 
The weeds to vigorously notwithstanding that they have been dug up. A be buried.

better way is to bury the weeds, and thus turn them into a green crop manure. The holes should not be dug too near the coffee trees, and the weeds must be buried in a different hole at each weeding. This is really by far the best system of disposal of the weeds, and it should always be adopted when possible.

ToppiNG.-If the coffee trees be allowed to grow unrestrained they will become very tall; indeed, the Liberian Advantages species has been known to grow forty feet high. In these of topping the trees. cases it is very difficult to pick the berries, for the trees, as a rule, bear mostly at the top, as, frequently, many of the lower branches dic out as the trees increase in height. The system of topping has therefore been devised, and it consists of cutting off the top of the tree after it has attained to such a height as will allow all the berries to be picked without difficulty. Besides this advantage, the topping increases the spread and the fruitfulness of the lower branches, and prevents strong winds from having as much effect on the plantation as they would if the trees were higher. In exposed situations in the mountains, the trees may be topped at three feet, and in shady places where the soil is good, they should never be allowed to grow higher than five feet. In some windy places in Ceylon the trees in a few extreme cases are topped at one and a half feet, but this is certainly too low Trees in the for any coffee cultivation in the West Indies. It has been lowlands not to be topped. recommended, in the case of coffee planted on lowlands, that the trees should be allowed to grow up unrestrained, as they are then more fruitful, but in this case the berries will have to be picked with the aid of step-ladders; for if the branches be pulled down, the stems are liable to break or split.

The import- PRUNING.-Proper pruning of coffee trees is very importance of pruning. ant, for if they are allowed to grow unchecked they will become a tangled mass of stems, branches and leaves, and 
they will bear very small crops. The tree having been topped, a rod the proper length being used as a guide, all suckers must be removed. These are vigorous erect shoots that spring out along the stems, and sometimes on the branches, and they will grow so vigorously if left alone as to rob the tree of the sap destined to form fruit, hence they are called "robber" or "gormandising" stems or branches. It is best to remove them whilst they are young and then they trees. can be rubbed off with the finger and thumb by a process called "handling." A well-formed coffee tree has a straight central stem from which side branches called primaries are given off, and these primaries give off other side branches called secondaries, which sometimes branch again. Now, in a proper system of pruning, none of the secondary branches close to the main stem must be allowed to remain, for they ought to be pruned off so as to allow a clear space round the stem for the free circulation of the air and for the entry of light. In this way the temperature is raised, stagnant moisture is prevented, and the growth of mosses, and other such plants, about the trees, is greatly hindered. These Epiphytes to cpiphytic plants, as they are called, must never be allowed be tak. to remain on the trees, as they will do a great deal of harm. On the primary or principal lateral branches, at each node or knot, the secondary branches are usually given off in pairs-one on each side of the branch, but sometimes instead of a pair, a whole bunch of branches growing in different directions may be met with. Pruning is required in such a case, for it is well to remove all but the two best branches with a sharp clean cut, as was explained in the chapter on pruning.

MANURING.--If forest land be cleared for the plantation, no manure will be necessary for several years, but the case is different if the land have been already cultivated. Then manure is indispensable, and, of course, farm-yard manure or compost is the best. It is well, therefore, for the coffee 
Farm-yard manure the best. planter, or indeed any other planter, to keep animals in order to be able to obtain valuable manure for his trees. At first the manure may be simply laid round the roots of the trees, and then covered over with surface earth, or it may be carefully forked into the soil around the roots; but, later on, it will be necessary to bury the manure in holes near the The holesfor trees. The holes should be about two feet long, a foot manure. deep, and a foot wide, and at a distance of not less than two feet from the stem. In digging, all the large roots of the coffee trees that are unearthed should be left, but the smaller ones may be cut with advantage. The manure should then be spread at the bottom of the hole and covered with weeds and surface earth, which ought to be well rammed down so The position as to prevent washing during heavy rains. If the coffee be of the holes. planted on hill sides, the holes ought to be dug above the trees, so that the soluble portions of the manure may be washed down to the roots; but, on level land, the position of the holes is of no importance, only they must not be dug in the same spot at each manuring.

CATCH Crop.-Whilst the young coffee trees are growing, the vacant ground may be planted in maize, plantains, tanias, sweet potatoes and other such food products, according to the desire of the planter or the requirements of the Catch crops local markets. This system, which is called catch cropping, recommended. is really a very good one, although some planters disapprove of it. The unoccupied part of the land will be giving some return, and the tillage of the soil necessitated by the cultivation will do good to the young coffee plants. Besides, the shade produced by the plants grown for the catch crops will prove beneficial to the coffee, and the weary waiting for returns from the cultivation will be broken by the sale of the

Catch crops to cease at the second year. produce. Of course, care must be taken not to allow the "catch crops" to encroach too much on the coffee, and after the second year they should be discontinued.

Enemies to The Coffee TreEs.-There is, perhaps, no 
cultivated plant that has so many enemies, both animal and vegetable, as the coffee tree. In Ceylon, the cultivation of The Ceylun coffee was practically ruined some years ago by a fungoid, or vegetable blight which attacked the leaves, and which was found to be incurable. In Dominica, as we have seen, "The white an insect blight called the "white fly" killed out nearly all the trees at the early part of this century; the same blight is now in Brazil, and it is doing harm to the coffee cultivation there ; it may be said to exist also in Jamaica and other of the West Indian Islands, but it does not commit there the depredations it did in Dominica. The mealy bug, a The mealy curious insect like a flake of snow, does much harm in some places, but it can be got rid of by planting pine apples between the coffee, as the bug is very fond of the plant and will quit the coffee trees for them. In some countries much The borer. damage is done to the trees by a beetle called "the borer," because it bores holes in the stem or root of the tree and thus often causes its death, but these insects can be searched for and killed. Scale and shell insects sometimes appear on Scale blight. the trees; they are little white or brown scales applied to the bark of the tree or the epidermis of the leaf; their excrement is often in the form of honey-dew, which is afterwards attacked by a black fungus, like soot. This is often found covering the leaves, and usually associated with ants. Associated The scale blight can easily be got rid of by washing the plant with soap and water, and most other insect blights can be killed by syringing, or watering the trees with soap-water, Insecticides. to which a very small quantity of kerosene oil has been added, the whole being thoroughly stirred up. Care must be taken not to put in too much of the kerosene oil, or it will kill the trees. In the case of all blights, it will probably be Weakly found that the trees are weakly on account of bad cultivation, an exhausted soil, or perhaps unsuitability of climate. Now the first thing to be done is to endeavour to restore the vigour of the trees by proper tillage, careful weeding, and judicious manuring, and very frequently these are the only 
resources of the planter. But, then, fortunately they are powerful agents in the prevention and cure of blights, for a vigorous tree may throw off a blight under which a weakly one would wither and die.

Vermin. Rats and mice when plentiful are very injurious to the crops. The fruit of the coffee consists of two seeds enveloped in a sweetish pulp of which these destructive Rat coffee. animals are immoderately fond. In crop time one will often see parchment coffee on the ground under the trees, and this is usually called "rat coffee," for the rats have eaten the pulp and dropped the beans enveloped in their parchment. The rats and mice may be caught in traps or poisoned, but perhaps the best way is to keep a good dog that has been taught to catch such vermin.

Gathering the crops.

Advantages of Liberian coffee.

Crops.-In the case of Arabian coffee, as soon as the berries become red they must be gathered, for otherwise there will be a great loss to the crops, as the fruit does not remain on the trees for any length of time, but falls to the ground. The reverse is the case, however, in regard to Liberian Coffee, for in this species the ripe berries remain on the trees and they can be gathered at the planter's leisure. This is an immense advantage in places where sufficient labour cannot be obtained to gather in the crops in a short time. The berries are usually picked from the trees; but, in Arabia, cloths are spread beneath the trees and the berries Ripe berries are shaken into them. This is a preferable way to gather only to be gathered. the crops when it can be employed, for by it none but ripe berries are obtained, and unripe fruit will deteriorate the The crop season. quality of the coffee. The crop time varies in different countries, but coffee is ripe at some period in the second half of the year, August, September and October being the most

Characteristics of Liberian coffee. frequent months. Liberian coffee, however, is much later as the full crop does not often come in until December and then goes on to January and February in the next year. But this species is very prolific, and it bears a few berries 
all the year round, thus buds, flowers, ripe and unripe berries are often seen on the trees at the same time; and, as the flowering frequently comes on before the crop is gathered, the planter is often bothered a great deal, for, as a rule, the trees must not be interfered with at all whilst they are flowering.

The yield of coffee varies, of course, according to soil, Returns. climate, and cultivation, but it may be said to be from four to twelve hundred-weights to the acre. A pound per tree, $\underset{\text { tree. }}{\text { A pound per }}$ on an average, would be a very good return, but in favourable situations and under proper cultivation some trees will yield much more. The Liberian coffee trees are much more prolific than the Arabian kind, and each tree yields from one to eight pounds of clean coffee. About three bushels of Ten pounds of berries may be picked by a good worker in a day, and this clean coffee will yield about thirty pounds of dry coffee or about ten of berries. pounds to the bushel in the case of the Arabian coffee, but the pulp of Liberian coffee is much thicker, and the berries of this kind will not give so much clean coffee to the bushel; but the trees, by bearing larger crops, compensate for the greater loss in pulp.

PULPING.-The operation of removing the pulp from the Berries not, berries-sometimes wrongly called "cherries"-is termed pulping, and it may be done by the hand, by pounding the fruit in a mortar, or by pressing the berries with a rolling motion between two flat boards. These methods, however, will only answer when a small quantity of coffee has to be treated, and, on a large scale, a machine called a pulper Machinery. must be used. The principle on which pulpers are made is that of a roller covered with a copper grater, and made to revolve against a smooth surface, the chop. The grater is approached so closely to the chop that the berries will be crushed without the coffee bean and its parchment covering being injured; and, as the chop is moveable, it can be set Mocha to the different sizes of the beans. Thus in pulping Mocha coffee. 
coffee, which is a variety of the Arabian species with very small beans, the chop must be approached very close to the grater, and, in the case of the large berries of the Liberian coffee, it must be set much further away. There is a hopper at the top to receive the berries and to conduct them to the grater, and below, a sieve is so arranged, on an inclined plane, that the crushed berries falling on to it are set in motion, the beans passing through the sieve and the pulp or tails rolling away.

FERMENTATION AND WASHING.-As the beans come from the pulper, they are covered with a sticky mucilaginous material, which is removed by fermentation or by soaking in Cisterns. tubs or cisterns of water. When they are to be fermented, they are put in barrels or tubs and allowed to remain for twenty-four hours, or until the mucilage is easily separated; and then they are washed in water, and put out to dry in the

Parchment coffee.

Hulling machinery.

Hulling not to be done in wet weather. sun in trays or on platforms. The coffee is then in the form of "parchment," and it may be kept so for a very long time, as it has its natural protective covering on it.

Hulling OR PEELING.-This consists in the removal of parchment and the thin under-coat called the silver-skin, which is done by various machines called hullers, or by pounding the parchment coffee in large wooden mortars. When the hulling has to be done on a very large scale a circular trough, in which a large and heavy wooden or stone wheel is made to revolve, is employed. The parchment coffee is put in the trough and the wheel is made to pass over it. The parchment is crushed and broken into small pieces, but the coffee itself, if properly dried beforehand, is uninjured. In all cases the parchment coffee must be well warmed in the sun before it is peeled, and on no account should the peeling operation be performed on a wet or damp day. A bushel of parchment coffee will usually give half the quantity of clean beans, but the proportions vary very 
much according to the kind of coffec and the condition of the cultivation.

WinNowiNG.-In order to remove the broken parchment and silver skin from the beans ofter the hulling process is effected, the whole is passed through a winnowing mill- The winnowwhich consists of a fan made of four plates turned rapidly by a handle, whereby the wind is made to pass through the coffee and the chaff, which fall gradually through a slit in the hopper. The coffee, being heavy, falls into a receptacle at the bottom, and the chaff is carried away by the wind.

DRY BERRY.-Sometimes the coffee berries, instead of being pulped, are dried whole by being spread out on platforms exposed to the full rays of the sun. The drying of the berries in this way takes three or four times as long as the drying of parchment coffee. When perfectly dry, the berries are hulled and winnowed in the manner first described, but the process is more troublesome and difficult than when the Drying the pulp has been removed. It is said, though, that coffee pre- duces better pared in this way is heavier and of a finer quality, and some coffee. planters recommend that the method should be generally adopted. There is a firm in London that receives the coffee in $d r y$ berry and prepares it for the market at a cost of about half-a-crown per hundred-weight, but the extra expense in regard to the freight may be regarded as a drawback to the general adoption of the system. 


\section{CHAPTER III}

\section{CACAO, Theobroma Cacao}

THE cacao tree is a native of the forests of Central Habitat of America, and species of it are said to have been found wild
the tree.

Description of the tree.

Trinidad cacao. in Jamaica, Martinique and South America. Nearly the whole of the cacao produced in the world comes from Central and South America and the West Indies, and it is only of recent years that the tree has been cultivated in Ceylon and other parts of the tropics of the old world. The tree, growing in a good soil, when left to itself will reach a height of 20 or 30 feet, and spread out to an extent of Io feet or more on each side. At the height of a few feet from the ground it sends out from three to six lateral branches, without any sign of a leading stem, and it is only when the branches are matured that a leader springs out from the side and not from the centre of these branches. The flowers are small, and they come off in a bunch from the stem or the larger branches, at the place where a leaf formerly existed. It is very rarely that more than one of the flowers develops into fruit, and thus many more flowers are borne on the trees than fruit pods.

VARIETIES. - There are many varieties of cacao, as is usually the case when fruit trees are cultivated; and, in all cacao countries, there are doubtless to be found distinct races produced by differences of soil, climate, and other influences. Not very long ago, Mr. Hart, the Supers 
intendent of the Trinidad Botanic Gardens, sent the author no less than eighteen distinct varieties of cacao growing in that island, twelve of which were described as first class kinds. It is unnecessary, however, to enumerate the names here, for if any one learn the distinctive characters of a good

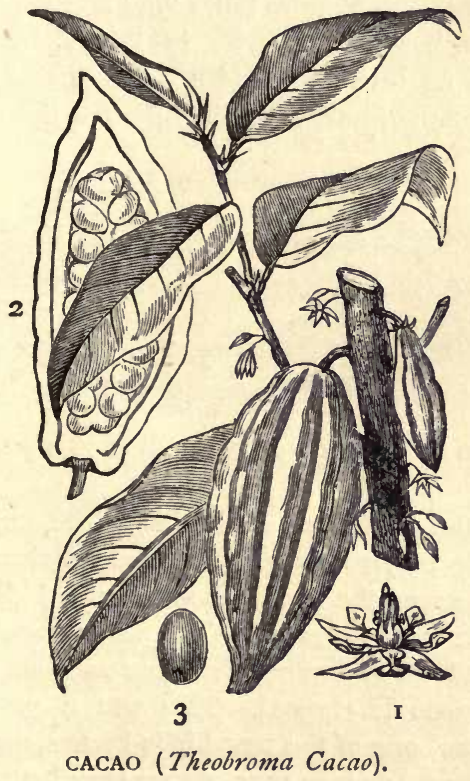

I. Flower. 2. Fruit cut open showing seeds. 3. Seed.

variety, he can always select the best seed himself. A draw- Descriction ing of a pod of one of the finest kinds of cacao is seen on the of a pod of ing of a pod of one of the finest kinds of cacao is seen on the the best next page. The pod was taken from a tree of the so- variety of called Trinidad cacao growing in the Roseau Valley, Dominica. It was nine inches long and nearly four inches in diameter at its widest part. The pod was pinched in at the 
top, and pointed below, the point being curved to one side. The skin was of a yellowish red colour, it had ten furrows, and the ridges were tuberculated or warty. On opening the pod, the skin or shell was found to be brittle and thin, not being more than from four to five eighths of an inch The number thick. There were 38 seeds, two being small and inferior, of seeds. and the remaining 36 were full, round and plump, measuring about an inch and a quarter in length, by nearly three quarters of an inch in breadth. On cutting open one of the seeds longitudinally, the plumule and the radicle and a

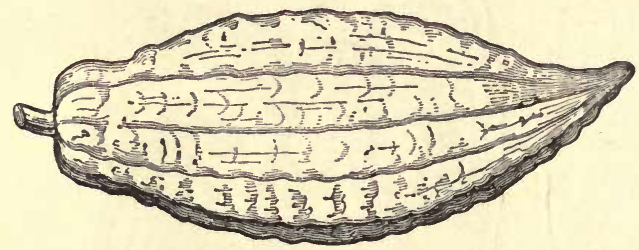

POD OF CRIOLLO CACAO GROWN IN DOMINICA. The seeds portion of the cotyledons were milky white, and at the upper nally.

margins the cotyledons were of a light pinkish colour. On chewing the seed the taste was nutty and slightly bitter with the distinct cacao flavour. The saliva was tinged of a pinkish, and not of a purplish colour as when a bean of the Caraccas common cacao is chewed. This was a pod of the real
cacao. Criollo cacao, one of the best kinds known, and as the other varieties approach it in type, so are they better in character and their produce more valuable in the markets.

The best soils.

Soll.- The cacao tree has a long tap root and it must, therefore, be planted in deep soil. The best soil of all is that occurring in valleys and undulating lands, along the banks of rivers or streams, and made by the decomposition of volcanic rocks. It will also grow well in loams and the richer marls, but it will not thrive in stiff, heavy clays. 
Climate.-A warm, moist climate is necessary for the cultivation of cacao, if large crops are expected; but, when the soil is suitable, the tree will grow and give fair returns in a moderately dry place, as is found in some parts of Dominica and Grenada. The ordinary cacao plant will not do well in the mountains above two thousand feet, and even at high elevathat height it becomes stunted and does not remain fruit- tions. ful for many years. The best elevation is from 300 to 500 feet; and, in sheltered situations near the sea shore, good crops are to be obtained, but the tree will not thrive if exposed to the direct influence of the sea breeze.

Cacao will not bear much exposure, and it does not do Shelter well usually, in places with a northern or eastern aspect. Sheltered lands and valleys with a southern or western aspect are the best situations to form cacao plantations.

Propagation.-Cacao plants are obtained from seeds which germinate readily and quickly; and the seedlings may be raised in nurseries in the same way as coffee plants. Nurseries. Selected pods from the best trees should be picked perfectly ripe, and then be kept for a week before planting, as this favours germination, indeed if left long enough the seeds will push out the radicles whilst the pod is unopened. That part How to sow of the seed attached to the stringy centre of the pod is the the seeds. one to be placed downwards in sowing; and, if the seeds have been already withdrawn from the pod, then they may be sown lengthwise, as there will be a difficulty in finding out the end where the plumule pushes forth. The seeds may be put in the nurseries four inches apart and nine inches between the rows. In a few months' time the plants will be a Transplantfoot high, and then they can be put out into the fields, care ing. being taken to remove them with a ball of earth around the roots. A better way is to raise the seedlings in bamboo pots; Bamboo for, if this be done very few of the plants will be lost. ${ }^{\text {pots. }}$ Planting at stake, as was described in the chapter on coffee, Planting at is, perhaps, the commonest method of propagation, and with stake. 
proper care it answers remarkably well. Three or four seeds are grown around the stake at distances of nine inches from each other; and, if all grow, the stake will be in the centre, and serve as a mark for the weeders. When the

Only one plant to be left.

Careless sowing.

Wasteful cultivation.

Shade belts. plants are well grown all must be removed except one-the strongest and the best formed plant being left. The plants taken out will do for supplying vacant holes, and they can be transferred on a wet day. Some careless and ignorant planters put the three or four seeds into one hole, and thus when the seedlings come up they are all growing together, and their roots are so entangled that when the time comes to remove all but the strongest plant, that is often drawn out with the rest. Other ignorant planters, seeing three or four nice healthy plants growing in a hole, will leave them all, or at least two of them, and thus in some plantations 2 or 3 or even 4 cacao trees are seen growing together, each one doing harm to its neighbour. This is, of course, wasteful cultivation.

Preparation of THE LAND.- The land is prepared in the same manner as for coffee. (See page 96.) But when the forest is cleared, shade belts should be left or afterwards planted in exposed places so as to shelter the cacao trees from the wind.

LiNing.- The cacao is a much larger plant than the coffee, and thus it must be planted at wider distances. On rich flat lands, from 15 to 18 feet will not be too wide, but on poorer soil and on hill sides, from Io to 16 feet will be the Distances. proper distance. In very steep places the trees may be planted closer in the descending lines than in the lateral ones; thus, if the lines be 15 feet apart laterally, the trees may be 10 or I 2 feet apart in the descending lines, for the branches of the trees above will spread out over those below, and yet allow Close ample space for light and ventilation. If cacao be planted planting. on rather poor soil, at elevations above I,oooft., the trees may be as close as ten feet, for they will not grow so large in 
such situations as in more favourable localities. But on no account must the trees be nearer than eight feet to each other, and if a good planter come into possession of a cacao plantation where the trees are closer, he will at once set to work to thin them out, for in this way, although he will Thinning decrease the number of his trees, he will greatly increase the crop.

HoliNG.-This has been duly described in the chapter on coffee. Except in the case of rich, friable and well drained soil, holes must always be dug for the plants. To put a Holing cacao seedling into hard, stiff land, without holing properly, is simply to court failure, for the plant will remain with scarcely any attempt at growth; and, if it do not die, it will take many years before it producss any fruit. The holes Size of the should be two feet square and two feet deep-that is eight cubic feet of earth must be taken out ; if this be done, and the holes be properly filled, cacao can be made to grow on almost any soil that is sufficiently deep. If the digger be driven into the ground at the bottom of the hole, and if it enter freely without touching rock the soil may be considered to be deep enough for the cacao plant.

Planting OUT.-This must be done very carefully, for the Transplantseedlings are extremely delicate, and plants taken from the ing to be nurseries will die in large numbers if dry weather come on weather. after planting. It is as well, therefore, to wait for the rainy season before putting out the plants into the field.

SHADE.-The cacao trees when young will not thrive with- Shade adout shade, and when they are fully grown, it is found that vantagects. they give better crops if shade trees are planted at intervals. For the young cultivation, the banana gives the best shade, Bananas. and it seems specially adapted for the purpose; besides which, its fruit is valuable, and will give a return from the land whilst the young cacao is growing. The bananas should not be put closely to the cacao plants. The best way is to 
place them in the middle of the lines; for, if they are too, near the young cacao, their roots do harm, and there is danger of the trees being injured when the bananas are cut, Shade trees. or when their stems are thrown down by high winds. For permanent shade, the immortelle tree (Erythrina umbrosa) or the "cacao mother," as it is called, is used in Trinidad ; but bread-fruit, bread-nut, trumpet tree, and guango or saman Ravines do trees may be planted. They should not, however, be closer not require shade trees.
Exposed situations to be avoided. to each other than 60 feet, and in narrow mountain ravines, where there is natural shade, they may be dispensed with altogether. In such a ravine, on a cacao plantation in Dominica belonging to the writer of this book, the shade trees had to be cut out, as they kept back the growth of the plants. In exposed places shelter belts are a necessity ; and they should be planted before the cacao. The kind of trees used for these belts may be left to the planter's judgment, care being taken not to select those that impoverish the soil - as hardwood trees do-and to reject all those with branches so brittle that the winds break them easily, and those that spread their roots close to the surface of the ground. Any fast growing tree obtainable in the neighbourhood of the estate may be employed.

WEEDING.-Of course land under cacao cultivation, as under all other cultivations, should be kept clear of weeds ; Cutlassing and proper tillage, by improving the soil, will do good to the on hill sides. trees. On steep hill sides cutlassing will be sufficient, and on level places an occasional hoeing will be required. When the trees are grown so that their branches shade the land, the weeds will not grow very fast, and, as a rule, they are so loosely rooted that they may be easily pulled up.

The necessity of pruning.
PRUNING.-The cacao planter will have to give careful attention to the pruning of the trees if he wishes to get large crops. As the pods are borne on the larger branches, the principle is to develop such branches by judicious pruning, and to see that they are not covered up by a mass of foliage 
and small twigs. A typical cacao tree should have one stem, The best giving off at a few feet from the ground three to five branches ${ }^{\text {type of a }}$ which spread in an open manner, and are free from leaves except at the tops-thus the leaves shade the open inner portion without interfering with a free circulation of the air. Only one If the young plants throw out more than one main stem, the main stem surplus ones must be pruned off; and, after the lateral grow. branches are formed, no upward prolongation of the stem must be allowed to grow. If the tree be left alone these upward growing branches will come off from the stem, just below the laterals, in the form of suckers, and to leave them Suckers on is to cause the strength to be taken from these fruitful to be laterals, as well as to allow the trees to run up, perhaps, for thirty feet or more, thereby causing much trouble in picking the pods. When the suckers are pruned off, fresh ones will grow after a short time, so that the trees will require frequent attention until they are mature, when the tendency to throw out suckers will be stopped. In gathering the pods, the suckers may be taken off at the same time, but the trees should not be pruned in the flowering season.

The first flowers, under favourable conditions, will come out at the third year, but as the tree is not mature then, they The trees not should by no means be allowed to produce pods, otherwise fruit when the plant will be so weakened by the fruiting that its growth will be greatly checked. The first flowers, therefore, should all be rubbed off. After waiting three years for produce it is no doubt rather disheartening to be compelled to prevent fruit from forming, but it must be done if the planter look to the future big gain and not the present small loss. Generally, crops cannot be expected from cacao under five years.

MANURING.-Unless in the case of sickly plants on poor soil, the trees will not require manuring until the crops are Importance taken off ; when, as may be imagined, it will be necessary to young. restore to the soil, in a cheap way, what has been removed in the valuable produce. A good deal will naturally depend on 
the nature of the soil and the yield of the trees. Should crops, which were abundant, be found to be falling off, it is an indication that manure is necessary ; and, in Chapter VII.

Continual cropping exhausts the soil.

Tanias and cassava.

\section{Hurricanes.}

The borer.

Blasted treees. of the first part of this book, it has been seen that continual cropping must, sooner or later, exhaust the soluble con. stituents of the soil.

CATCH Crops.- These may be raised between the cacao trees, for the first few years with advantage, for the light shade given by them to the young cultivation is beneficial. Tanias and cassava are especially suitable for this shade, and they will give some return to the planter. When the cacao trees are grown, and begin to bear, all temporary shade plants must be cleared away.

Enemies to The CACAO TREE. - The principal enemy to the cacao tree is the grub of a beetle, which bores holes into the stem, thereby killing it, but the hole is easily recognisable and the insect may be dug out and some earth or clay or wood ashes rubbed into the place; or, better still, the wound may be painted with tar. Hurricanes are peculiarly destructive to the cultivation, and especially to the young trees. The enormously powerful gusts of wind break down the branches in all directions, and if the roots become shaken, as those of nearly all the young plants certainly will be, the trees will dry up and look as though blasted. Much of the young cacao cultivation was killed out in this way in Dominica by the hurricane of 1883 , and many persons imagined that the trees had been blasted by lightning. As

Epiphytes to cacao plantations are damp and shady, mosses, ferns and
be removed. other epiphytes, are very liable to grow on the stems and branches of the trees, but they must be removed at once, as they will otherwise injure the trees and prevent the delicate flowers from coming out properly.

Crops in five Crops.-Returns from a cacao plantation cannot be ex-
years. pected until five years after planting, and it will not be in 
full bearing before from seven to ten years. A few trees may bear earlier than five years, but these are very favourably situated and they are exceptions to the rule. The trees bear nearly all the year round, but there are two principal crops-one from April to June, and the other from November Two crops annually. to January, the latter crop being much the more abundant of the two. The crops are usually termed Easter and Christmas, after the seasons of the year during which they are gathered.

The average yield of dry cacao from each tree, of course, varies very much. The limits may be said to be from a Return per pound and a half to eight pounds per tree. On the rich, alluvial lands of Surinam, from eight to nine pounds per tree are said to be obtained; but, in the bad cultivation of West Indian peasant proprietors, it is doubtful whether a pound per tree is got.

The pods must not be picked until they are fully ripe. little observation and experience is all that is necessary to picked. tell at once, by the look, whether the pod be ripe or not. If it be within reach it may be tapped with the knuckles or the handle of a knife, and if it sound hollow it is ready for picking. As the varieties of cacao vary so much in colour, no precise rules can be given as to the peculiar shade of a ripe pod. The fruit must be cut from the tree with a cutlass, cacao knife, or a cacao hook ; and on no account ought it to be twisted or torn off the tree. The cut should be clean, and Pods not to be torn off as close to the pod as possible. For, if a tree be examined it will be found that at the base of the stalk of the pod there is a little swelling, called the eye, and it is from this part that the flowers for the next crop will come out. If, therefore, Importance the eye be torn away, no more pods can come out from picking. that part of the stem; and by a non-observance of these facts many cacao trees have been ruined, the crops have failed, and the planter has thought that something was wrong with the soil!. The cacao hooks are made in many cacao different shapes, they are fixed on to a bamboo rod, and used hooks 
to gather the pods out of the reach of the knife. The stalk of the pods can be cut by these hooks with either a thrusting motion or a pulling jerk. Some of them have a chisel at the end, and all the hooks are sharpened on the concavity like a sickle.

Breaking the The pods having been gathered, they are placed in heaps pods. under the trees and they may be broken at once or left for a day. The seeds or beans or nibs-they are called by either of these three names-are then taken out of the pods, which are either opened with a cutlass or broken by knocking them Drawing the against each other or on a stone. The seeds may be drawn seeds. with the fingers, or by means of a wooden spoon, and at the same time the white fibrous tissue is taken away. This stringy stuff and the broken pods should be put in heaps to

Shells used as manure. rot for manure, or be spread over the roots of the trees, or, better still, be buried between the trees, and in this way something will be given back to the soil.

Fermenting.- The beans are now carried away to the cacao house for the purpose of being made to undergo a sweating or fermentation process. This is a very important Importance matter for the planter, inasmuch as on its proper performentation.

How to ferment the beans. mance depends, to a great extent, the value of his produce. In some places the cacao beans are simply dried as soon as they are taken out of the pods, and the cacao thus prepared is sold or shipped to the markets. But it is very inferior stuff with a bitter, unpleasant taste, and it fetches the lowest prices, and gives a bad name to the bulk of the cacao shipped by the colony, thereby doing harm to the planters generally.

Sweating is simple and inexpensive. It may be done in boxes or barrels or in an air-tight room. The cacao is put into a receptacle, it is covered with plantain leaves, boards are put on the top and it is left to ferment for about three days, when it is removed to another receptacle and closed up again and allowed to sweat for three days longer. The ob- 
ject of opening the cacao is to cause the fermentation to be equal ; for, in changing it, that which is on top at first becomes the bottom layer in the second receptacle, and thus The heaps to uniformity is secured. When the cacao is sweated in heaps in a closed house, the heaps can be turned over or stirred up on the third day; and, in this way, the outsicie beans will get their due turn of the full fermentation process. Some fine kinds of cacao do not require to sweat so long, but experience alone can determine this point. In the fermentation the first stages of the germination of the seed go on. The moisture, warmth, and a certain amount of air, cause the seeds to swell, carbonic acid is given off, and the food stored up in the seed for the use of the embryo is converted into soluble matter, and this accounts for the modification of the bitter taste of the raw bean brought about by the sweating process.

CURING.- The beans having been properly sweated they Drying the are to be dried ready for shipment, and this drying process is termed curing. The drying may be done in wooden trays, or on paved or cemented platforms called barbecues. In Trinidad, the trays are fixed, and a roof on rollers is Drying placed over them. When the sun is out the roof is rolled houses. back and the cacao is exposed; during rain and at nights the roof is rolled over the trays, and in this way time and labour in carrying out the trays and taking them in again are spared. On the Malgré-tout estate in Dominica the roof is a fixture, and large trays on rollers are pulled out like the drawers of a clothes press. The sweated beans are spread out thinly, well rubbed and exposed to the sun in the morning, and at mid-day they are put back in the sweating boxes or houses to undergo another partial fermentation for if they be dried straight off they will deteriorate in value.

The second day they are kept longer in the sun, and the third day they are kept out as long as the sun lasts. They when cured are put out on succeeding days until they are thoroughly 
dry, which is told by their producing a crackling sensation when pressed between the thumb and forefinger. In Ceylon the cacao, after being fermented, is well washed to get rid of the mucilage, and it is then carefully and gradually dried so as to produce plump, clean, and attractive-looking beans. The Ceylon cacao thus cured fetches the highest prices in the London market.

How to clay Claying.- Sometimes the cacao is clayed, and this is
the beans. done in the following manner: When the beans are removed from the sweating boxes, they are sprinkled with red clay that has been dried and pulverised. On the second day the same process is gone through if the clay has not tinged all the beans. Then the beans are rubbed between the hands for an hour or so in order to clear away the surplus mucilaginous matters. The drying is afterwards finished as usual. Clayed cacao has a reddish appearance, and the colour is uniform, and it usually fetches high prices in the markets. The principal supply of clayed cacao comes fron Venezuela and is usually known as Caraccas cacao. It is not recommended in English colonies to clay any cacao. If improvement is sought it should be in the direction of Ceylon Mildew. cacao. The rubbing process above described may also be employed when the cacao becomes mouldy in very wet weather, it cannot then be sunned sufficiently, and, for this reason, on large estates, it is sometimes necessary to effect the drying, with artificial heat, in a kiln. 


\section{CHAPTER IV}

\section{TEA. Camellia theifera}

THE tea shrub, of which there are many varieties, is a Habitat of native of China, Japan, and North India. It has been culti- the tea plant. vated from time immemorial in China and Japan; and, in

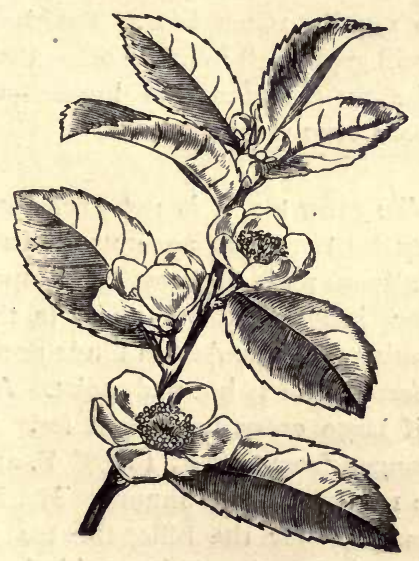

TEA (Camellia theifera).

recent years its cultivation has extended rapidly in India and Ceylon. The plant grows very well in the West Indies It thrives in but as yet tea has not become an article of export from these the West 
countries, nor has it been produced in sufficient quantity to supply local wants. Thus it happens that large quantities of tea grown in the Eastern Tropics are imported, through Europe, into the West Indies, notwithstanding the fact that the plant appears to flourish as well here as it does in China Varieties. and Ceylon. There are two principal varieties of tea, the China and Assam, and a third kind partaking of the characters of both, called the Assam hybrid, is also extensively cultivated.

The best soils.

Soll.--The best soil for tea is a light loam, with an abundance of vegetable matter. As the plant has a long tap root the soil must be deep, and it must also be well drained, for stagnant moisture is fatal to it. A subsoil of reddish clay is considered to be not unfavourable to the plant, but it does The plant a not appear to require much lime. Tea, however, is very hardy one. hardy, and it will grow well in many other kinds of soil, provided there be an abundance of humus-which can be supplied by green crop manuring.

Climate.-To grow tea, it is not necessary to have one uniform climate, for the shrub accommodates itself to many Chinese tea. different elevations and degrees of temperature. The Chinese variety, however, thrives best in the hills up to 5,000 feet elevation, and the Assam kinds prefer low valleys Heavy and plains where the air is hot and moist. A good rainfall necessary. is necessary if large crops be sought for. In Assam the temperature ranges from $50^{\circ} \mathrm{F}$. to $96^{\circ} \mathrm{F}$. and the rainfall is from 100 to 120 inches per annum. Mr. Morris says, in Tea in regard to Jamaica, "for the hills, the tea plants already" Jamaica. established here, being the Chinese kind, are admirably suited; but for the parish of Portland, with its warm, moist climate and splendid rich valleys, the Assam kind appears to be more suitable." There are about twenty to thirty acres of tea established for some years in Jamaica, and small quantities of produce have been prepared of excellent quality. 
The trees must be protected from heavy winds; and, Shelter belts in exposed situations, therefore, shelter belts ought to be planted.

PROPAGATION.-Tea is propagated from seed, which may be sown in nurseries or at stake in the fields. The seeds are enclosed in hard coverings, and some planters advise that they should be put in the sun until the shells split, as, in this way, germination is more rapidly effected, but it is quite un- Sowing the necessary to do so, and the seeds may be sown as they come ${ }^{\text {seeds. }}$ from the trees.

The seeds must always be fresh before they are planted, Seeds must for they contain a large quantity of oil which becomes rancid if they be kept out of the ground. They may be preserved, however, for a time, in dry earth, and when they have to be sent long distances it is recommended that they be packed in this manner. The seeds are sown four inches apart in the Nurseries. beds, six inches between the rows, and at a depth of two inches below the surface. When transplanted, care should be taken to remove a ball of earth with the roots, for the seedlings are delicate, and they will soon die out if they are not dealt with carefully.

Planting.-The land having been prepared in the usual way, as described in the chapters on coffee and cacao, and pickets having been set at distances of four feet by four Distances. feet, or four by five, or five by five, according to the nature of the ground, holes must be dug, but they need not be so large as for coffee and cacao. In planting out the seedlings Transplantfrom the nursery, which may be done as soon as they are ing. from nine to twelve inches high, particular care must be taken not to injure, or double up the tap root.

Cultivation.-The tea "gardens," as they are called, must be kept free from weeds, and the soil is to be loosened occasionally between the rows. All weeds should be buried ; Green crop for, as the tea plant requires a vegetable soil, green crop 
manuring is very beneficial. As the plants are set close together in the fields, catch-cropping cannot be recommended, for otherwise the permanent cultivation will suffer merely to benefit the temporary one. The plants will require much attention for the first two years, by which time they become firmly rooted, and then they are very hardy.

PRUNING.-When the plants begin to grow, they will throw out many branches, and when these attain to the

Prune to i:. duce a bushy habit. length of six or eight inches it will be well to pinch off the ends, so as to induce a branching and bushy habit. This pruning process, somewhat similar to the "handling" of coffee, may be continued until the third year, by which time the plants should be ready to give their maiden crop.

Tea of commerce got from the young shoots.

Bushes to be topped at four feet high.

Prunings to be buried between the trees.

The tea of commerce is simply the dry and prepared immature leaves, in fact the ends of the shoots advised to be plucked off in the preceding paragraph; the object of pruning, therefore, is to force the plant to produce successive growths of new shoots-and these are called fushes. All old wood, and badly branched stems, should consequently be cut away in the manner described in the chapter on pruning in the first part of this book. No precise directions can be given, for it is simply a question of judgment on the part of the planter. Tea bushes should not be allowed to grow more than four feet high; and they should be induced by proper pruning to spread out laterally, the central stem may be clean, up to about six inches from the surface of the ground, and then the more branches it has the better.

All the branches pruned off must be buried between the lines before they wither, and this is important as they form valuable manure, and just the right manure for the tea plants.

CROPS. - These commence at the third year and go on increasing up to the sixth year, when the plantation may be Return per considered to be in full bearing. In India the maiden crop acre. gives from 75 to $100 \mathrm{lbs}$. of prepared tea to the acre, and 
when the estate is in full bearing an average of 250 lbs. of tea to the acre is obtained. The yield depends naturally on the number of flushes; and these, on high lands, may be from ten to twelve in the season-which extends over six or seven months. In lower lands, however, where the soil and climate are suitable to the plant, and where manuring and high cultivation generally are practised, as many as twenty-five flushes have been got. The part picked consists of the The leaves three end leaves with the bud and stalk; the leaves and the to be tender stalk must be tender, for otherwise the tea made is coarse and of little value. The end of the branch is simply nipped off just beyond a bud, and this is usually done in tea countries by women and children, who after a little practice become very expert.

ManUfacture of THE TEA.-A flush having appeared on the bushes, and the young terminal shoots having been picked, the next thing is to manufacture the tea, which process usually occupies only two days, and may be done without the aid of any expensive machinery. Indeed, whenever Machinery the weather is dry, and the sun bright, machinery may be not absodispensed with if the cultivation be on a small scale. necessars. There are four processes to be undergone, namely-I. Withering. 2. Rolling. 3. Fermenting. 4. Firing.

W.ithering.-The leaves are spread out in the sun or on shelves in well-ventilated sheds for about two hours, by which time they will become softer and more pliable-in fact they will be withered, a term known to every one as expres- Leaves sive of the drooping and softening of leaves and flowers cut withered and kept in dry places. The withering prepares the leaves for rolling ; and by partly drying the cells of the epidermis, Flavour of it assists them to retain the juices on which the flavour of tea depends the tea depends. When the leaves are gathered in wet weather, the withering may be done in an iron or tin pan under which fire is put so as to cause moderate heat. This 
pan will be described later on. The leaves may also be withered by spreading them thinly on the floors of building.

RolliNG.-This process is an important one, and by it the leaves are made to have that twisted shape so well known to all. The object of rolling is not, however, to twist the leaves, for that is simply an accident of the process, it is to

Rolling presses out the bitter juices.

How the rolling is done.
Red and coarse leaves to be picked out.

Fermentation deve. lops the flavour. press out the bitter juice and to prepare the leaves for the stage of fermentation. In China the process is always done by hand, but in India and Ceylon special machines are used. The rolling by hand, however, answers the purpose quite well ; and, until tea becomes extensively cultivated in the West Indies, no other process can safely be recommended. The rolling is commonly done on a smooth table, covered with the Indian matting used for floors, in the following manner: A ball of withered leaves is taken in the hands and rolled backwards and forwards, or from side to side, considerable pressure being exerted at the same time. This causes the leaves to have a soapy feel, and it twists them up in various ways. When juice exudes and the leaves have the proper twist the operation is completed. A hard working man can roll 30 lbs. of leaves per day.

FERMENTING.-The rolls may be open so as to pick out red and ripe or coarse leaves, or they can be put into baskets or heaped up on the floor until they ferment, in which case the bad leaves are picked out afterwards. The fermentation is sometimes dispensed with, but it is an important process as it develops the peculiar flavour of the tea. No particular time can be mentioned as the proper period for the fermentation process. It is entirely a matter for experiment and experience.

FIRING. - This term is applied to the last stage in the manufacture, because the leaf is usually dried with artificial heat, in open pans or in one of the many machines, called driers, used for the purpose in tea countries. But the process 
can be effected by the heat of the sun, the only thing neces- How to dry sary being that the rolled leaves are spread thinly on mats, or on clean trays. With a bright, hot sun the leaves will dry in a little more than an hour, but they will require an occasional stirring in order that the lower layers may dry as quickly as the upper ones. In firing on a small scale, an The leaves iron or tin pan, three feet in diameter, seven inches deep, and flat at the.bottom, may be used. The fire is made with charcoal, and the heat must be just too much for the hand to bear, say from $180^{\circ} \mathrm{F}$. to $200^{\circ} \mathrm{F}$. The leaves are put in the pan as soon as fermentation is complete, and they are stirred until they are perfectly dry, which happens very soon. Great care must be taken to prevent the heat from being too Heat not to be great. great, otherwise the leaves will be charred, and the tea will be ruined.

BULKING.-The dry tea must now be prepared for the Greatcare in market, and this is an important operation, for its condition, $\begin{gathered}\text { preparation } \\ \text { necessary }\end{gathered}$ and therefore its value, depends greatly on the care it has received after it has been manufactured. On large plantations in the East, the tea is sorted into various classes as we shall see later ; but where small crops are produced, it is ad- Sorted and visable to ship the tea unassorted -it must, however, be free teas. from dust and unrolled leaves. The dust is easily removed by a slight fanning operation, in the same way as the parchment is winnowed from coffee, care being ta'sen that the wind does not blow away the finer parts of the tea; and the large leaves, that have come out unrolled, are broken up and added to the bulk. In India and Ceylon they are cut up by machinery and sold as "broken leaf." The term " unassorted tea" does not mean, however, that the produce is packed in the chests or boxes anyhow, for the tea must first be bulked, Contents of that is to say, it must be carefully mixed so that each chest chests to be contains tea exactly similar in character. Bulking is done similar in by machinery on important estates in the East, but on a small scale it may be effected in the following manner. A 
How the tea large square box is raised on posts some feet above the is bulked. ground, and at the bottom of the box a square hole is made, and so closed with a sliding trap door that the outlet can be enlarged or reduced according to necessity. The door being closed, the tea is put into the box in thin layers-one quality on the top of the others. The trap is then opened, and the tea runs out from the top taking a portion from each layer in its downward course. So as to ensure that all the tea runs out evenly, it will be well to make the bottom of the box slope slightly towards. the central aperture. The principle of this plan is the same as that of the sand-glass. It is very simple and at the same time efficacious.

SORTING.-On large tea plantations the tea is sorted into various classes. Before tea cultivation was taken up in India, the greater part of that consumed in the world came from China, and it was believed that each kind was the produce of a different variety of the tea plant. Afterwards it was discovered that all kinds of tea came from the same bushes, the different qualities being produced mainly by

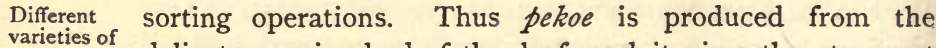
varieties of delicate opening bud of the leaf, and it gives the strongest tea in the cup. Pekoe Souchong is the next finest kind. Souchong is a tea somewhat coarser in appearance, Sorting on a and in Congou the leaves are larger still. On a small small scale. scale, tea may be sorted on trays by boys and girls, whose quick fingers can accomplish a good deal of this light work in a short time. Whilst the various qualities of teas are separated, all red leaves, and useless and foreign matters, must be picked out, as otherwise the tea would be deteriorated. Sorting with The various classes of tea may also be separated by sieves
sieves. with different sized meshes; and, when the process has to be gone through on a large scale, machinery is employed. Machinery The tea industry of India and Ceylon has become so large in the East. and important that anything money and skill could accomplish has been utilised in producing machinery as perfect as 
possible, with the result that the tea leaves brought fresh from the fields of the extensive tea gardens in these countries, are converted, in a short time, into the various grades of tea entirely by mechanical contrivances.

PACKING.-The bulking and sorting should be done as Tea to be soon as possible after the tea has been manufactured, and it out delay. should be packed before it has had a chance to absorb any moisture. When, however, this cannot be done, the tea should be slightly fired before packing to ensure its perfect dryness. It is usually packed in chests lined with lead, great Tea chests. care being taken that there are no holes in the lead lining, and that the top is soldered down so as to exclude all air. The tea is not to be thrown into the box anyhow, but everything is to be done with deliberate care. About a fourth of Packing to the quantity of tea is put in and pressed down with a board carefully. until it is quite firm, another fourth is then put in with the same precautions, and so on until the box is filled.

The packages used commonly in India and Ceylon are Sizes of square and of three sizes, namely, chests which contain 8olbs. packages. of tea as near as possible, half-chests which contain from 40 to $45 \mathrm{lbs}$., and boxes which contain 2olbs. A break of tea consists of ten chests, that is about 8oolbs., and it has been advised by London merchants that no smaller quantity should be shipped at one time. Latterly, tin and iron boxes have been used for shipping teas, as there is less chance of injury to the contents. These boxes are supplied in sheets, Metallic grooved at the edges, so that they can be easily put together, but it is necessary to solder the joints; and, when iron boxes are used, it is advisable to line them with paper so as to prevent rust injuring the tea. One of the $20 \mathrm{lb}$. tin boxes used in India measures $16 \frac{3}{4}$ ins. by 11 ins. by $10 \frac{1}{4}$ ins., and costs A break of half-a-crown. Four of these boxes may be packed in $a^{\text {tea. }}$ wooden case, or in a crate made of battens, and forty boxes will make a break of tea. 


\section{CHAPTER V}

\section{SUGAR CANE. Saccharum officinarum}

Suzar in the UNTIL within recent years, the greatest attention of West
West Indies. Indian agriculturists has been directed towards the production of sugar, which has been, in most instances, made on estates of considerable size employing a great number of labourers. Of late, however, the increased production of beet root sugar (the export of which from foreign countries has

The sugar bounties.

Low prices. the manufacture of sugar, operations attended with but little profit.

The smaller sugar planters have been in most cases compelled to give up the production, and it would appear that

Sugar does not pay on a small scale.

Central factories. sugar can now be made to pay well only when the manufacture is conducted on so large a scale as to require enormous expenditure and very complicated machinery. The system of usines, or central factories, is being introduced into various parts of the West Indies, and it promises to do much good, in a general way, to those tropical planters who, without much capital, are desirous of cultivating the cane. The usines buy the canes from planters at remunerative prices, and so the agriculturist has only to confine his attention te Planting and proper agricultural matters. This is as it should be, for the manufactur ing incompatible. double system of carrying on the businesses of a cultivator and a manufacturer, is not likely, in these days, to be followed 
with success. To expect the English farmer to raise corn and then to make it into flour and bread, would be regarded as absurd. The farmer is the cultivator, and he confines his attention to matters agricultural ; the miller is a manufacturer, and it is for him to prepare what the farmer has grown. The same argument applies to the West Indian sugar planter. He should be content to raise the canes on Advantages his land, and to allow the manufacturer to make the sugar. of the usine his land, and to allow the manufacturer to make the sugar. system. The planter will then raise better and more abundant crops, and the manufacturer will make better and cheaper sugar. In a large factory, scientific matters can receive due atten- Lconomy tion, and the management must be cheaper and more effec- ciency in the tive than it can possibly be in any of the many small "sugar of the cen ral works."

fac:ories.

SolL.-The sugar cane wiil grow upon almost any soil. Most soil Clays, loam, marls, and calcareous soils, are all suitable, more or less, for cane cultivation. Indeed, considering that canes are grown in all the principal West Indian colonies, with their wide diversity of soils, one might feel inclined to come to the conclusion that the nature of the soil was of no account in the cultivation. And neither was it of great Large profits moment when large profits were made by the sugar planters, of forms. but now that such low prices are got for the produce, the canes can be cultivated profitably only on land that is best suite 1 for them. Rich, porous clays, and alluvial soils on The b.st low lands through which rivers run, are the most favourable for cane cultivation, with the exception, perhaps, of loams formed by the decomposition of volcanic rocks. Such a The soil of soil as the last mentioned is found in St. Kitts, and sugar can St. Kitts. be produced in that island cheaper than in any other part of the West Indies.

Lime is a necessary ingredient in all cane lands, and thus when there is a deficiency of it in the soil, it must be added as a manure. A writer on the sugar cane says, "Lime is Lime in the beneficial to almost any soil, particularly new, and especially soil a neceswhere the salts of iron are found:" but, of course, this does 
not refer to soil where lime is found in quantity, as in the

The soil of Barbados.

The soil of Antigua. marls and calcareous soils. In Barbados, where the soil is peculiarly adapted to the sugar cane, lime exists in considerable quantity, for nearly the whole island is of coral formation; and, in parts of Antigua, some of the rich cane lands have been formed by the decomposition of a kind of limestone.

Climate. - The sugar-cane is essentially a tropical plant ; it will grow well in sub-tropical climates, but it does not there give anything like the return that it does in the tropical zone.

A hot moist climate the best.

A lowland plant.

Marine climate. A hot, moist atmosphere, alternating with periods of dry weather, such as is found on the plains and in the valleys of the West Indian colonies, is the typical climate for the cane. It does not do nearly so well in the hills as it does in the lowlands, and when planted in the mountains it takes a long time to mature and ceases to give remunerative crops. Moderate sea-breezes are not inimical to its growth, and for this reason alone cane cultivation is eminently suited to the West Indian islands where the climate is a marine one. Indeed, on the windward coast of the islands, where the land is exposed to sea-breezes bringing in air laden with saline particles, scarcely any cultivated plant but the cane can be grown.

Cane plants. Propagation. - The cane is propagated entirely by cuttings, for, although the plant flowers, it rarely bears seed. These cuttings are called plants, and they consist of the two or three upper joints of the cane. Each joint contains an eye, or bud, from which shoots run up to find air and light, and roots descend into the ground, in much the same way as Good seed. occurs in the case of the germinating seed. It has been shown, in the first part of this book, that a good planter, in order to obtain the best and largest crop possible, where propagation from seed is concerned, should select the finest Improve- fruit, and the largest seed from that fruit. By a close obserment of crops. vance of this rule, European and American agriculturists have improved grain, root crone and fruits immensely. One would 
naturally conclude therefrom, that the sugar-planter, in order to increase the returns from his fields, would be extremely careful in the selection of his "cane plants"-which are, as we have seen, very similar to seeds in their mode of growth. But, strange to say, many sugar planters have paid no atten- Care in the tion to so important a matter, and they invariably obtain selection of tion to so important a matter, and they invariably obtain cane plants their plants from "thrown up or exhausted fields." If the of the sugar planters had taken as much care to improve the quality importance. of their canes, as the European and American horticulturists have done to improve their fruit trees, by this time the sugar- Advantage cane would have been so much improved that its greatly in- agriculture. creased yield would have preserved the industry from much of the misfortune that has come upon it.

Planting.- The cuttings are planted in furrows made by Preparing the plough, or in holes dug with the hoe in places where ploughs cannot be used, or where, for some reason or other, their use is rejected. In the latter instance, it is well to pickaxe the holes before the cuttings are planted, so as to loosen the soil for the free entry of the delicate rootlets. The holes Caneholes. are from eight to twelve inches deep, and their size depends on the distances at which the plants are set, and this in its turn depends on the nature of the soil and climate. Formerly the canes used to be planted much closer than is Distances. customary now. Three feet between the rows and two feet apart were common distances, but now in good lands the rows are often seen seven feet apart and the plants six feet from each other in the rows. The average distance in the West Indian Islands, however, is 5 feet by 5 feet. On hill Planting on sides, and in poor soils, their distances may be decreased, and in places where the canes are planted in furrows made by a double mouldboard plough, it is customary to place the cuttings much nearer to each other.

Two cuttings, or plants, are placed in each hole in a slant- Putting in ing direction. They are usually about six inches long; and, as about an inch is left out of the ground, five inches are buried in the soil. In favourable weather they will send up 
sprouts above the ground and become rooted in from ten to fourteen days. These sprouts or shoots become the motherCut out the plant, and they send up other shoots in time. The mothermother plant. plant should be cut out as soon as it begins to joint; for, in this way, all the strength will be sent into the surrounding shoots and cause them soon to develop into canes. When, owing to dry weather, or to other causes, some of the cutSupplies. tings do not take root, it is necessary to supply the vacant holes, and, in order that the supplies may not produce canes backward in growth, as compared with the rest of the cultivation, growing plants are dug from the roots or stoles Nurseries of of canes thrown out of cultivation. An infinitely better plants. plan would be to establish nurseries of plants raised from selected cuttings; for, in this way, the returns from the supplies would be greatly increased, as the weight of canes obtained from each hole governs the quantity of sugar made. Return from A Barbados planter has calculated that "a bunch of canes plant. grown in one hole weighs 54lbs. on an average, which yields 4 gallons of juice, from which 4 lbs. of muscovado sugar are got." At this rate over three tons of sugar would be got from an acre of cane land, but on many estates in the West Indies, owing to bad cultivation and other causes, barely half this quantity is obtained.

The better the tilth the greater the returns.

Subsoil ploughing.
Cultivation.-Tillage is one of the most important operations in cane cultivation, for the better the tilth the greater the returns. Before planting, the land should be well hoed and ploughed, and the weeds ought to be buried so as to form a green crop manure. Except in heavy clay land it is a bad system to burn the weeds and rubbish, for the fire dissipates the nitrogenous substances, and thus prevents their retention in the soil as plant food. If the land be ploughed a subsoil plough should be run in the furrows where practicable, as the turning up of the deeper layers of the land greatly increases the soluble constituents available for assimilation by the roots of the cane.

After planting, the fields must be kept clear of weeds 
until the canes grow up and shade the soil, when the weeds Frequent will no longer give trouble. In some of the West Indian weedings Islands, such as Barbados for instance, the "farm" or "garden" system of weeding has been adopted with great The garden success. A portion of the cane field is given out to labourers system. who receive regular pay for keeping the land absolutely free from weeds. In places where this system has been established, it is found that the weeds do not after a time give very much trouble, for their constant eradication prevents seeding and tends to kill them out. Some planters Light plough lightly between the rows after the canes have made some little growth, and this acts beneficially by loosening fows benethe soil, and by exposing some of its under surfaces to the fertilising action of air and sunlight.

From October to January is generally considered the best Planting time for planting canes in the West Indies, but no general rule can be laid down, as climate and local circumstances must be taken into account. In October, the canes throw out flowering stems, called arrows, and these are long Arrowing. terminal shoots bearing pyramidal tufts of mauve-coloured, downy blossoms. The flowers are sometimes collected and used in the stead of feathers for pillows.

As the cane grows, the lower leaves wither and dry up Trashing and usually remain attached to the stem. In dry weather, not necesthe dead leaves, called trash, must be left alone, but on rich soil and in wet weather they will interfere so much with the circulation of air amongst the vegetation and in the ripening of the canes that it becomes the duty of the planter to have them separated from the canes and strewn on the ground over the roots. This is termed trashing, and by leaving the trash at the roots of the canes it will rot and form excellent manure.

At the time of "arrowing" or flowering, the canes are The matupoor and weak, the juice being watery and deficient in sugar. ration But the flowers do not form seed-save in exceptional cases, and the plants soon recover from the exertions they have put forth in flowering. Canes are usually ripe and fit for 
cutting in about twelve to fourteen months from the time

Plant canes and rattoons.

Different kinds of rattoons.

\section{Fallowing.} cultivation of canes from plants has hitherto been considered, but on some sugar estates only a portion of the land is occupied by these plant canes as they are called, the other part being cultivated in rattoons, which are simply canes grown from the stoles or roots left in the ground after the plant canes are cut. Rattoons are called first, second, third and so on, according to the number of crops taken from them. On very rich soil, the rattoons have been known to produce crops for twenty years, the canes having been cut annually, and the stoles allowed to throw up shoots again. But this continuous cropping of the same soil exhausts the land, and causes the canes to deteriorate so much in size and quantity as to give unremunerative returns. It rarely happens, therefore, that rattoons are cultivated beyond the third or fourth, or at most the fifth year, the land being then allowed to fallow so as to prepare it later on for plant canes.

When the canes are cut.

Mature canes.

How distinguished.

Unripe canes.

Crops.-The crop-time in the West India Islands is usually from January to May, but the cutting operations must not be commenced till the canes are ripe. "The maturity of the cane is indicated by the skin becoming dry, smooth and brittle; by the cane becoming heavy; the pith grey, approaching to brown; and the juice sweet and glutinous." On cutting a ripe cane across, the inner tissue is dry, and it contains white particles; in an unripe cane, on the other hand, the interior is soft and moist from the presence of unelaborated sap, and in this condition it is unfit for cutting. If an unripe cane be bent it will break off at the joint or node, as if cleanly cut with a knife. A ripe cane, on the other hand, will not break off in this manner as the tissues are more fibrous. The mature cane varies much in length and breadth according to differences of soil and climate, and also according to the variety of the plant. 
There are many different varieties cultivated in the West Varieties. Indies, but the Otaheite and Bourbon are the kinds most often planted. In the rich and most alluvial lands in British Guiana, the canes sometimes attain the length of 20 or Average even 25 feet, but from Io to 12 feet are the lengths most length. often met with, and in a good deal of the cultivation in the West Indian Islands they are not even as long as 10 feet.

The canes are cut right down to the ground as near to How the the stole as possible, for the root end is always richer in canes are sugar than any other part, and the close cutting increases the vigour of the rattoons. For the convenience of handling, the canes are sometimes chopped into lengths of four or five feet and tied up in bundles. These are then carted to the Grinding the works to be ground in the mill, by which process the juice is pressed out of them.

Plant canes yield a larger return of juice, and therefore of The cane sugar, than rattoons; but the juice from the latter is richer in saccharine matter and it gives a finer quality of sugar. Besides, there is much less trouble and expenditure in cultivating the rattoons, and the sugar is manufactured from them with less difficulty. It follows, therefore, that the Rattoons cultivation of rattoons is more profitable than that of plant more profit canes, but as the former deteriorate year by year, it is plant canes. necessary to have recourse to fresh planting at stated intervals.

In British Guiana it has been found that good cane culti- Returns vation gives about 30 tons of canes to the acre, and this of canes. will yield about 25 tons of juice containing from 15 to 18 per cent. of crystallisable sugar. But only six or seven per cent. of this sugar is extracted by the best manufacturing processes, and thus the return is only two hhds. or $36 \mathrm{cwt}$. to the acre. These figures may be taken as fair average ones for cane culture, but in certain instances the returns are larger or smaller according to the peculiarities of soil, climate or cultivation. 
CHAP.

MANURING.- On most of the sugar estates in the West Indies the canes have been planted on the same soil for very many years, and thus if the planters had not manured their

Sugar cane an exhausting crop.

Composition of sugar.

The quantity of ash of the cane. lands, the soil would have become barren long ago, for the cane is a very exhausting crop, as it extracts large quantities of inorganic matter from the land. Sugar itself is composed of three organic elements, viz. : carbon, oxygen and hydrogen, all of which are obtained from the atmosphere and water alone. But, in order to build up the sugar in its tissues, the organs of the plant require quantities of inorganic materials which must come from the soil. Careful analysis has shown that ripe sugar cane (Otaheite) contains $0^{*} 48$ per cent. of ash, which is about one part in ncarly every two hundred. A crop of 30 tons to the acre would remove, therefore, nearly three hundredweights of the inorganic constituents of the soil which exist in a soluble form ; and, as the cane refuse or megass is used for fuel, and the tops are used as fodder for cattle, nearly the whole of this inorDrain on the ganic matter is taken away from the soil absolutely. The so:l.

Aralysis of the sugar cane.

following table is calculated from an analysis of the ash of a ripe cane and its leaves by Dr. Phipson, and it shows at glance what constituents are removed from the soil by the canes, and what special kind of manure may be necessary to keep up fertility :-

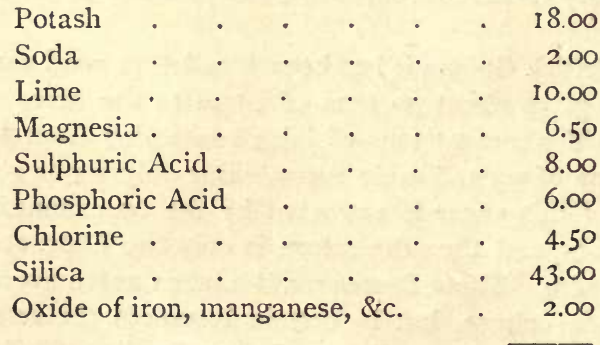


When farm yard manures are obtainable, they will supply all the necessary constituents for the cane, but it is rarely that sufficient are available, and it is necessary for the sugar planter to make up for the drain on the land by the applica- Special tion of special manures, such as guano, gypsum, \&c. In all manures. cases of cane cultivation on a large scale, it is advisable that the planter should have samples of his soil, both surface and sub-soil, analysed in order that he may know what of the constituents of the ash of the cane are absent or deficient in quantity and what proportion are in a condition to be available for plant food. He can then supply the deficiency by using a manure, rich in the constituents wanting in his soil. But to apply manures haphazard, is to run the risk of throwing away money in purchasing what the soil does not require ; and, therefore, what is utterly useless.

MANUfACTURE OF SUgar.-Two principal kinds of sugar Two kinds are now made in the West Indies, namely, raw or muscovado of sugar. and crystals. The muscovado sugar is shipped to Eurnpe and North America, and there it is, for the most part, converted into loaf sugar in the various refineries. The cryst.als "Crystals." go to the consumer without any further preparation; aind as they are made only on large estates by complicated machinery, it would be out of place to give a sketch of the process in this book. Muscovado, or raw sugar, is prepared Muscovado on the smaller properties; and, in those colonies where the sugar industry has not attained to very large proportions, it is the only kind made. The various stages in the manufacture are well known to most persons in the West Indies, and it is only necessary to allude to it briefly here.

The ripe canes are brought to the mill in such quantities that the manufacture can keep pace with the cutting, for the juice is exceedingly fermentable, and it must therefore have The cane heat applied to it for the purpose of clarification as soon as juice ferit leaves the mill. Various kinds of mills are used, some easily. with the rollers placed vertically and others with them Mills. 
How the mills act.

Megass.

The impuri. ties of the juice.

Scum.

Charging the boilers.

Striking from the teache. Granulation of the sugar.

arranged horizontally. In all the mills the canes receive two compressions to force out the juice, and the fibrous material left by the canes after the juice is extracted is called megass, and it is used as fuel for the furnaces under the boiler and clarifiers.

The cane-juice as expressed by the mill contains in suspension various matters such as particles of woody tissue and cellular substances, \&c. In order to remove these impurities the juice is run into vessels or pans called clarifiers, and a little unslaked lime is added so as to neutralise the vegetable acids. The clarifier is then heated and the impurities rise as scum, which is removed and the juice is said to be defecated. The hot juice is now run into the first of a series of cast iron or copper open pans or boilers where it is subjected to great heat. As the juice boils, the scum which Skimming. rises is skimmed off ; and, in consequence of the evaporation of the water of the juice, the bulk is decreased and the liquor becomes thicker. It is then ladled out into the next boiler, which is smaller than the first one, and more juice is run into the large boiler from the clarifier. As the liquor becomes denser it is transferred from boiler to boiler, which usually decrease in size, until it enters the last and smallest one which is called the teache, and which is usually the fourth boiler. The liquor, which has now become a concentrated syrup, is boiled in the teache until it is in a fit state to granulate into sugar, when it is transferred to flat open wooden coolers, and this is termed striking. The sugar granulates in the coolers, but it is mixed with much uncrystallisable saccharine matter called molasses. After remaining a sufficient time in the cooler the sugar is potted; that is, it is dug out and packed in hogsheads with holes at the bottom for the molasses to Draining of drain off. In order to assist the drainage the stalks of the plantain leaves-which are long enough to reach the top of the hogshead-are put through the holes in the bottom, and they are withdrawn as soon as the molasses are drained off. 
In all the operations for the manufacture of sugar, clean-Cleanliness liness should be observed. After grinding, the mill should essential. be properly cleaned, and the parts of the iron that the juice has been in contact with ought to be brushed over with Cleaning the lime so as to neutralise the vegetable acids, which would otherwise do much harm to the juice at the next grinding. 


\section{CHAPTER VI}

\section{FRUITS}

\section{The Orange. Citrus Aurantium}

Importance IN commercial importance for its fruits, the orange family of the orange is said to come next to the vine, but the greater part of the
family. grapes cultivated are made into some form of wine or spirits, and so, taken simply as a fruit, the orange and its allied species may be said really to be the most important of all the fruits cultivated by man. The orange can be raised in quantities only in tropical and sub-tropical climes; and, as the consumption of the fruit is greatest in temperate zones,

The orange a very large trade is done in its cultivation and sale. Until trade. within comparatively recent times, nearly all the oranges sold in the great fruit markets of Europe and North America, were raised in the islands of the Atlantic lying off the Northern coast of Africa, and in the countries bordering on The West the Mediterranean Sea. But the increase of steam commuIndian trade. nication with the West Indies has caused the fruit trade of - some of the West Indian Islands to become greatly augmented, and a trade in oranges has been established between the United States and Jamaica, the Bahamas and Dominica. By careful packing and selection the fruit can be kept so as to undergo long sea voyages: and, as the orange trees grow in the West Indies perhaps more luxuriantly than in any other part of the world, there is no reason why the bulk of the oranges consumed in the United States should not be 
grown in these colonies. There is very little fear of over production, the only serious competition would come from The Florida Florida, but sometimes an occasional ice wave passes over that country and kills back the orange orchards so that several years must elapse before the trees recover from the death of their principal branches. A writer, who published

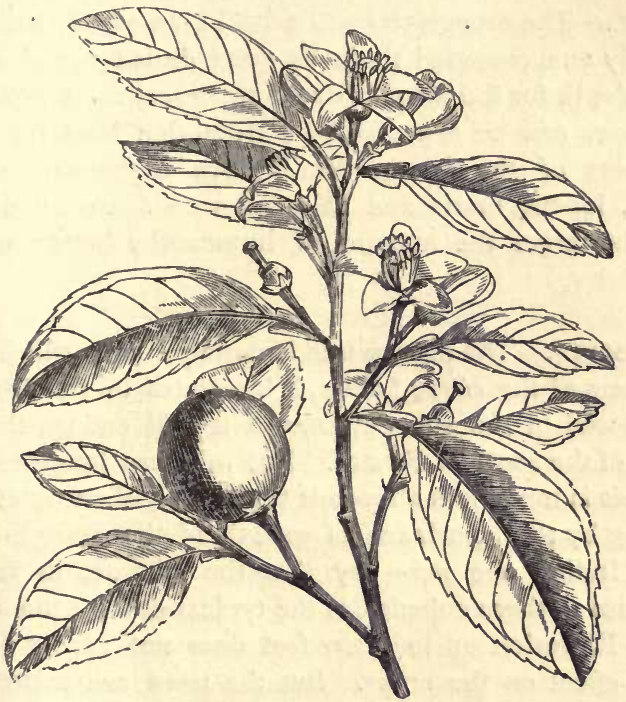

ORANGE. Citrus Aurantium.

a book on orange culture in Florida several years ago, said that "The present yield of fruit grown in the United States "furnishes hardly one consump"furnishes hardly one orange a y'ear to each inhabitant. Our tion of "population will nearly double, judging the future by the oranges in "past, in the next thirty or forty years. To furnish such a Statss. "population with one orange or lemon a day, will require no "less than thirty thousand millions of oranges or lemons per 
"annum." Such being the case, it need not be feared that the orange industry of the West Indies is likely to be killed out by the competition of Florida and California ; and, when

The cultivation a profit. able one. the fruit can be sold to local buyers, there is perhaps no more profitable cultivation than the orange, for small proprietors to engage in.

SolL.-The orange tree will grow in almost any soil except a sandy one, provided there be good drainage and a sufficient depth for the long tap root to descend. Good crops, Rich soils however, can be expected only from rich land, for all the
the best. members of the orange family love a "generous soil." Clays, loams, marls and calcareous soils are all suitable, and the larger the amount of humus the better will the tree thrive.

Climate. - The orange tree is perhaps the hardiest of the

Tropical climates best. members of the citrus family, it luxuriates in the tropics, it grows well in the sub-tropics, and it will endure the mild frosts of the south of France. But in these latter climates, the fruit is much less abundant than it is in the tropics ; and, judging by the luxuriance of growth of the oranges of the West Indies, one may say that the climate, in favoured localities in these colonies, is the typical one for the orangetree. Elevation up to 2,000 feet does not appear to have Elevation. much effect on the crops. But the trees are raised more easily, and the fruit is larger and more luscious in warm,

Shade unnecessary. moist localities in the mountains. Shade is quite unnecessary, for the tree delights in the sun, and overhanging shade causes the stems to run up like whips. The roots take so firm a hold on the ground that the tree bears a good deal of exposure, but in very windy places, the crops are short by reason Shelter. of the flowers and young fruit being blown off. Shelter belts of trees are therefore advisable in such places, but they must be used as "break-wind fences" and not-as overhanging shade. 
PROPAGATION.--In the West Indies, orange-trees are for Seedlings. the most part raised from seed, and no better oranges can be grown in any other part of the world than those produced from some of these seedling trees. In Florida and other parts of the Southern United States, the oranges are mainly propagated by budding sour stocks, ior the sour Budding orange has become wild in some parts of those countries. In Europe the best oranges are grafted, and as a grafted Grafted fruit is very variable in the variety grown from its seed, it oranges: has been said that oranges will not "breed true," and grafting or budding is necessary to preserve the characteristics of the fruit. This, however, is a fallacy as far as the West The seed Indies are concerned, for in these countries the seeds for the breeds true most part breed true and no other method of propagation is Indies. adopted.

The seeds should be planted in nurseries prepared in the Nurseries. manner described in former chapters; or, if the cultivation is not to be carried out on a large scale, it is perhaps better to sow them in boxes raised off the ground, as rats and mice are particularly fond of them. The seeds must be planted Fresh seed fresh from the fruit, for they lose their germinating power necessary. on drying, and they cannot be carried long distances unless they be preserved in earth, for, strange as it may appear, seeds kept in earth will remain fresh much longer than those left in a dry place above the soil. This is a wise provision seeds lie of nature whereby seeds, which have been dormant in the dormant in soil for years, wake into life as soon as the conditions are long periods favourable for plant life. One orange seed often contains Several several embryos [see next page] and this is why it happens embryos in that when the seeds are planted at distances several seedlings are found afterwards growing close together. The seeds Distances must be sown three or four inches apart, and there should be in the from six to nine inches between the rows. As the tap root is long, the nursery beds must be dug deeply so as to loosen the sub-soil. The seeds will soon germinate, and the plants can be put out in the fields when they are a year old. 
PLANTING.-The distances at which the trees are planted Distances in depend principally on the nature of the soil. In rich forest the fields. land with a deep and porous soil, 25 feet each way will not be too far, but in drier places and on poorer soil 20 feet is the proper distance. At 25 feet there would be 70 trees to the acre, and at 20 feet there would be 108 .

Except in very favourable places, where a rich, deep and Holing the friable soil is found, holes must be prepared for the plants, land.

which should be put in at the commencement of the rainy Pruning the season. In removing the plants from the nurseries, if the tap root. tap root be broken it should be pruned with a sharp knife,

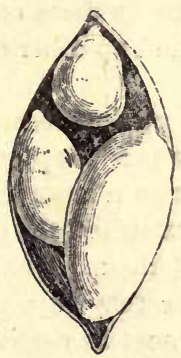

AN ORANGE SEED, WITH SEVERAL EMBRYOS.

as it is a bad system to put in the young tree with a jagged wound of the main root. With proper care there will be very few "misses," for the orange is very hardy in the West Indies, and even moderately large trees can be successfully transplanted in the wet season.

Importance of good. cultivation.
Cultrvation.- When an orange grove is formed, the returns will depend greatly on the cultivation. The trees will grow and give crops without anything whatever being done to them, but such trees will improve wonderfully if they be properly attended to. The ground should be kept weeded and well stirred up. As the tree throws out many superficial 
roots the soil in the immediate vicinity of the stem must not be stirred deeper than a few inches, except at intervals of a year or so when careful pickaxing will do good. Between Deeptillage the rows the deeper the tillage the better. On level land the between the plough may be run so as to form several furrows in the centre of the lines, and it will prove advantageous if the subsoil be turned up at the same time.

On many West Indian properties it is not practicable to form a regular "orange grove"-which is the term applied to the plantation; but a great number of trees may be grown along roads, and in odd corners of the property. The tree, The trees as was pointed out, is a very firm rooter, and after the recent rooted in hurricane in Dominica orange-trees were found standing the ground, erect, and almost unhurt, whilst other trees in the neighbour- withstand hood were blown down or even torn up by the roots. The stable nature of the trees may, therefore, be taken advantage of by planting several rows of them wice apart through coffee, cacao and other plantations, for in the event of hurricanes these belts will serve as sure protection.

MANURING.-No other tree, perhaps, responds so readily to judicious manuring as the orange. On poor soil with a deficiency of vegetable matter, the tree will look sickly, its leaves will be yellowish, and its crops small; but the free application of a nitrogenous manure will soon cause a won- Nitrogenous derful alteration in the vigour of the tree, and the number of manures the fruit borne. When the young trees are well rooted and cial. growing, the application of farm-yard or green crop manure will push them on very much; and when the trees are bear- The trees to ing they should be manured every year. Guano and wood be manured ashes are sometimes used with success, and liquid manure poured over the roots is most beneficial. Indeed, the soil should be made as rich as possible, for the richer the soil the greater the return.

CATCH CROPS may be grown between the trees with ad- Catch crops vantage, for as the distances of planting are wide, and as the $\begin{gathered}\text { to be recom- } \\ \text { mended. }\end{gathered}$ 
trees take from five to seven years to come into bearing, the land would be kept idle for too long a time if inter-cropping

Cultivation in the Azores. were not resorted to. In the Azores, melons, pumpkins and annual vegetables are raised between the bearing trees, and the stirring of the soil by this cultivation exerts a beneficial effect, provided the orange trees be manured so as to keep up the fertility of the soil.

Necessity of PRUNING.- The trees require pruning from the first. pruning.

How to prune the trees.

After the plants are put out and vigorous growth takes place a lot of stems sometimes spring up around the central one. These must be carefully pruned off, and the young tree must be trained to send up a clean, straight stem branching about five feet above the ground. As the tree grows up, the lateral branches close to the ground must be removed with a clean cut close to the stem, so as to enable the bark to grow over the wound. But too many of these branches must not be taken away at a time, as heavy pruning retards the general growth greatly. When the trees are mature, dead and illshaped branches should be removed with the fruning saw, the wound being trimmed with a knife, and tar being painted over it to prevent decay entering into the heart of the tree.

CRops.-In the West Indies the crops are usually in from September to February, some trees bearing earlier and some Advantages later. The earlier the produce gets to the market, the of early crops. greater are the prices obtained, as the Mediterranean oranges are not in full season until the beginning of the year, and so every attempt should be made by the planter to induce

How to get early crops. his fruit trees to bear early crops. A good deal in this direction can be done by irrigation, careful pruning, and by keeping back the fruiting period, and when a very early bearing orange tree is obtained it should be propagated by budding and grafting.

The yield of The yield of oranges varies very much-soil, climate and oranges from individual trees. cultivation being important factors in determining the extent of the crops. In California from 400 to 600 oranges are 
borne annually by the trees. In the Azores and in Florida, these figures are much exceeded, and in the West Indies from 3,000 to 8,000 oranges are not uncommonly gathered from single trees. As many as 14,000 have been taken off Dominica large trees in Dominica, and 8,000 are a common yield in oranges. that fertile island.

In gathering the oranges, particular care must be taken Gathering not to bruise the fruit, as one bruised orange will often cause the oranges. all the other oranges packed in the same box to become rotten. Ladders must be used for tall trees and the stalks must be cut, for to tear the fruit off the trees is to run the risk of serious loss. Oranges gathered with a portion (about a quarter of an inch) of the stem attached are called "stemcut" oranges. These keep better than others and always fetch a higher price.

Enemies to the Orange TREe.-The orange, like most other cultivated plants, has its enemies, but, fortunately, in the West Indies, these are neither numerous nor formidable. The most important is the scale insect or coccus, which if The scale left to itself may kill out the young trees and prevent the blight. fruitfulness of the matured ones. It may, however, be got rid of by brushing the stem and branches with a solution of whale-oil soap in water, to which a small quantity of kerosine oil has been added. A decoction of tobacco, beaten up with Insecticides. carbolic soap so as to form suds, is also a valuable insecticide if it be brushed over the bark of the trees and allowed to dry on. And to paint or syringe the trees with wood ashes and water, or with white-wash made into a thin fluid, very frequently destroys blights both animal and vegetable. The rust on the oranges is caused by an insect blight which may Rust. be killed out by dusting quick-lime over the trees, it being usually sufficient to stand under the tree and to throw up the lime in handfuls when the leaves are moistened by dew or by light showers, but particular care must be taken that none of the lime gets into the eyes of the operator. 
PACKING FOR THE MARKETS.-It has been shown that extreme care should be taken in gathering the fruit, and the

Unripe oranges to be gathered for export.

Oranges to be packed dry.

Packages.

Boxes.

Wrapping the oranges.

Number of oranges in the box. same care is necessary in packing. The oranges intended for export must be gathered before they are ripe, but they ought to be fully formed. It is not necessary that they should be yellow, for they will ripen after they are gathered, and in the ripening process the green skin turns yellow. A dry day should be selected on which to gather the fruit; as, before packing, all the moisture about the skin must be evaporated. The best plan is to set the oranges on shelves for a day or so, in the packing shed, and, when they are dry, any bruise or defect is easily seen.

Oranges are shipped from the West Indies in empty flou: barrels, and in boxes. The barrels usually have holes cut in the staves for the purpose of ventilation, and each barrel will contain about 300 oranges. But a much safer plan is to ship in boxes, the usual size being 2 feet and a half long by one foot in depth and one foot in width. The ends of the boxes are solid, but the top, bottom and sides are boarded up with laths 3 inches wide, a space of about 2 inches being left between the laths. The box is divided into two equal compartments by a solid piece of wood, similar to the pieces used for the ends. The boxes are usually put together by the shipper, the various pieces being imported from the United States already cut up to the various sizes, and thus with a few wire nails, an industrious person can fix up a number of boxes in a very short time.

Each orange must be wrapped in paper, care being taken to reject all inferior or damaged fruit. The paper used is the common yellow wrapping sort, imported from the United States, and it should be cut into sizes sufficiently large to wrap up the oranges smoothly and evenly. Each of the boxes will contain about 150 wrapped oranges of the larger kinds, but $\mathrm{I} 80$ of the smaller fruits can usually be stowed away in the same space. The packing should be so close that the oranges will not shake about, indeed in nailing 
up the laths on top it is as well that they should slightly compress the fruit as it dries and decreases in bulk on the voyage. The oranges in each box should be of the same size and of the same degree of ripeness. These are matters of great importance. Before packing the fruit ought to be The oranges sorted out, each kind being packed separately, for when a to be sorted. buyer takes a sample orange out of a box he expects to find all the fruit of the same size and quality as the sample. After the boxes are packed they should be handled carefully, for Careful fear of bruising the fruit; and, if the estate be far from the handling shipping place, it is as well for the packages to be carried in light spring waggons as in Jamaica, lest the jolting of a cart should injure the delicate contents.

\section{The LIME.-Citrus Medica var. acida.}

IN regard to commercial importance, the lime comes next to the orange. The acidity of the fruit is more pronounced than that of the lemon, and many persons prefer it on that account. Limes are shipped in small quantities to Europe and North America packed in the same way as oranges; but, as the lemon is a better known fruit, it will take some Lemons. time before there is a demand for limes in the great fruit markets.

Limes are now, however, principally grown for the sake of Concentheir juice, which is shipped from Montserrat and Dominica juated lime in a concentrated form, and from these two islands-as well as from Jamaica and Trinidad-it is sent to Europe and the United States, in its natural or "raw" state. The concentrated juice is the source of a considerable portion of the citric acid used in medicine and the arts, and the natural Citric acid. fruit juice is bottled up and sold in Europe and America as a refreshing and wholesome beverage. It is also used as an Raw juice. antiscorbutic,-that is, to prevent the outbreak of scurvy on board ships and elsewhere-and all English vessels leaving Great Britain for long voyages are bound to have a good 
supply of lime juice on board. The spread of temperate habits in many parts of the world is calculated to increase the demand for the juice of the lime, for it makes a most grateful and perfectly innocuous drink in hot weather, and, Lemonade. indeed, at any other time. A sip of lemonade, made from pure lime juice, allays, better perhaps than anything else, the raging thirst of fever, and many distinguished medical men recommend a decoction of the whole lime as a very efficient febrifuge.

Soll.-Those soils suitable for the orange are the best for the lime, and the richer they are in nitrogenous constituents and potash the larger will the crops become. The The lime a lime, however, is hardier than the orange, and although it hardy plant. has a tap root, the main supply of food from the soil is taken up by the lateral roots which spread for long distances close to the surface of the ground. It follows, therefore, that the lime will grow in shallower soil than the orange, but in such situations it grows slowly and it bears small crops.

The best climate.

Climate. - The best climate for the lime is a hot, moist one, such as is found in sheltered valleys from 300 to 500 feet above the sea in the well-wooded West Indian Colonies. The tree will bear a certain amount of exposure, but high winds knock off the flowers and young fruit, and thus very

Shelter belts. seriously diminish the crops. Shelter belts of trees should, therefore, be grown when the lime is planted in exposed situations.

Propagation.-This takès place by seeds which are very Seedlings. abundant in the fruit. The seeds are planted in the same way as those of the orange, but as they are so plentiful they may be sown broad-cast in the nurseries and afterwards raked into the soil. Soon after germination has occurred, the weakly seedlings can be weeded out, and the whole nursery may be thinned with advantage. 
Planting.- This also is done in the same way as is Planting at adopted in the case of the orange, but some planters sow a stake. few seeds in the field when the trees are to remain. When the seedlings are 18 inches high, all but the one to be left are to be weeded out, or they may be dug up carefully so as to be used for supplies, or for increasing the planted area.

The distances at which the lime trees are usually planted Distances. vary from Io to 20 feet, and this gives an average of 15 feet between each plant and between the rows, but the same distances cannot be adopted for the planting of all lands. On steep hill sides to feet will not be too close, and on rich bottom lands, at 20 feet distance from each other, the trees in ten or twelve years will meet and completely shade the ground

Cultivation.-This is the same as for cacao or oranges, and with careful weeding and an occasional stirring of the soil, the trees will commence to bear in three years from the time of planting. Some planters do not weed, but allow Pasture pasture grass to grow between the trees for the purpose of between raising cattle ; but this plan cannot be recommended, except on steep hill sides where the low grass will prevent the soil from being washed away from the trees, and even in these situations the ground must be tilled occasionally.

Catch crops may be taken off the land for the first few Catch crops. years, or until the limes are bearing, but as the lime roots run close under the surface, nothing should be planted too near to the trees. Beyond removing all suckers, dead Pruning. branches, and those that lie too close to the ground, no pruning is necessary, indeed, the cultivation of the lime-tree is simplicity itself, for the more the plant is left to its natural growth the better will be the results.

Manuring will be necessary to keep up the fertility of the Manures soil, farm-yard manure being the best; and failing that, necessary. some special nitrogenous and potash manure may be em- 
ployed. The writer of this book, on his lime plantation in Dominica, has the skins and pulp of the fruit, after the juice is expressed, put on the roots of the trees so as to give back to the soil as much as possible of the produce raised from it. This system answers remarkably well, and it has been adopted by other planters. When the juice is concentrated and wood is used for fuel, the ashes from the furnace should be applied to the roots of the trees, for, as was pointed out in the first part of this book, wood ashes contain a large proportion of potash.

Yield per CROPS. - The yield per tree varies considerably, according
tree. to soill, tillage, rainfall and climate ; but, with careful cultivation, a fair average soil, and a rainfall of about 60 inches per annum, from three-quarters to a barrel of limes can be reckoned on from each tree. The flowering usually begins Crop time. in March, and the crop commences in June or July, and continues to December, but a few limes may be gathered all the year round, except at the end of the dry seasons, during which time vegetation is at rest.

Except when the fruit is exported, the limes should not

The fruit to be allowed to fall to the ground.

Squeezing out. the juice.

Mills.

\section{the}

be picked off the trees. They should be allowed to fall to the ground, and in this way the fruit is got in the best condition for obtaining the juice. On no account must the trees be shaken or beaten to cause the limes to fall, for the crop would then be lessened, by many flowers and much young fruit being thrown down.

Preparation of the JUice.-The juice is extracted from the limes in various ways, but the process of squeezing underlies them all. Cider presses are used in some places, the fruit being cut up before it is put in the press. Small sugar cane mills are used in other places, and they do the work remarkably well. The best form of mill is one made with heavy horizontal wooden rollers covered with sheets of copper roughly perforated so as to catch the limes. With a good press or mill from seven to eight gallons of juice can 
be obtained from every barrel of limes ; but, sometimes, on Quantity of account of defective machinery, no more than five and a-half or six gallons are got.

juice to a barrel of

When the juice is exported in its raw state, it is necessary to take particular care to exclude all dirt, fruit pulp, and limes. seeds. If the limes be gathered in rainy weather the mud must be washed off them before they are passed through the mill, and it is well to strain the juice through several copper Straining the sieves with meshes of decreasing size. Another good plan is to allow the juice to remain in puncheons or casks with a tap put in about ro inches from the bottom. The juice will then "settle," the seeds and the heavier part of the pulp falling to the bottom, and the oil and other impurities rising to the top. The juice can be drawn off in three or four days, and it is allowed to run as long as it is clear. The casks in which the juice is exported must be completely Packing the filled, so as to exclude the air, and they should be bunged up as soon as possible. If this system be adopted the juice will remain in good condition for many months. When it is Prevention necissary to keep it for a long time, half an ounce of sali- of fermentacylic acid can be added to every fifty gallons of juice, the acid preventing the fermentation and consequent destruction of the product. The salicylic acid will not interfere in any way with the wholesomeness of the juice.

Concentration of THE JUICE.-Concentrated lime juice How the is prepared very simply by evaporation in open copper pans juice is con until the required density is obtained. In Dominica, the juice is usually boiled down until it reaches one tenth or one twelfth of its original volume-the resulting product, which will contain over 100 ounces of citric acid to the gallon, being a very acid stuff about the colour and consistency of molasses. The concentration of the juice requires a great Fuel. deal of fuel, about two cords being required to produce a hogshead at a density of Io to I. It is necessary for the planter therefore, to look to the available sources of supply 
of fuel before he commences to cultivate limes for concentration of the juice. If he have no forest land on or near to his property, fast growing trees should be planted at the same time as the limes, and the cultivation of trees for fuel should go hand in hand with the cultivation of the limes. 


\section{CHAPTER VII}

\section{FRUITS (continued)}

The Banana.-Musa sapientum. The Plantain.-Musa sapientum var. paradisiaca

OF all the vegetable productions of the world, the banana is, perhaps, in regard to magnificence combined with utility, the most wonderful. Its grand, herbaceous sa-called stem, Description composed of the succulent leaf-stalks rolled one over the of the other, and its splendid crown of enormous light green leaves radiating from the centre-from which issues the bunch of fruits gracefully curving downwards, make it one of the glories of the tropics. The fruit of the plantain supplies food Its uses. for multitudes of people, indeed it is " to the inhabitants of the torrid zone, what bread and potatoes are to those of the north temperate zone." It is rich in those substances neces- Its nutrient sary for the nourishment of man, and it has been said that qualities. a pound of plantains contains "more nutriment than three pounds of meat, whilst as a food it is, in every sense, superior to the best wheaten bread." But not only is it so valuable in regard to its nutritious qualities, it is also the most prolific of all the food plants known. Humboldt, the Its fruitfulgreat German traveller and naturalist, calculated that thirty- ${ }^{\text {ness. }}$ three pounds of wheat and ninety-eight pounds of potatoes require for their growth the same space of ground as will produce 4,000 pounds of bananas. 
The banana and the plantain, formerly held to be two distinct species of the genus Musa, are now considered by many botanists as simply varieties of the same plant, which Habitat. is a native of both the old and the new world tropics. The plantain is usually eaten unripe as a vegetable, and is not exported to any extent. The banana, however, is a fruit esteemed highly by the inhabitants of cold as well as hot climates, and it is exported from the West Indies in great The banana quantities to the United States. Jamaica is now the centre trade of Jamaica. of the banana trade of the West Indies. In 1881 the exports were 217,592 bunches valued at $£ 22,665 \mathrm{I} 6 s$. $8 d$., and in 1888 they had increased to $3,093,393$ bunches valued at $£ 270,672$.

Varieties. There are a great number of varieties of the banana, as might be expected when it is remembered that the plant is cultivated throughout the whole tropical world-on different soils, in different climates, and under different conditions. The kinds most liked, however, in the American markets are the Martinique variety with its large yellow fruits, and the Cuban variety which has shorter and thicker fruits with a dull-red skin. The Martinique kind is now the principal one exported, and it is known throughout the United States as the Jamaica banana. In Dominica it is called 'Figue la rose', and in Trinidad 'Gros Michel' banana. The banana is often called 'fig' or 'figue' in the West Indies.

SolL.-The banana will grow in nearly every soil, except those composed almost wholly of sand or of calcareous matters, although even in these situations the plants will struggle on and perhaps bear small bunches of inferior fruits. The

The best soil. best soil for the cultivation of the plant is a warm, welldrained, but rather moist, deep loam, with a good proportion of humus. In such a soil, and with a favourable climate, bananas will yield enormous crops. A writer on the subject has given the following table. showing what 
should be the composition of the best soil for plantains and bananas:-

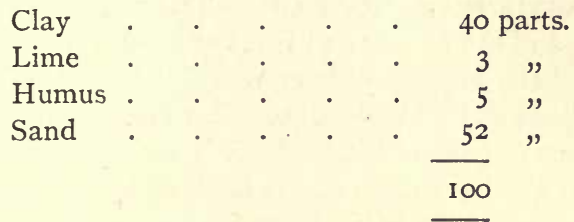

On referring to the table of classification of soils in the first part of this book, it will be seen that such a soil may be accurately described as a rich loam with lime.

Climate. - The banana is essentially a tropical plant, and thus it will not bear a cold climate, but many varieties do extremely well at moderate elevations in the mountains, pro- Hot climates vided they are protected from the withering blasts of high necessary. winds. The banana will bear a cooler climate than the plantain, but both do best, and fruit earlier, near to the sea coast, an atmosphere impregnated with salt having no deleterious influence on the plants.

PROPAGATION.--The underground stem of the banana Suckers. sends off a number of side shoots, or suckers, which if left to themselves will grow up into a variety of stems, and in badly cultivated plantain walks it is not unusual to see a clump of a dozen or more stems growing from the same root stock. The banana seeds only in very exceptional instances, indeed seed. so few people have seen the seed that it is believed by most persons not to occur at all. Fortunately, however, the plant Cutting the is easily propagated by the suckers which are detached from suckers. the stem by means of a cutlass or a sharp spade, the earth being first of all removed carefully so as to expose the junction of the off-shoot with the parent plant. The best Size of the size of the sucker for planting is about two feet over all, suckers. 
smaller ones are too weak and delicate, and larger ones do not root so easily.

PREPARATION OF THE LAND. - The weeds having been hoed up, and the bushes and roots of trees stumped out, the land should be dug with hoes or well ploughed where possible.

The weeds On hill sides and on broken ground the weeds may be buried to be buried. in trenches dug with the hoe, for it is far better to bury the weeds than to burn them on the land, as by the latter plan a considerable portion of the plant food is carried off into the Drainage. atmosphere. If the land be sodden with moisture, it may be drained by trenches being dug, as is explained in the chapter on drainage ; and, where the soil is dry and water is available for irrigation, the cultivation will be immensely imIrrigation. proved by carrying irrigation canals through the land, in such a way as to distribute the water as equally as possible. The water must not be allowed to run continually throughout the year, so as to turn the land into a marsh; but in such a matter as this, a little observation will soon enable the planter to decide on the proper time to stop the irrigation. When the plants are fruiting it will be advisable to turn off the water, as too much moisture at this time is disadvantageous.

Distances. Planting OUT.-The suckers should be set at distances of not less than fifteen feet from each other. A good system is to plant in rows eighteen feet apart, the plants in the rows being at distances of fifteen feet. This will give about 160 plants to the acre, and at the third year a yield of 500 bunches of bananas may be looked for from every acre of good land properly cultivated. Between each third or fourth row, a drainage or an irrigation trench may be dug, all such trenches being made before the plants are put out.

Holing the The sucker must be planted a foot deep in a specially prepared hole; and, when the land is poor, a little manure can be put at the bottom of the hole. When planted, the earth 
should be firmly pressed down by the feet all round the sucker, so as to prevent the entry of too much air to dry up the roots when they shoot forth. By some planters it is Set the advised to plant the suckers in a slanting direction, but this $\begin{aligned} & \text { suckers } \\ & \text { straight in }\end{aligned}$ is a bad system, and has nothing whatever to recommend it. the ground. The so-called stem of the plantain and banana grows up perfectly straight, and when the young plant is out of the perpendicular, a portion of the energy of growth is expended in the effort to straighten the stem.

Cultivation.- There is perhaps no tropical plant easier of cultivation than the banana. The suckers having been planted out at the commencement of the rainy season, they Crops. will grow vigorously and produce fruit in about a year. The land must be kept free of weeds; and an occasional turning up of the soil will prove beneficial. Before the plant throws out its flowering stem, suckers will make their appearance above the ground and these will require careful attention. Whilst the plant is young all the suckers except one Cutting out should be cut away, the best plan being to sever them with a the suckers. sharp spade. Thus all the vigour of the plant is thrown into the fruiting of the first stem and the growth of the one to supplant it, and in this way fine large bunches can be reckoned on. Afterwards, when the stool has matured, from three to The number five stems may be allowed to grow ; but, on no consideration, should a larger number be permitted to shoot up-if fine bunches of fruit are looked for. The second stem usually The size of produces a finer bunch of fruit than the first, but as the land the branche. becomes exhausted, the bunches, of course, decrease in size, and this shows the necessity for manure in some form or other. After the stool has borne a crop or two, the earth should be loosened round the stems, and manure or decayed leaves and banana stems forked in, the whole being moulded Moulding up with surface soil from the vicinity. When the stool shows up. signs of exhaustion, as it probably will after a few years, it should be stumped out, and a fresh sucker planted in its Replanting 
place, or better still in the intervening space between the former stools, the fertility of the soil being restored by a free application of manure. When the land is intended to be kept in permanent banana cultivation, a good plan-after lining out-is to plant each alternate hole one season, and to plant the vacant spaces another season. In this way the stools will not become exhausted at the same time, and by a judicious application of the system continuous crops may be expected. The chief drawback to this plan is that the land at first carries only one-half the usual number of plants, while the cost of weeding and cultivating is much the same.

When the crops are gathered.

Cutting the branches of fruit.

CROPS.-With proper cultivation, a good soil, and a suitable climate, the first crop may be gathered in about a year from the time of planting ; and, as some plants may be backward whilst others are forward in growth, bunches will be gathered at all times thereafter. The bunch must be cut with a portion of the stem for the convenience of the handling, and the terminal flower-buds should be removed at the same time. The trunk must then be cut down to within a few feet of the ground, and if it be chopped into short lengths, and arranged around the remaining trunks, it will rot and The fruit not help to manure the soil. The fruit should be cut about a to ripen on the plant. week or ten days before it is ripe; and, from the time it leaves the stem until it is placed in the market, it must be

Careful handling essential.

Bruised fruit. handled with the greatest care and gentleness, otherwise its value will be much lessened. An immense quantity of fruit, worth a very large sum of money, is lost every year by careless and rough handling-a bruise that may not be apparent at the time, will soon cause decay of the delicate structure of the fruit, and this decay, once set up, is liable to spread to other fruit in the vicinity. In fruit culture one of the first things to learn is care in the handling of the produce, and the planter will have to be constantly on the alert to see that his labourers exercise this necessary care. 
Bananas are used extensively as shade for young cacao Bananas trees ; and, in places where an export banana trade has been as shade established the formation of a cacao plantation is a very inexpensive matter, as the return in fruit from the bananas will pay for the cultivation of the cacao until the trees are able to give a small crop.

\section{THE Cocon-Nut. Cocos nucifera.}

AMongst the remarkable trees of the tropics, the first to strike the attention of a stranger are the palms. The long and The beauty usually straight stems, crowned with tufts of most graceful of palms. green leaves waving in the breeze, is a sight that the northern traveller never forgets. The cocoa-nut has been rightly called The prince "the prince of palms," for although it is, perhaps, not the of palms. finest of this most beautiful family of plants; yet, in regard to its utility to man, it is unsurpassed by any of the productions of the vegetable kingdom. In the West Indies the The many uses of the cocoa-nut palm and its produce are many, but uses of the one has to go to the East and to the coral islands of Polynesia palm. to find out the multifarious uses of the prince of palms. Every part of the tree is put to some useful purpose. The roots are used as a remedy for fevers, the trunk is used for The roots. house-building, boat-building, and for making furniture, its hard outer portion is known in England as "porcupine The wood. wood" and it is highly esteemed on account of its beautiful grain. The leaves are used for thatching houses, and for The leaves. making baskets, hats, mats, and other such articles. From their foot stalk combs are made. The fibrous net-work at the base of the leaves serves for sieves, and some of the natives weave it into clothing. The flowers are used as a medicinal The flowers. astringent ; from the cut flower-stalks palm-wine or "toddy" is obtained in great quantity ; and in Ceylon, a spirit called Arrack and "arrack" is distilled from the toddy, this spirit being to the tcddy. natives what rum is to the West Indians. From the toddy, Jaggery sugar, called "jaggery," is got, and vinegar is also one of the sugar. 
useful products obtained from the juice. The fruit is wellknown and highly esteemed in all parts of the world. The

The husk and the shell.

The kernel. and such like things. The white kernel, or albumen (called "copra" when dried and exported), contains much oil, which is largely used in Eastern countries for cooking and lighting purposes ; and, in Europe and America, it is made into soap and candles. After the oil is extracted the refuse, called "poonac," is valuable as food for cattle and poultry, and for manure. The kernel is a food product of great importance to the inhabitants of many parts of the tropics. In the Laccadive Islands, it forms the chief food of the people, each person being said to consume at the rate of four nuts a day. The milk. Inside the nut is a large cavity filled with a deliciously cool fluid which when the nut is young is used as an agreeable beverage and as a medicine in some complaints. The albumen of the young nut is a soft, jelly-like substance which is highly nutritious and of a delicious flavour. Finally, a very singular and highly-prized pearl is found under very rare circumstances in cocoa-nuts, and a specimen has lately been added to the Museums of the Royal Gardens at Kew. In the enumeration of all these uses to which the cocoa-nut palm is put, many have been left out, but sufficient have been mentioned to show that the tree is one of the most The value of valuable known to man. In Ceylon it is said that the wealth the tree in Ceylon. of a native is reckoned by the number of cocoa-nut trees he possesses; and Sir J. Emerson Tennant, in his work on Ceylon, gives particulars of a law suit in which the subject in dispute was "a claim to the 2,520th part of ten of the precious palms." The cocoa-nut, like the banana and other Varieties. plants that have been cultivated in many different countries from ancient times, has many varieties, but the differences consist principally of variations in the size, shape and character of the fruit. In some instances the fruit is small 
and round, in others large and oblong, or divided into three well-marked ridges. In some, again, the fibrous envelope is developed largely at the expense of the nut, and in others the reverse obtains, whilst the albumen contains much oil. In countries where the cocoa-nut palm is cultivated, all these and other differences may be observed by any intelligent person.

SoIL.-The low alluvial flats, near to the mouths of rivers, Alluvial soils more especially lands subject to occasional inundations, are the best situations for the cultivation of the cocoa-nut, for, in these places, the alluvial loam is usually rich and deep. The next best soil is a brown loam which may be of a gravelly nature ; then come the sandy soils found in abundance along the coast-line of the West Indies. In these sandy and apparently sterile soils the trees derive their nourishment from underground springs flowing into the sea. Cocoa nut trees will not grow on a clay soil nor on thin gravels; and it is useless to attempt the cultivation, with the expectation of profits, on any but a suitable soil.

Climate.- It is said that the lowest average temperature that the cocoa-nut will thrive in is $80^{\circ}$ Fahrenheit, and that the annual rainfall must be at least seventy inches; but the trees will grow and give crops at a lower temperature, and with less moisture. 'The climate, however, must be a maritime A maritime one, the palm delighting in the saline atmosphere of the sea necessary. coast. When the tree is planted inland, in order to make up for the want of a saline atmosphere, it is usual to put salt in the holes before the seedlings are set out, and as much as half a bushel of salt is sometimes used in this way for each Salt put in tree. Sea breezes are not inimical to the growth of the the holes. palm, and for this reason it may well be used to fringe the windward coasts of the West Indian islands so as to protect the cultivation further inland. A writer on the cocoa-nut makes the following remarks in regard to the tree delighting in a maritime situation. He says the palm "flourishes so "very near the sea, that its roots are in many places washed 
" by its waters without injury to the tree, until it is actually " undermined. It is likewise remarkable, that those trees

The palm delights in the sea breezes.

Care to be observed in the selection of seed nuts.

How to sow the seed.

The nurseries to be watered. "which are nearest the shore all bend their heads towards "the sea, notwithstanding the violence of the south-west "winds, which blow incessantly from that quarter from "May to September inclusive; and the regular sea-breezes "which prevail in the day, during February, March, and "April. In addition to which circumstances, they are per"fectly sheltered from all winds blowing on the land side."

PROPAGATION.-The cocoa-nut palm is propagated by seed, ripe nuts being sown in nursery beds until they germinate, and then they are planted out in the places where the trees are to grow. The greatest care must be exercised in obtaining good ripe nuts for seed. It is well to select a healthy middle-aged tree and to allow the nuts to ripen on it for seed. When the nuts are thoroughly ripe they must be picked before they become dry, and then kept for a month before planting, in order that some of the moisture may be absorbed and the outer skin rendered water-proof. The Nurseries. nursery beds must be made in a sheltered place where the soil is light, and the earth must be dug up to the depth of two feet-all stones and roots being removed. Trenches should then be made about six inches deep and the nuts laid in them on their sides with the stalk ends slightly raised, an interval of about a foot may be left between each nut. As much earth is then returned into the trench as will cover all but about two inches of the crown of the nuts, and over all should be laid about six inches of straw or grass or canetrash. If the weather be dry for some days after planting, a good watering will prove beneficial, as it will settle the earth around the nuts. A considerable number of the seeds All the seeds will usually not germinate, or will produce bad or weakly
will not germinate. plants, so that it is well to sow fully 50 per cent. more nuts than the number of plants desired to plant out in the field. An occasional watering is necessary in dry weather, and the 
nurseries must be kept free of weeds. In from five to eight The time of months the plants will be ready to set out, and those nuts germination. that are tardy in germinating should be rejected as they will not produce vigorous trees.

Planting out.-The land must be lined so as to give a Distances. clear space of twenty-five feet between each tree, for if planted closer the leaves will interlace, and the crops will be lessened. The usual distance is half-a-chain or thirty-three feet between each tree, giving forty trees to the acre. Holes, two feet deep Holes, and three feet wide, should be dug some time before the plants are put out, and the earth taken out of the holes must be heaped all round the margins so that it may gradually be washed down to the roots of the growing tree. The holes, after being allowed to remain open for a time, are to be not to be filled with surface earth to within eighteen inches of the filled entirely. level of the land when the seedling is planted, thus the crown of the young tree is half a foot below the level of the ground, but in the process of time this becomes filled up, and so ensures a deep and firm hold of the ground by the roots of the plant.

Cultivation.--After the plants are firmly rooted in the weed round ground, very little cultivation is required beyond keeping the land free of weeds for some little distance round the young tree. Many planters recommend that cattle should The grazing be allowed to graze amongst the trees, but if this system be of cattie. adopted the young plants will have to be fenced in so as to prevent the cattle from eating up the leaflets of which they are very fond. Catch crops such as maize, cassava, potatoes Catch crops and such like may be taken off the land when alluvial loams may be are planted with cocoa-nuts, but it must be remembered that these crops tend to impoverish the soil and an effort should be made to return in manure what has been taken away by the catch crops. Where possible the land should be irrigated, Irrigation. as the young plants require a great deal of water to bring them rapidly into bearing, and to produce vigorous and 
healthy trees. The Hindoos are alive to the necessity of watering the plants, and they have a pretty adage, specially An Indian applied to this part of the cultivation: it is-"Water me
adage. "continually during my youth, and I will quench thy thirst "abundantly during the whole course of my life" In good When the land, and with careful cultivation, the trees will begin to trees begin to bear. flower in the fifth year, or even earlier in some instances, but the full bearing will not commence before a period ranging from the seventh to the twelfth year from planting, and thereafter until about the twentieth year the crops will go on increasing provided a proper system of cultivation be kept up.

ENEMiES OF THE TREES. - Fortunately the cocoa-nut palm has not so many enemies in the West Indies as in the East, but great attention must be paid by the cocoa-nut planter to the cultivation, so as to detect at once the ravages of any blight or animal that may be injuring the trees or ruining the crops. It is the old story of a "stitch in time saving nine." A disease, taken at the commencement of the symptoms, may often be easily overcome ; but, if it be allowed to make progress, it will often defy every remedy.

Scale blight. In some places the leaves of the cocoa-nut palm are attacked by a scale insect, or coccus, which may easily be detected by careful examination. Little scales are seen closely applied to the leaves, after a time the leaves attacked turn brown and die, and eventually the plant may be killed. Such blights are prone to attack weakly trees planted in unsuitable situations, and badly cultivated, but sometimes they invade healthy trees, properly cultivated, in the best soils Affected and climates. When a few trees only are affected they may trees to be destroyed if they are not numerous.

be cut down and destroyed by fire. Or, the following emulsion, used to kill the scale insect on orange trees, may be applied to the affected leaves :-

Kerosene . . . . 2 gallons

Insecticide.

Soft Soap

Water $\frac{1}{2}$ pound

I gallon 
The soap is dissolved in the water, which should be boiling, and the solution mixed with the kerosene. The mixture should then be churned up with a large "swizzle" stick, until it forms a cream. Before using, one part of the emulsion is diluted with nine parts of cold water.

A beetle which destroys the young plants before they come into bearing, is found in some parts of Jamaica and elseThe beetle blight. where. The larva of this beetle feeds on the terminal bud of the palm, and thus kills the plant. Where possible this grub must be dug out and destroyed, and it has been recommended that slaked lime or salt should be freely applied to the bud of the tree, as they have proved of advantage in many instances.

The crops are often much lessened by the attacks of rats Rats. which easily climb the trees and destroy immense numbers of the young nuts. The depredations of the rats may be easily prevented by covering the trunks of the trees to an extent of twelve inches with sheets of tin or galvanised iron, How to prefor the rats are unable to climb over the smooth metal. Of vavages. course the trees must be freed from rats before the metal sheets are nailed on, and to do this the nests should be destroyed and poison freely placed amongst the bases of the leaves.

CROPS.- The yield of nuts depends on soil, climate and cultivation, and, as may be imagined, the crops of different trees vary widely. In Ceylon it is said that the general average return of cocoa-nut estates is not over thirty nuts per tree; but individual trees have been known to give over 300 Returns. nuts every year for a period of ten years. This enormous yield, however, is most exceptional ; but, with a good climate, a fair average soil, and judicious cultivation, the return ought to be at least fifty nuts a tree, and at twenty-five feet distance, this would give a yield of 3,500 nuts per acre. By the application of suitable manure the returns may be increased to eighty nuts a tree or over 5,000 per acre, but such a yield 
The ripe nuts.

Husking.

The use of copra.

The kernel rich in oil.

How to make the oil. cannot be expected from the light sandy soils of the coast-line.

The nuts are sometimes shipped with the husk on and sometimes without it. The fruit is usually allowed to drop from the tree, and in this way it is obtained perfectly ripe. It is a certain fact that most of the nuts drop during the night, and to this may no doubt be attached the rarity of injuries from nuts falling on the heads of persons working in a "cocal"--as a cocoa-nut plantation is usually called in the West Indies. The process of husking is very laborious, yet simple. The husk is torn off after it is split by striking the nut smartly on the point of a crowbar firmly fixed in the ground, or a sharpened stake made of hard wood may be used for the same purpose. The fruit may be shipped loose, or packed in coarse bags which hold a hundred nuts.

COPRA.- In some parts of the world, and especially in the South Sea Islands where the cocoa-nut is cultivated extensively, the kernels are broken up into small pieces and dried in the sun, in which form they constitute copra, shipped to Europe and used principally in France and Germany for the manufacture of oil-which is used extensively for making soap and candles. Copra contains more than half its weight of oil, so that $\mathrm{I}, 000$ nuts will yield 50olbs. of copra. Only ripe nuts can be used for making this product and they should be kept for some weeks after gathering, as the copra then dries more quickly and gives a larger proportion of oil, and, moreover, does not turn mouldy.

OIL.-The kernel, as we have seen, is very rich in oil, which may be extracted from fresh nuts, or from copra. When the oil is to be obtained from fresh fruit, the kernel is extracted and scraped to a pulp, which is boiled in water, and the oil soon rises to the top and is skimmed off. For commercial purposes, however, this process would be too expensive, and various kinds of machinery have been devised for extracting the oil. The usual system adopted is to 
crush out the oil from the copra by hydraulic machinery. Oil machinOr the copra is first ground into a mass like saw-dust, this is ery. subjected to steam, and then pressed by powerful machinery, the oil running out and the refuse forming a cake called poonac which, as has been already pointed out, is a valuable cattle food.

ColR.-The fibre obtained from the husk of the cocoa-nut is called coir, and, as we have seen, it is put to a variety of uses. The husk, or pericarp, of forty nuts yields about 6lbs. The yield of of coir on an average, but the returns depend, of course, on coir. the size of the nuts. In the East Indies the husks are soaked for six or eight months in pits filled with water, in order that the substance binding the fibres together may become rotten. The husks are then taken from the pits, and the How to fibre is beaten out with thick, heavy clubs. Machinery, make the however, has been invented to obtain the fibre more expeditiously and in a more cleanly manner. The husks are first Coir maput in a crushing mill, so as to straighten them out, and they chinery. are then applied by machinery to a wheel set with many small teeth, which teaze out the fibres and clean them. The fibres are then sorted out into their different classes according to their fineness or coarseness. Usually cocoa-nut fibre is received in Europe as "bristle" fibre and "mat" fibre. The bristle or brush fibre is tied up in small bundles with the fibres straight and clean. This is worth about $£ 30$ per ton. The mat fibre is the next in quality and it is sent "towselled" or with the fibres loosely packed in bales. This is worth about $£ 20$ per ton. A third class of fibre is composed of the refuse fibres or "a rough stuffing sort" worth about $£$ io per ton. In all cocoa-nut fibres, at least, the bristles and the mat should be kept separate. The fibre is manufac- The uses of tured into brushes, brooms, mats and other such articles, the coir. which sometimes come back to the same countries where the cocoa-nut that produced the fibre was grown. 


\section{The PINe-APPle. Ananas sativus.}

THE pine-apple is universally acknowledged to be one of the most delicious fruits in existence. Before the wonderful strides made in rapid passages between Europe and tropical countries by steam vessels, great numbers of pine-apples

Hot-house pines.

The pineapple trade.

Cultivation in the West Indies.

Habitat.

Varieties.

The best soil.

Lime in the soil advantageous. were grown in hot-houses for the home markets : and to such a degree of perfection did gardeners attain in this industry, that the English hot-house pines were considered to be the finest in the world. But now a large and increasing trade has been built up by the exportation of pine-apples from the West Indies and elsewhere, to the great fruit markets of England and the United States. Indeed, in the Bahamas, the cultivation of the pine-apple is one of the chief industries of the colony, and the cultivation has been taken up in Jamaica, Antigua, and in other islands of the West Indies. The pine-apple is a native of tropical America, but it has been greatly improved by cultivation-some of the finest varieties being the Jamaica Ripley, the black Antigua, the Queen, the Sugar-loaf, and the smooth Cayenne.

Solls. - The best soil for the cultivation of pine-apples is a sandy loam with good drainage, and next come the free sands and gravels. Clay of all kinds, and badly drained lands are unsuitable to the cultivation, but the plant can be successfully grown on red, loamy clays, if the land be well tilled and properly drained. A good proportion of lime is advantageous; the soil of the Bahama islands, where the pine-apples are grown, consists of decomposed coral rock, and, in Antigua, a considerable portion of the soil is formed from broken-down limestone.

Climate.-The coast zone of the West Indian islands may be taken as the typical climate for pine-apples, for the plant in an apparently wild condition is found in Dominica and others of its sister colonies. Pines will grow at high 
elevations in the mountains, but the fruit is not so fine, nor Mountain of so delicate a flavour, as that produced in the plains and climates the lower spurs of the hills.

Propagation.-When a pine-apple plant has borne its Suckers. fruit, a number of suckers are formed around the parent root-stock, and each of these suckers, when detached and planted, will produce an independent plant. Separate plants Crowns. may also be grown from the crown of leaves that rises above the fruit, but it is hardly worth while doing so. Many pine- Seeds. apples contain seeds, which appear as little black or brown bodies buried in the fruit near to the skin, and plants may be obtained by sowing these seeds. Some of the finer varieties have been produced from seed by English gardeners; but, commercially, the best and quickest mode of propagation is by suckers.

Cultivation.-The land having been cleaned and weeded, it should be deeply ploughed, or trenched with the hoe or spade to a depth of at least two feet, all the weeds and rubbish being buried in the trenches. In lining, the distances Lining. should not be nearer than three feet, which will give nearly 5,000 plants to the acre. A better plan, however, would be to line out the land in rows six feet apart, and to plant the suckers at distances of three feet in the rows, this would Distances. allow nearly 2,500 plants to the acre; and, after the first crop, a few of the suckers, say four to each plant, could be left, and then this would give nearly 10,000 fruits for the second crop. The advantage of leaving a clear space be- Aclear space tween the rows is found out when the weeding and cropping to be left operations are in progress; for, owing to the sharp prickles rows. set at the edges of the leaves, the labourers experience great difficulty in the cultivation. In the Bahamas, the men, women and children, when working amongst the pine-apples, are compelled to protect their legs with strong canvas leggings, and their hands with heavy gloves to which gaunt'cts are attached. The plants must be kept free from weeds, and 
properly moulded up, and when the dry weather comes on the roots should be protected by an application of leaf Manures. mould-which serves as good manure. Animal manure, unless perfectly rotted, should not be put near the plants, as it is inimical to their growth. After three or four years the Replanting. plants will show signs of exhaustion, they must then be rooted up, and the land prepared for fresh plants. In lining, care must be taken that the rows are set off in land that was not occupied by the old plants, and the wide space that was left between the rows will enable this system to be carried out.

CROPS.-The fruit will come to maturity in from eight to nine months from the time of planting, but it must be cut The pines to before it is ripe in order that it may bear the sea voyage to be gathered before they are ripe. the English and American markets. Every effort should be made to propagate those plants that bear early in the year, for far higher prices are paid for early pines than for late ones. The fruit must be cut, by means of a sharp knife,

Careful handling essential. with a portion of the stalk attached, and every care is to be taken in the handling so that the pines may be shipped without bruises, for a bruised pine-apple will soon become a rotten one.

PACKING.-This is a very important operation, for on it depends entirely the success or not of the industry. Usually pine-apples are shipped to the home markets in old flour Barrels. barrels, holes being cut in the staves for the purpose of ventilation. But this is a very unsatisfactory method, as a large quantity of the fruit usually decays on the voyage. In order to get the pines to the markets in the best condition, Boxes. boxes, similar to those described in the chapter on oranges, should be used. These boxes being made of laths with wide openings allow free ventilation; and, as they are divided into two compartments, each to contain either three or six pines only, the fruit is not bruised by pressure. The best pines having been selected, they must be carefully examined 
in order to reject bruised and ripe fruit, they are then Bruised and wrapped in paper or maize husks so as to leave the crown of ripe fruit to leaves free, and gently packed in the boxes and kept in a cool dry place until they are shipped.

The pine-apples from Madeira and the Canary Islands, The best which arrive in England in such an excellent condition, are way to pack packed in light boxes with a separate compartment for each fruit, and it would pay West Indian shippers to adopt this plan for the best pines of the early crop. 


\section{CHAPTER VIII}

\section{SPICES}

The NutMeg. Myristica fragrans.

Habitat. THE nutmeg tree is a native of the Molucca Islands, and it is largely cultivated there and in many of the other islands of the Eastern Archipelago. The Moluccas, or spice islands as they are sometimes called, were taken possession of in 16I9 by the Dutch, who encouraged the cultivation of nut-

The Dutch spice monopoly. megs and cloves in some of the islands, whilst they used every means in their power to create a monopoly in the spice trade. Only a certain number of nutmeg and clove trees were allowed to grow, all others being ruthlessly destroyed. When the crops were too abundant, immense quantities of spices were actually burned so as to keep up the high prices in the markets. Although enormous profits were made in this way by the Dutch, they kept the natives who raised the spices in a condition of abject poverty, and so great did the oppression bear on the poor people that the natives of the island became nearly extinct. Fortunately, How the cul- this disgraceful monopoly was broken down; clove trees were tivation was extended to other countries. found growing on some of the islands not taken possession of by the Dutch, and the French carried plants to Mauritius and from thence to Cayenne. And, it is recorded that the nutmegs were sown, in other islands, by a species of pigeon, and in this way plants sprang up and became disseminated. 
The nutmeg tree which grows to a height of from thirty Description. to fifty feet, bears a fruit which resembles the apricot of tem- of the tree. perate climates. The fruit, when ripe, bursts into two pieces The fruit. and discloses, inside, a dark nut covered with a brilliant scarlet reticulated covering called an aril-and this is the mace of commerce. The tree is diœcious-that is, the male The flowers. flowers are borne on one tree and the female on another;

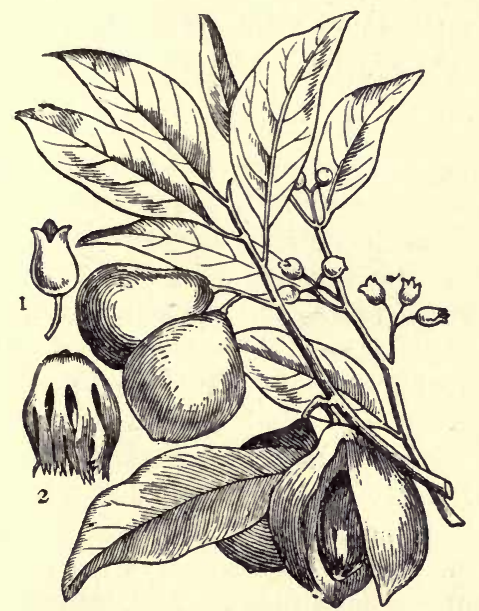

NUTMEG. Myristica fragrans.

I. -Flower. 2.-Nutmeg with mace.

pollination, therefore, can only be effected by the agency of winds and insects.

SorL.--The best soil for the nutmeg tree is an alluvium The best formed of a deep, friable loam, with good drainage. The soil. plant will not thrive on sandy soils, and stagnant water about the roots will soon kill it. Virgin forest land, with a soil of Forest land. red loam covered with a layer of humus, is well adapted to 
the cultivation, and in such a situation, if the climate be suitable, the trees will bear large crops.

A hot and moist climate necessary.
Seed.

Nurseries.

Transplanting.

Fresh seed necessary.

Climate.-A hot, moist climate is requisite, and the trees must be sheltered from high winds, which would blow off the flowers, and shake the trees too much-for the roots take a slender hold of the ground. The rainfall should be at least sixty or seventy inches per annum ; and, as the nutmeg is essentially a lowland plant, its cultivation is not likely to prove successful at a higher elevation than I,500 feet above the sea.

PROPAGATION. - Plants are raised from fresh seed, which may be sown in nursery beds, in bamboos, or "at stake" in the fields. The nursery beds having been made in a place sheltered from the sun and from winds, large, ripe, round nuts, quite fresh, are selected and planted a foot apart at the distance of about an inch below the surface of the soil. The nurseries must be watered every day in dry weather, and then the seedlings will appear in from thirty to sixty days. When the plants are about two or three feet high, they may be transplanted to their permanent situations during wet weather. If the seed be planted in bamboos, great care must be taken that the earth does not become dry; for if this occur, germination will not take place. And, furthermore, the nuts will not germinate if they become so dry as to rattle in the shell when they are shaken. A Grenada planter, who has much experience in nutmeg cultivation, recommends the seed should be planted in the place where the tree is to grow, as the plants then come on much faster and fruit earlier. A drawback to this system is that the land is occupied with plants, many of them possibly staminate, and therefore useless and the expenses of cultivation are greatly increased.

Distances.

Cultivation.--The distances at which the plants are set out should be from twenty-five to thirty feet, the wider space 
being adopted on rich level lands. Holes are then dug and left open for a time, and filled in with surface soil, rubbish, and cow-dung mixed with burnt earth; but if the land be very rich, the manure may be dispensed with. After the Shade. young trees are planted out, they must be shaded; and in dry weather, they should be well watered every week at least. Bananas will answer well for shade, and they will give good Bananas. returns until they have to be cut down to make room for the growing nutmeg trees. The land will require constant weeding, and care must be taken not to injure the roots, which often break through the surface. When the trees are backManuring ward in growth they should be manured with farm-yard compost or good leaf mould. The ground is carefully loosened all over under the trees, so as not to injure the roots, and then the manure is lightly spread or scattered around the trees close to the stem, and allowed to work its way into the soil. It The roots will not do to dig holes for the manure, as the roots would injured. be injured, and this often results in the death of the trees. When the roots are uncovered, as often happens on sloping land owing to the wash of heavy rains, they must be moulded up. Should dry weather come on, the ground around the stem of the trees may be "mulched," that is covered up Mulching with straw, or leaves or stable litter. All parasitic and epiphytic plants, which attach themselves to the stem and branches of the trees, should be removed at once, for otherwise they will have a most injurious effect. The pruning Pruning. operations are simple. All suckers must be cut away with a sharp knife, and the lower branches should be removed gradually until there is sufficient space for working under the trees.

When the trees flower, the sexes must be determined, so as Male and to ascertain whether there is a larger proportion of female female trees. trees. One male to every eight or ten females is quite enough; and those male trees should be, if possible, on the windward side of the plantation, so that the pollen may be carried by the wind to the pistils. 
How to determine the sexes.

The ma* flowers

The sexes of the trees can only be made out with certainty when the flowers appear. The staminate flowers are from three to five, or more on a peduncle, and the pistillate flowers are often solitary. Both kinds of flowers are small, of a yellowish colour, and the perianth is bell-shaped with three or four teeth at the top.

On cutting open the flower longitudinally, with a sharp penknife, the sex may be determined. The anthers are set around the top of a central column; and, if the flower be

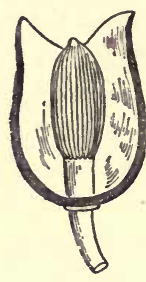

FIG. I.

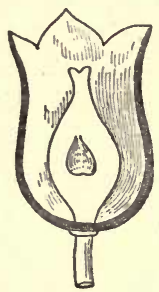

FIG. 2.

MALE AND FEMALE FLOWERS OF THE NUTMEG.

FIG. x.-Staminate or male flower, with half of the perianth removed to show the stamens.

Fig. 2.-Pistillate or female flower, with half of the perianth removed to show the pistil.

The female fully open, the yellow pollen may be easily seen. In the flowers. pistillate flowers, it will be noticed that the pistil is shorter than the perianth, that it is swollen at the base, and crowned with the stigma - which is indistinctly cut into two lobes.

Male plants occur more numerously than female ones, a writer on the subject stating that this excess is from ten to fifteen per cent. This estimate may, in some circumstances, be too low, for in exceptional instances as many as seventyGrafting the five per cent. have proved to be males. Should there be too males. many males on the plantation they may be headed down, and grafted with scions taken from female trees. Mr. P. F. Higgins, of St. Vincent, has grafted nutmegs in this manner; 
but he is the only person, as far as the author is aware, who has succeeded in doing so. A good plan is to plant two trees in each hole-at a distance of two feet from each other, and when the flowers appear, it will rarely happen that both trees will turn out to be males. The male can then be cut out, and the female left.

CROPS.-When grown under favourable conditions the nut- Trees bear meg tree will commence to bear at the seventh year or earlier, seventh and the produce will go on increasing up to the fifteenth year. year, when a full crop may be expected. In the East, there are usually three crops a year, and the ripe nut takes a little over six months to grow from the flower. The fruit is picked Gathering up every morning after it has fallen to the ground, or, if the trees are not too high it is gathered by means of a hook attached to a long stick; the mace is then stripped off and the nuts are dried in sheds, in wickerwork trays, raised about ten feet above the earthen floor on which smouldering fires are kept up all night and put out during the day time. The heat should not be more than $140^{\circ}$ Fahrenheit. The nuts Drying the are turned in the trays occasionally; and, when they are thoroughly dry, the shells are broken with wooden mallets, and the nuts are rubbed over with sifted dry lime to prevent Liming the worms attacking them, and then packed in tight casks for nuts. export. It is well to smoke the: inside of the packages Packing. and then to white-wash them. If boxes are used for shipping the nutmegs, the seams must be stopped up, for every precaution is to be taken to prevent the nuts from becoming worm-eaten. In the West Indies, the nutmegs are usually dried in the sun, but they then become more shrivelled and lose some of their value.

With proper cultivation, a return of from 1,500 to 2,000 Returns. nuts should be obtained from each tree in full bearing, and, in some cases, as many as 20,000 have been gathered from single trees. When the produce reaches the home markets Garbling. it is garbled, that is the nuts are sorted according to their 
size and the worm-pricked ones are thrown aside. Large fine, round nuts are worth double the price of small ones, and so in planting the seed the largest and roundest nuts must be selected.

Market grades.

There are usually three grades in the market, according to the number of nuts that go to the pound. These grades are as follows :-

Large . 60 to 80 nuts to the lb.
Medium . . 85 to $95, ", "$,
Small . $\quad$ I00 to $125, ", "$,

Drying the MACE.-The scarlet aril of the nutmeg is stripped off mace. as soon as the fruit is gathered, flattened by the hand, and placed on mats, or in trays, to dry in the sun for three or four days. It then turns to a yellowish-brown colour and Packing. becomes the mace of commerce. Mace is usually shipped in bales or in bags, and it should be packed tightly to prevent Returns. it becoming broken. The yield of mace is about a fifth in weight of that of the nutmegs, so that if a tree give a crop of 1,800 fruits, the net return would be about $20 \mathrm{lbs}$. of nutmegs and 5 lbs. of mace.

\section{The Clove. Caryophyllus aromaticus.}

Habitat. THE clove, like the nutmeg tree, is a native of the Moluccas, The Dutch or spice islands. The Dutch, as we have seen, endeavoured monopoly.

Introduction of the clove into Dominica.

to monopolise the trade in these spices; and, to that end, they restricted the cultivation of the clove to the small island of Amboyna, and made every effort to extirpate the plant elsewhere. But the French succeeded in carrying living plants to Cayenne, and from thence it was brought in the year 1789 to Dominica by a M. Buée, who successfully cultivated the clove and other spices only to be ruined in the end, by the operation of the duties imposed on West Indian spices in England, through the jealousy of influential persons 
who were interested in the trade of the East. Although a The reason hund hundred years have elapsed since the unfortunate $M$. Bué spices were introduced the spices into Dominica, one of the clove trees notcultiplanted by him is still alive and flourishing, and the cinna- West Indies. mon bushes have become almost wild, as the seeds are disseminated by birds. From Dominica, the clove tree was carried to Martinique, and to other islands of the West Indies.

Cloves are the dried unexpanded flowers of the tree. The Description corolla forms a ball on the top of the bud between the four teeth of the calyx - from which the ovary tapers downwards. Thus the spice has somewhat the appearance of a nail, and, indeed, the name clove is derived from the French word clou, which means a nail. From nine to fifteen flower-buds come out at the end of a branch to which they are jointed, and thus they are easily detached when the trees are beaten lightly with reeds or sticks. The buds are at first green, When cloves and, as they mature, they become pale yellow and then gathered. bright red-at which stage they are ready to gather. If the buds be left on the tree, a certain number of flowers will become fertilised, the ovaries covered with the lower part of the calyx then swell and form the fruit, which is a large ovoid purple berry, containing one or two seeds, and known as the "mother clove."

SolL. - A clayey loam is the best soil for the cultivation of The best the clove, provided the land be well drained. The trees grow well on sloping land, as in such situations stagnant moisture cannot exist. The plant does not thrive in clays or sands, and a marshy soil is fatal to it.

Climate.-Although the clove is a native of the small A marine islands of the Moluccas it will not grow quite close to climate to the sea, or in places where the atmosphere is laden with saline particles carried inland by strong sea breezes. Nor will the tree thrive in the mountains, although it will do well on the slopes below 1,000 feet elevation. The tree must 
be planted in sheltered situations, for high overhanging shade is inimical to its growth.

I.ayering. PROPAGATION.-Plants may be raised from seed, or by layering. If the young branches are laid down and kept Nurseries. moist, they will take root in about six months. The nursery beds, made in a sheltered situation with rich mould, should be sown with the seeds at distances of about a foot Fresh seed from each other. Fresh seed must be planted, as it soon
necessary. loses its vitality; and, as germination takes place within a few weeks, the seed must be sown not more than two inches Transplant- below the surface. The seedlings require frequent waterings
ing. in dry weather, and they should not be transplanted until they are three or four feet high. The plan so successfully adopted at the end of the last century by M. Buée, on his plantation in Dominica, is so admirable that it may with advantage be transcribed here from the account in Porter's "Tropical Agriculturist," published in 1833 . "The "seeds were sown at about six inches ${ }^{1}$ apart from each other " in beds. Over these beds small frames were erected about "three feet from the ground, and plantain-leaves were spread

Shelter sheds.

Shade required. " on the top in order to shelter the young plants from the "sun. The leaves were allowed gradually to decay and, at "the end of nine months, the young plants, which by that " time were strong, were allowed to receive the benefit of the "sun; but if not protected from it when very young, they "were found to droop and die."

Cultivation.-The land must be lined at twenty feet distances, and holes dug as described in the case of the nutmeg. The seedlings are transplanted at the beginning of the rainy season, and shade is necessary for the first two or three years by which time the plants are strong enough to bear the sun. At the sixth year the young trees will commence to bear, and the crops will go on increasing year by year until the full height of thirty feet or more is reached. In the Moluccas

1 This is too close : a better distance is twelve inches. 
the trees are topped at 8 or 9 feet for the facility of gather- Topping the ing the crops, but this plan appears to decrease the yield considerably. The general cultivation is the same as that The clove described for the nutmegs; but the clove is a hardier tree the nutmeg. than the nutmeg, and it does not, therefore, require such careful attention.

CROPS.-When the flower-buds begin to grow red the reap- How to ing operations must begin. The nearest clusters may be crops. taken off with the hand, but the more distant ones are to be pulled off with crooked sticks, or beaten off gently with bamboos. The trees must not be rudely handled, lest the next year's crop be diminished by the injury to the branches. The ground underneath the trees must be swept clean, or cloths may be spread so as to catch the cloves as they are knocked or pulled off from the branches.

The yield varies year by year. Usually, at intervals of Returns. from three to six years very heavy crops are borne by the trees, but now and then a year comes when they do not bear at all. On an average, it is said, five pounds of dried cloves may be expected from each tree; but, in Dominiç, trees Large crops have been known to give more than ten times this quantity at one crop.

In the East Indies the cloves are cured by being smoked $\begin{aligned} & \text { Smoking the } \\ & \text { cloves. }\end{aligned}$ on hurdles, covered with matting, over a slow wood fire until they become of a deep brown colour, when they are further dried in the sun. Sometimes the buds are scalded with hot water before being smoked, but this is an unnecessary process. The fires, however, may be dispensed with, for by the sun. simply drying the buds in the sun, they may be properly cured. The crop loses 60 per cent. of its weight by drying. When cured, the cloves may be packed in bags or Packing. in barrels for export, and care must be taken that the packages are dry, for any dampness will cause the spice to become mouldy, in which condition it will fetch little or nothing in the markets. 


\section{Pimento. Pimenta officinalis.}

Habitat. Pimento is the dried, unripe fruit of a tree which grows wild in Jamaica, Dominica and other parts of the West Indies, as well as in Central and South America. But, strange to say, Jamaica is the only country from whence this spice is

Exports from Jamaica. Description of the spice.

The tree.

Thrives on poor soils.

\section{Climate.}

How the plantations are established in Jamaica. exported. In the year 1882 the exports of pimento from Jamaica were over $76,000 \mathrm{cwt}$. valued at nearly $£$ II 3,000 . Pimento, or Jamaica pepper as it is sometimes called, is round, of the size of a small pea, of a dark colour, with the remains of the calyx attached, and it possesses an agreeable odour and flavour, supposed to resemble a combination of those of cinnamon, cloves and nutmegs, and hence the name allspice, under which it is commonly known in domestic use.

The tree is a very handsome one, reaching to a height of 30 feet, and possessing, usually, a single, smooth, clean stem with a light ashen or brown-coloured bark, which peels off in thin flakes as the trunk increases in size.

Soll and Climate.-Pimento is the only one of the spices which grows on a poor soil, indeed one writer goes so far as to say that it thrives on barren land. The soil must be of a friable nature and well drained, such as is found along the rocky or stony slopes of the sea-board of some of the more mountainous of the West Indian islands. The tree does not do well in clay or sandy soils, and it will not grow in marshy situations. The best climate is a hot and dry one, and exposure to wind does no particular harm.

Formation of a Pimento WaLK. - The system of propagation and planting out, adopted in the case of most other cultivations, is not employed in the formation of a pimento "walk"-as the plantation is usually called in Jamaica. Mr. Morris thus describes the peculiarly easy way in which a pimento plantation is established. "In Jamaica the present system of establishing a pimento walk, is to allow a piece 
of land in the neighbourhood of already existing pimento trees to become overgrown with bush, which, in the course of time, is found to contain numerous pimento seedlings, grown from seeds devoured by birds and deposited there. When the plants are of a certain size, the bush is cleared, and the pimento trees allowed to grow up." In places where the trees are too close together, the surplus ones must be removed, and some of them may be planted in situations where vacancies occur. In order to ensure good crops the Distances. trees should not be allowed to grow closer than twenty or twenty-five feet from each other.

CROPS.-In about seven years small crops may be Returns. gathered; and, until the trees attain their full height and spread, the crops will usually increase year by year. The green berries are collected, soon after the blossom falls, in the following manner: Persons climb the trees and break Gathering off the young branches, with the fruit attached, which are the spice. thrown down to women and children under the trees who pick off the berries from the stalks and carry them to the drying places. The man up in the tree can usually keep three persons fully at work below. Care must be taken to separate, Ripe berries as far as possible, all ripe berries from the green ones, for to be sepaotherwise the produce will be deteriorated.

The green berries brought in by the women and children Drying the are dried in the sun in the same manner as is coffee, on spice. barbecues or in trays, the drying process varying from three to twelve days. In wet weather the system employed in smoking cloves may be adapted to the drying of pimento, or an American fruit evaporator can be used. The proper degree of dryness is ascertained by the wrinkled appearance, the dark colour of the spice and the rattling noise made by the seeds when they are shaken. The spice is then packed in bags or in casks for shipment.

The returns from the plantation depend on the seasons Crops. and the state of the markets. Sometimes the crops are 
very large-a hundredweight of dried spice having been got from a single tree, at other times the produce is very small. In drying, the berries lose a third of their weight. There is not an increasing demand for pimento and during some years the prices are so low that it is found not worth while to harvest the crop.

BAY LEAves.-From the leaves of the pimento, and an allied plant, called botanically Pimenta acris, an essential Bay rum. oil is distilled, which, added to rum, makes the well-known The bay leaf Bay rum used so extensively in America. In Dominica, industry of Dominica. although the spice is not gathered, the leaves of Pimenta officinalis, and $P$. acris, are a considerable article of export to the United States, and bay oil is also distilled in the Island. The leaves are gathered and dried on the floors of houses or in large sheds, in which are erected platformsone a few feet above the other-of wattles. The air easily passes through and around these platforms, and the leaves Baling. become dry in a few days. They are then packed in bales weighing from 200 to $250 \mathrm{lbs}$. each, and shipped to the American ports, where they fetch a good price.

\section{Cinnamon. Cinnamomum zeylanicum.}

Habitat.

The Dutch monopoly.

CinNAMON is the prepared bark of the young stems of a tree which grows wild in Ceylon, some parts of India, Cochin China, and many of the islands of the Malayan Archipelago. Most of the cinnamon of commerce, however, comes, and has always come from Ceylon, where the Portuguese and afterwards the Dutch, in the seventeenth century, succeeded in making the trade a monopoly. All the operations of the trade were carried out by government officers, and so cruel Oppressive and oppressive were the laws on the subject that the selling laws, or giving away of even a single stick of cinnamon were made done away with by the English.

a crime punishable with death. After the English captured Ceylon, in 1796, from its Dutch masters, all these barbarous 
restrictions on the trade were done away with, but the East India Company kept up the monopoly until the year 1832 when the cinnamon trade became free to all. The tree, when Description left to itself, grows to a height of thirty feet with a straight of tree. stem ; and, in general appearance, it is not unlike an orange tree. But, in cultivation, the tree is cut down to the ground Coppicing. at about the sixth year, when straight shoots spring up to be again cut down two years afterwards, so that the plant becomes really a coppiced bush, and in process of time the stools attain to a great size. The whole of the tree is useful for some purpose. A camphor may be obtained from the roots The uses of the tree. by distillation, cinnamon is made from the bark, a fragrant wax is got from the ripe fruits by boiling them in water, and a volatile oil is distilled from the refuse bark, leaves, fruit, young shoots and root bark.

Soll and Climate.-The cinnamon tree is one of the The plant a hardiest of the spices and it will grow on almost every soil and in almost any situation in the tropics, but the quality of the bark is very inferior unless the soil and surroundings are favourable to the plant. In Ceylon, the tree is often planted on worn out coffee estates, and in dry sandy soils unsuitable to most other cultivations. But a sandy loam mixed with The best humus is the best soil, and sheltered situations up to I,500 soil. feet above the sea level are best adapted for the cultivation.

PROPAGATION.-Plants may be raised by cuttings, by layering, and from ripe and fresh seed. The usual way, however, of establishing a "cinnamon garden," as the plantation is generally called, is to plant the seed out in the fields at dis- Planting at tances of six or seven feet apart. The land being lined at these distances, the ground is well broken up at the stakes, wood-ashes are mixed with the soil, and four or five of the berries are sown. To protect the seedlings from the sun Shade. branches of trees are placed over the earth where the seeds are sown, and left to rot on the ground. But if dry weather come on after germination takes place, many of the 
seedlings perish, and then it is necessary to re-sow the ground.

Nurseries. It is advisable, therefore, to raise plants in nursery beds, so that the vacancies can be supplied with young growing plants. The seeds germinate in from two to three weeks.

Weeding. CULtivation.-After the plants are established in the fields very little cultivation is required beyond keeping the ground clear of weeds-which may advantageously be buried in Crops. trenches between the trees. By the sixth year the first shoots can be cut, when it will usually be found that two or three of them are five or six feet high, and in a condition for peeling. Two years afterwards, the shoots that have grown up after the first cutting may be reaped, and from four to seven of Firing the them will give good bark. The stems are cut close to the stumps. ground, and it is said that if a fire be kindled on the stump, so as to consume it, the roots will throw out a number of long straight stems which yield the very finest cinnamon.

HARVESTING.-The shoots are cut and the tops removed so that they are left from three to five feet long, they are then tied into bundles and carried to a shed for the preparation

Preparing of the bark. The leaves and side branches are cleared from bark. the stems, and then two longitudinal slits are made with a sharp knife, one on each side of the shoot. When the cutting has taken place in rainy weather the bark is loose-as the sap is in free circulation-and it comes off easily, but it Rubbing the is usually necessary to rub the sticks strongly with the handle sticks. of the peeling knife, or with a piece of smooth hard wood six inches long and an inch in diameter. This rubbing process disengages the bark, which is then removed from each side in entire slips. The pieces of bark, after an hour or so, are put one within the other, collected into bundles, and Ferment- pressed and bound together. The bundles of bark are then ing. left for a day, or even longer, until slight fermentation sets up, which loosens the epidermis or outer skin of the bark and thus allows its easy removal in the following manner :The inside of the bark is applied to a fixed piece of rounded 
wood, and the whole of the epidermis, and the pulpy matter Scraping off underneath it, is carefully scraped off with a curved knife. the epiderThe knives sold for the purpose of reaping cocoa pods answer for this purpose very well. After the epidermis is removed the bark is put one in the other, cut in lengths of about 12 inches or a little more, and placed on wicker work platforms in the shed until the second day when the drying is finished Drying. in the sun. As the bark dries, it contracts and acquires the appearance of a quill-which is the name sometimes applied to it. When the spice is perfectly dry, it is made up into Baling. bundles of about $30 \mathrm{lbs}$. each, and three bundles are made into a small bale which weighs between 90 and roo lbs. The bark of the bigger and coarser shoots cannot be quilled, so it is removed in thick pieces; and when mixed with the bark of the prunings, and of those sticks that do not peel chips. well, is known as chips, which fetch a low price in the markets. Chips have not such a delicate flavour as quilled cinnamon; but what is wanting in delicacy is made up in pungency, and, therefore, for some purposes this inferior spice is preferred. In Ceylon, it is reckoned that the yield per acre is 150 lbs. of prepared cinnamon, but on good soil acre. and with careful tillage and judicious manuring, larger returns ought to be obtained.

OIL.-Cinnamon oil is made by distillation from the bark unfit for shipment, and from the leaves and other parts of the plant. It varies much in character, some being ${ }_{\text {Light and }}$ light, and some so heavy as to sink in water. The oil does heavy oil. not exist in the bark in a large proportion, for 8olbs. of bark will yield only $6 \frac{1}{2}$ ozs. of heavy oil, and $2 \frac{1}{2} \mathrm{ozs}$. of light oil. 


\section{CHAPTER IX}

\section{SPICES continued}

\section{GINGER. Zingiber officinale.}

Habitat. GINGER is the dried, underground stem of a plant which grows wild in South East Asia and some of the islands of the Malayan Archipelago, but it is cultivated extensively in South America and the West Indies, and more especially in

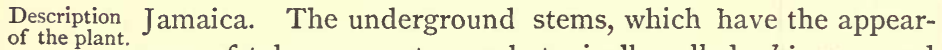
ance of tuberous roots, are botanically called rhizomes, and they are known in commerce as races. The real roots of the ginger plant are the fibres which are given off from the rhizomes. From the underground stems, aerial, leafy shoots rise up above the ground to the height usually of from twelve to eighteen inches; but, under favourable conditions of soil and climate, they may attain to a height of three feet. The flowers are borne on a separate stalk to the leaves, and the flower spikes are commonly about a foot high.

A rich soil necessary.

Soll AND Climate.-In order to cultivate ginger with success, none but the richest and best soils should be chosen. The plant will not thrive on sands and clays or in a dry soil. A rich, vegetable loam is suitable to the cultivation, and the soil must be well drained, for otherwise the rhizomes will Climate. rot. The plant endures a wide range of climate in the tropics, for it may be grown from the sea level to high mountainous regions provided the rainfall be abundant, or irrigation be adopted. In the Himalaya mountains, lying to the 
north of India, ginger is cultivated up to 5,000 feet above the sea level.

PROPAGATION.-The plant is propagated entirely by divi- Cuttings. sion of the rhizomes, and the cuttings are set out at once in the fields, no preparation of plants in nursery beds being at all necessary. A rhizome, or "race," is carefully divided into small pieces, care being taken to leave at least one shoot bud on the cutting, and each piece is then planted in the hole that has been specially prepared for it.

Cultivation.-The land should be well cleaned and Trenching. trenched, all weeds and rubbish being buried in the trenches so as to enrich the soil. When possible, deep ploughing may be advantageously employed some time before March or April-which are the best months for planting. The cultivation is very like that of the potato. The soil is raised Ridges. in ridges three or four feet apart, and small holes are opened at distances of twelve inches in the ridges. The holes are filled with well-rotted manure, and the cuttings of the rhizomes are planted in the holes at a depth of about three inches. When possible, a thick layer of leaves should be placed over the holes, so as to keep the cuttings cool and moist, besides which, when the leaves rot, they will give extra nourishment to the young, growing plants. The land must be kept weeded; and, as ginger is a very ex- Weeding. hausting crop, manure should be dug into the land if the cultivation be kept up for successive years in the same fields.

CROPS.-The cuttings having been set in March or April, the plants will flower about September, and afterwards the shoots will wither, and the rhizomes will increase in weight and size. By January or February the spice will be ready Crops to gather, the process being simply to fork the plant out of gathered in the soil, care being taken not to injure the races, or " hands" as they are called in Jamaica. The hands, of course, vary 
in size according to the soil, climate, and care in cultivation, but sometimes they are very large and weigh considerably over half a pound.

Preparation The hands, having been raised from the ground, are of the ginger. divested of the fibrous roots and cleared of all adhering mould and dirt. They are then plunged for some minutes in boiling water so as to destroy their vitality, and afterwards dried in the sun-when they become the ginger of commerce.

Scraping. Another method of preparation is as follows:-the larger and better hands, instead of being scalded, are carefully scraped with a knife until the whole of the dark outer skin is removed, and then they are dried in the sun. The pro-

The two kinds of ginger. duce prepared in this way is known by the names of "scraped," "uncoated," and "white" ginger, in contra-distinction to the " unscraped," "coated," and "black" ginger -which are the terms applied to the spice prepared by Bleaching. scalding and drying. The darker kinds are sometimes improved in appearance by bleaching, which is effected by exposing the spice to the fumes of chloride of lime or burning Returns. sulphur. The returns from an acre of land vary considerably; but, when cultivated under favourable conditions, the crops ought to be 4,000 lbs. and upwards. Ginger may be shipped in barrels or bags, the bags commonly used holding about a hundredweight of the spice.

\section{CARDAMOMS. Elettaria Cardamomum.}

Habitat. CARDAMOMS are the produce of a ginger-like plant growing wild in the moist mountain forests of Southern India, Ceylon

Description of the spice. and Java. Unlike ginger, however, the part of the plant yielding the spice, is the fruit, which consists of triangular, three-celled and three-valved leathery capsules, of a yellowish straw colour, enclosing many angular seeds-which have an aromatic odour and a pungent, spicy flavour. Up to now all the cardamoms of commerce come from the East Indies, 
but the plant thrives well in certain situations in the West Indies, especially in Jamaica, where it was introduced on a large scale by Mr. Morris in I88I, and the spice might become a considerable article of export.

Soll and Climate.-The best soil is a rich and moist The best loam with a good proportion of humus, such as is found by ${ }^{\text {soil. }}$ the banks of streams in the mountain forests of the tropics. Dry hillsides are unsuited to the cultivation, and the plants will not bear well in poor, gravelly and sandy soils, or in stiff clays. Undulating land is better than flat places, but steep inclines should, if possible, be avoided. The necessary climate. climatic conditions may be summed up in the three words elevation, moisture and shade. Until within the last ten years, most of the cardamoms used in the world were gathered from plants growing in almost a wild condition, in Malabar the moist forests of Malabar, at elevations of from 1,800 to cardamoms.

3,500 feet above the sea level. The natives went into the woods, cut down the undergrowth and felled a few of the larger trees so as to let in light and air. Soon afterwards How grown. cardamom plants sprung up in all directions, and it was only necessary to thin them out where they were too thick, and to supply them where vacancies occurred. The cardamom jungle was then left alone for two years. In the third year a light weeding was done and a small crop picked. In the climate. fourth year, the natives returned, weeded the plants thoroughly, and picked a good crop. In this cardamom region, the average mean temperature is said to be $72^{\circ} \mathrm{F}$. and the rainfall about 120 inches a year. Within the last few cultivation years, Ceylon planters have taken up the cultivation on $\mathrm{a}$ in Ceylon. very large scale indeed, and prices have gone down fully one third. There is a slight local market for cardamoms at Trinidad and British Guiana amongst East Indian immigrants.

Propagation.-Plants may be raised from ripe seeds, or by division of the rhizome which is sometimes erroneously 
Nurseries. alluded to as a bulb. Nursery beds are prepared in the usual manner, and the seeds are placed in "drills" - which are drawn with the finger or scratched with a stick. The Germination seeds germinate slowly, and may not appear above the
slow. ground until the expiration of four months. In about a year the seedlings will be a foot high, with eight or ten leaves on Transplant- the shoot, and they may then be transplanted. When the ing. plant is propagated by division, a piece of the rhizome should be carefully cut with not less than three shoots to it, and attention must be paid that the plants are injured as little as possible.

Cultivation.-A good site having been selected in forest land, all undergrowth must be cut away, as well as young Jungle
cultivation. tree should be felled, so as to open up the land to some of the rays of the sun. The trash may be burnt before it is quite dry, so that the burning may be as light as possible, or it may be allowed to rot on the ground. Holes a foot deep, and $\mathrm{a}$ foot and a half wide, are then to be dug at distances Distances. of 6 feet; but, in very rich soil, the holes may be 7 feet apart or even more. Surface soil is filled in, and the cuttings or seedlings are set in the holes, but they must not be planted too deep or they will rot off. As the cultivation will practically form a forest undergrowth, there will be very few weeds to eradicate, and the expense of keeping the cardamom plant clean will be small. One or two light weedings a year

The stems to be kept clean. are all that are necessary. Care must be taken not to heap leaves and rubbish round the stem of the plants, as the flowering stalks spring from the roots and lie close to the ground. At the third year the plants will be about 4 feet high, and they will then yield a very small crop, but at the fourth year a full crop may be expected.

The unripe fruit to be gathered.
CROPS.-The fruit must not be allowed to ripen, or the capsules will split and the seeds will fall out. The proper 
time to gather the capsules is when they are full and firm, and commencing to turn from a green to a yellow colour. The "pods," as the fruits are sometimes called, are to be Pods to be cut with scissors, and a portion of the stalk must be left cut off the attached. If the pods be pulled off by the hand they may split, and thus ruin the spice. The fruit is cured by exposure Pods dried to the sun, but the drying must be gradual so as to prevent the splitting of the pods. A few hours' sunning in the early mornings and in the afternoons, will be sufficient at first, and later on the exposure may be longer. When properly prepared, the spice is of a light straw colour. After the Winnowing capsules are thoroughly dried, the remains of the stalks are easily rubbed off, and they are then separated from the spice by winnowing. In drying, cardamoms lose greatly in bulk, four or five bushels of green pods shrinking to about one bushel of dried produce.

The returns from an acre vary greatly in different seasons. Returns. In the jungle cultivation of Mysore not more than 28lbs. are got from an acre, but in Ceylon the average is about I7olbs., although under most favourable conditions as much as $400 \mathrm{lbs}$. have been obtained.

In the home markets three kinds of cardamoms are recog- The three nised, under the curious names of "shorts," "short-longs," market and "long-longs." Shorts are capsules from a quarter to half an inch long and a quarter of an inch broad, and the longest of the long-longs is about an inch in length.

The cardamoms described here are those known as Malabar cardamoms. There is another sort found wild in the forests of Ceylon with longer and larger fruits. This used to come to European markets as Ceylon cardamoms, but since the extended cultivation of other cardamoms in the island this distinction has gradually become obliterated. At the present time cardamoms produced in Ceylon consist also of Malabar and Mysore sorts. 


\section{PEPPER. Piper nigrum.}

Habitat. PEPPER, or black pepper as it is sometimes called, is the dried fruit of a vine found growing wild in the forests of

Large consumption.

Malabar and Travancore. It is one of the most important of the spices, and its consumption annually is something enormous, pepper to the value of nearly a million pounds sterling being imported every year into the United Kingdom alone. The vine is cultivated extensively in Southern India, Siam, Malaya, Cochin China and the larger islands of the in the West Malayan Archipelago ; and, although it grows well and bears Indies. good crops in the West Indies, planting enterprise has not yet been directed to this important industry. The early history of the pepper trade is similar to that of the other The Dutch Eastern spices ; the Dutch for a time succeeded in establishmonopoly. ing a monopoly and long strove to restrict the cultivation to the island of Java.

The best soil.

SoIL.-The plant is a hardy one, and it will grow in most soils, but the crops will be small on poor sandy soils and on clays. The best soil is a deep, well-drained vegetable loam, such as is found along the alluvial banks of rivers in Malabar. The vine must not be planted on steep hill sides, as the soil is liable to be washed away from the roots Reclaimed during heavy rain. Swamps that have been reclaimed by
swamps. good drainage are suitable to the cultivation by reason of the large proportion of vegetable matter in the soil.

Climate.-A hot humid climate, such as is found in the sheltered valleys of Jamaica, Trinidad and Dominica, is the Abundant best for the cultivation. The rainfall should not be less than
rainfall necessary. from 80 to 100 inches per annum, and it must be evenly Shade. distributed. Shade is essential: in the Straits Settlements the Chinese, who are the principal pepper growers there, generally establish their pepper gardens in forest clearings. 
PROPAGATION. - The vines may be raised by cuttings, or from seed. The cuttings are usually eighteen inches long, Cuttings. and they may be set out in the fields, or put in nursery beds until they have rooted. The ends of the vines make the best cuttings as they have a growing terminal bud, and they should be put in the ground when the rain falls incessantly. When Nurseries. plants are raised from seed, nursery beds must be made, in the usual manner, in a moist and shady locality. Good selected ripe berries are soaked in water for three days, the outer skin is then removed, the seed is dried in the shade, and then sown in the nurseries in drills. Frequent waterings will be necessary, unless the weather be very rainy, until the seed'Transplanting. lings have over four leaves, by which time they will be ready to be transplanted.

Cultivation.-The land having been cleared, it is lined out seven feet by seven, and holes are dug two feet square and fifteen inches deep. The holes are filled in with good Holes. soil, and leaf mould when it can be got, but the earth is not to be heaped up as it is better to have a depression for the plant. The next thing to be done is to put in, at the side of Posts. the holes, the supports for the vine, which may be hard wood posts, or living trees may be utilised. The posts should be twelve feet long and about eight inches square, the lower two feet being tarred so as to prevent the wood decaying in the ground. Tree fern stems will answer the purpose very Tree fern well, and they are likely to last until the vines are exhausted. If living supports be used it will be necessary to establish the trees before the pepper is planted out, and they must be topped at ten feet, and kept pollarded so as to prevent too much shading of the vines. The mango and the cashew tree Live have been recommended for the purpose, but it has been supports. found that a species of the "bois-immortelle," (Erythrina corallodendron), is the best. When the cultivation is on a small scale, the holes may be dug close to the roots of low trees already growing on the land. The plants should be put in 
How the cuttings are set.

Mulching the vines.

Letting down.

Manuring.

Burnt earth. The Chinese pepper growers of Singapore use burnt earth from the vicinity.

the holes as distant as possible from the supports, and the growing end should be directed towards the posts or tree on which the vine is to run. When cuttings are set out in the fields, three must be put in each hole, and their rooting ends should be turned from the post and inserted six inches deep in the ground. It is as well to bury all the cuttings except about four inches, which should be placed against the post. The plants should now be carefully covered up with leaves, or dried grass and weeds, so as to protect the roots from the sun, and to keep the ground moist and cool. The vines will soon begin to grow rapidly if the planting operations have been done in wet weather; and, when they have run up the posts for a distance of two feet, the ends must be nipped off so as to cause lateral shoots to be developed. In some places, when the vines have grown up the post to a height of five feet, they are carefully detached from their supports and the ends coiled up and buried in the ground. This operation is called "letting down," and it induces more vigorous growth and ensures larger crops. The land must be kept free from weeds; and, if the plants are of slow growth, manure may be applied to the surface of the ground over the roots. It must not be forked in, but it may be lightly covered with soil extensively as a manure, and it appears to answer very well for the purpose ; rotten fish is also employed advantageously.

When the vines bear.
CROPS.-In from two and a half to three years a small crop may be expected, and the vines will be in full bearing by the sixth or seventh year. Good crops may be reaped for several years thereafter, and then the vines will decline in vigour and fruitfulness. Under most favourable conditions of soil and climate, however, the plants will go on bearing well for much longer periods, and in certain instances crops have been gathered up to the thirtieth year. The fruits are small, round, and berry-like; they grow loosely 
to the number of 20 or 30 on a pendulous stalk, or "spike" as it is called. At first the fruit is green, then it becomes red, and finally yellow-when it is ripe. As soon as one or Gathering two of the berries commences to turn red, the whole spike is the crops. gathered and dried in the sun, the berries are then rubbed off the spike with the hand, the stalks are picked out, and the spice is winnowed to free it from dirt and foreign matters Winnowing. and then packed in bags for shipment. Each bag contains about I42lbs. of the spice.

The yield varies very much, and it may be from half a Returns. pound to seven pounds for each vine; and these figures give for plants at seven feet distances, from $443 \mathrm{lbs}$. to over $6,000 \mathrm{lbs}$. per acre. With good cultivation and a suitable soil 4,000 lbs. an acre ought to be obtained.

WHITE PEPPFR.-This is simply the black pepper deprived of its outer covering. The largest and ripest berries, after Fermenting. being gathered, are placed in heaps for several days in a closed place, and allowed to ferment. The heaps are then trodden down and trampled upon so as to loosen the outer skin, which is washed off, and the pepper is dried in the sun. At Travancore another and slightly different method is followed. The berries are allowed to ripen on the vines, and they are then gathered and kept in the house for three days. After this they are washed and rubbed in a basket till all the stalks and pulp are removed.

\section{VANILla. Vanilla planifolia.}

VANILLA beans are the cured fruits of a climbing orchid Habitat. found growing wild in the hot humid forests of Central and South America. When the Spaniards conquered Mexico they The uses of found vanilla in use among the Aztecs for flavouring chocolate, the spice. and it is used for the same purpose by the English and French chocolate manufacturers of the present day. The vine is now cultivated in Mexico, Brazil, Honduras, Guadeloupe, 
Réunion, Mauritius, the Seychelles, Java, and Tahiti in Polynesia, but a considerable portion of the vanilla of commerce is gathered from wild plants found growing in the

Cultivation by small proprietors.

forests of Mexico. In Guadeloupe, Réunion and Mauritius the plant is cultivated by small proprietors, and many of the householders in these islands make money by selling the pods grown on vines cultivated in their gardens, and on the walls of their houses.

The best soil.

Drainage necessary.

Climate.

Soil and Climate.-A rich vegetable soil, such as is found in the dense forests of the tropics, is the best for the vanilla. Sands are too light, and clays are either too dry in hot weather, or too wet in the rainy season. An undrained, water-logged soil will cause the roots to rot, and it is, therefore, quite unsuited to the cultivation of the orchid. The climate should be hot and moist, and sheltered situations are indispensable, but the plants must not be too much shaded or the fruits will not ripen.

Cuttings.

should be long.

Propagation.-The plants are raised from cuttings, and it is not necessary to set them in nursery beds to strike root. Cuttings four or five feet long are planted at the foot of trees or other supports used for the vine to grow on; and if the weather be favourable, they will soon take root. The cuttings may be got from any part of the vine; and, in cases where it is impossible to obtain a sufficient number of long cuttings, shorter ones may be employed, but the plants will sooner come into bearing if the cuttings be the proper length.

Supports for the vine.

Cultivation.-The vanilla vine, as we have seen, requires a support to grow upon, and as the fertilisation of the flowers will have to be done artificially, it will be necessary for the plant to be trained so as to bring the flowers within reach of the hand. When the cultivation is carried on in gardens, stone walls, trees, or wooden trellis work can be utilised for supports; but, in cases where the plants are grown on a 
larger scale, trees will have to be specially planted, or posts will have to be fixed in the ground for the vines to attach themselves to. These posts should be of some hard wood Posts. that will not rot in the earth, and to that end the lower portion may be charred and afterwards tarred. Unbarked logwood, calabash, or tree-fern stems may be employed, and the portion out of the ground should be about five feet high. It is Living trees far better, however, that the supports should be living trees, the best and the best for the purpose is the Physic-nut, Fatropha Curcas, which may be raised from seed or grown from live posts, which, if put in the ground in rainy weather, will in most instances soon take root. Holes are dug and the sup- Holes. ports planted, in the same way as advised in the cultivation of the pepper vine, except that the distances, at which the Distances. supports are placed, should not be more than six feet. The holes should be filled in with rich loam mixed with sand and decayed leaves, and if the plantation be in the vicinity of the forest, the rich humus found on the surface of the ground Humus. should be used in filling up the holes. The soil must be heaped up so as to prevent stagnating moisture; indeed it is better to form a bed about six inches above the level of the Beds. ground, and this bed may be prevented from washing down during the rains by encircling it with a rough wall of stones. The three lower leaves of the cuttings are removed, and that portion of the stem planted three or four inches below cuttings. the surface; the remainder of the stem is then tied to the post or tree by a flat band of plantain fibre, or by a cocoanut leaflet. Round cord must not be used as it is liable to cut into and injure the green succulent stem of the vanilla. The ground over the buried part of the cutting is then Mulching. mulched with leaves or light brushwood; and, if dry weather Watering come on, frequent waterings will be necessary, until the vine necessary. has taken root.

The ground must be kept free from weeds, and unless it be lightly shaded by the growing physic-nut trees, it will be advisable in dry weather to keep the roots constantly mulched. 
Transverse supports.

Manures.

Artificial fertilisation essential. fourth year.
Crops in the crops may be expected in the fourth year. In Central and South America, where the orchid grows wild, fertilisation of the flowers is effected by means of insects or other agency. The parts of the flower are so arranged that self-pollination is impossible ; and, therefore, it must be effected by some foreign agency. It is usually said that this agency is an insect one, but none of the writers on the vanilla give any description of the insect or any particulars regarding it. The author of this book once gathered a few vanilla pods from vines growing in his garden in Dominica, and as none of the Fertilisation flowers were artificially fertilised that year it is probable that by humming birds.

Description of the flowers.

pollination was effected by humming birds, which were frequently seen to insert their long beaks into the flower for the purpose of extracting the nectar. It is likely, therefore, that birds may have as much to do with fertilisation of the vanilla orchid as insects. In the cultivation of the plant, however, it will not do to depend on such precarious agencies, and the planter, in order to ensure crops, must fertilise the plants himself.

The flower of the vanilla orchid is very different from the type of flower described in the first part of this book; but, mence to flower in the second year after planting, and full supports, bamboos may be fixed horizontally from tree to tree or post to post, and the vines trained along them. The trees must be kept down low so that the vines do not get out of reach, and the branches must be judiciously lopped in order to prevent too much shade. No animal or artificial manures should be used, but rotten leaves and vegetable soil may be applied to the roots after each crop is gathered. on examining it carefully, the outer floral envelope, consisting of three sepals, and the inner one, consisting of three petals, may be made out. The lowest of the petals is very different from the others; it is called the labellum, or lip, 


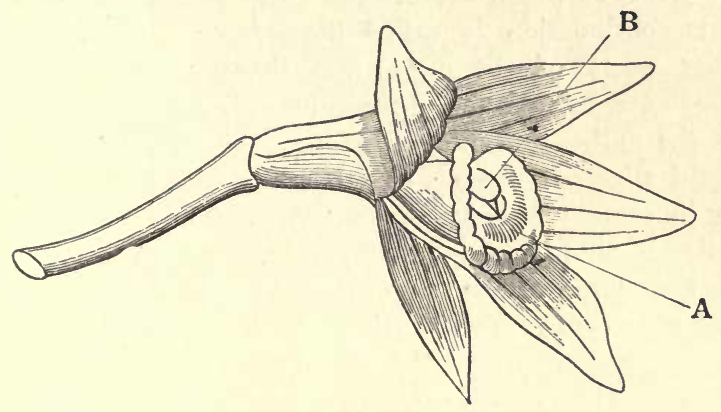

Fig. 1 .

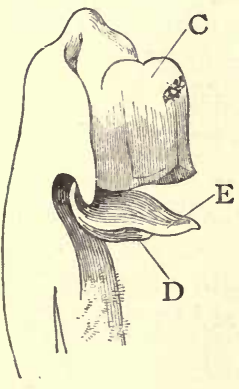

FIG. 2.

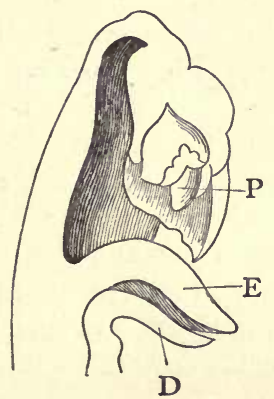

F1G. 3.

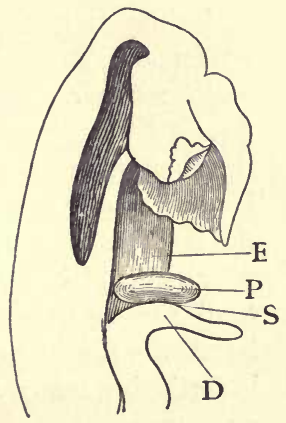

FIG. 4.

A. VANILLA FLOWER TO ILLUSTRATE THE METHOD OF ARTIFICIAL FERTILISATION.

Fig. I.-Flower of VANilla.

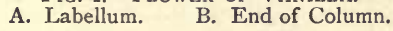

Fig. 2.-Enlarged View of top of Column.

C. Anther covered with hood. D. Stigma. E. Lamellum.

Fig. 3.-Enlarged Section through top of Column.

D. Stigma. E. Lamellum. P. Pollen masses.

Fig. 4.-Enlarged Section through top of Column.

D. Stigma. S. Stigmatic surface. P. Pollen mass adhering to viscid stigmatic surface. E. Lamellum pushed up under the anther, which has the hood attached. 
Two obstacles to selffertilisation.

Artificial fertilisation, how accomplished.

and it envelopes the columnar continuation of the axis of the plant on which are set the curious anther and stigma. This continuation is called the column, and it and the other parts of the flower are shown in the foregoing wood-cuts. At the top of the column is a hood which covers up the anther and pollen masses, and below this is the viscid stigmatic surface, protected and hidden by a projecting lip sometimes called the lamellum. Thus we see that the pollen is shut in by the hood, and the stigma is shut in by the lamellum, so that two obstacles prevent self-pollination. The object of artificial fertilisation is to remove these obstacles, and to permit the pollen masses to approach the stigma. This is easily effected, firstly, by detaching the hood, which is accomplished easily by touching it lightly with a piece of sharpened wood ; secondly, by slipping the lamellum under the anther; and, thirdly, by ensuring contact of the pollen and stigma by gentle pressure between the thumb and forefinger. The operation is performed in a few seconds after a little practice, and it may be facilitated by holding the column between the thumb and middle finger of the left hand, whilst it is supported at the back with the forefinger ; the right hand is then free to use the fertilising instrument, which should be rather blunt and flattened at the end. A tooth broken from an old comb, and fixed into a piece of thin bamboo a few inches in length, has been used by the author in fertilising many vanilla flowers.

CROPS.-If the fertilising operation prove successful, the flower will gradually wither whilst the pod will grow rapidly. If unsuccessful the flower will fall off before the second day, and the ovary will remain undeveloped, turn yellow, shrivel up, and drop off the stalk.

The flower- The flowers come out in February and March in clusters ing season. of from ten to twenty, but not more than half a dozen of the cluster should be fertilised; and, in this way, fine large pods 
will be secured. Fertilisation should be commenced about The hour to 9 or ro o'clock in the morning, for if it be left too late pollina- fertilise the tion may be incomplete, or fail altogether. The fruit goes on growing for a month, but it will take at least five months longer to ripen sufficiently for harvesting. The pods are to Gathering be gathered when they begin to turn yellow at their ends, or the pods. when they produce a crackling sensation on being pressed lightly between the fingers. Each pod should be gathered separately, by being bent to one side, when it will snap off the stem. It is very important to gather the pods at the right time, for if they be too ripe they will splitiopen in curing ; and if too green, they are dried with difficulty, and they will have little or no perfume.

CURING.-After the beans are gathered they are plunged The pods to for half a minute in hot water that is almost boiling. They be plunged are then put on mats to drain dry, and afterwards they are water. spread out on blankets and exposed to the sun. Every even- Drying on ing they are rolled up in the blankets, and shut up in tight boxes to ferment. The sunning process is continued for a Straightenweek, or until the pods become brown and pliable, when they ing the pods. are squeezed between the fingers to straighten them, and to cause the seeds and oily substance inside to be evenly distributed. Should any of the pods split they should be closed Binding up up and bound round tightly with silk thread or narrow tape. the split As they dry and shrivel the thread should be unwound and the pods tied up again. When the pods are brown, the drying process should be finished in the shade, which may take many weeks. Sometimes the beans are slightly anointed with castor or olive oil, but this cannot be recommended as the oil may become rancid, and thus spoil the product.

PACKING.-The dried beans are to be sorted according to Sorting. their length, the long thin ones being the most valuable. Beans of the samelength are to be tied in bundles of twenty- 
five or fifty, the ligatures usually being applied close to each end of the bundle. The bundles are then packed in closely fitting tin boxes, which are enclosed in rough wooder cases. In Guadeloupe the bundles are put into clean kerosine oil tins, which are soldered up so as to exclude all air and moisture. 


\section{CHAPTER X}

\section{TOBACCO. Nicotiana Tabacum}

THE plant producing the leaves from which tobacco is pre- Habitat. pared by a process of drying and fermentation, is a native of tropical America, where its use was discovered by Columbus in the year I492. It is related that when Columbus and his followers landed in Cuba they found the natives accustomed to smoke tobacco leaves rolled up into something like the form now familiar to us as a cigar, and the Spanish explorers on their return to Spain introduced the "weed" into that country. It was not until nearly a century Tobacco afterwards, namely in 1585 , that the celebrated Sir Walter introduced Raleigh carried the custom of smoking tobacco into Eng- by Sir land. At first it met with much opposition from kings, Raleigh. popes, and other potentates. King James the First wrote a Its use at book against tobacco smoking, under the title of "A Counter- first forblast to Tobacco," and Eastern princes sentenced smokers to cruel deaths. But, in spite of all this, the custom spread Its use now rapidly in every part of the civilized world, and it may now be considered to be universal. Of all the varied vegetable productions of the earth, tobacco is said by one authority to be the "most universally used by mankind," and another writer states that the plant "forms one of the most import"ant factors of national wealth in the countries where it is "largely and efficiently cultivated."

When the West Indian Islands were first colonized by Europeans, tobacco became an important cultivation in 
Extensively nearly all of them ; but now, unfortunately, its culture is cultivated throughout the West

Indies when they were first colonised.

The cultivation a very profitable one.

Potash, lime and humus required in the soil.

almost wholly confined to the Spanish Islands. It is to be hoped that the industry, which is a very profitable one, will be revived in the English islands and thus help to increase their wealth and prosperity. Sir William Robinson has striven, with some degree of success, to re-introduce the tobacco industry into the British West Indies. Whilst Governor of Trinidad he wrote a pamphlet on the subject in which he points out that Cuba cannot produce enough tobacco for the great cigar trade of that country, and says "Colonial "Legislatures, Planters, as well as Governors have been "very much to blame in allowing Hayti, San Domingo, and "Germany, to forestall the West Indies in that profitable "trade, which properly should have been theirs, of supply."ing Cuba with thousands of tons of tobacco annually for "filling purposes." Cuba.

A rich soil required.
Heat and humidity essential to produce the best tobacco.
The soil of nitrogenous compounds exist in it in large proportions. The celebrated Vuelta-abajo district of $\mathrm{Cuba}$, which produces the finest tobacco in the world, possesses a soil of this description. Alluvial lands, when light and well drained, are suitable to the cultivation, but the plant will not thrive on clays

SolL.-The best soil for the cultivation of tobacco is a light sandy loam, rich in potash, lime and vegetable matter, for an analysis of the plant shows that lime, potash, and and calcareous soils. As tobacco requires a very rich soil, newly opened forest land should be chosen where possible; and, if ground that has been long tilled be planted in tobacco, heavy manuring with farm-yard compost is a necessity if good crops be wished for.

Climate.-As the tobacco plant is a native of the tropics of America, the climate of most of the West Indian islands is suited for its cultivation. A certain amount of humidity is necessary, and the heat of the lowlands is also essential. The plant, however, is a hardy one, and it grows well in northern latitudes in the summer time. In fact a large 
proportion of the tobacco of commerce is raised in the temperate States of America, and in some of the countries of Europe.

Propagation.-Tobacco is raised entirely from seed, but after the first cutting, successive crops may be gathered from rattoons. Great care is to be observed in the selection of the Seed to be seed, which, in the first instance, should be obtained if pos- carefully sible from Havana. There are many varieties of the tobacco plant cultivated in various parts of the world; but, in the West Indies, Havana seed will produce the best crops and it alone should be sown. The seed should be gathered from Havana seed the finest plants with strong stems and large leaves, and the tobacco farmer should always allow a certain number of his best plants to run into flower and seed. The seed capsules are usually dried in the sun, and when dry they are broken The seed up by rubbing between the hands, afterwards the broken capsules and stalks are separated by winnowing, or a fine sieve may be used. The seeds are then kept in glass bottles properly corked up, and they will remain fresh for a long time.

NURSERIES.-In Cuba the seed is sown in August or September, and the same season may be adopted generally in the West Indies. A piece of rich land in a convenient situation having been chosen, it is to be well hoed up and then covered with a layer of dry grass, or brush-wood, which should be burnt as soon as weeds have sprung up, and in this way passed over the insects which are very destructive to the seedlings are destroyed. The land may be with advantage hoed up again, covered with rubbish and burnt as before, the ashes serving to supply plant food for the seedling tobacco. The beds may The seed then be made four feet wide and ten in length, and raised about an inch above the general surface of the ground. In order to provide light shade for the young plants, maize may be sown in a line running through the centre of the beds, the corn plants being about eighteen inches apart. The 
flowers of the maize should be taken off as they appear so

Seed to be mixed with ashes.

Hand weeding.

A fine tilth essential.

Harrowing. as not exhaust the soil. As the tobacco seeds are very small it is advisable to mix them with wood ashes, or fine earth or slaked lime, in order to sow them evenly and not too thickly. After sowing, the seed is to be lightly raked into the soil, and if the weather be not showery, the beds should be watered and kept moist. Allweeds should be pulled up by the hand as they grow, and care must be taken that the seedling plants are not injured by insects. In about six weeks the seedlings will be about three or four inches high, and they can then be transplanted into the fields after a good shower of rain.

PREPARATION OF THE LAND.-The soil must be well tilled so that the delicate roots of the young plants can easily penetrate it. To this end ploughing and cross-ploughing should be done several times, or until the weeds are rotten and the soil is loose and free. The clods of earth must be broken up by the harrow. When this cannot be done a few pieces of bamboo twelve feet long, with as many branches and leaves as possible, may be drawn on the ground by an ox or horse. The bamboo branches, in fact, answering the The furrows. same purpose as a harrow. The land is then ploughed into furrows six inches deep and three feet apart, and the tobacco Distances. seedlings are planted in the furrows at eighteen inches distance Manures. from each other. In newly cleared land no manure will be necessary, but in land that has been already cultivated rich farm-yard manure should be applied before the final ploughing. The Cuban planters have abandoned artificial manures although tobacco is a very exhausting crop, but lime, comPigs put on post and wood ashes are used extensively, and pigs are the land.

Transplanting. sometimes put on the land so as to improve the soil.

Planting OUT.-A wet day should be selected for transferring the seedlings from the nurseries to the fields. The young plants must be taken up carefully and the earth shaken from the roots. It is advisable to plant in the after- 
noon in order that the seedlings may have the benefit of the dew and the cool night air before they are exposed to the sun. They must not be set in the ground so that the stems and lower leaves are covered up, or a certain portion of them will rot off. If dry weather come on, each plant should be The plants to watered until it is firmly rooted, and fered watered until it is firmly rooted, and after about a week the in dry fields must be gone over, and fresh plants put in the places weather. where the seedlings have died.

Cultivation.-When two or three leaves have grown after the plants have been set out in the fields, the furrows are partly closed with the hoe, the earth being drawn to the Moulding up plants so as to mould them up. This operation may be perthe plants. formed every fortnight until the furrows are completely closed, and the soil raised somewhat around the stems of the tobacco plants; but this hoeing should not be done in very wet weather, as the soil will then be too tenacious to be satisfactorily dealt with. Not a single weed should be allowed All weeds to grow in the field, and the hoeing must be done often eradicated. enough to keep the soil friable and well aired.

TopPING.-In from thirty to forty days after the seedlings The flowers. are planted out, the flower buds will begin to appear at the top of the plants ; and, except in the case of those plants left to produce seed, the end of the stem with the flower bud is to be nipped off with the thumb and forefinger. By this operation from ten to fourteen leaves will be left, and these only should be allowed to mature. The number of leaves The number allowed to grow will depend on the strength of the plant, and allowed to the planter must use his own discretion in the matter. grow.

SUCKERING.- This is the term applied to the operation of removing the buds which appear in the angles formed by the stem and the upper part of the leaf stalks. If these buds why the were allowed to develop they would grow into side branches $\begin{gathered}\text { axillary } \\ \text { buds are }\end{gathered}$ and thus draw away nourishment from the principal leaves. nipped off. The buds begin to spring forth in about a week after the 
plants have been topped, and they are easily broken off with the fingers. After a time fresh buds will appear and they must be removed also, each plant being gone over at regular intervals so as to prevent the formation of side shoots, thereby causing the whole vigour of the plant to be diverted to the leaves. Suckering is an incorrect term to be applied to this operation, but it is in general use amongst tobacco Disbudding. planters. Disbudding would describe the process with accuracy, and the employment of that word is, therefore, to be recommended.

Larve. Enemies of the Tobacco Plant.-The principal enemies of the plant are caterpillars, or larva as they are scientifically called, of butterflies and moths. The larvæ are usually found on the under surface of the leaves; and, unless they be sought out and destroyed, they will greatly injure The turkeys the crops. Turkeys kill the larvæ in great numbers; and, kill the in the tobacco districts of the United States, flocks of these
insects. birds are kept for the purpose of destroying the "worms," as the larva are sometimes improperly called. On tobacco farms it is necessary for the "worming" to be done twice a day, for one larva, if left on a plant for twenty-four hours, The larva of will commit sad havoc with the leaves. The caterpillar that the sphinx moth.

does most damage is a big green one, and it is the larva of a large sphinx moth of a greyish black colour with orange spots on each side of the body. (Sphinx quinquemaculatus.)

Cutting. HARVESTING.-As soon as the tobacco leaves are ripe, the plants must be cut down close to the root; and, after being allowed to wither in the sun, they are carried to the drying house where the leaves are converted into the manufactured tobacco so well known to everyone.

Two methods of cutting.

There are two methods of cutting. The first is that employed in Cuba and other places where the finest tobacco is grown. A number of sticks are cut and supported some distance above the ground by forks or by a rough frame-work. The cutters then with sharp curved knives quickly cut the 
leaves from the plants in pairs, throwing the best leaves - Cutting the the wrappers, on one side, and the inferior leaves-the paves in fillers, on the other. The leaves are then hung close to- Withering. gether on the sticks, each kind of leaf being kept separate, and they are allowed to remain in the sun until they wither. The withering makes the leaves tough, and prevents them being broken when they are handled. The withering process being accomplished, the sticks laden with tobacco leaves are carried to the drying house, where they are hung up, the sticks resting by their two ends on beams or bars put up to support them.

In the second system of cutting, each plant is cut close to Cutting the the ground and laid on one side to wither in the sun. Then whole plant. the plants are tied up in large bundles with bands about eighteen inches wide, and the bundles are carried to the drying house. Flat bands are used in order that the leaves may not be injured when they are tied up.

Care must be taken not to cut the leaves until they are Leaves not quite ripe, or inferior tobacco will result. The leaves take to be cut almost three months to mature from the time of the germi- are ripe. nation of the seed, and they exhibit the following characteristics when they are ripe:-The surface is gummy to the How to distouch, and if the end of a leaf be doubled up it will break off tinguish short; the colour is a yellowish green, and spots appear in places, and the edges and the tips of the leaves usually curl downwards. Cutting should not be done on a wet day; Cutting to and, if the weather be favourable, a sufficient time in the be done in morning must be allowed for the dew drops to dry up. If rain come on during the harvesting, all cutting must be stopped, and the leaves that have been reaped should be carried to the drying house with all speed.

Tobacco-House. - Some authorities give very minute cietails regarding the building of the drying house, but this may be left to the taste and the ingenuity of the tobacco planter, who has to remember that the structure is 
The use of the house.

Arrangements to be made to hang up the tobacco in the house.
The great importance of proper curing.
The alkaloids of tobacco.

How the leaves are dried. to protect the tobacco from sun, wind and rain, and to allow it to dry by a free circulation of air. The house may be an elaborate building, erected on stone wall and covered with a shingled roof, or it may be knocked up roughly with a thatched roof and wattled sides. It is better for the building to run north and south, and to have several doors so arranged as to permit free circulation of air. The inside of the house is to be arranged with a frame work of poles and cross rails on each side, so" that the sticks laden with the drying tobacco may be hung up until desiccation is complete. The rails which are nailed horizontally on the upright poles should be one above the other at distances of about three feet, so that the tips of the tobacco leaves on the upper sticks do not touch the bases of the leaves on the lower ones.

CURING.-If tobacco leaves be taken off the plants and simply dried, they will become dry "weeds" but they will not be tobacco ; for in order to turn the leaves into tobacco, they must be cured, and this process is one of the utmost importance, as on it depends the value of the crop. The finest leaves, raised from the finest seed, grown on the richest soil in the best climate, may be so spoiled by improper curing as to turn out a worthless product fit only for the rubbish heap. During the curing of tobacco certain important chemical changes are set up in the leaves by fermentation, whereby new compounds are formed. To two of these compounds, called nicotine and nicotianine, the peculiar odour and properties of tobacco are due ; and, unless the leaves be properly cured, these substances will not be formed in their due proportions, if indeed they be formed at all. When the first method of cutting the leaves in pairs is adopted, the sticks with the leaves hanging on them are placed close together on the framework in the house so that the leaves on separate sticks touch each other, and they are left in this position for three days, and afterwards separated from each other by a distance of twelve inches in order 
that the air may freely circulate amongst them and dry the leaves.

When, however, the whole plant is cut and brought to the house in bundles, the bundles are untied and the plants spread about the floor to allow the leaves to cool and to prevent fermentation. Afterwards two plants, or four plants Tying up if they be small ones, are tied together with string so as to the plants enable them to be hung on sticks to dry. These sticks are sinilar to the ones used in carrying the leaves from the fields when they are cut in pairs, and they should be about an inch or a little more in diameter, and not too long or they will bend in the middle by the weight of the tobacco plants. In tying the plants together, a turn of the string should go below the first leaf so as to prevent it slipping as the stems dry up.

The tobacco leaves and plants must be kept hanging up The leaves until the mid-ribs are perfectly dry, which will not be until are kept the lapse of at least thirty days, but the drying process may until they be hastened by putting the poles or sticks on frames in the dry. sun for a few hours every fine day for three days. When dry, the leaves and plants are taken down, and stripped off the stems and put in heaps to ferment. A damp day should be selected for this work in order that the humidity of the air may make the leaves soft and pliant. In removing the The wrapleaves from the stalks, the wrappers must be kept apart from pers kept the fillers, as this will prevent the trouble of sorting out the the fillers. different qualities after the leaves are cured. If the tobacco The plathouse be unfloored a platform must be constructed by laying boards or wattles on blocks of wood; and the leaves must be heaped together on this platform, each leaf being spread out evenly with the tips all in one direction. The heaps The heaps. may be two or three feet high, and they should be covered with dry plantain leaves and a weight put on top. After the Fermenfirst day the heaps are to be opened and changed, so that the tation. leaves in the centre of the first heap may be the outside ones in the second. This may be done several times so as to 
prevent over-fermentation. After the heaps have been left for from thirty to forty days, all the heat will be gone, and the leaves will have acquired the qualities of tobacco. Then, Tying the in damp weather, the heaps are broken up, and the leaves hands. tied together in bundles of twenty-five or thirty; these bundles are sometimes called "hands." To make a hand properly, an unsound leaf is twisted into the form of a rope and wrapped round the upper part of the bundle, and secured tightly by tucking the end into the middle of the leaveswhich are gently separated for the purpose.

Packing the The tobacco may now be packed in bales, or boxes, or tobacco. hogsheads for shipment, considerable pressure being exerted so as to compress the leaves and to exclude as much air as possible. In Cuba and other places, before packing, it is The bétan. usual to sprinkle the hands lightly with a wash, called bétan and afterwards to arrange the hands in heaps, on the fermenting platform, pressed firmly together, for the space of from four to six days. The bétan is made by allowing some of the stalks to remain in water until they become rotten, which will usually be in about a week's time. Sometimes, the leaves are damped slightly with the wash before they are made into hands, and after the damping process they are put

The press. back in the press for a few days. The press is the term usually applied to the platform on which the tobacco is bulked and pressed during the fermentation process, and it is as well to have the press arranged in a separate compartment of the drying house. 


\section{CHAPTER XI}

\section{DRUGS}

Cinchona. Cinchona succirubra, C. officinalis, and other species

Cinchona trees, from which the important drug quinine is Habitat. obtained, are natives of the mountain forests of New Granada, Bolivia and Peru. The trees are mostly found in the valleys of the western slopes of the great Andean range of mountains at elevations of from 4,000 to 12,000 feet above the sea. The History of medicinal properties of cinchona bark were undoubtedly the drug. known to the earlier inhabitants of these regions, and the Jesuits who followed the Spanish conquerors of South America learnt its use from the natives of these countries. Its powerful curative effects in malarial fevers first became a matter of notoriety in the year 1638 when the drug was administered to the Countess of Chinchon, the wife of the Viceroy of Peru, and cured her of a fever that baffled the skill of the Spanish physicians. The Jesuits kept the nature The Jesuits. of the drug a secret, but they carried it into Europe, where it became known as Jesuit's bark, and later on as Peruvian bark. Until within a comparatively recent period the drug was given in the form of the powdered bark, and of tinctures and extracts made from it ; but now the active principles, called alkaloids-the chief one of which is the well- Alkaloids of known quinine-are used in preference to the bark, and their the bark. consumption in the world is enormous. Formerly all the 
The bark cinchona bark of commerce came from the forests of the

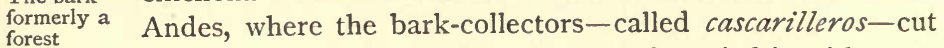
product. down the trees, removed the bark, and carried it with great The destruc- labour to the ports of shipment. This was a costly proceedtion of the ing, and as the trees were destroyed for their bark, the drug
trees.

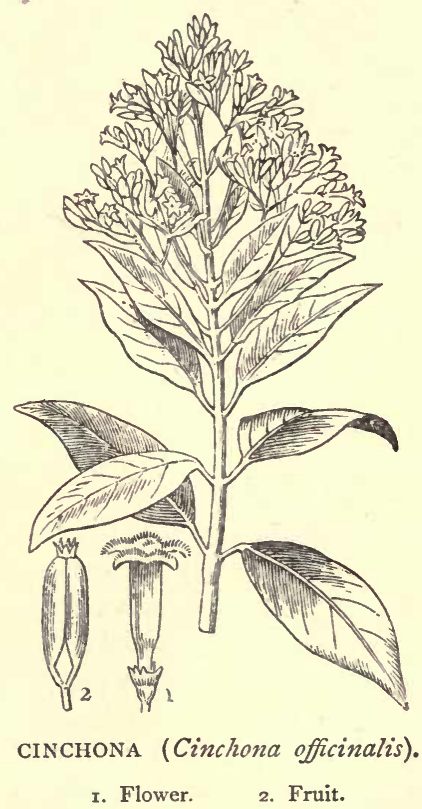

became scarcer and dearer year by year, so that it was feared the valuable medicine, in process of time, would be Dr. Royle. entirely lost. It was suggested, however, in 1839, by Dr. Royle, a distinguished Indian botanist, that an attempt should be made to cultivate the quinine tree in the mountains of the East Indies, but this suggestion was not given practical effect to until twenty years later, when the govern- 
ment of India-who were expending over $£$ 1 2,000 a year in the purchase of quinine-sent two expeditions to South America for the purpose of searching for plants and seeds of the true cinchona trees. These expeditions, headed by Mr. Messrs. Clements Markham and Mr. Richard Spruce, were entirely and Spruce. successful, and quinine bearing trees were introduced first of all into Kew and afterwards into northern India and the Nilgiris. Seeds and plants were also introduced to Ceylon, Java, and other countries of the East, and to Jamaica and Martinique in the West Indies. To the enlightened action The Indian of the Indian Government, therefore, is due the saving from government. extinction of this most valuable plant; and, its cultivation in various countries has so increased the world's supply of the drug as to cause quinine to become plentiful The present and cheap thereby enabling it to be employed in restor- of quinine. ing the health and saving the lives of the poor as well as the rich.

Until the successful labours of Markham, Spruce and The different others, Peruvian bark was thought to be the produce of two species of or three species of cinchona at most, but now it is found that there are many species yielding the alkaloids, over twenty of which have been introduced into cultivation. In Jamaica, however, which is the only island in the The Jamaica West Indies where cinchona plantations have been es- plantations. tablished on a considerable scale, it is found that Cinchona succirubra, the red bark of commerce, and Cinchona officinalis, the crown or Loxa bark, are best adapted to the climate and soil, and consequently prove the most profitable to the planter. It must be mentioned, however, The Jamaica that a hybrid has been produced by cross-fertilisation in the Jamaica plantations, which also yields satisfactory results.

SoIL. - In the cultivation of cinchona a rich open soil is A rich soil necessary, and the subsoil must be well drained, for stagnant necessary. moisture about the roots will speedily cause the death of the 
trees. The trees will grow better on newly cleared forest land than on grassy lands, but in all cases the subsoil should be examined to see whether it be suitable. Clays must be avoided, and so must poor sands. A rich deep vegetable loam resting on a porous gravelly sub-soil is the best for the growth of the plant, and the locality must be well sheltered from strong winds. Such land exists in quantity in the mountains of Jamaica, Dominica, and elsewhere in The soil of the West Indies. Mr. Morris states that the "soil of Jamaica Jamaica.

is so evidently suitable to cinchona, and the growth and vitality of the plant are so satisfactory, as compared with Ceylon and India, that there is little doubt that cinchona cultivation will pay as well, if not better, in Jamaica, than in the East or anywhere else."

A mountain Climate.-The climate must be a mountain one, for climate essential. although some of the species of cinchona, and especially $C$. succirubra grow well at low elevations, the bark yields little

Elevations in Jamaica at which cinchona grows. or no alkaloid. In Jamaica, the cinchona plantations are situated at elevations varying from 4,500 feet to 6,500 feet above the sea; the mean temperature is $63^{\circ} \mathrm{F}$., and the annual rainfall average about IIo inches. Although the climate in such situations answers well for most of the cinchonas, it is rather too high for $C$. succirubra, which may be grown at elevations of from 2,000 to $4,000 \mathrm{ft}$. When the Shelter belts forest is cleared for the establishment of a cinchona planta-
to be left on the ridges. tion broad shelter belts of trees should always be left on the ridges.

Propagation.-Plants may be propagated by cuttings and by layering, but the best way is to raise seedlings in Nurseries. nursery beds, or in boxes. When shallow boxes are used, they should be pierced with holes below, and the soil should rest on a layer of broken stones placed on the bottom of the box for drainage, and covered lightly with moss or sphagnum to prevent the earth washing down between the stones. The soil may be composed of leaf mould, garden earth, and fine 
sand in equal proportions. The seeds must be sown evenly The soil so as almost to cover the soil, and then fine earth must be of the sprinkled over the seed in order to cover it lightly. The boxes must be placed in a shady and sheltered position, and kept from the rain. Frequent waterings with a very fine rose The soil to are necessary, indeed the soil should be always moist. Germi- be kept nation will take place in about three weeks; and, when the seedlings are two inches high, they should be transplanted to nurseries to be hardened off. When seed beds are made Transthe soil should be well dug up and all roots and stones replanting. moved, and about two inches of a made soil similar to that used in the boxes should be laid on the beds. The beds The beds to must be under cover so as to keep off rain and sun and high be under winds from the young plants; a rough thatched roof erected over the beds will answer the purpose. The beds must be watered in the same way as recommended in the case of the boxes; and the young plants are to be transplanted to nurseries-also covered in with rough roofs-when they are a few inches high. As the plants increase in size and vigour Hardening the shade may be gradually removed so as to accustom the off the seedlings to the sun, and when they are eight or nine inches high they may be put out in their permanent places in the fields.

Cultivation.- The land having been laid out, holes must Holing the be prepared for the seedling plants. These holes should be land. about fifteen inches deep and eighteen inches wide, roots and stones must be taken away and the same earth taken out should be put back into the holes. Formerly cinchona trees were planted at wide distances, but this has been found out Close plantto be a mistake. In close planting the trees cover the ground quicker and thus shade the roots and keep down weeds, the high winds do less damage, the stems grow straighter and cleaner; and, as the trees become big, they may be thinned out and a return of bark will thus be got at the third or fourth year. The distances now usually adopted are four Distances. 
feet by four for Cinchona succirubra, and three feet by three for $C$. officinalis. This latter is more of a shrub than a tree.

When the holes are filled up the young plants are put out during the October rains, a damp cloudy day being chosen.

Planting out the seedling The roots alone should be covered with earth which is to be pressed firmly around the stem, and temporary shade may be given by fixing a small branch of a tree or a fern frond in the earth close by the seedling. Beyond keeping the plants clean and supplying vacancies, very little cultivation will be The weeds to required during the first few years. The weeds should be be cut close, chopped down with the cutlass, and on no account should
and not hoed. the ground be hoed up, as the delicate superficial roots would Staking the thereby be injured or destroyed. In windy places, where the plants.

plants are two or three feet high, they may be tied to stakes driven firmly into the ground in a slanting direction, so that they touch the plants at only one part. A little dry grass may then be placed between the tree and the stake to protect the bark, and the tying must be done firmly with some flat fibrous substance-such as mahoe fibre.

Thinning out the trees.

HARVESTING. - When the trees have been planted close together, they will require thinning out about the fourth year, when about 25 per cent. of the trees may be uprooted. This process may be continued year by year until, at the end of the seventh year, only a half of the trees originally planted will be left, and these may be allowed to grow until they encroach too much on each other when a further thinning may be judiciously undertaken. The trees are uprooted and Barking. barked in the following manner :-The roots are sawn off at the stool and washed in water, and all the branches of the trees are cut off, the bark from them, and from the roots, being peeled or whittled off, care being taken not to remove any of the woody tissue. Root bark is more valuable than that from other parts of the tree, as it is richer in the alkaloids. Rings are cut round the stem at distances of eighteen inches apart, a longitudinal cut is then made along the stem, 
and the bark is lifted off in sections with a flat iron spatula, care being taken not to break the pieces of bark, which as a rule come off easily as they are full of sap. The bark is dried Drying the in the sun for three or four days; and, when dry, it is usually about one third of the weight of wet bark, and each tree of crown bark, about four or five years old will yield at least about a pound of the commercial article. The red bark trees will yield much more.

The bark is harvested from standing trees in four ways : namely,-I. Lopping, 2. Coppicing, 3. Shaving, 4. Mossing.

Lopping.-In this system the branches of the trees are lopped off, and the bark removed from them in the usual manner; the trees, in fact, are pollarded. Later on fresh branches shoot out, and, when they grow to a sufficient size, they are again lopped off. Formerly this system was much The lc ping adopted, but lately it has given place to coppicing and shav- dystem now. ing as these two methods give large crops, and do less harm to the trees.

Coppicing. - The trees, when about six years old, are $c_{\lambda t}$ down to the ground, and barked, and shoots are allowed to grow up, which in their turn are cut down when they are sufficiently stout and strong to yield a good return of bark. The system is the same as that employed in harvesting cin- The system namon, and it has been fully described in Chapter VIII. In of coppicing the case of trees that are destined to be coppiced, one or two ployed for suckers may be allowed to grow up from the lowest part of cinnamon. the stem, in order to give a greater surface from which bark may be removed. When the trees have been cut down The weaker usually a number of shoots spring up, and the stronger ones, cut. to the number of from three to five, may be allowed to grow, the weaker ones being pruned out. It has been calculated that about three per cent. of coppiced trees die, and these must be replaced by fresh seedling plants.

Shaving.-This plan was invented by Moens, who did M. Moens. much to render cinchona cultivation successful in Java. It is a kind of whittling of the bark of the tree, and 
it may be done expeditiously with an ordinary spokeshave. The bark is shaved as near to the cambium layer as possible,

The cambium. without, however, reaching it. The cambium is that portion of the stem lying between the wood and the bark, and it consists of a thin layer of delicate cells full of the vital fluids Bark re. of the tree. The bark is renewed quickly after shaving, but quickly after if the cambium zone be injured, fresh bark will not be formed shaving.

New bark richer than the old.

at the seat of the injury. The new bark is always richer in quinine than the original bark, and thus the system of shaving has become general in the East. Some planters shave the tree all round the trunk, but this is not to be recommencied-the best plan being to shave two strips from each side of the stem, and in this way the tree does not receive injury. In dry weather it is usual to tie dry grass over the shaved portions, but in most instances the trees if planted The opera- closely will do well without this precaution. The operation tion easy. of shaving is easily learnt, and it is expeditious ; besides the shavings are very convenient for drying and packing, and crops may be harvested every seven months.

Mr. McIvor. Mossing.-This system was introduced by McIvor, the most distinguished of the able men who established the Indian cinchona plantations from the plants and seeds obtained in South America by the successful labours of MarkHow the ham, Spruce, and Cross. The operation is performed in the mossing is done.

Renewed bark richer than the old bark. following manner :-The bark of trees, eight years old and upwards, is removed as far as one can reach in alternate ribbon-like strips $I_{2} \frac{1}{2}$ inches wide ; and, afterwards, the trunk is protected by a covering of moss tied on with some fibrous material. In damp weather the long wounds soon heal up, and in less than two years the denuded portions of the trees become covered with thick layers of bark richer in quinine than the original ones. In about a year after the stripping has been done, the bark that was left is to be removed, and the trees again mossed up. It is said that there appears to be no limit to the number of times the bark may be removed 
in this manner. In Jamaica, the club-moss, Lycopodium Mossing in clavatum, was employed by Mr. Morris for mossing; it was Jamaica. made into ropes by a twisting process, and these were wound continuously round the trees, so that all the wounds are covered.

DRYING AND PACKING.-The bark is usually dried in the Drying to sun on barbecues. It is better that the drying should be be done gradually. done gradually, and, for this reason, the bark must not be kept too long in the sun at first. In rainy weather the drying may be accomplished in well ventilated sheds in which a fire may be kept burning, or the bark may be speedily dessicated Sun drying in an American evaporator. Sun drying, however, is the the best. best, and the other methods should only be employed in cases of necessity. According to the method of harvesting, and the part of the plant from which the product comes, the Root bark bark occurs in commerce in various forms. Thus there are alkaloids. the root bark, which is always the richest in alkaloids; the quill bark, which is that from the branches and small trunks rolled up into pipes and quills by the process of drying; the shavings, produced by the shaving method of harvesting; and flat bark, which is mostly that from large trunks, the bark being subnitted to pressure so as to permit it to pack easily.

The dried bark is usually shipped in bales which vary in Packing the size according to the fancy of the planter; but it may be bark. shipped in boxes or barrels, care being taken, however, to keep each kind of bark in a separate package.

\section{CASTOR SEeds. Ricinus communis.}

THE castor oil plant, sometimes called "Palma Christi," on account of its beautiful palm shaped leaves, is well known to every one living in the West Indies. It is supposed to be a Habitat. native of India ; but it is now extensively cultivated in the East Indies, in the warmer parts of Europe, and in the Southern United States. In the West Indies it can scarcely 
Grows wild in the West Indies.

History of the plant.

The use of the oil.

Its value as a lamp oil.

Wide range of climate.

The best soil.

The explanation of an error. be said to be cultivated, for it grows spontaneously on most waste lands, and in some places it is a troublesome weed. The valuable properties of the plant were known in very ancient times, and seeds have been found in tornbs in Egypt supposed to have been 4,000 years old. The oil was used by the Greeks and the Romans, and the plant is believed by some authorities to be the gourd mentioned in the Scriptures. The Romans, seeing a resemblance between the seed and the unpleasant insect now known as a tick, called both Ricinus, and this Latin name has been adopted by botanists present to indicate the genus of the present plant.

The oil has been used from time immemorial as a purgative medicine, and for lighting purposes; and, recently, it has been largely employed as a lubricant for machinery, watches, clocks, \&c., and for the making of soaps, pomatum, and perfumed oils. It is one of the best and safest lampoils known. It burns slowly and thus effects a saving, it gives a good white light, it is free from danger, and it gives rery little soot. Owing to these advantages, it is used for lamps on all the Indian railways. The cold drawn oil gives the best light; indeed, one authority states that "no other oil can vie with this light, it being almost electrical in its brilliancy."

Soll and Climate.--The plant is a hariy one, and it will stand a wide range of climate. In the tropics it grows from the sea level to a height of 5,000 feet, and it will thrive in the summer time in England and the Northern States of America. In temperate climates, however, the plant is an annual, whilst in the tropics it becomes a small perennial tree, attaining sometimes to a height of from twenty to thirty feet. The best soil is a rich, well-drained sandy or clayey loam ; and light ioose sandy and wet heavy soils must be avoided. It is said to improve the richness of soils on which it is grown; but this is an error, for the seeds contain much nitrogen, potash and phosphoric acid, and thus heavy crops 
would remove considerable quantities of these substances from the soil. The plant has many roots which penetrate deeply, and, therefore by their decay they would open channels for the penetration of the atmosphere, and thus increase the valuable constituents of and add organic matter to the land, thereby temporarily increasing the available quantity of plant food, and so the error of imagining that the plant enriches the soil may be explained in this way.

Cultivation.-Plants are propagated by seeds which are The prepara. sown in the fields. The land is cleared, and prepared in the land. usual way ; deep tillage, and subsequent harrowing, being necessary to render the soil open and free so that the roots can penetrate easily. Before sowing, hot water should be Soaking the poured over the seeds, and they may, with advantage, be left seeds. to soak in the water for twenty four hours. Then the seeds Distances. are planted at distances of six feet by six, or eight feet by eight, in good rich land. The best time for sowing is just before the rainy season commences. Four seeds should be Sowing the planted in each hole, at the distance of six inches from each seeds. other; and, when the plants are from six to ten inches high, all but the strongest seedling should be pulled up. The seeds will usually germinate in about ten days, and the plants will grow rapidly, and commence to bear in four months from the time of sowing. The ground will have to Weeding be kept ciear of weeds, and the plants may with advantage and mo be moulded up occasionally. As the object of the planter is to produce trees with many fruit-bearing branches, it will be Nipping necessary to nip back the main stem when it is making too stem. rapid growth, otherwise long lanky stems with few flowering spikes will result. The castor oil plant has few enemies, for most insects shun it ; and for this reason, it has been recommended, in cases of insect blights on other plants, that Blights. castor oil bushes should be planted at intervals in the affected fields. In older plants, however, the bark of the stem becomes attacked with various insects such as the 
Insecticides. scale blight, Coccus, and the mite, Acarus. Should these pests appear to injure the trees, they may be killed by applying lime wash, or kerosine oil emulsion, to the affected stems with a brush.

Varieties. CROPS.-There are two principal kinds of castor oil seeds cultivated - the large and the small varieties. The large seeds yield from 25 to 30 per cent. of oil, but the oil is of an inferior quality, and it is used only for lighting and lubricating The oil. purposes. The small seeds give from 38 to 40 per cent. of oil, which is of a finer quality, and this variety is the one from which the medicinal cold-drawn oil is obtained. The plants commence to bear at the fourth month, and the crops will become larger as the trees increase in size. In India, Returns. sometimes a yield of $15 \mathrm{lbs}$. of seed is obtained from single trees; and, in the United States, it is reckoned that from fifteen to twenty-five bushels are got from an acre of land under castor seed cultivation. There is a ready sale for the cleaned seed in the American and European markets. In The
markets. the United States, the seeds are sold by the bushel of $46 \mathrm{lbs}$, and the produce may be shipped in bags or in barrels.

In harvesting, the spikes are gathered as soon as the capsules commence to turn brown; for, if they were left on the trees to ripen thoroughly, the crops would be lost as the capsules burst open suddenly with some force and scatter the

The seeds dried in the sun. seed to wide distances. The spikes, when cut off, are carried to the drying house, or they may be exposed to the sun on barbecues. During the day the spikes are turned over with a rake once or twice, so as to allow the lower layers to receive the rays of the sun. In from three to four days all

Winnowing. the capsules will have burst, and then the seeds may be cleaned from the husks and foreign matter by winnowing. Should rain come on whilst the spikes are exposed out of doors, they should be raked into heaps, and covered up with tarpaulins, or boards. As the seeds "pop" to some distance it is usual to confine the drying-place by a board fence four 
or five feet high ; but, if a clear space of twelve feet can be left outside the drying layer of capsules, this fence may be dispensed with. The spikes should be spread in a thin layer of not more than six inches in deptll, for the thinner the layer the quicker will be the drying.

CASTOR OIL. - The cold-drawn oil is made in Europe and the United States by several rather complicated processes requiring the aid of expensive machinery and skilled labour ; Machinery but there is always a ready sale in the great northern markets for crude oil which is sometimes refined, and sometimes sold without further preparation for lubricating purposes. In East Indian India the crude oil, which is exported in large quantities, is made in the following manner :- The seeds are broken be- How to tween rollers set so that the outer hard covering is cracked make the off. The whitish kernels are then separated, placed in hempen cloths, and submitted to heavy pressure in powerful screw or hydraulic presses. The oil which runs out is then Straining boiled with water to separate the mucilage and albumen. the oil. The clear oil is finally drawn off, strained through flannel and put into tins, barrels, hogsheads or dubbers for exportation. A dubber is a globular leather vessel or bottle used by the natives of India to hold oils and such like.

A common oil is made in the West Indies on a small scale West Indian in a very simple way. The seeds are first scorched in an earthenware pan over the fire and then pounded in a mortar, the husks are sometimes removed and sometimes left, but their separation produces a better oil. The broken The seeds seeds are then tied in a linen bag and boiled with water in a with water large pot, and the oil is skimmed off as it rises to the surface. The oil is then strained, and it may be bleached by exposing it to the sun in clear glass bottles. In this way the Returns. seeds will yield at least a fourth of their weight of oil. 


\section{CHAPTER XII}

\section{DRUGS.--continued.}

\section{CocA. Erythroxylon Coca.}

Habitat. CocA consists of the dried leaves of a shrub growing wild in the Cinchona regions of the South American Andes at elevations of from 2,000 to 9,000 feet above the level of the sea. The plant is extensively cultivated in the warm mountain valleys of the eastern slopes of the Andes, and the leaves are universally chewed by the Indians-both men and women, and by many of the other inhabitants of New Granada, Chewing the Bolivia, Peru, and the neighbouring countries. The chewing
leaves. of the leaves exerts a pleasureable effect on the mind, and Remarkable under the influence of the drug the Indians are able to peraction of the drug when chewed. form long and rapid journeys, and to carry heavy loads, without sleep or food. In New Granada, coca is called spadic, and Spruce states that an Indian with a chew of spadic in his cheek, will go two or three days without food,

Mr.

Markham's experience. and without feeling any desire to sleep. Markham, whilst travelling in the Cinchona districts, says he chewed coca very frequently, and besides the agreeable soothing feeling it produced, he found that he could endure long abstinence from food with less inconvenience than he would otherwise have felt; it enabled him also to ascend precipitous mountain sides with a feeling of lightness and elasticity and without Antiquity losing breath. The Indians sometimes chew the leaf alone,
of the of the and sometimes mixed with small quantities of lime or of the 
ashes of banana roots. The custom of masticating coca leaves is of great antiquity in Peru, and the Spaniards on arriving in that country found that the leaves were so highly valued as to be used in lieu of money.

Within recent years the drug has come to be extensively used as a tonic to the nervous and digestive systems, and its

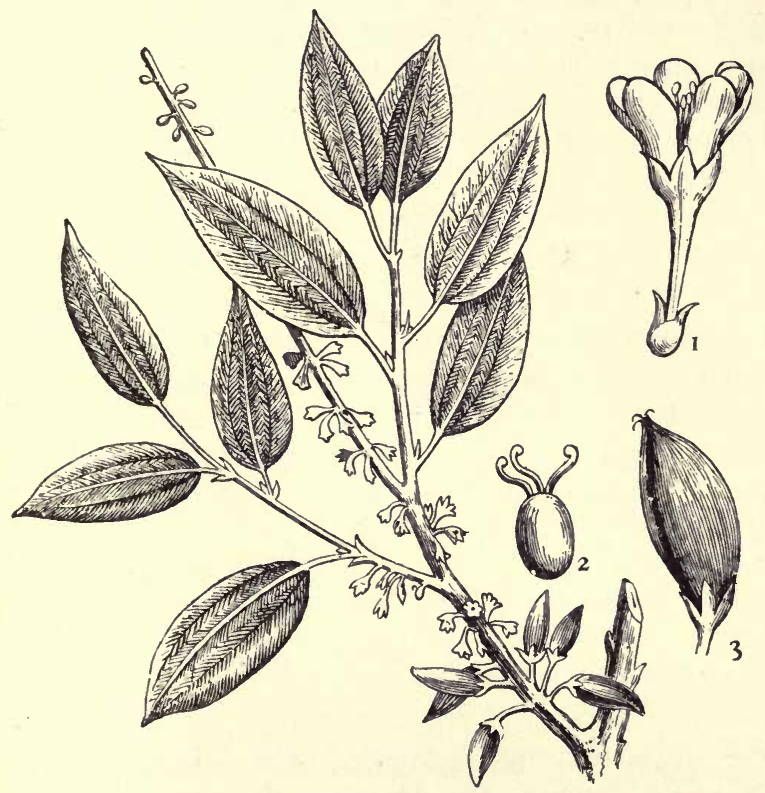

COCA. Erythroxylon Coca.

I. Flower. 2. Ovary and Stigmas. 3. Fruit.

virtues are highly extolled by many medical men. An alka- The alkaloid, called cocaine, has been separated from the leaves, and it loid. has been found to have the remarkable property of rendering various tissues of the body totally insensible, thus enabling certain surgical operations to be performed without pain. 
Proportion of the cocaine in the leaves.

The best soil.

The best climate.

Germination.
The leaves contain only from a half to three quarters per cent. of cocaine, so that large quantities are consumed every year in the manufacture of the alkaloid alone.

Soll and Climate.-The coca shrub is hardy; and, although it will grow on many kinds of soil, for its successful cultivation a rich and light soil is necessary. Well drained moist loams rich in humus are the most suitable; and, as the plants exhaust the land, judicious manuring will be necessary after heavy crops are reaped. Although the shrub is a native of the highlands of South America, one variety of it has been found to thrive at sea level in the West Indies in places where the air is usually moist and the soil suitable, but the lower slopes of the hills produce leaves richest in the alkaloid.

Propagation.-The plant will grow from cuttings; but when it is cultivated to any extent, seedlings should be raised Nurseries. in nurseries. The beds are prepared in the usual way, and the seeds are strewn on the surface and lightly covered with fine earth. The seedlings are to be protected from the sun by the erection of thatched roofs in the manner described under the head of cinchona, and frequent watering is necessary until the plants are strong. The seeds will germinate in about a fortnight after sowing, and the plants may be put out into the fields when they are from eight to ten inches high.

Cultivation.-The land having been well tilled, so as to destroy the weeds and to render the soil light and free, the Distances. seedlings are planted at distances of six feet from each General other, and this will allow over 1,200 shrubs to the acre. principles of The employment of the general principles of cultivation is
cultivation. all that is required, for the plants do not need any special treatment.

CROPS. - The first harvest may be looked for at the end of eighteen months from the time of planting, and the shrubs. 
will yield crops for forty years. The leaves are ready to Gathering gather when they become rigid, and when they crackle and the leaves. break on bending, their size and colour not being regarded. Two, or three or even four crops may be obtained in the The number year from strong plants growing in rich soil. The leaves are of crops. picked singly, care being taken not to injure the buds, and on no account should the young leaves and shoots be plucked off. A fine dry day must be chosen for harvesting; and the The leaves picking should not be carried beyond noon in order that the to be kept leaves may be exposed for several hours in the sun to dry, for if they become damp they will ferment and turn to a dark colour, in which condition they are valueless. The drying Leaves dried is accomplished by spreading the leaves in thin layers in the sun. on barbecues and lightly raking them over from time to time. In favourable weather the drying will be complete after three or four hours exposure to the sun, and then the leaves should be put in a dry place for a day or two and then packed.

In South America coca is packed, by means of a wooden Packing. press, in square bales covered with coarse cloth and weighing about 25 lbs. each. Two bales are then tied together and enveloped in dried plantain leaves, and three of these larger packages weighing about 150 lbs. make up a mule load. As, The drug however, coca is easily damaged by heat and moisture, the damaged by best way is to seal it up as soon as it is dry in packages moisture. similar to those used for tea, and they should be shipped without delay, for the leaves keep in good condition a much longer time in cold and temperate climates than in the tropics.

\section{JALAP. Ipomaa purga.}

THE jalap plant is a beautiful climber, with rose coloured Habitat. flowers, found growing wild in the mountains of Mexico, and it derives its name from the city of Xalapa which has long been the emporium of the jalap trade.

Jalap occurs in commerce in dry pear-shaped masses usually 
Description called tubers, and varying in size from that of a small nut to of the drug. that of an orange. The so-called tubers are, however, simply enlarged divisions of the root known botanically as tubercules. A tuber is an enlarged underground stem, and the term is therefore incorrectly applied to the transformed roots of the jalap plant.

Cultivation in India.

Until within the last few years all the jalap of commerce came from Central America, but now the cultivation is carried Cultivation in Jamaica. on in India on a small scale, and the plant has been established on the Cinchona plantations of Jamaica where it thrives remarkably well. Mr. Morris recommends its cultivation on a small scale by those possessing suitable land at the proper elevation; and, as a secondary crop, it may well engage the attention of small proprietors.

A rich soil necessary.

SOIL AND Climate.-Jalap requires a rich soil for the crop is an exhausting one. Formerly the plant was grown amongst the Cinchona trees, but this system had to be abandoned for the jalap throve at the expense of the Cinchonas. A rich deep vegetable sandy loam is best suited to the cultivation; and, although moisture is necessary for the welfare of the Climate. plant, undrained soils are fatal to it. In its natural condition, the jalap plant is found " in shady mountain woods, at "an elevation of from 5,000 to 8,000 feet above the sea, in " regions where rain falls almost daily, and where the tempera"ture during the day ranges between $60^{\circ}$ and $70^{\circ}$ Fahr." A climate as near as possible approaching this one should be chosen, but it is quite possible that the plant may yield profitable returns at much lower elevations in the West Indies.

Cuttings. Propagation.-Plants may be obtained from cuttings of the side shoots set in a sandy soil in a shady place and kept constantly moist ; but for cultivation on a considerable scale, Tubercules. the smaller tubercules should be planted, or cuttings of underground stems may be buried a few inches below the surface. The tubercules should on no account be exposed 
to the sun, or they will lose their vitality, and they should be planted out as soon as possible after they have been dug out of the ground.

Cultivation.- The land should be well tilled and trenched Trenching. to the depth of two feet. The trenches may then with advantage be partially filled with compost or farm-yard manure, which should be covered with surface soil. The tubercules are planted, in the trenches, one foot apart and to the depth of about six inches. When the vines grow, stakes must be firmly fixed in the ground for them to run on, in fact the creeper is treated in the same manner as are yams or green peas. After the plants have made some growth they should weeding. be moulded up with earth taken out of the trench, and weeding is done at intervals so as to keep the land free from weeds.

CROPS.-At the third year a return may be expected, and Returns. it is found in India that at least $\mathrm{I}, 000 \mathrm{lbs}$. of dry tubercules can be gathered from an acre under jalap cultivation, and crops may be reaped at every third year thereafter. It is advisable, however, to lift two or three plots one year, whilst others are left undisturbed until the following year, and so on. In this manner crops will be got every year, and there will be less difficulty in preparing the product for the markets, as there will be fewer tubercules to dry at a given time. The drying process is a difficult and trying one, for 70 per Drying cent. of the weight has to be evaporated; and it frequently happens when the tubercules are dried in the sun, that there is a considerable loss on account of some becoming mouldy Mouldiness and others becoming subjects of fermentation. This loss may and fermenbe prevented to a great extent by gashing the tubercules, or by cutting them up into slices, but jalap prepared in this way fetcches a lower price in the English and American markets. The American evaporator answers very well, but too much heat is to be avoided as it spoils the product. The Indians The Mexiof Mexico prepare jalap in the following way :-The tuber- of drying. 
cules, when gathered, are freed from earth and foreign matter, and then hung up in a net over a wood fire kept constantly burning in the hut; and, in consequence, the jalap acquires a smoky flavour which is considered by buyers to be one of the tests of "good tubers." The method of the Mexican Indians may be adopted by those engaging in jalap cultivation. Wood fires. Rough inexpensive trash sheds can be constructed, and the tubercules may be dried slowly in them over wood fires, at a slight outlay and with little trouble. To prevent accidents the fires should be put out at nights, for the smoke and the heat will prevent fermentation and mouldiness.

The purchasers of the drug.

As jalap is used in medicine alone, in order to obtain the highest prices, it is necessary to place the product on the market in the form best known to the wholesale druggistswho are the principal purchasers. The British Pharmacopcia, which is published under the authority of the Imperial Parliament, contains accurate descriptions of all the drugs recognised officially by the General Medical Council of the United Kingdom. The following is the description of Jalap contained in this publication :-

JALAP.-The dried tubercules of Ipomaa (Exogonium) purga... Imported from Mexico.

Official description of the drug.

Characters.-Varying from the size of a nut to that of an orange, ovoid, the larger tubercules frequently incised, covered with a thin brown wrinkled cuticle; presenting, when cut, a yellowish-grey colour, with dark brown concentric circles.

\section{SARSAPARILla. Smilax officinalis.}

Habitat. The well-known drug Sarsaparilla consists of the cord-like roots of a slender climbing plant, inhabiting the forests of the lower lands of Central America. The drug is obtained from several varieties of Smilax, but the kind known best and fetching the highest price is "Jamaica Sarsaparilla"-the 
dried roots of $S$. officinalis. This species, although cultivated sparingly in the island, is not a native of Jamaica, the association of names being due to the fact that considerable quantities of the drug have been imported from Central America into England by way of Jamaica.

Dr. Garrod, in his work on Materia Medica, thus describes the product :- "Sarsaparilla consists of the rhizome or rootDescription of the drug. " stock, called also the chump, with numerous roots attached, "generally several feet long, but of different lengths and " thickness in different varieties; these roots often give off " secondary rootlets, which are themselves again finely sub" divided ; they are then said to be bearded. On a trans"verse section of the roots they are seen to consist of cortex " or rind, and a ligneous cord, or meditallium inclosing the "pith."

Soil and Climate.-The best soil is a light, well-drained The best sandy loam, but the plant may be grown on alluvial flats, and soil. on newly cleared land as long as the soil contains a large proportion of the original humus of the forest. The climate Climate. should be hot and moist, and, therefore, the cultivation is unsuited to the highlands.

PROPAGATION.-Plants may be raised from suckers from Suckers. the roots, from layers, or from seed. The suckers are divided with a portion of the root attached, and planted out in rainy weather. When reproduction is effected by layers, the vine Layers. or stem is lifted off the ground, the soil is loosened, and the vine buried slightly and kept firmly in position by pegging it down with a forked stick; it will then root freely, and form a new stock. The seeds are enclosed in berries which are seeds. borne in great numbers in bunches hanging from the vine like grapes. Seeds are sown in nursery beds in the usual Nurseries. manner, and the seedlings are transplanted when they are five or six inches high. Plants may also be reproduced by Cuttings. 
cuttings ; and in this way they bear crops earlier than when they are raised from seed.

Distances. Cultivation.-The ground should be broken up by good tillage, and holes dug at distances of six feet by seventhe extra foot between the lines increasing the facilities for weeding and harvesting the crops. These distances will allow 42 square feet of surface to each plant, and will

Support for the vines.

Gathering the harvest.

Cleaning the roots.

Packing.

Returns per acre.

Bundles. enable I,037 plants to be cultivated on every acre. The ground must be kept weeded, and stakes or trellises will have to be arranged for the vines to climb over. The plant grows something like the common yam, and it "requires similar treatment."

CROPS.-The cultivation will give a return in from two to three years, and the roots may be harvested every year after the first crop is gathered. The roots are carefully dug up and cut off near to the stock, which is then moulded up with surface soil. Fresh roots will soon spring out, and they will grow rapidly. The roots, after being dug up, are freed from adhering earthy particles; and sometimes, to clean them properly, it is necessary to wash them in water. They are then dried in the sun, and afterwards tied up in bundles and packed in bales for export.

Mr. Morris records that "the first crop in Jamaica is said to yield as much as 20 lbs. of dried roots per plant." The negroes who grow it usually plant Sarsaparilla at about 20 feet apart with other crops. The vines are trained to stakes and trellises. The first crop is reaped in about two years and a half from the time of planting. When prices are high the gross returns on Sarsaparilla cultivation is very great. The market for this product is, however, very limited. For export it is usual to tie up the roots in bundles about a foot or eighteen inches long and weighing from $12 \mathrm{lbs}$. to 20 lbs. each, and these bundles are packed in bales weighing from 80 lbs. to Ioolbs. or more. 
The British Pharmacopaia contains the following description of the drug :-

Jamaica Sarsaparilla.-The dried root of Smilax officinalis. Native of Central America, imported from Jamaica.

ChARACTERS.-Roots not thicker than a goose-quill, Official degenerally many feet in length, reddish-brown, covered with scription of rootlets, and folded in bundles about eighteen inches long, scentless ; taste mucilaginous, feebly bitter, faintly acid. 


\section{CHAPTER XIII}

\section{DYES}

\section{AnatTo. Bixa Orellana}

Habitat. THE plant producing the anatto dye is a native of the West Indies and other parts of tropical America, and it is now cultivated in the Eastern tropics, as well as in Mauritius Description and Réunion. It is a small shrubby tree of a hardy characof the tree. ter, growing to the height of from eight to twelve feet or more, with heart-shaped leaves, and bearing at the ends of the branches loose bunches of handsome rose-coloured The fruit. flowers. The fruit consists of mitre-shaped capsules, covered The seeds. with soft spinules, and splitting into two valves, on the inside of which are attached from thirty to forty seeds covered with a thin coating of reddish waxy pulp, called botanically the The dye. testa. This waxy substance, when removed from the seeds Different spelling. is the dye known as anatto. The name, however, is spelt and pronounced in a variety of different ways, the principal of which are, arnatto, annatto, annota, and arnotta ; but the usually accepted form of spelling by authorities on the subject is that placed at the head of this chapter.

History of The use of the dye was well known to the fierce and the dye. warlike Caribs who inhabited the islands of the lesser Antilles, and portions of Guiana, when America was discovered by Columbus. These Indians called the dye roucou, the name now applied to it and the plant bearing it by the French, and hence erroneously believed by some to be a 
French name. The Caribs painted their faces and their The Caribs. naked bodies with the roucou until their appearance became most fierce and hideous. Bryan Edwards alludes to this custom in his work on the West Indies, and he thus translates the reference to the subject in the work of Rochfort, a French writer on the Antilles, who published his book in I658:- "But, not satisfied with the workmanship of Nature, How the they called in the assistance of art, to make themselves more Caribs used formidable. They painted their faces and bodies with arnotta so extravagantly, that their natural complexion which was nearly that of a Spanish olive, was not easily to be distinguished under the surface of crimson." Bryan Edwards goes on to say that "as this mode of painting themselves was practised by both sexes, perhaps it was at first introduced as a defence against the venomous insects so common in tropical climates." A number of the pure The Caribs blooded descendants of these once cannibal Caribs now dwell of Dominica. in Dominica on lands specially reserved for their use by the Government; but, although brave still, they are now gentle and retiring in disposition, and they no longer use the roucou as a pigment to paint their bodies.

At the present time anatto is used extensively as a colour- Modern uses ing for butter and some kinds of cheese, and as a dye for of the dye. calico, silk, wool, skins, feathers, ivory, bone and such like. The dye produces a fast colour of a fine tint, and it is some- The dye protimes used to give a deeper shade to simple yellow dyes. A red colours. colour, as well as a yellow one, can be obtained from anatto.

Soil AND Climate.-Anatto is a hardy plant, and it will $\mathrm{A}$ hardy grow, in suitable climates, on almost any soil except those plant. soils that are swampy. Although it will grow and yield crops in places where the soil is poor, it will give much larger returns when cultivated on rich lands such as the banks of rivers and alluvial well drained flats. The plant grows from The best the sea level to elevations of 2,000 feet ; and, in Ceylon, it soils. thrives up to 3,000 feet above the sea. The best climate, Climate. 
however, is a moist one where the mean temperature ranges from $75^{\circ}$ to $80^{\circ}$ Fahr., and the rainfall is abundant.

Nurseries. Propagation.-The plant is grown entirely from seed, which should be sown before it is perfectly dry in nursery beds made in a cood, shady place. Or, several seeds may be Planting at planted in specially prepared beds in the fields; and, when stake. the plants are about a foot high, all but the strongest one in each hole should be pulled up. The seedlings will be fit to be put out from the nurseries in about four months from the time of sowing, and they should be transplanted in rainy weather, when, if proper care be taken, but few of them will fail to take root in the fields.

Distances. Cultivation.-The land having been lined off at distances of from six to twelve feet, holes are to be dug and filled in as described in former chapters. The distances will depend on the character of the soil ; on hill sides, where the soil is somewhat poor, the lesser distances may be employed, but on rich flat lands, even fifteen feet apart may not be sufficient to allow for the luxuriant growth of the trees. The Planting seedlings, which should be from six to eight inches high, are
out the out the
seedlings. then planted in the filled holes, and the land is to be kept clear of weeds, which should be hoed up and buried in trenches between the plants.

Early crops. CROPS. - Full crops may be expected in three or four years but seeds may be gathered in eighteen months or even earlier. The author recently planted a patch of anatto, and many of the young plants flowered in less than a year from the time of sowing the seed. It has been calculated that the Full crops. first full crop will yield about five hundredweights of seed to the acre, and the returns will increase for several years Gathering afterwards. When the capsules split open and disclose the the crops. seeds, they are cut off by women and children and carried to sheds, where the seeds are extracted and then dried in the Packing. sun. They are afterwards packed in barrels for shipment, 
but the packing should not be done until the seeds are perfectly dry ; for, otherwise, they will become mouldy, or fermentation will be set up, and then the colour will be destroyed and the product will be valueless.

PREPARATION OF ANATTO.-The seeds are valuable solely for the reddish-yellow waxy testa which envelops them, and sometimes this is removed and shipped in cakes or rolls. Cake and The former is known in commerce as roll or flag anatto, and the latter as cake anatto, and ten pounds of the seeds will give at least a pound of the cake.

The preparation of anatto is very simple. The freshly Preparation gathered seeds are put in a tub, and boiling water is thrown on them, the mass being frequently stirred so as to wash off the waxy testa from the seeds. After some days the mass is Sieves. passed through a sieve so as to separate the seeds, which should come away free from the dye. The liquid is then left Fermenfor a week to ferment, and to allow the dye to subside to the bottom of the vessel, and the clear water is decanted off. The deposited dye is afterwards removed to shallow pans, in Evaporaorder that the excess of moisture may be evaporated in the shade. When the substance is of the consistency of putty, it may be made into rolls of two or three pounds weight each, and wrapped in banana leaves, and it then becomes the Anatto flag or roll anatto-which is exported in great quantity from in banana Brazil. It may, however, be allowed to become drier by leaves. a longer exposure in shallow pans, and then it can be moulded into square cakes weighing eight or ten pounds each, Cake anatto. which should be wrapped in banana leaves. The cakes are usually packed for export in casks containing five hundredweight of the product. Cake anatto is brown externally, but the inside is of a reddish or yellowish colour ; and in this form it fetches the highest price in the markets. The cakes should be thoroughly dry before they are packed, to prevent them losing their value by becoming mouldy after they are shipped.

In the French colony of Guadeloupe, where roucou is ex- 
The Guade- tensively cultivated, a different mode of preparation has been loupe process. adopted. The seeds are thoroughly crushed between rollers, Crushing the so that they come out as fine powder intimately mixed with seeds. the dye. The product is then put into water, and when it has subsided to the bottom, the surface water is run off, and the paste is boiled for four or five hours. It is afterwards put in boxes pierced at the bottom with holes that are covered with a cloth so as to prevent the paste passing through. A Pressing out board is placed on the top of the paste, and weighted down, the moisture. so as to press out the excess of moisture through the bottom holes. The paste is then packed in casks, in layers, separated with banana leaves, and this is done so as to retain moisture, and to prevent fermentation. If the paste be too dry water

The anatto kept moist.

The advantage of preparing a pure dye. is sometimes poured into the cask, for unless the anatto be kept moist it will deteriorate in value. The product, of course, contains only a proportion of the dye mixed with the powdered seeds, and it is, therefore, not nearly so valuable as the pure cake anatto. The purer the dye is sent to the markets, the higher will be the prices obtained for it ; and, unless a fine article be prepared, it is better to ship the dried seeds, from which the dye is extracted in England and the United States.

\section{TURMeric. Curcuma longa.}

THE plant producing turmeric belongs to the ginger family, and it closely resembles ginger in its growth and habit as Habitat. well as in appearance. It is a native of some districts of India and of Ceylon, but it is now grown in all parts of the tropical world. The plant was introduced into Jamaica by Zachary Bayley Edwards in 1783 , and it has become wild in many parts of that island, as well as in Dominica and other islands of the West Indies.

The dyes. A beautiful yellow dye is obtained from the rhizome of the plant, but it is not now used very extensively as the colour is not of a stable nature. It is employed, however, on a comparatively large scale to give the yellow colour to var- 
nishes. In some of the Polynesian islands the natives use Its uses. the dye to paint their bodies in much the same way as the Caribs used the testa of the seeds of the roucou plant. In chemistry a solution of turmeric is employed as a test for the presence of alkalies-which change its yellow colour to a reddish brown. But turmeric paper is more frequently used Turmeric than the solution. This is simply unsized paper steeped in a tincture of turmeric and dried by exposure to the air. When dry it is of a light yellow colour, which is turned to a deep brown in the presence of alkalies. Turmeric is sometimes Medicinal used as a medicine, more especially in certain affections of the stomach-where its bitter tonic and aromatic stimulant action is sometimes followed by useful results. In Eastern Used as a countries the product is used extensively as a spice or condiment, indeed it is said that most of the native dishes are flavoured with turmeric, and it is an ingredient in all good curry powders.

The plant requires the same soil and climate as ginger. Soil and And, the method of propagation, and cultivation, and gathering and preparation of the crops is the same for both plants. It is unnecessary, therefore, to enter into all these particulars as they have been fully treated of under the head of ginger in Chapter IX.

In Nepaul, a country lying to the north of India, turmeric Cultivation is planted after wheat as a rotation crop ; and, when a proper climate. Cultivation. system of rotation is employed in the West Indies, the cultivation of turmeric may with advantage be undertaken on lands from which a heavy crop of maize or one or other of the tropical cereals has been reaped.

In commerce Turmeric occurs in three forms, known as Fingers, fingers, bulbs and cut bulbs. Fingers are the longer and culbs and narrower rhizomes, bulbs are the shorter and thicker ones, and cut bulbs are simply the rhizomes cut into pieces before they are dried. For medicinal and chemical purposes the cut bulbs are best liked, and they should be of a yellow colour externally and of a deep orange internally. 


\section{LOGWOOD. Hamatoxylum campechianum.}

Habitat. THE logwood tree is a native of Central America, and it is found in great abundance in the lands bordering on the bay of Campeachy,--hence its botanical name. It was introduced into Jamaica from Honduras by Dr. Barham, in 1715 , and later on it was carried to other parts of the West Indies. In Jamaica and Dominica it has spread by self-sown seeds over large districts of the coastlands as well as some parts of

Naturalized in the West Indies.

The seeds.

The dye.

History of the dye. the interior. Dr. Macfadyen, in his flora of Jamaica, published in 1837 , says :- " Few plants have been so completely naturalized. It thrives in every situation, with the exception of the loftier mountains, and, with the Opoponax and Cashaw, occupies our plains." The seeds, being winged, are often carried far away from the parent plant by the wind, and to this fact is due the wide distribution of the plant.

Logwood is used in medicine as an astringent, but its principal use is as a dye. It was introduced into Europe by the Spaniards some time after the discovery of America by Columbus, and it was used in England as a dye in the reign of Queen Elizabeth. The dyers of those days, however, knew nothing about mordants-which are chemical substances used to fix the colours in fabrics-and the result was that the logwood dyes washed out from the cloths. The people, therefore, became greatly prejudiced against logwood, and in the 23rd year of Elizabeth's reign an act of parliament was passed prohibiting its use and ordering it to be burned Uses of the wherever it was found. This law was not repealed until dye. nearly a century afterwards, by which time the dyers had learnt to fix the colours permanently. The chief use now-adays of logwood is for dyeing woollen goods "on which it produces, with various mordants, shades of blue from a light lavender to a dense blue black according to the amount of logwood used." It is used also by calico printers, cloth dyers and hat makers, and the fine black silkiness of the 
"top-hats" is produced by logwood dye in combination with indigo and mordants. Besides blue and black, many other Great colours are produced by acting on a decoction of the wood valietyrs. with various chemicals, and so the red logwood may be made to create nearly all the colours of the rainbow. The common black inks, too, are made from logwood, and it is used by unprincipled persons in making up unwholesome compounds which they sell as claret and port wines. Indeed, it is a The wood common saying in Dominica that some of the logwood ex- used to ported from that island to the French colony of Martinique, is brought back in the form of claret!

The tree is a low spreading one rarely reaching to the Description height of forty feet, with a trunk at the most not more than ${ }^{\text {of the tree. }}$ eighteen inches in diameter, and usually ribbed longitudinally. The stem is frequently crooked, and the smaller branches are covered with a whitish bark. When found growing in hot dry places the branches are spiny, but in wet mountainous districts they are unarmed.

Soll and Climate.-Logwood will grow well on most The best soils, except loose sands and heavy clays. It grows best, however, and produces finer heart-wood on moist rich soils where there is an abundance of vegetable matter. The cli- Climate. mate must be hot, but not arid ; although the plant, when it has become firmly rooted in the ground, stands a drought very well. Mr. Morris states that the logwood grows in great abundance in the moist lands lying to the north and west of British Honduras, it being found in these places in immense thickets ; and, in Hayti, the best wood comes from the interior.

Propagation.-The plant is propagated by seed, and Nurseries. seedlings may be raised in nursery beds in the usual way. In countries, however, where the tree has become naturalised, young plants can be got in great numbers in the Seedlings. neighbourhood of old trees. The seedlings should be dug up 
carefully during the rainy season, and at once planted in the places where they are to grow.

Cultivation.-Logwood can scarcely be said to be cultivated, for most of the blocks are cut from self-sown trees.

A suitable cultivation for waste lands.

A large demand for the best wood.

Distances. But, waste lands, unsuitable for other cultivations, may with advantage be planted with logwood, and properly tended trees will always give a finer product than those growing wild. In fact it is stated, in one of the Consular reports from Hayti, that "There is a very good demand, larger in fact than the supply, for the better varieties of logwood."

Holes are to be prepared, as described in former chapters, at distances of fifteen feet-which will allow about two hundred trees to the acre-and the seedlings should be put out when the ground is thoroughly wet; and, if this be done, but

weeding. few plants will be lost. An occasional weeding will cause the young trees to grow faster, or cattle may be folded in so Pruning. as to eat down grass and weeds. All suckers and side shoots should be pruned off, and, whilst the plants are young, some of the lower branches may be sawn off close to the stem so as to produce trees with clean straight trunks which produce the best logs, and give less trouble in removing the sap wood.

Felling. Cutting THE Logs.-At about the age of ten years the trees will be ready for felling, which is done by axe-men, who afterwards junk up the trunks into large logs or billets

The wood. about three feet long. The sap wood, which is light and valueless, is then chipped off, and this is the most troublesome of all the operations. The heart-wood is very heavy and of a deep brownish-red colour; and it makes very

Chips. pretty cabinet work, as it takes a high polish. When the logs arrive at the home markets they are usually cut into chips by powerful machinery, as the dyers are better able to manipulate the wood in this form. In places where logwood is cut on a large scale for export, it would pay much better to manufacture the chips at once and 
pack them in closely pressed bales. For, if this were done, How to much waste would be prevented as the whole of the heart- increase the wood, including the chippings, could be worked up, and thus add considerably to the quantity obtainable, from a single tree.

In Jamaica quite a large business has been established in digging and exporting logwood roots left in the ground when the trees were felled during the last twenty or thirty years. Some idea may be formed of the importance of log- The English wood as a dye when it is remembered that the imports into England alone are valued at more than a quarter of a million sterling for a single year.

\section{InDigo. Indigofera Anil, and I. tinctoria.}

THE blue substance called indigo is obtained from several species of Indigofera, and the cultivation of indigo plants and the preparation of the dye were practised in India from An ancient the earliest times. The dye was known to the Romans as indicum, and the distances it had to be brought in the days when such journeys were difficult and dangerous rendered it very costly, and caused its origin to be shrouded in mystery. Some of the early writers describe the dye as a mineral, whilst History of others supposed it to be a vegetable exudation mixed with mud. In the fifteenth century the Dutch brought the dye from the East in considerable quantities; but, as it interfered with the manufacture of woad-a blue dye obtained from Woad. Isatis tinctoria, a piant cultivated in European countriesthe use of indigo was forbidden by several governments. In Germany, a law was passed in 1654 prohibiting the use of The devil's indigo and stigmatising it as devil's dye ; and, in Nuremberg, the magistrates compelled the dyers to take an oath once a year not to use indigo. In France, from 1598 until 1737 the use of the dye was forbidden in order to protect the woad growers, so that it was not until about the middle of the last century that dyers were permitted to use what substances 
The former cultivation of indigo in the West Indies.

Description of the dye.

The present sources of the dye.

Habitat.

Seeds.

The best soil.

Climate. they liked. At the end of the last century, and at the early part of the present one, indigo was cultivated to some extent in Jamaica and Dominica, and Bryan Edwards mentions the fact that the old indigo planters of Jamaica amassed much wealth. The cultivation was given up, however, on account of the precariousness of the crops, and the unhealthiness caused by the effluvium resulting from the fermentation of the plants in the process of the manufacture of the dye.

Indigo is now met with in commerce in square cakes measuring between two and three cubic inches, and usually stamped on one side with the name of the plantation, initial letters, or other particulars. Most of the dye now used comes from India and other eastern countries, but some of the supplies are got from Central and South America.

Indigofera Anil is a native of the West Indies and of tropical America, it grows in favourable situations to a height of five or six feet; whilst Indigofera tinctoria, which is a native of the East Indies and other parts of Asia, is a shrubby plant not more than three or four feet in height. Both plants bear small pods containing numerous small angular seeds, and they have long tap roots which penetrate deeply into the ground.

Soil and Climate. - Inảigo plants, and more especially I. Anil-which is a troublesome weed in some parts of the West Indies-are hardy and will grow on most well-drained soils in a suitable climate. The best soil, however, for the profitable cultivation of indigo, is a rich loam with a light, free subsoil that permits the running off of all surplus moisture. The soil must not be too dry and sandy, nor too wet and clayey, but a medium between these two. If the subsoil be wet, the plants will either die, or grow up sickly, and give very poor returns. Formerly indigo was cultivated in South Carolina, but it was found that the climate there was too cold, for the plants yielded little dye. Now the cultivation is confined entirely to the tropics, in places where the tem- 
perature never falls below $60^{\circ}$ Fahr., and where the atmosphere is not laden with moisture. The plant is a lowland one, and no attempt should be made to grow it systematically in the mountains.

Cultivation.-The spring is the best time for sowing, Preparation and the land should be well prepared before hand. Several of the land. ploughings should be done, and the subsoil should be broken up as much as possible. The surface soil is then to be brought to a fine tilth by careful harrowing ; and, in order to produce what is called a good "seed bed" the land may be lightly rolled afterwards. The seed, which should be as fresh Sowing the as possible, is mixed with sand or ashes, and sown by means of a machine called a drill in lines distant about two feet from each other. The seed must not be sown broadcast, for if this were done weeding would be impossible, and the plants would therefore soon be choked by fast growing indigenous vegetation. In places where the drill cannot be used, the seed may be deposited in small shallow holes made with the hoe, at distances of from ten to fourteen inches apart in the lines. Or, as many seeds as can be taken up between the thumb and forefinger may be deposited in each hole and covered with about half an inch of earth. The quantity of The quanseed used varies from ten to fifteen pounds for every acre; required. and, on indigo plantations, a considerable number of the best plants are always left to produce seed pods for the next crop. Ten bushels of pods yield about a bushel of clean seed.

In favourable seasons the plants spring up in three or four Weeding. days after sowving, and then they must be weeded by hand, all the weeds being carefully pulled up so as not to injure the seedlings. When the plants are a few inches high the hoe may be used, and three weedings will be necessary before the indigo is ready to cut, which should be when the flowers appear, and this will occur in about three months from the time of sowing the seeds. As March is the best month in the 
The sowing season. Cutting.

Rattoons.

Blights.

Manures.

West Indies for sowing indigo, the cutting operations will commence in June. The plants are usually cut down to within a few inches of the ground with sickles, and then tied up in bundles to be carried to the place where the indigo is manufactured. As exposure to the sun injures the cut plants, the operation should be begun and finished in the afternoon. After being cut down the plants will rattoon ; and, in favourable circumstances, as many as four cuttings have been obtained from the same roots in a year; but this is unusual for the plants quickly deteriorate, and seed must be freshly sown every year.

The indigo plant is liable to be attacked by many insect enemies, which in. some instances so infest the leaves as to destroy the entire crop. Some species of caterpillars are extremely fond of the leaves, and when the plant is cultivated on the same soil in succeeding years the enemies increase greatly in numbers ; it has been advised, therefore, that fresh soil should be chosen every year.

Indigo contains a considerable proportion of nitrogen, and thus when the same land is cropped often, manures rich in ammonia should be used. The refuse of the plants, after the indigo is extracted, is perhaps the best manure, and it makes an excellent fuel. Where the refuse cannot be returned to the soil, farm-yard manure with a top dressing of lime will answer the purpose very well.

MANUfaCtURe OF THE DYE.-The substances which form indigo reside in the leaves, but the whole plant for the sake of convenience and economy is subjected to the process of fermentation and agitation by which the dye is manufactured. How the dye The fermentation of the plants under water causes the dye is formed.

matters to be dissolved out ; and these, combining with the oxygen of the air, produce the blue colouring substance known

The dye made experimentally. as indigo. On a small scale indigo may be made experimentally by infusing the leaves in hot water, when the dye will be deposited by allowing the infusion to stand exposed 
to the air, and the process may be accelerated by occasional agitation of the fluid.

When manufactured on a large scale, however, large wooden vats. vats, or stone cisterns, placed like steps, one higher than the other, are necessary. The upper cistern, usually called the Cisterns. steeper, sixteen feet square and two and a half feet deep, has a bottom sloping gradually towards the end from whence the contents are discharged into the second cistern by means of a cock inserted near to the bottom. The second cistern, called the beater, should be twelve feet square and four and a half feet deep, and these cisterns will be sufficient to manufacture the dye from plants growing on seven acres of land. Below the beater a third cistern may be placed into which the contents of the beater is run and allowed to stand for the dye to settle at the bottom. But, unless the operations be done on a large scale, the settling of the dye can take place in the second cistern, which should be furnished with several cocks, at different elevations, so as to allow the clear fluid above to drain off from the precipitated indigo.

Bundles of freshly cut plants brought from the fields are Manufacput into the first cistern or vat in regulars layers until they ture of reach to within ten inches of the top. Planks are then laid on the plants and wedged down by some mechanical contrivance, and water is run in so as to cover the plants to a depth of three or four inches. The water must be pure, clear river Pure water water giving the best results; and, as a large quantity is essential. necessary, indigo cannot be manufactured with success in places where an abundant supply of water is unobtainable. A few hours after the water has been run into the cistern, Fermenfermentation will begin, and it should last from twelve to tation. sixteen hours. When the leaves become of a pale colour, and the tops are tender, fermentation has gone far enough ; for, if it be continued after this stage, putrefaction will set in and the dye will be destroyed. The water, which has dissolved out the soluble substances that become indigo after they have taken up oxygen, is of a light green colour, and it 
The refuse is run off by the cock to the second cistern. The refuse plants.

Noxious odours.

Beating. plants are then taken out of the first cistern, and either dried in the sun for fuel, or at once placed on the land for manure. They have a noxious odour, due to the putrefying vegetable matter, and this accounts for the unhealthiness characteristic of indigo manufacture.

The liquor, now being in the second cistern, is to be constantly agitated for a period of from one-and-a-half to three hours. The agitation prevents further fermentation, and by exposing successive layers of the liquor to the air, it enables the whole in time to become oxidised, and thus causes the formation of the insoluble blue dye. The liquor may be agitated by some mechanical contrivance, or by men going into the cistern and beating and churning the fluid with

The formation of the dye. wooden paddles. As the agitation or beating goes on the green liquor becomes of a deeper colour and then gradually turns to a blue shade as the insoluble indigo forms in minute particles called the grain. Then a small quantity of clear lime water is added in order that it may combine with the carbonic acid formed during the process of fermentation, but this is not really necessary, and some planters prefer to Lime water. do without the lime water as it is said to harm the indigo. The beating having been concluded, the colouring matter is allowed to settle, and in two or three hours the indigo will have subsided to the bottom, and an amber coloured fluid will remain on top. This clear fluid is then to be drawn off by means of the cocks, the highest one being opened first, and after the liquid has ceased running from it, a lower one is to be opened, and so on until nothing is left in the cistern but the indigo which looks like a bluish black mud. This

Draining off the moisture.

Cakes. mud-like stuff is then taken out and put into conical linen bags which are hung up so as to allow the surplus moisture to drain away. Afterwards the dye is taken out of the bags and put into shallow trays to dry in the shade. Before it is completely dry, however, it is cut into small cakes and stamped with the plantation mark. 
In India and other eastern countries the mud-like indigo, Boiling the before drying, is boiled in copper vessels for at least two indigo. hours, and afterwards spread on cloths stretched over bamboo frames, in order that the moisture may drain away-which will usually happen in from twelve to fourteen hours. The indigo is then pressed, cut into cakes, stamped and dried for the market.

It has been calculated that eight pounds of the leaves Returns. yield about half an ounce of indigo; and, three hundred pounds of the dye may be reckoned on as the annual return from an acre of plants. But, in former days, when Large indigo was cultivated on a large scale in Jamaica, as much $\underset{\mathrm{Jamaica}}{\text { return in }}$ as five hundred pounds have been got from an acre of good land. 


\section{CHAPTER XIV}

\section{TROPICAL CEREALS}

\section{MAIZE. Zea Mays}

Habitat. Maize, or as it is often called Indian corn, is a native of tropical America, where it was cultivated by the inhabitants from the earliest known times. In extra tropical regions it grows with great luxuriance in the summer time, and the early settlers in the United States finding the grain culti-

Origin of the name. vated by the aboriginal Indians, called it Indian corn. Nowa-days maize is grown in enormous quantities in the States, and the term corn has been universally applied to it there, Used by the other cereals being known as grain. The Spanish discoverers Caribs. of America found maize extensively used as food by the Stone imple- Caribs, and other inhabitants of the West Indies. The grains ments. of corn were ground into meal by these ancient West Indians with stone mullers formed into beautiful symmetrical shapes; and the author has some very fine specimens of these mullers which were found with other Carib stone implements in the A staple Islands of Dominica, St. Kitts and Nevis. Even now maize
food. is the staple food of the Indians of Central America who make its flour into thin cakes, called tortillas, which are baked on griddles. In the United States, Indian corn prepared in various ways forms a very important part of the food of the people, and one of the Judges of that country once said "Maize was as indispensable to a Yankee, as "the potato to an Irishman, or the oat to a Scotchman." 
No other cereal except rice is so extensively cultivated as Extensive maize; from America the plant has been carried to the oultivation warmer regions of Europe, Asia, and Africa as well as to Australia, New Zealand, and the islands of Polynesia. As The many the corn is very rich in nutritious matters, it is used all over plant. the world as food both for man. and animals; sugar can be made from the stalks; paper from the spathes or sheaths of the ears; and the green leaves and stalks form excellent fodder for animals. Moreover, in some parts of Fiji the Used in Fiji natives grow large quantities of maize for the purpose of topay taxes. paying the assessed taxes, the government sending on the corn to Australia in order to convert it into money. A fine flour, called maizena and corn-flour, is prepared from maize, and often used as a substitute for arrowroot; and, as it is very nutritious and digestible, it is used as a valuable article of diet for children and invalids. One advantage that maize Advantages has over other cereals is the short time it takes to come to of the maize. maturity, and another is that the corn may be used for food long before it is thoroughly ripe.

Maize is a monœcious cane-like grass growing to a height Description of from five to ten feet, or even higher. The male or stamiof the plant. nate flowers are borne at the summit of the plant in a loose feathery panicle, and the female or pistillate flowers occur in The flowers dense spikes springing from the axils of the leaves, and enveloped by sheaths or spathes, the long pink styles hanging out like silken tassels. The staminate flowers produce an immense quantity of pollen, which, being easily wafted by the wind, effects cross fertilisation. The number of spikes of female flowers varies according to the vigour of the plants; as mary as seven have been found on the same plant ; but usually, from two to five are met with. When The fruit. fertilisation has taken place, the female infloresence becomes what is known as the ear of corn. The seeds are arranged in rows upon a fibrous core called the cob, and the whole is embraced by the spathes which are sometimes called the husks. 
Varieties.

The variety best suited to the West Indies.

Improvement of the quality.
The best soil.

Drainage necessary.
Long conținued cultivation in different climates and soils, and cross fertilisation of separate kinds, have produced innumerable varieties of maize, suited to the various conditions under which the plant is grown. The varieties are distinguished chiefly by the characters of the seed. Thus, in regard to colour, there are the white, red, and yellow. In regard to the number of rows of seeds on the cob, there are the eight, ten, twelve, or twenty-four rowed kinds. In regard to the shape of the seeds there are rice corn, horsetooth corn, and other descriptions. And, in respect to the flavour, there is the sweet corn used as a vegetable, and the common kinds used for food for man or grain for animals. Again, there are varieties suited to different climates and soils.

In the West Indies the common eight rowed yellow corn is the hardiest and best for general cultivation; but, unfortunately, owing to bad cultivation, and carelessness in the selection of seed, this kind has deteriorated in many of the islands. A careful planter, however, may in a few seasons greatly increase the quality and yield of his corn, by simply selecting seeds from the best plants in the field, and then choosing the finest ears from these plants, and sowing only the largest seed in the ears. If this system be kept up for two or three years, the beneficial change will be most marked.

SoIL--Maize grows well in widely different soils, and it can be profitably cultivated, according to one authority, "on "a soil so poor as one containing ninety per cent. of sand." But, of course, the richer the soil the larger will be the returns. The best soil is a sandy loam such as is found on alluvial flats by the banks of rivers, and the loams formed by the disintegration of volcanic rocks in many parts of the West Indies are admirably adapted to the cultivation. Clays and cold wet lands are to be avoided, for maize requires a well drained soil through which the long roots can easily penetrate. 
Climate.-The plant will thrive and give large returns in widely different climates. "The warmest regions of the "torrid zone produce maize in abundance, where three crops "can be taken in a season, while the short summers of Canada "have a variety adapted to them." In the tropics the plant Elevation. grows from the shore to a height of more than 9,000 feet above the sea level; but, until a prolific mountain variety has been bred by careful and long continued selective processes, its cultivation in the higher regions will not be followed by success. In the West Indies elevations of from 200 to 900 feet may be considered to be the best.

Cultivation.--The land should be well ploughed up, and Importance the subsoil turned over to a depth of seven inches. Then of good the land should be harrowed so as to pulverise the soil as much as possible, for the better the tilth the greater will be the returns. The land being prepared, it may advantageously Furrows. be marked out in squares of three feet by means of a light plough, the furrows being first run one way and then cross furrows being run at right angles to them. At the points Sowing the when the furrows cross each other from four to six seeds should be sown at a depth of two inches and the earth pressed down lightly over them. If the land be too much Distances. broken up to permit the use of the plough, it can be lined out at distances of three feet, and the soil loosened with the hoe where the seeds are to be planted. Seedling plants may Nurseries. also be raised in nurseries and transferred to the fields when they are five or six inches high, for they bear transplanting very well. As soon as the young corn is growing in the Moulding up field, a top dręssing of wood ashes, or lime, or superphos- the plants. phate should be applied, and each plant earthed up so as to provide soil for the growth of the roots which spring from the lower part of the stem. No more than four plants should be allowed to grow in each hill; so that, if all the six seeds have germinated, the two weakest seedlings should be pulled up. The land must be kept free of weeds, and the Weeding. 
earth should be stirred up with the hoe whilst the weeding is in progress. The plants send up suckers from the roots near

Nipping off the suckers.

Fodder. the stem, and these suckers should be nipped off or otherwise they will injure the crops; the suckering should be done if possible before the plants are earthed up. When fertilisation has been accomplished the tops of the plants may be cut off so as to enable the ears to come to maturity earlier by exposing them to the light and air; and as the seeds harden, the leaves may be stripped off the stem. These tops and leaves make excellent fodder for cattle.

CROPS.- When the seeds have become perfectly hard, and the spathes have turned white, the crops may be gathered. Harvesting. This is done by simply detaching the ears and drying them afterwards; or, the stalk may be cut close to the ground, and stacked up for some days in the field so as to Corn in the dry in the sun. Of course dry weather must be chosen for these operations. If left in the ear the corn will remain in good condition for long periods. The best way is to pull back the husks, and to tie two ears together by Drying the knotting the ends of the husks. They may then be hung corn. up on sticks in houses or barns, in the same way as tobacco is in the curing house. (See Chapter X.) When the maize is stripped off the cob, it is known as shelled corn. Corn
shellers. If the stripping be done by hand it is a very tedious and

Uses of the cobs and husks. laborious operation; but machines have been invented for shelling the corn, and as they are inexpensive and work quickly they soon pay for themselves by the saving in time and labour they effect. The cobs, after the corn has been separated, make excellent fuel; and the husks are used in America for stuffing beds instead of straw, for they are much softer and do not crumble into dust. The shelled corn should be very carefully dried, if it be kept for any Kiln drying. length of time, as it is prone to mildew. In the United States maize is preserved by being dried in a kiln-the heat not being allowed to rise above $212^{\circ} \mathrm{Fahr}$. In this 
way the germ is destroyed, and all surplus moisture is driven off.

In the tropics maize will give a return in from two to Returns. three months, and thus several crops may be taken off the same ground during the year. But unless the land be very rich, high manuring will be necessary, and no crop, Manuring. perhaps, shows better results for expenditure in manures than maize. The returns vary much, according to soil, climate and cultivation. From fifty to eighty bushels should be Heavy obtained from good land, but much heavier crops are often Crops. reaped, and roo bushels to the acre is not an uncommon yield in some parts of the United States.

\section{RICE. Oryza sativa.}

OF all the grain crops, rice supplies food for the principal The enornumber of the human race. It is said to be the greatest mous consustenance of a third of the population of the globe. And rice. Porter says of it, in his Tropical Agriculturist, "From "time immemorial it has formed the staple food of the "great mass of the vast population of China, and of a large "proportion of the natives of India and the adjacent isles."

The plant is supposed to be a native of the warmer regions Habitat. of Asia; but, as it has been found growing wild in several places in South America, it is thought by some botanists to be also of American origin. The cultivation, formerly confined to the East, has now spread over most of the tropical and sub-tropical countries of the world. In the Southern Cultivation States of America the cultivation of rice began about the in America. year 1700 , seed having been introduced by the captain of a vessel that had come from Madagascar; and, before long the Carolina rice became the finest in the world. Atwood' Carolina in I791, writes, "Rice grows extremely well in Dominica," and he states that it was introduced by the American refugees, and that it yielded crops "in great perfection." At the beginning of this century Lunan wrote that it "thrives cultivation well in many parts of Jamaica," and he expresses his regret Indies. 
that the cultivation was almost altogether neglected in that island. It is now being revived. Description Rice is an annual grass, with a round jointed stem, reach-
of the plant. ing to a height of from one foot to six feet. The seed is borne at the termination of the stem, and it is protected by a rough yellow husk. The term paddy is applied to the grain in the husk, and in this condition it keeps sound for Varieties. several years. There are very many varieties of the plant, as might be imagined when one considers the number of ages it has been in cultivation in different countries, but the

Common rice and mountain rice. two principal kinds are the common or aquatic rice, and the mountain rice. The former can be grown only in land that is hot and marshy, the latter will thrive on ordinary soil at elevations of even 6,000 feet above the sea, and it will stand a degree of cold that would speedily kill the common aquatic rice-which needs a temperature of from $60^{\circ}$ to $80^{\circ} \mathrm{Fahr}$. to ripen it. The cultivation of these two kinds is quite dissimilar, and it will be convenient, therefore, to consider them under separate heads.

\section{COMMON Rice.}

The best soil.

Climate.

SOIL AND Climate.-The best soil for rice is a sandy loam overlying a substratum of clay, the loam forms a bed for the easy penetration of the roots of the plant, and the clay prevents the draining away of the water, without which common rice cannot be cultivated. It follows from these facts, therefore, that pure clays and loose sands are unsuited to the growth of the plant. The climate must be a hot one ; and, as rice delights in the sun, all shade is harmful. The great rice districts of the East are the hot, humid, and unhealthy lowlands along the banks and estuaries of the large rivers.

Irrigation. PREPARATION OF THE LAND.-In places where the soil is not naturally wet irrigation is absolutely necessary. In Eastern countries, when water cannot be turned on to 
the land from streams and rivers, owing to their low level, it is pumped up by various devices, some of them being very rude and requiring much labour. In certain dry places in India large tanks and artificial lakes have been constructed, simply for the purpose of storing water for the irrigation of rice lands ; and, in other districts, the water is obtained
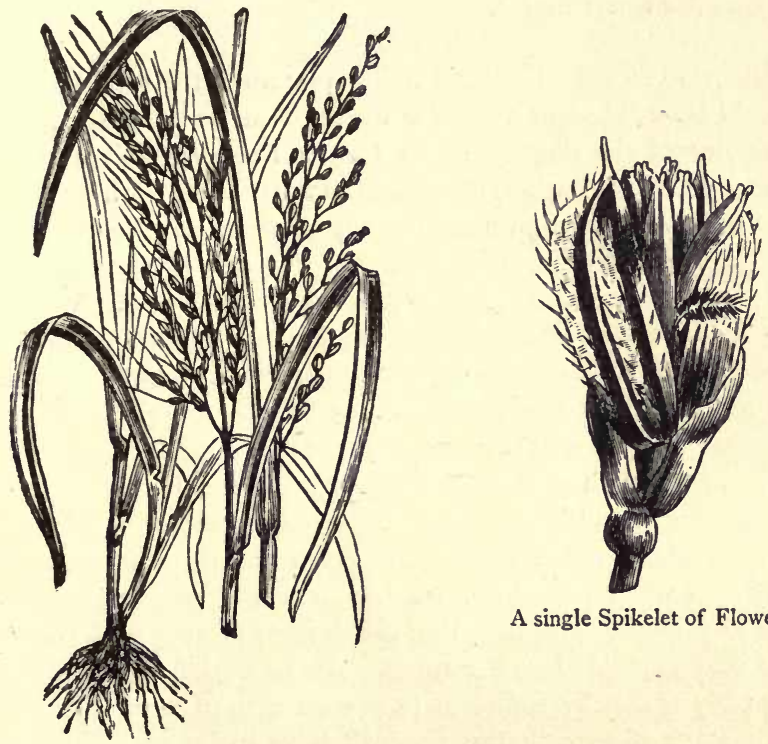

A single Spikelet of Flowers.

RICE. Oryza saliva.

from wells, being drawn up in buckets worked usually by bullocks.

The surface of the land is marked out and levelled into Fields and small fields which are surrounded by banks two feet high to banks. keep in the water. On sloping land terraces are formed, and these are also divided into compartments by earthen walls. 
The banks are pierced in convenient places for the purpose of letting in the water and allowing it to run out again. On Terraces. the terraces the water in the upper fields being allowed after a time to flow over the lower ones. When the banks have been built up, the land inside is weeded and ploughed, or Puddling the land. turned over with the spade or hoe. The water is then let in, and the soil is worked up into a puddle in which state it retains the water better.

Nurseries. Cultivation.-The land being prepared, the seed which should be steeped in water for twenty-four hours is sown in a corner of the field so as to form a nursery. When the young plants spring up, it is usual to water them with a solution of lime so as to prevent the depredations of insects. In

Lime water. China this sprinkling with lime water is considered to be a very important operation, and it is never neglected. When

Transplanting. the seedlings are seven to eight inches high, they are transplanted quickly so as to prevent their roots being exposed for any length of time. They may be planted singly or in bunches of two or three at distances of from six to nine inches from each other, either irregularly over the fields or in lines. Some cultivators sow the seed broadcast and then thin the plants out if they grow up too thickly - the surplus seedlings when pulled out serving to supply vacant patches. It is considered, however, that the nursery system is the best, Quantity of and that it yields larger returns. About a bushel and a half seed required to sow an acre of land. of paddy is usually sufficient to sow an acre of land. In the early stage of growth the rice will have to be kept free of weeds, and as the plants are close together the weeding will Weeding. have to be done by hand. The weeds can be buried in the mud, and in this way they will nourish the soil, as they will soon decay. The fields are kept flooded with water until the flower appear, and then they may be irrigated at intervals of three or four days in dry weather. When the heads of water. grain are well formed, the water should be shut off so as to hasten the ripening process. 
CROPS.-Harvesting usually commences within five or six months of the time of sowing; and thus, as by irrigation the planter is independent of the rain, two crops may be got in the year. May and November are the sowing seasons, and Harvest October and April the times of harvest. When the grain turns yellow, it is ready for the sickle; the whole plant is not mowed down, but the head is cut off with about a foot length of the stalk. The crop is tied into small sheaves; and, after some exposure to the sun, the sheaves are carried to the houses or sheds where the grain is threshed out. The Threshing. threshing is usually performed in Eastern countries by bullocks or horses, the animals being made to walk in a circle, and the heads of rice thrown under their feet are soon separated into grain and straw. Threshing may also be done expeditiously by means of a flail. The paddy, after being winnowing. threshed, is separated from the straw and winnowed, and it may then be kept in good condition for a very long time. To prepare the clean rice from the paddy a hulling operation Hulling.

is necessary. On a small scale this may be done by rubbing the grain between flat stones and blowing the husks away, but on a large scale a mill or a hulling machine will be necessary. The Americans, who are unsurpassed for in-Machinery. genuity, have invented many most useful machines for this purpose, and small ones able to operate on considerable quantities of grain may now be purchased at cheap prices. After hulling, the rice is winnowed and it is ready then for the market. The proportion of clean rice to paddy is from one half to two thirds.

The yield of rice from an acre of land varies of course ac- Returns. cording to the richness of the soil ; but, with good land and careful cultivation, the returns should be about fifty bushels. In Bengal the rice is divided into three qualities. The first The three and finest kind is called table rice and this is mostly exported to Europe ; the second quality is called ballam rice; and the commonest, which is mostly consumed by the people, is known as moonghy rice. 
Manuring.

High cultivation in. China.

When rice is cultivated on the same land for successive years manuring is necessary, compost and animal manures giving the best results. The Chinese, who are very skilful cultivators, manure their fields with all kinds of animal and other refuse, in fact they destroy nothing that can in any way add to the fertility of the soil, thereby teaching a lesson that should be taken to heart by Western nations. Human hair is considered by the Chinese to be of extreme value in rice cultivation; and, as these people shave the greater part of their heads, immense quantities are collected by the barbers who sell it to the farmers at a penny a pound.

\section{Mountain Rice.}

Upland or mountain rice, though producing a similar grain to the common or aquatic kind, differs greatly in its Climate. habit and cultivation. It thrives at elevations of from 3,000 to $6, \infty 00$ feet above the sea in the mountainous regions of northern India; and it will grow in temperate climates. although it will not yield crops of grain in such latitudes, Irrigation is not practical in its cultivation, the treatment of the plant being similar to that of the common cereals

Fodder. It makes excellent fodder, and it will pay to grow as a green crop, two cuttings being obtainable during the year. It may be cut and made into hay; sheep, cattle, and horses Large crops. being extremely fond of it. The crops yielded are larger than those of common rice, but only one harvest can be gathered in the year. Aquatic rice is said to yield from twenty-five up to eighty-fold of grain, whilst mountain rice returns a hundred-fold and even a hundred and twenty-fold.

Sowing the seed.

Cultivation.-The land is ploughed and manured in March, and in May it is again ploughed and then harrowed, and the seed is sown in drills, or it may be sowed broadcast. Another plan is to make small holes with the finger at a span's distance from each other, and then to drop a few seeds in each hole, and cover them lightly with mould. The 
saeds spring up in about a week from the time of sowing, and when the plants are a few inches high the ground is to be weeded. Another weeding may be undertaken before the Weeding. rice grow too high, and then it may be left to take care of itself until the crops are gathered, which will be about September.

CROPS.-The harvesting and other operations conrected Harvesting. with the crops of upland rice are similar in every respect to those already described under the head of common rice, except that in gathering the crops, it is usual to cut off the ears without allowing any length of straw to be attached to them, and as the plant does not grow higher than three feet this is the easiest way of reaping.

\section{Guinea CORn. Sorghum vulgare.}

MILLET, which is known generally in the West Indies as Habitat. guinea corn, is a native of India, but several species of Sorghum are found in tropical Asia, and the grain from them is comprised under the common term millet. Of the several millet grains, however, the most important is Sorghum vulgare, and it has been cultivated in Eastern countries from time immemorial. It has the advantage over other cereals climate. of thriving and giving large crops in hot arid regions; and in Syria, North Africa and the Soudan, the grain, which is called Dhurra in those countries, is the chief sustenance of the people. F. L. James, in his interesting work, "The A staple Wild Tribes of the Soudan," says :- "Dhurra is the staple food in the " article of food throughout the Soudan; it contains a great "deal of starch, and it is said to be more nourishing than "wheat flour. The natives cook it in a variety of ways, and " add beans and onions, when obtainable, to it. Horses will " not thrive unless they get a daily supply of it, and a small " quantity is of great use in keeping the riding-camls in "good condition." In addition to its valuable use as a food Beer. plant, a kind of beer is made in Africa from the malted grain; 
and the leaves and young stems form excellent fodder for animals, whilst the stalks, owing to the saccharine matters Sugar. they contain are sometimes used to manufacture sugar. Indeed, one of the millets, Sorghum saccharatum, is cultivated extensively in the North Western States of America for Millet flour. making sugar, molasses and syrup. The flour of the seeds is very white and makes good bread, and the panicles, after the removal of the seeds, become hard and rigid, and they are used extensively in England and America for the manufacture of brooms and clothes brushes.

Wide distri- The plant, and its allied species, are now cultivated extenbution of the plant. sively in all the warmer regions of the earth, and various names have been given to the grain in different countries. Thus it is called in the United States broom corn; in India, jowarrie; and in South Africa, Kaffir corn.

The best soil.

Soll AND Climate.-The plant will grow and yield a crop in nearly every soil, but the soil best suited to the cultivation is a rich light sandy loam, well drained and not too Climate. moist. The climate should be a dry one; and, in order to obtain large crops, the lowest temperature should not fall much below $60^{\circ}$ Fahr. Guinea corn will stand drought remarkably well, so that the hot and dry lowland regions of the West Indies are peculiarly adapted to the growth of this valuable cereal.

Sowing the seed.

Cultivation.- The land having been ploughed and harrowed so as to bring it to a good tilth, the seed is sown in furrows, or drilled in by the means of one of the useful seed drills now made by the manufacturers of agricultural imDistances. plements. The lines or furrows for the seed should be from three and a half to four feet apart, and the plants should be thinned out after they have sprouted, so that the seedilngs Weeding. may not be less than twelve inches apart in the rows. As soon as the corn is a few inches high the field must be thoroughly weeded, and a second weeding may be necessary iater on, or a light plough or cultivator may be run between 
the rows so as to turn up the soil and destroy the weeds. Very soon the plants will cover the land by their luxuriant foliage which grows with great rapidity.

CROPS.-The best season for sowing is June, and crops may be reaped in four or five months afterwards ; although, when grown under favourable conditions, returns have been got in three months. When the corn has arrived at matu- Harvesting. rity, it is harvested by cutting off the ears near to the top of the stem, and then carrying them in baskets to the house or shed. The ears are kept in heaps for a few days, and Threshing. afterwards they are spread on the floor of the building, and the grain is threshed out by means of a flail. In some parts of the East, millet, like rice, is threshed by bullocks being made to tread on it, and this process dates far back into primitive times. Indeed, in some Eastern countries, agri- Primitive cultural systems and manufacturing processes have been the East. handed down unchanged from remote ages to modern times; descriptions by ancient writers of the every-day life of the people, being in some instances faithful delineations of what is seen at the present time.

The crops of Guinea corn got from an acre of land vary Returns. considerably, fifty bushels, however, may be considered as a good average return. But double that quantity is mentioned by Porter as being a not unusual crop from good soil. 


\title{
CHAPTER XV
}

\author{
FOOD PLANTS
}

\section{Cassava. Manihot utilissima}

Habitat. THE cassava plant is a native of South America, where it is found from Guiana and New Granada to Brazil and Peru. History of Its cultivation by the inhabitants of tropical America dates
the plant.

far back, and it has always formed a great portion of their food. From the grated tuberous roots they obtained not only meal and bread, but they also manufactured by fermentation an intoxicating drink called piwarri from cassava cakes, which were first chewed and then spat into the wooden Cultivation fermenting vessels. The plant is now cultivated extensively Indies. throughout the West Indies, and more especially in Dominica, and the French colonies of Martinique and Guadaloupe, where its meal enters largely into the diet of the people. Tapioca. It contains much starch and other nourishing matters; and tapioca, one of its products, is well known as a light and easily digestible article of food for children and invalids. Productive- The cultivation is simple and inexpensive, and the returns
ness of the plant. are large ; indeed, the plant is said to be one of the most productive in the world, an acre of cassava yielding more nutritive matters than six times the same area under wheat. Cassava is a shrubby plant with knotty stems growing to a height of from five to eight feet, and the roots swell out into large tubers of a yellowish colour. These tubers sometimes attain to a very large size, and from them is obtained the 
starchy cassava meal and tapioca. There are two varieties Varieties. of the plant, one the bitter cassava (Munihot utilissima) and the other sweet cassava (Manihot Aipi). The two kinds have, however, not very distinct specific characters. Sweet cassava may be used as a vegetable without any preparation ; but bitter cassava contains juice of a very poisonous nature. This poisonous juice, in which there is inuch hydrocyanic or The poison. prussic acid, is fortunately dissipated by heat, and so the ous juice. bitter cassava is commonly cultivated as it gives much larger returns than the sweet kind.

SoIL AND Climate. - The best soil is a sandy loam which The best must be well drained, for the roots soon decay in waterlogged ground. The soil, too, must be rich, for cassava is Manuring. a very exhausting crop, and without manure it cannot be raised on the same land more than two or three years running. The climate should be a hot and dry one, and the Climate. plant thrives best in the lowlands in the neighbourhood of the sea. No shade is necessary, and high winds do not damage the plants.

Cultivation.-The modes of propagation and cultivation Cuttings. are simple. Full grown woody stems are cut up into pieces from four to six inches long, and these are set in a slanting direction in the ground, with about an inch left above the surface. Previous to planting, however, the soil should be well prepared by ploughing and cross ploughing; or, on a small scale, it may be worked up with the hoe or spade. Another plan is to plant the cuttings in small shallow holes filled in with good surface soil, or in furrows made at the proper distances with the plough. The distances vary from Distances. four feet to six feet each way, the wider distances being chosen on the best land. The cuttings will begin to grow in about a fortnight after planting, and the ground must be kept free of weeds until the plants grow up and cover the land with thin vegetation, which they will usually do in about three months from the time of planting. In 
Weeding. weeding with the hoe or cultivator between the rows, care must be taken not to turn up the soil too deeply, for otherwise the lateral roots which bear the tubers will be injured and thus interfere with the yield.

The crop CROPS.-Planting having been undertaken between Sep-
time. tember and May, the crops may be reaped in from eight to twelve months afterwards, but the roots can be left in the ground for a considerable time without injury. In harvesting, the tubers are carefully lifted and separated from the Washing the fibrous roots, and washed so as to remove all adhering tubers. earthy particles. They must then be manufactured into the commercial product without delay, for they soon dry or decay after they are dug up.

Peeling the tubers.

Preparation of Cassava Meal.-The tubers, after they have been washed, are divested of their dark-coloured rind Grating. by being peeled with sharp knives. The peeled roots are then reduced to a coarse meal by being pressed against a rapidly revolving wheel covered with a copper or tin grating surface, or they may be rubbed down to meal by means of a flat tin grater nailed on a board. In the latter case, however, the operation is very laborious; but, nevertheless, a large portion of the cassava meal made in Dominica and

Grating. manioc in elsewhere is prepared in this tedious way: the natives fix Dominica. the large flat grater against a tub, and, leaning over it with tubers in each hand, they grate quickly and rhythmically to the sound of a drum and they are encouraged to extra exertions by the stimulating influence of inspiriting local songs, and more often than not by large potations Pressing out of intoxicating drinks. The pulp is then put into bags the poison. ous juice. and pressed so as to force out the poisonous juice. The Indians of Dominica and South America press the pulp The by means of curious baskets called matapies. These baskets are made of plaited strips of the long smooth stems of a native plant closely allied to that producing arrowroot. When empty the matapie is long and narrow, but when 
filled with the grated roots it becomes short and thick. It is then hung up to the branch of a tree and heavy weights are attached to the lower end. The basket then becomes longer, and by the constricting pressure most of the juice is forced out. Afterwards the meal is sifted by means of Sifting the sieves, which separate the woody fibres and the small portions of the roots that have not been properly grated. The meal is then dried rapidly in large, shallow, flat iron pans set in masonwork, with a flue passing underneath so Drying the meal. as to conduct the heat from a wood-fire. The meal is spread thinly in the pan and constantly moved backwards and forwards with a wooden rake. The heat must not be so great as to brown the meal, the object being not to bake the product but to dry it. In the process of drying, any remaining traces of the highly poisonous juice are rapidly dissipated. Cassava bread is simply the fresh wet Cassava meal formed into thin round cakes, and dried on hot plates, or on flat pieces of tin held over a fire.

CASSAVA STARCH. - The starch made from cassava is of a very superior nature; and, as it can be made cheaply, and in enormous quantities, it ought to become an important article of export from the West Indies. The method Preparation of preparation is very simple. The grated cassava meal of the starch. is stirred up with water and then passed through sieves. This is done several times so as to wash the starch clean, Washing the and the mesh of the sieves is decreased in size after each starch. washing so as to leave the starch free from any foreign substance. After the last washing the water is allowed to remain for a time, when the starch will settle at the Drying the bottom of the vessel ; the clean fluid on top is then drawn starch. off or decanted, and the starch is dried in the sun.

TAPIOCA.- In the account of the preparation of cassava meal we have seen that the juice is forced out of the rasped roots by pressure. Now, if this poisonous juice be allowed The fine to settle, a considerable quantity of very fine starch will be starch. 
deposited. The juice is poured off, and the starch is heated on tin plates or in flat iron pans; the starch grains then

The bursting of the grains.

The value of tapioca as a food.
Dangerous nature of the poison. ous juice boiled down. Antiseptic qualities of cassareep. swell up and burst, and become agglutinated together, thus forming the tapioca of commerce-which is a large export from Brazil. The starch grains having been ruptured by the heat, they are partly soluble in water, and for this reason tapioca is especially valuable as food in cases of weak digestion.

CASSAREEP. - The poisonous juice of the tubers of the bitter variety of the cassava plant should not be thrown away as it can be converted into a valuable product known widely as cassareep. The juice is simply boiled down until it becomes of the consistence and appearance of molasses. In this condition it is a powerful antiseptic, and it is capable of preserving all kinds of meat in a fresh condition for considerable periods. It is the basis of many celebrated sauces, and of the well-known pepper-pot of the West Indies. Thus by reason of the boiling process, this highly poisonous juice is converted into a wholesome food product, for which there is usually a ready sale in England and elsewhere. As the juice of the bitter cassava contains so much of the poisonous prussic acid, the greatest care must be taken to keep it away from children and animals. Many deaths have been brought about by carelessness in the disposal of the juice, so that too many precautions cannot be taken to prevent Antidote. accidents. It may be mentioned that the Indians of Guiana use red peppers (Chillies) steeped in rum as an antidote to the poison.

\section{ARrowroOT. Maranta arundinacea.}

ARROWROOT is a white, tasteless and odourless powdery substance-consisting of starch granules, and used as a bland article of food, more especially for children and invalids. It is obtained from the white, fleshy rhizomesHabitat. sometimes called tubers-of a reed-like herbaceous plant 
found growing wild in tropical America and the West Indies. The name arrowroot is derived from the fact that the Origin of rhizomes were used by the Indians as an application to the name. wounds inflicted by poisoned arrows; and, even now in Dominica the starch and the pounded tubers are used by the people to make poultices for the healing of wounds and ulcers. The plant is cultivated extensively in Bermuda and St. Vincent, as well as in the East Indies and Natal. Bermuda arrowroot is considered the best, and it fetches a Bermuda much higher price in the home markets than any other kind, and this superiority is "attributed to the extreme care and cleanliness exercised in the different processes of manufacture." It is probable, however, that soil and climate and more especially an abundant supply of clear spring water have a good deal to do with the matter, for arrowroot is grown to a large extent in St. Vincent, and on some of the estates in that island greater care and cleanliness cannot be observed, and yet St. Vincent arrowroot is much less valuable than the Bermuda product.

Soll and Climate.-A light loamy well drained soil is The best the best for the cultivation. If the soil be too wet the soil. rhizomes will rot off ; and, if it be of a clayey nature, they will not develop properly, and there will be much difficulty in digging them up when they are mature. The plant will climate. grow very well on lands near to the sea; and, as it does not attain to a greater height than three feet, strong winds do not affect it injuriously. The richer the land, the greater will be the returns; and, if successive crops be taken off the same soil, manuring will become necessary. As much water A good is required in the manufacture of the starch, the cultivation of water should be established only in the neighbourhood of a stream essential. or a spring of good clear water. Arrowroot will grow from Elevation. the coast line up to elevations of several thousand feet above the sea, but the returns are larger in the lowlands, and largest in the rich valleys situated at elevations of two or three hundred feet. The crops are "less affected by vicissi- 
tudes of weather than almost any others that can be produced" in the tropics, wet weather and dry weather appearing not to alter the yield to any appreciable extent provided the soil is good.

Propagation.

Cultivation. - The plant is propagated by means of young shoots detached from the parent stool, or by division of the rhizomes. Thesland should be ploughed deeply and then harrowed. Afterwards furrows are made to a depth of six inches at the distance of three feet from each other.

Furrows. The shoots are planted in these furrows about twelve inches apart, and covered with soil either by means of the plough weeding. or the hoe. The land is kept weeded; and, in the early stage of growth of the plants the soil may be advantageously

Cutting off the flowers. turned over between the rows by light ploughing. It has been advised that the flowers should be cut off as they appear, so that the rhizomes may be increased in size and number by preventing the waste of the strength of the plants in the effort of flowering. Such a system is in accordance with scientific teaching, and its adoption is to be recommended.

Returns in eleven months.

CROP.-Returns may be expected in eleven months, and as May is the best month for planting, the rhizomes may be dug up in March or April, and they will then be found to be densely packed with starch granules. The maturity of the rhizomes is known by the flagging and falling down of the leaves; and when this occurs the plants should be Digging dug up with the fork, and the rhizomes should be broken up the rhizomes. off from the leafy stems, and washed so as to remove the adhering particles of earth. In the process of lifting the plants, small pieces of the stems and roots are always left in the ground, and from these remnants fresh plants The hardy spring up. For this reason, it is very difficult to eradicate nature of the arrowroot from land where it has once been cultivated, for
plant. the plant is of a hardy nature, and thus very small portions of the rhizomes are capable of growing into large clumps. The rhizomes contain twenty per cent. or even more of 
the starch ; but, owing to the rude processes of manufacture usually employed to separate the fecula, it is seldom that more than fifteen per cent. is got, and this would give about seven hundredweights of prepared arrowroot to the acre. But with high cultivation on rich soil much larger Returns per returns may be looked for; indeed, in Natal, as much as a acre. ton of arrowroot has been made from the rhizomes grown on an acre of ground.

Preparation of the ARrowroot. - The rhizomes Paring the having been dug up and washed they are to be pared with sharp knives so that every portion of the outside skin is removed; and, at the same time, all unsound portions are cut away. The skin contains a resinous substance which The resin in would discolour the arrowroot and give it a disagreeable flavour; it is necessary, therefore, that great attention be given to the paring of the rhizomes. After the skin is Washing. removed, a second washing is necessary ; and then, in order to get out the starch, the rhizomes are to be reduced to a pulp. This may be effected in three ways; namely, I. By The three pounding them in wooden mortars; 2. By passing them methods of between the rollers of a mill ; 3 . By pressing them against a rapidly revolving wheel covered with rough tin like a nutmeg grater-which tears the mass to pieces. In places The grating where arrowroot is cultivated on a moderately large scale the last mentioned pulping process is the best, for the grating mill can be made at very little expense. The next thing to The fecula do is to mix the pulp thoroughly with good clear water, and sieves. then to pass the whole through a fine sieve which separates the fibrous substance and permits the fecula to be carried off with the water through the meshes of the sieve. The fibrous refuse is thoroughly squeezed to force out any of the starch entangled in it, and it is then thrown away, or, preferably, used as manure for the next crop. The water and the The settling starch are run into cisterns or tubs and allowed to settle, of the starch. when, after a time, all the starch will subside to the bottom 
Washing the and the water can be drawn off. The fecula is then stirred starch.

up with fresh water, passed through a second sieve of a finer mesh--which may be of brass wire or muslin, and allowed to settle as before, the supernatant fluid being drawn off when all the starch has fallen to the bottom. This process may be repeated several times, or until the water appears perfectly clear over the starch. The object of the several washings is to remove everything from the pulp but the starch, which, in its pure state, is the arrowroot of com-

Draining and drying. merce. After the last washing the water is drawn off, and the pasty starch is taken out of the tubs or vats and put on trays with calico bottoms to drain and to dry, the drying process being usually effected in the sun or in sheds, the sides of which are left open or enclosed simply with galvanised wire netting to allow a free circulation of air. In Bermuda it is calculated, according to Simmonds, that "four barrels of peeled and cleaned rhizomes will yield in "good seasons about Ioo lbs. of good arrowroot, and will "take from five to six puncheons of clear soft or tank water, "it will be about twenty-fours hours in the water from the "time of grinding till it is upon the cloths or drainers." The The advantages of quick drying. arrowroot will take about three or four days to dry properly ; but the hotter the sun or the drier the air and the more quickly the product is desiccated, the whiter will be its colour and the better its quality. After it is dried the starch will be in cakes which will have to be broken up into small lumps The air to be before it is packed. Arrowroot, when made properly, will excluded from the arrowroot. keep a very long time without spoiling if it be packed so as to exclude the air, for it absorbs moisture readily, and it acquires the odour of any decomposing or strong smelling substances brought close to it. Unless, therefore, it is sealed up in tins, it should not be shipped in vessels carrying sugar, hides, \&c. In St. Vincent, the arrowroot is shipped in tins containing 25 lbs. or 50 lbs., and in well-coopered American flour barrels, which are lined with paper gummed together with arrowroot paste. 
In the process of manufacture the greatest cleanliness Cleanliness must be observed, and care must also be taken to exclude essential. dust and insects from the arrowroot. On estates in St. Vincent and Bermuda, where the starch is made in large quantities, the buildings and the machinery are kept scrupulously clean, and highly polished German silver shovels are used to take up and pack the arrowroot. In St. Vincent, Glass too, the various process of manufacture and drying and packing are done in houses roofed with glass so as to keep away dust and other foreign matters, and thus to ensure the making of a product of great purity.

\section{TOUS-LES-MoIS. Canna edulis.}

A KIND of arrowroot called tous-les-mois was imported into Cultivation England from St. Kitts about the year 1836 ; and, as it was in St. Kitts. found to be a valuable article of food, it has made a place for itself in the home markets. The imports into England are still mainly from St. Kitts, but the plant producing the starch is now cultivated extensively in Australia. The The starch starch granules of tous-les-mois are very large, and they can $\begin{gathered}\text { granules are } \\ \text { very large. }\end{gathered}$ be distinguished with the unaided eye; whilst, in the case of all other starches, with the exception of that from the potato, the granules can only be detected by means of the microscope.

Tous-les-mois is obtained from the fleshy underground Habitat. stems, or tubers, of Canna edulis, a plant closely allied to the Marantas, and found growing wild in Brazil, Peru, and Trinidad. Other varieties of Canna, producing tous-lesmois, are natives of Jamaica, Dominica and St. Kitts, but C. edulis is the one usually cultivated for the sake of its starch, It is a very hardy plant, and in Peru, where it is called Adeira, it is eaten like potatoes. The flowers are Description highly coloured; in Canna edulis they are bright red, and of the plant. in other species they are various shades of yellow and orange, 
The plant is a very ornamental one, and, for that reason, is cultivated in English hot-houses. The seeds are round. hard and black, and it is said that they have been used by the natives of India as shot, and hence the name "Indian shot," which is sometimes applied to Cannas generally.

Useful qualities of the starch.

Propagation.

Cultivation. Tous-les-mois is very soluble in boiling water; and, on this account, and because of the large starch granules composing it, medical men recommend it as one of the best starchy foods for children and invalids.

The plant is propagated by division of the underground stem, or by seeds which will germinate after being kept for many years. The land is ploughed up and prepared in the usual way, and the sets are planted a few inches under the ground in rows three feet distance each way. The cultivation of the plant is similar in every respect to that of ordinary arrowroot, and the starch is prepared in the same way as the arrowroot starch, which has been fully described in the preceding section of this chapter

The YAM. Dioscorea alata, and other species.

YAMS are the esculent tubers of several species of Dioscorea that have been cultivated in warm countries for ages. More Food value nutritious than the common potato, they supply an abundof the yam. ance of wholesome food to the inhabitants of tropical and sub-tropical regions; and, in the West Indies, they enter very largely into the diet of all classes of the population. Habitat. Most of the cultivated varieties of yams are probably natives of tropical Asia, that have been introduced into the West Indies at an early period of their colonisation by Europeans, and now become almost wild. The only yam of good flavour and food value, that naturally belongs to the flora of the West

The wild yam of Dominica. Indies, is the "waw-waw" of Dominica, Rajania pleioneura, which grows abundantly in the forests of that island. It is dug up by the woodmen and sold in the markets of the chief 
town, for it is deservedly held in much estimation. After the hurricane of $\mathrm{I} 88_{3}$, when most of the provision grounds in Dominica were laid waste, many of the country people subsisted for weeks almost entirely on waw-waws, dug up in the forests. All the yams are the produce of plants with slender twining stems measuring often as much as twenty Description feet in length, and bearing underground tubers which spring from the principal roots. The tubers vary in size and weight from the small cush-cush no larger than an ordinary potato, to the enormous yam weighing thirty or forty pounds, and measuring three feet in length. There is confusion in regard Nomento the names and characters of the different yams, each country appearing to have its own nomenclature. There species. are four kinds of yams, however, commonly cultivated in the West Indies, and the most noticeable particulars concerning them are as follows:-

White Yam. Dioscorea alata.-This is sometimes called Habitat. the Barbados yam, is a native of the Moluccas and Java. The stem is square and winged at each angle. The leaves are large, heart-shaped, and opposite on the stem. A pecu- The bulbils. liarity of this plant is that bulbils, or small yams, are borne on the stem, and when they are ripe they fall to the ground and reproduce the species. The tubers are large, weighing The tubers. from eight to ten pounds when grown in good soil. There Varieties. are two principal kinds, the white and the red, the surface of the latter is of a deep purplish, and the interior of the tuber of a light purplish colour. A third kind, called the water yam, The water is characterised by the interior of the tuber being of a yam. moist and clammy nature. These yams will keep well out of the ground, and they are much liked on account of their digestibility, and their superior flavour.

NEGRo YAM. Dioscorea sativa.-This is sometimes Habitat. called the yellow, creole, or common yam, and it is a native of Java and the Philippine Islands. The stem, which grows to a length of fifteen or twenty feet, is round, prickly below 
and smooth above. The leaves are heart-shaped and The tubers. alternate on the stem. The tubers grow to a large size, weighing usually about ten pounds; they are palmated in shape, and they are so brittle as to be easily broken. They are of a white or yellowish colour within, but the white kind is liked best. These yams do not keep in good condition for any length of time after their removal from the ground.

Guinea Yam. Dioscorea aculeata.-In Jamaica this is Habitat. sometimes called the Afou yam. It is largely cultivated throughout the West Indies, but its native country is Cochin China, and it comes also from Malabar. The stem is round, prickly and much branched. The leaves are broadly heart-shaped, and either alternate or opposite on

The tubers. the stem. The tubers are very large, reaching a length of two or three feet, a diameter of six or eight inches, and a weight of from fifteen to twenty pounds. The interior is of a white or yellow colour, and when cooked the flavour is somewhat bitter.

Cush-Cush Yam. Dioscorea triphylla. In Jamaica this is sometimes called the Indian yam; and, in Guiana, it is known as the buck yam. The stem is roundish, the leaves are opposite on the stem, and divided into three leaflets.

The tubers. The tubers are roundish-indeed, something like a potato in shape. They rarely exceed nine inches in length, and three inches in diameter, but they are usually much smaller. It is said to be the smallest and most delicate of all the Varieties. yams. The plant is prolific, sometimes bearing a dozen tubers on the roots. There are two principal kinds, the white and the red, the latter hearing tubers that are purplish within.

The best soils.

SOIL AND Climate.-All the yams require a rich sandy loam, deep and friable, for the rich tubers will not be able to develop properly in stiff heavy soils. The white yam, however, will grow well on calcareous soils of a moderate 
depth. Good drainage is necessary, and this applies to most plants bearing underground tubers. The climate must Climate. be warm, but not necessarily hot, as the plant thrives in the mountains and in extra-tropical regions. One authority states that yams will grow within a wide zone extending thirty degrees north and south of the equator.

Cultivation.-Most of the yams are propagated in the Propagafollowing way: When the tubers are ready to be dug up, the tops are cut off with the vines attached and care is taken not to disturb the plant more than is really necessary. The top is then buried again in the ground, and it and the base of the vine is moulded up with good soil, and left undisturbed for about three months, when another yam, called the head, is produced. Plants are then made by Yam plants. cutting the head into pieces, care being taken that each cutting possesses an eye, or bud, from which the new plant develops.

The land is usually lined out at distances of two feet each Distances. way, or in rows three feet apart, the plants being set at distances of eighteen feet in the rows. At the site of Hills. the pickets the land is dug up, all stones and roots being removed, and the surrounding soil is then raked up so as to form small hills in which the yam plant is set several inches below the surface. In each hill, a stout stick eight feet long Supports. is simply fixed at the side of the plant so as to form a support for the vine to climb on. Sometimes two plants are set in each hill. The land must be kept weeded, and an Mouldng occasional moulding up may be necessary, as the heavy the plants. rains tend to wash down the hills. Catch crops of maize, and sweet potatoes are sometimes taken off the land between the rows, but this system is a bad one except in very rich soil. From January to April is the best planting season, and the yams require from nine to eleven months to mature. Yams may Planting, may, however, be undertaken in every month of the all the year year, so as to ensure a constant supply of the esculent tubers. round. 
It has been calculated that an acre of land will yield four or five tons of yams in the year, and it is said that the same quantity of sweet potatoes may be taken as a catch crop off

Returns the ground, this brings the return up to nine tons-that is the yield of ordinary potatoes from an acre of good land in England. But as yams and sweet potatoes contain more nutriment matter than the common potato, the actual yield of food is greater in the case of the tropical vegetables.

\section{The Sweet Potato. Ipomaa Batatas.}

Habitat.

History of the plant.

THE origin of the plant producing the sweet potato is obscure, but it is thought by botanists to be a native of both hemispheres. It formerly grew wild in the woods of the Malayan Archipelago, and batatas, a Malayan word, is the name given to the potato in the far East. The tuberous roots of the plant are said to have been first mentioned by an author named Pigafetta, who visited Brazil in the year I 519 , and found the potato in use among the Indians as an article of food; it is probable, therefore, that it is a native of South America. Soon, afterwards, the plant was carried to Spain, and it spread over Europe, and was introduced into Fngland long before the common potato-which has now taken its place.and also its name. Dr. Pavy says, "The tubers were imported into England by way of Spain, and sold as a delicacy before the potato was known, and it forms the article referred to when the name is mentioned by English writers previous to the middle of the seventeenth

Wide distribution of the plant. century." Sweet potatoes are now cultivated extensively in all the warmer regions of the globe, and in some countries they form a large part of the food of the people. The starchy and sweet tubers have an agreeable taste, and they contain more nutritious matters than the common potatowhich is the staple food of the peasants of Ireland. 
The sweet potato is a convolvulus with a trailing herba- Description ceous stem and purple flower. The stems are from six to of the plant. eight feet long, sending out roots at every node that rests on the ground. The original roots, and those sent out from the stems bear many tubers-one plant yielding sometimes as many as forty or fifty potatoes of various sizes. The tubers, The tubers. in rich soil, grow to a very large size. They usually weigh from three to twelve pounds each when they are fully grown, but it is stated that in Java they have attained to the enormous weight of fifty pounds.

There are several varieties, varying in size, shape and flavour Varieties. of the tubers. The two principal kinds, however, are the white and the red potatoes. The white variety has a round entire leaf ; and, in the red one, the leaves are divided into lobes.

Soll and Climate.-The best soil is a light friable one, The best with but little clay in its composition. It should be so well drained as to be rather dry, and to produce large crops it must be enriched with vegetable matter. The climate must Climate. be a warm one, and, although the plant will grow in the mountains, up to considerable elevations, it thrives best in the hot lowlands, and a saline atmosphere is not inimical to it.

Cultivation.-Plants are propagated by cuttings of the Cuttings. stems. The cuttings should be about twelve inches long, and about half of their length is buried in the soil. They readily take root, even in dry weather, and once having rooted they grow vigorously. The land must be well ploughed, or dug up with the hoe, all grass and weeds being turned into the soil, so as to rot and serve as a green crop manure. The A good tilth more the soil is worked up by the plough, hoe or spade, the necessary. better will be the returns. The land is then to be ridged, which may be accomplished by the plough or hoe, the ridges being at a distance of two feet from each other. The potato Distances. cuttings are then set in the ridges a foot apart, and this will give an area of two square feet for each plant. As soon as 
Weeding. the vines commence to grow, the ground must be weeded, great care being taken not to injure the foliage of the plants. At the second weeding it may be necessary to mould up the potatoes, if heavy rains have washed down the ridges. Sweet

Rotation. potatoes should not be grown constantly in the same land, but should be rotated with other crops; and this rule applies to most of the cereals and other food crops, as well as to the cultivation of any plant that does not permanently occupy the soil. This system, which unfortunately is not well understood in the West Indies, is treated of in the first part of the book, under the heading of rotation of crops. In cases, however, where it is necessary to cultivate the same Manuring. plant continuously on the same land, manuring is absolutely necessary, if the fertility of the soil is to be kept up, and if remunerative returns are hoped for.

CROPS.-Sweet potatoes are usually planted from September to May, and crops are gathered in from three to four Returns. months from the time of planting. The returns are usually considered to be from four to five tons to the acre when the cultivation is carried on under favourable conditions. After the first crop is dug up, the stems and roots are to be carefully covered with mould, and a second crop may be obtained in a month or two afterwards. Indeed, in rich soil, Successive several successive crops may be gathered from the same crops. plants. The leaves and succulent stems make excellent Fodder. fodder for the horses and cattle, besides which sheep, goats rabbits and other herbivorous animals are extremely fond of the potato vines.

\section{THE TANIA. Colocasia esculenta.}

Habitat. TANIAS are the tuberous rhizomes of a plant extensively Ancient cultivation of the plant. cultivated in most tropical countries. It is a native of India, but it has been grown in Egypt from time immemorial, its former botanical name, Colocasia antiquorum, indi- 
cating that it was cultivated from the earliest known times. Like other widely distributed food plants, there is a good deal of confusion in regard to the nomenclature. In Jamaica Nomenthe tubers are called cocoes, and in other parts of the West Indies they are called eddoes and tanias, the last mentioned

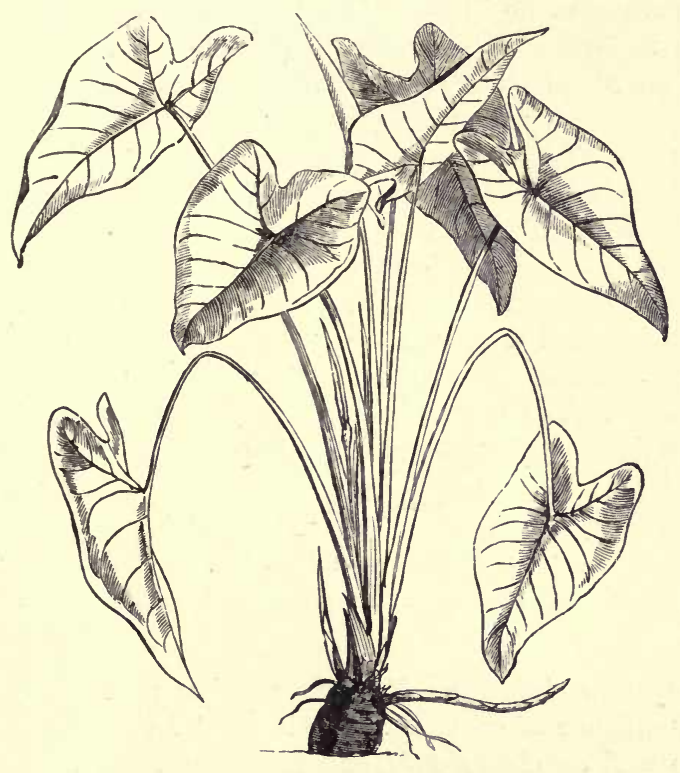

tANia. Colocasia esculenta.

name being spelt sometimes tannias, taniers, and tanniers. In the Pacific islands they are known as taros, and an old French writer on Santo Domingo alludes to them as Tanias not tayaux. The name tania has been adopted by the author, for the reason that it is the one most generally used throughout the West Indies and South America, and because it is 
employed by the old writers on these islands. The Jamaican name, cocoes, should certainly be discarded, inasmuch as it is liable to be confused with cacao, coca, and cocoa-nut, owing to its similarity of spelling and of sound.

Description
of the plant. The plant producing the tania is a very handsome herbaceous one. It has only a short stem, and the large arrowshaped leaves are borne on long petioles or foot-stalks rising from the ground. The tuberous rhizomes are sometimes as much as six or seven inches in diameter, and they contain a large proportion of starch which renders them very nourishing food. They contain, also, an acrid substance which, however, is dissipated by the heat of cooking. When boiled, the tubers which are white internally, turn to a yellowish

Food value of the plant.

colour. They are used as vegetables like potatoes, and they make a most nutritious soup. An excellent starchy food, resembling arrowroot, may also be obtained by grating the tubers and washing out the starch in the manner described in the section of this chapter relating to arrowroot. There Varieties. are two principal varieties of tanias; one with green stems and leaves, and the other with purplish ones; but the The value of tubers are identical in both kinds. The young leaves
the leaves. are sometimes boiled and eaten as spinach, and the mature leaves and stalks are excellent fodder for cattle, and food for pigs.

The best soil.

Climate.

Propagation.
Soll and Climate. The best soil is a sandy loam with an abundance of organic matter in it. The plant does not do so well on clayey soils, and it does not thrive on pure sands. All warn climates are suitable for the growth of Colocasias, and they bear great extremes of heat and moisture within the tropics. They give the best returns when there is abundance of moisture, but they also bear well in dry situations.

Cultivation.-The plants are propagated in the same way as are yams. That is, when the crops are reaped, the head of the tuberous rhizome is cut off and the leaves are 
detached, leaving a few inches of the lower part of the leafstalks. These heads are then planted, and soon a number of plants bud forth from the top of the head, and produce a crop of tanias. The heads may be kept some time before planting without suffering any harm, and thus they may be carried to long distances. The land should be well ploughed Distances. up, and harrowed, and the heads set in the ground at distances of from three to four feet from each other. Or, the land may be lined off, and small holes prepared, in the usual way, for the reception of the plants. Weeds must be kept down by hoeing between the rows, and the soil should be stirred up at the same time. Tanias are often planted as Tanias as shade for young cacao plants, their large, cool, succulent leaves-which give off an abundance of watery vapouraffording an excellent shade for, and providing grateful moisture to the cacao seedlings.

CROPS.- Tanias may be planted all the year round, except The plantin very dry weather, but the usual planting searon extends ing season. from September to May, and the crops may be reaped within from nine to twelve months. One advantage of tania cultivation is that the tubers may be allowed to remain in the ground, without deterioration, for a considerable time after they are ripe, so that they can be dug up as they are required. In good land the returns are large, one head often producing Returns. enough plants to yield nearly a bushel of tanias. Altogether The value of Colocasia esculenta may be reckoned amongst the most valu- the plant. able of the food plants of the West Indies. Its tubers, as we have seen, are an important article of diet, its young leaves form a good green vegetable, its mature leaves make excellent fodder, and the whole plant-like a careful nurseprotects from adverse influences the tender seedlings of cacao, spice, and other such trees that help to build up the prosperity of the country in which they are extensively cu!tivated. 



\section{APPENDIX}

THE following Table, showing the number of plants to the acre at various distances, and the area in square feet available for each plant, will be found useful to the young planter:-

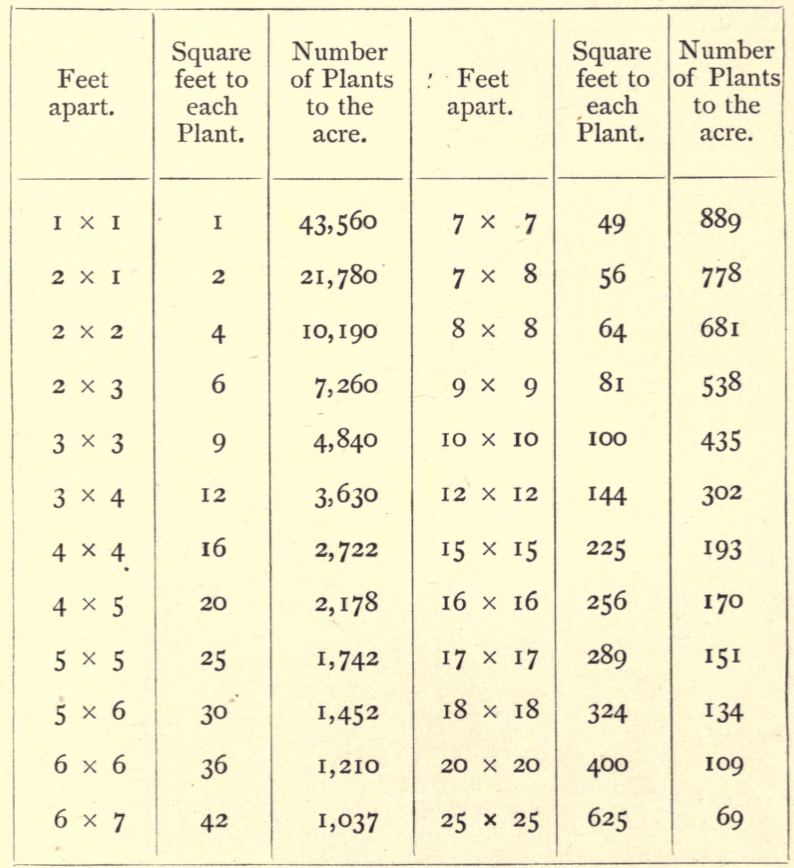





\section{N D EX}

\section{A}

Abyssinia, 9I

Acarus, 232

Acid, 24, 58

carbonic, 58, 59

humus, 18

hydrochloric, 18

nitric, 55

phosphoric, 56, 58, 62

soils, 67

sulphuric, 58,60

Action of glaciers, 5

Adeira, 283

Afou yam, 286

Agency of water, II

wind, I I

sea, 9

Agriculture, 3

Agricultural chemistry, 39

Air, 36

Albumen, 166

Alkaloids, 22I

Allspice, 188

Alluvial deposits, 9

Alluvium, I 79

Alumina, 13, 21, 25, 57 phosphate, 57

Amboyna, 184

American evaporator, 229, 239

Ammonia, 18, 22, 23, 24, 25 ,

$$
38,52,55,66
$$

oxalate, 18

sulphate, 55
Analysis of plants, 39

$$
\text { sugar, } 140
$$

Ananas sativus, 174

Anatto, 244

Anther, 208

$$
\text { masses, } 208
$$

Anthers, 29, 34

Antigua, 134, 174 pine-apple, I 74

Apricot, I 79

Aquatic rice, 270

Arabia, 48

Arabian coffee, 91, 106, 98, 100

Argillaceous soils, 15

Arid regions, 70

Aril, I 79, .184

Aristolochias, 33

Aristolochia trilobata, 34

Arnotta, 244

Arrack, 165

Arrowing of canes, 137,

Arrowroot, 44, 278

Artificial manures, 5I

Arts, 20

Aruba, 57

Ascending axis, 28

Ashes of plants, 38,6 I

Aspect, 47

Assam tea, 124

Assimilation, 78

Atmosphere, 6, 14, 22, 24, 55,

64

"At stake," r8o

Attraction, capillary, 20 
Atwood, 265

Australia, 283

Axis of plants, 27

Azores, I50, I5I

Aztecs, 203

BaHama Islands, 174

Bahamas, 144 pine-apples, I 75

Ballam rice, 269

Bamboo pots, 95

Bamboos, 44. I80, 214

Bananas, 43, I0I, I8I, 159, I60, I6I, 163, I64

roots, 235 suckers, $43, \mathrm{I} 6 \mathrm{I}$

Barbados, 134, 136, 137

Barbecues, I2I

Barham, Dr., 250

Bark shavings, 229

Batatas, 288

Bay leaves, 190 rum, 190

Beans; 35, 53

Bees, 33 Bengal, 54

Beet root sugár, 132

Beetle, 33 pests, I 7 I

Begonia, 45

Bengal, 48 beans, 54

Berlin, 32

Bermuda, 279, 283

Bétan, 220

Bitter cassava, 275

Bixa Orellana, 244

Black Antigua pine-apple, I74 ginger, 196 fungus, 105

Bleaching of ginger, 196

Bleeding of trees, 80

Blights, 64, 23I

Blood, 53
Bog, 17

Bois Immortelle, 201

Bolivia, 70, 221 , 234

Bones, 53, 56

Borer, 105

Bounties, 132

Bourbon, I 39

Brazil, I05, 203, 278, 288

Bread fruit, I 16 nut, 116

Break of tea, I 3 I

Break-wind fences, 146

Bricks, I3

Brindisi, 32

Bristle fibre, 173

British Guiana, 59, 139, 197 Honduras, 25I

Pharmacopoia, 240, 243

Broken leaf, I 29 shells, 60

Broom corn, 272

Browne, 9I

Bruised fruit, I64

Brush fibre, I 73

Buck yam, 286

Budding, 81, 82

Buds, 4I oranges, 147

Buée, I 84

Bulbs, 4I, 42

Bulking tea, 129, 130

Burnt earth, I8I

Bushes, 6I

Butterflies, 33, 216

C

CACAO, 27, 49, 50, 72, IIo, I 13,165

Criollo, II2

hooks, II 9

knives, 193

mother, I 16

Trinidad, I Io, II I

varieties, I ro

. Cajanus indicus, Ior

Cake Anatto, 247 
Calcareous manures, 54, 59 sand, 12 soils, I6, I33

Calcium, 2I, 39, 57 phosphate, 58

California, 146, 150

Calyx, 29, 34, I85

Camellia theifera, 123

Camphor, I9I

Canals, 70

Canary Islands, I 77

Cane, 50

arrows, I37

holes, 135

juice, 141

mills, I4I

plants, I34

stools, I 38

trash, 5 I

varieties, I39

Canna edulis, 283

Capillarity, 66

Capillary attraction, 20, 66, 67

Capital, 49

Caraccas, 122

Carbon, 21, 22, 37 dioxide, 2 I

Carbonic acid, 6, 13, 21, 22, 28, $38,58,59,66$

Cardamoms, 44, 196, 199 Malabar, 197

Careful pruning, 79

Careless planting, 90

Caribs, 244, 245, 249, 260

in Dominica, 245

Carolina rice, 265

Carpels, 29

Carrot, 27

Cascarilleros, 222

Cashaw, 250

Cassareep, 278

Cassava, 44,274 bread, 277 meal, 276 starch, 277

Castor oil, 63, 229 seeds, 229
Catch crop, I04, I18, I49, I55, I 69,287

Catch-work irrigation, 71

Caterpillars, 216

Cattle, 56

Caulicle, 35

Cayenne, 178

Cellulose, 39

Central America, I 10, 206, 240

Central factories, 132

Ceylon, 98, 102, I05, I10, 122, 123, I 28, I66, 190, I9I, 193, 196, 197, 199, 223, 245,248 cacao, 122

Chalk, I3, 6o

Charcoal, 2 I, 129

Chemical composition of soils, 20 elements, 20

Chemistry, agricultural, 39 of soils, 20

Chili, 56, 7o

Chili saltpetre, 56

Chillies, 278

China, I 23, 124, 1 28, 265 ware, 13

Chinese pepper growers, 202

Chlorine, 23, 24, 39, 6I

Chocolate, 203

Cinchona officinalis, 221, 222, 223,226 succirubra, 221, 223, 226

Cinchona, 221, 222, 223, 225, 229

coppicing, 227

in Jamaica, 223, 238

lopping, 227

mossing, 227, 228

shaving, 227

Chlorophyll, 39

Cinnamon, 185, 190, 191, 193

chips, 193

garden, I9I

oil, 193

Cinnamonum zeylanicum, 190

Circulation of sap, 8o

Citric acid, I 53 
Citrus family, 146

Citrus Aurantium, 144, I45

Citrus Medica var. acida, I53

Clay, 11, 12, 13, 15, 17, 21, 133

burnt, 13

varieties of, 13

Clayey loam, 185

Claying, 122

Clarifiers, 142

Classification of soils, 15

Clean soil, 72

Climate, 46, 47, 92, 113,124 , $134,146,154,161,167,180$, 188, 191, 194, 197, 200, 204, 212, 224, 230, 236, 238, 24I, 245, 25I, 263, 266, 272, 275, 279, 286, 289, 292

Clod crusher, 77

Clods, 214

Clouds, 47

Clove, I34, I85, 187 trees, 178 cured, 187 dried, 187 packing, 187

Clover, 53,63

Club-moss, 229

"Coated" ginger, 196

Cob, 26r

Coca, 234, 235

Cocaine, 235

Cocal, 172

Cocoa-nut, 35, 47, 6x, 165, 166, $167,168,170,171,172$, 173

coir, 166

milk, I66

nurseries, 168

oil, 172

pearl, 166

Coccus, I5 I, I 70, 232

Cochin China, 190, 200, 286

Cocoe, 30

Cocoes, 292

Cocos nucifera, 165

Coffea arabica, 91, 93

liberica, 9I
Coffee, 27, 49, 50, 72, 91

Arabian, 91, 93, 98, 100, 106

blights, 9x

cultivation, 9I

elevation, 92

Liberian, 98, 100, 106

parchment, 108, 109

propagation, 92

requirements, 96

soil, 91

Coir fibre, 166, I 73

Cold drawn oil, 230 soils, 67

Colocasia antiquorum, 290 esculenta, 290, 293

Colocasias, 292

Colours of flowers, 35

Columbus, 21 I , 244, 250

Column, 208

Common rice, 266 salt, $6 \mathbf{I}$

yam, 285

Compost, 52, 214

farm-yard, I81

heap, 53

Concentrated lime juice, 157

Congo pea, Ior

Congo, 130

Constituents, dormant, 62

Convolvulus, 289

Cool vapours, 47

Coppicing, I9I

Coppicing Cinchona, 227

Copra, 172

Coprolites, 57

Coral, 9, 13

sand, 12

Corolla, 29, 34

Corn, 50

broom, 272

flour, 26I

Kaffir, 272

Cotyledons, 35

Coulter, 76

Countess of Chinchon, 221

Covered drains, 68

Cow-dung, I8I 
Creeping stems, 43

Creole yam, 285

Crops, 49, 50, I 26, I38, I50, 156, 163, 171, 176, 183, 187, 189, 192, 195, 198, $202,208,236,239,242$, $246,264,269,270,276$, 280,293

coffee, I06

fodder, 63

green, 53

maize, 63

rotation, 62

Cross, Mr., 228

Cross fertilisation, 33,35 ploughing, 2I4

Crowding plants, 97

Crown grafting 84

Crude salt, $6 \mathrm{I}$

Crystal sugar, I4I

Cuba, 2II, 216

Cuban banana, I60

Cultivation, $50,125,136,148$, I49, I 55, I63, I69, I 75, I 80, 186, 192, 198, 201, 204, 215 225, 23I, 239, 242, 246, 252, $255,263,268,270,272,275$, $280,287,289,292$

Cultivators, 75,76

Curcuma longa, 248

Curing cacao, I2 I tobacco, 218 vanilla, 209

Cush-cush yam, 286

Cushions, 34

Cutlass, 73

Cutlassing, I 16

Cuttings, 44, I 95.

\section{D}

DAMP SoIL, 67

Darwin, Dr., I I

Date-palm, 32

Dates, 32

Dead leaves, 52 plants, 24

Decayed weeds, 6I
Decomposition, 38

Deep tillage, 73

Defecated juice. I42

Destructive insects, 64

Dew, 23

Dhurra, 27I

Digger, 73, 75

Digging, 72

Dioecious plants, 32

Dioscorea aculeata, 286 alata, 285 triphylia, 286

Disbudding tobacco, $2 \mathrm{I} 6$

Discoveries, scientific, 64

Dominica, 9, 10, 34, 47, 9r, 92, 98, I05, I I 2 , I I 3 , I I 6 , I 2 I, I44, I47, I49, I5 I, I 56. I57, I60, I 74, I84, I85. I86, I87, 200, 206, 224, $254,260,256,283$

Dormant constituents, 62

Double silicates, 25

Drainage, 66, I62 and fertility, 68

Drain outlets, 68

Drains, 68 open, 68 covered, 68

Dresden, 32

Dried cloves, 187

Driers, 128

Drugs, 22 I, 234, 240

Dry berry, I09 weather, 99

Drying cloves, 187 jalap, 239 pimento, 189

Dubber, 233

Dung fork, 73,75 heap, 52

Dutch, 184, 190, 200

Dyes, 244, 248, 253

\section{$\mathrm{E}$}

Earth Chisel, 73, 75 worms, II

East, 185 
Eastern Archipelago, 178

East Indies, 196, 222, 229

Eddoes, 29r

Edwards, Bryan, 24I, 254

Edwards, Z. B., 248

Effect of rain, 66

Effervescence, 18

Egypt, 48

Electricity, 23

Elements, inorganic, 63 organic, 56

Elettaria Caräamomum, 196

Embryo, 35, 36, 37

England, 177, 184

Epidermis, 28

Epiphytes, 118

Epiphytic plants, 103, 181

Equator, 46

Eugenza Jambos, 100

Europe, 144, I 53, 229

Evaporation, 24, 67

Examination of soils, I8

Excrements, 49, 5I

Exhausted soil, 50

Exhaustion, 50

Experiments, 63

Exposure, 47

Erythrina corallodendron, 201 umbrosa, 116

Erythroxylon Coca, 234, 235

\section{F}

FALLOW LAND, 62

Fallowing, 138

Famines, 71

Farm system, 137

Farm-yard compost, 181 manure, $5 \mathrm{I}, 54,55,155$

Female flowers, 32 nutmeg-trees, r8r, 182

Fermentation, 52, 108, 219

Fermenting, I 20, 127,128

Fern foliage, 54

Ferruginous soils, 59

Fertilisation, 30 by insects, 33
Fertilisation cross, 33

of flowers, 32

of vanilla, 206

Fertilising orchids, 209

Fibre, plantain, 205

Figue la rose, 160

Fiji, 26r

"Fillers," 217

Firing, 127, 128 tea, 129

First flowers, II 7

Fish, 53

Fixing ammonia, 60

Flag anatto, 247

Flat bark, 229

Flies, 34

Flint, 13

Floral envelopes, 30

Florida, 145, 146, 147, $15 \mathrm{I}$

Flowers, 27, 29, 33

Flüshes, 126

Fodder crops, 63 nitrogenous, 53

Fogs, 47

Food plants, 274, 278, 283, $284,288,290$

Forest, virgin, 179

Forests, 8, 13, 47, 49 tropical, 8

Fork, 73, 74

Formation of soils, 5

Fossil remains, 10

Fossils, 57

France, 146, 172

Free soils, 19

Friable loam, I 79

Frost, 7

Fruit, 27, 144, 153, 159, 165, 174 evaporator, 189

Fuel, 157

Functions of leaves, 28

G

Ganges, $7 \mathrm{I}$

Garbled, 183

Garden system, I37 
Gardens, tea, 125

Garrod, Dr., 24i

Gas, $3^{8}$

Gases, 21, 28

General manure, 50, $5 \mathrm{I}$

Germany, 172

Germination, 36

Ginger, 44, 194 bleaching. 196

Glacial action, 5

Glacier, 6, Io

Glands, 33, 34

Goglets, I 3

Good seed, 42

"Gormandising" stems, 103

Grades of nutmegs, I84

Grafted nutmegs, I 82

Grafting, 8I oranges, 147 by approach, 85

Grasses, 27, 28, 53

Grating manioc, 276

Gravel, 9, IO, I I

Great Britain, I 53

Green crop, 53 manure, 5I, 6I, 125

Grenada, I 13, I80

Grinding canes, I 39

Gros Michel, 160

Grubber, 76

Guadeloupe, 203. 204, 210, 274

Guango, 116

Guano, 55, 149

nitrogenous. 55

phosphatic, 55

Guiana, 244, 286

Guinea corn, 271

Gums, 39

grass, 44

yam, 286

Gutter scrapings, 52

Gypsum, 60

$\mathrm{H}$

HAMATOXYLON CAMPECHA. NUM, 250

Hail, 23
Hair, 53

Handling bananas, I64

Hardwood trees, I 6

Harrows, 75, 76, 2 [4

Hart, Mr., I Io

Harvesting, 216, 226

Havana tobacco, 2 13

Hayti, 252

Heat, 46

Himalaya Mountains, 194

Hoe, 73, 74

Holing, $73,162,148$ cacao, II 5 coffee, 98

Holland, 46

Honduras, 203

Honey, 33

Hood, 208

Hot.house pines, 174

Hullers, 108

Hulling, 108

Humboldt, 46, I 59

Humming birds, 33

Humus, I3, 16, I 7, 18, 19, 179, 205

acid, 18

Hurricanes, I I8, I49

Husking cocoa-nuts, 172

Husk of cocoa-nut, 166

Husks, 26I

Hydrochloric acid, I8, 22

Hydrocyanic acid, 275

Hydrogen, 21, 22, 39

\section{I}

Ice Remains, IO

Immortelle tree, I 6

Importance of experiments, 63

Inarching, 85 mangoes, 85

India, 7 I, I 28

Indian corn, 260 shot, 284 yam, 286

Indicum, 253

Indigo, 253, 256 
Indigofera Anil, 253 tinctoria, 253

Inflorescence, 30, 50

Ingx laurina, 100

Inorganic compounds, 38 elements, 50, 51, 63

Insect fertilisation, 33 pests, 64,65

Insecticides, 105, 151 , 170

Insects, 35

Insoluble starch, 37

Ipomaea Batatas, 288

purga, 237, 240

Ireland, $\mathbf{2 8 8}$

Iron, 2 I oxide, 39

Irrigation, 70, 162, 169, 266 works, 71

Isatis tinstoria, 253

\section{J}

JAGGERY, I 65

Jalap, 237, 238

drying, 239

Jamaica, 34, 46, 47, 110, 144, 153, 174, 188, 194, 195, 200, 224, 229, 248, 254, $265,283,286$

banana, 160

pepper, 188

sarsaparilla, 240, 243

tea, 124

Japan, 123

Jatropha Curcas, 205

Java, 196, 204, 223, 227, 285

Jesuits' bark, 22 r

Jowarrie, 272

K

KAFFir CORN, 272

Kainit, 6I

Kernel, I66

Kerosene oil, 105, 170, 210 emulsion, 232
King James I., 2 I I

Knives, cacao, 193

L

LABELLUM, 206

Laborie, IOI

Laccadive Islands, I66

Lakes, 24, 47, 70

Lamellum, 208

Lamp-oils, 230

Larvæ, 216

Latitude, 46

Law of minimums, $5 \mathrm{I}$

Layering, 4I, I86

Layers, 43

Leaf functions, 28 mould, 181 veins, 28

Leaves, 27, 28, 6r

Leguminous plants, 53

Liberian coffee, 91, 92, 98, I00, 106

Lichens, 8

Liebig, 3, 51, 57

Light, 46

Lightning, 23

Lillies, 30

Lime, 12, 1 7, 18, 21, 25, 38, 39, $53,55,58,60,63,133,263$ fruit, 153 juice, $153,154,156$ mills, 156 varieties of, 13 water, 258

Limestone, 6, 13, 60 rocks, 6

Liming nutmegs, 183

Lining, 97, 114, 175

Liquid manure, 52, 149

Litmus, 18

Loaf sugar, I4I

Loam, clayey, 185 red, 179

Loams, I 5,133

Loamy calcareous soil, I 5 sands, I 5 soils, 15 
Local soils, II

Logwood, 250, 253 chips, 252

Lopping cinchona, 227

Lowland soils, ro

Loxa bark, 223

Lubricating oil, 233

Lunan, 265

Lycopodium clavatunt, 229

\section{M}

MACE, I79, II3, I84 yield, 184

Macfadyen, Dr., 250

Machinery for tea, 129

Magnesia, 21, 39, 55, 63

Magnesium, 2I, 6 I

Maize, 27, 35, 260, 287 crops, 63 preserved, 264

Maizena, 261

Malabar, 197, 200, 286 cardamoms, 197

Malaya, 200

Malayan Archipelago, 190, 194, 288

Male flowers, 32 nutmeg trees, :81, I82

Manganese, 39

Mango, 47

Mangoes, inarched, 85

Manihot Aipi, 275 utilissima, 274, 275

Manual husbandry, 73 implements, 73

Manufacture of indigo, 256

Manufactures, 20 .

Manures, 49, 50, 52, 60, I 76 calcareous, 54, 59

farmyard, 54, 55

green crop, 6I, 125

nitrogenous, 54 phosphatic, 54, 59, 60 potash, 54,61

Manuring, I17, 140, 149, 155, 181 coffee, 103
Maranta arundinacea, 278

Marantas, 283

Marine climate, I34, I85

Maritime countries, 47 situations, 167

Market grades of cardamoms, 199

Markham, Mr. Clements, 223, 234

Marl, I7

Marley soils, 16

Marshes, 47

Martinique, I 10, 185, 25 I, 274 banana, 160

Mat fibre, 173

Matapies, 276

Materia Medica, 24I

Matters, nitrogenous, 55

Mature canes, I38

McIvor, Mr., 228

Mauritius, 178, 204, 244

Mealy bug, I05

Megass, I40, 142

Melons, 150

Metals, 20

Mexico, 203, 237

Micaceous sand, 12

Mice, Io6

Mildew, 122

Millet, 27 I

Mineral phosphates, 57

Mite, 232

Mixed cultivation, 89

Moens, M., 227

Moisture, 36, 46

Molasses, 142

Molucca Islands, 178

Moluccas, $184,185,186$

Monobasic phosphate, 58

Monœcious grass, 26I

Moonghy rice, 269

Morris, Mr. D., 90, 188, 224, 238, 242, 251

Mosses, 8, I 3

Mossing cinchona, 227

Montserrat, 153

Mother clove, I85

Moths, 33, 216 
Mould, 13 board, 76

Moulds, 52

Mountain climates, 47,175 , rice, 270 slopes, 10 soils, Io

Mountainous countries, 46

Mud, 9

Mulching, I8I

Musa paradisiaca, 159 sapientum, I 59

Muscovado sugar, 136, 141

Mushrooms, 7, 65

Mustard, 53

Myristica fragrans, I 78

Mysore cardamoms, 199
Non-metals, 20

Norfolk, 63 course of rotation, 63

North Africa, 27 I

North America, I44, I 53

North India, 123

Nuremberg, 253

Nurseries, 147, I80, I86 192, 213,214

for coffee, 94

Nutmeg, 178, 179, 180, 184, 187 grafted, 182

Nutrition, 38 of plants, 37

Nutritive substances, 28 Nuts, 183

O

\section{$\mathrm{N}$}

NATAL, 28I

Natural drainage, 67

Navassa, 57

Nectar, 33, 34

Nectaries, 34

Negro yam, 285

Nepaul, 249

Nevis, 260

New Granada, 221, 234

Nicotiana Tabacum, 2II

Nicotianine, 218

Nicotine, 218

Night-soil, 53

Nile, 71

Nilgiris, 223

Nitrate of potash, 53

Nitrates, 24

$$
\text { of soda, } 55,56
$$

Nitric acid, 22, 24, 55

Nitrogen, 6, 21, 22, 24, 38, 53, 54

Nitrogenous fodder, 53

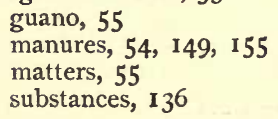

Object of Drainage, 67,68

Odours of flowers, 35

Oil, cinnamon, 193 castor, 63

Oils, lamp, 230

Open drains, 68

Operations of drainage, 68,69 of tillage, 72

Opoponax, 250

Orange, 144, 148, 152

boxes, 152

consumption, 145

flower, 29, $3 \mathbf{I}$

packing, 152

seed, 148

trade, 144

Orchids, 33

Organic, 50

acid, 24

elements, 2I, 50, 56

substances, 52

Oryza sativa, 265

Otaheite cane, I39, 140

Otranto, 32

Ovary, 29

Over-draining, 68

Overflow of rivers, $7 \mathbf{I}$ 
Overhanging shade, 146, 186

Ovules, 29, 30

Oxide of iron, 21, 39

Oxygen, 6, 21, 22, 28, 39 action of, 8

\section{P}

Packing Cloves, 187 oranges, 152 pine-apples, I 76, I 77 tea, I3 I vanilla, 209

Paddy, 266

"Palma Christi," 229

Parasitic, I8I

" Parchment," I08 coffee, 108, I09

Parenchyma, 28

Parent plant, 44

Parry, Dr., 288

Pearl of cocoa-nut, 166

Peasant proprietors, 49

Peat, I7

Peeling, 108

Pekoe, I30 souchong, I 30

Pepper, 200 Jamaica, 188 pot, 278

Perianth, 30, 182

Peru, 55, 56, 70, 22 I, 234

Peruvian bark, 22 I

Petals, 29

Philippine Islands, 285

Phosphate alumina, 57 mineral, 57 monobasic, 58 reduced, $56,58,59$ tricalcic, $5^{8}$

Phosphatic guano, 55 manures, $54,55,59,60$

Phosphoric acid, 39, 56, 58, 62

Phosphorus, 21, 39, 56

Physic-nut, 205

Pickaxe, 73, 75

Pigafetta, 288
Pigeon, 178

pea, IoI

Pig iron, 59

Pimenta acris, 190 officinalis, 188, 190

Pimento, 188 drying, 189

walk, 188

Pine-apple, I 74

Piper nigrum, 200

Pistil, 29, 33, 181

Pistillate flowers, 30, 32, 182 , 26I

Pizvarri, 274

Plantain, 43, I0I, I59, I60, I61, 163,164

fibre, 205

Plant canes, 138

egg, 35

food, $50,62,97$

leguminous, 53

life, $7,27,4$ I

roots, 7

Plants, analysis, 39

Planter's duties, 90

Planting, 99, I I 5, I $_{35}$, I $_{4} 8,{ }_{55}$ I62, 214 at stake, Ioo operations, 90 tea, 125

Plaster of Paris, 60

Ploughing, 72, 2I4

Plough pan, 76 share, 76

Ploughs, 75,76

Plumule, 35, 37

Pois doux, 100

Poles, 46

Pollen, 29, 33, I8I grains, 35 masses, 208

Pollination, 33

Polynesia, I65

Ponds, 70

Poonac, I66, I73

Porcupine wood, 165

Porosity, 66

Porous earthenware, 67 
Porous soil, 66

Porter, 186, 265, 273

Portuguese, 190

Potash, 21, 25, 38, 39 carbonate, 18 manures, 54, 6I nitrate of, 53 salts, $6 \mathbf{I}$

Potassium, 21, 24, 6I

Potato crops, 60

Potatoes, 64

Pots, I3

Prairies, 49

Preparation of arrowroot, 28I of land, I 44

Preserved maize, 264

Press, 220

Primaries, 103

" Prince of Palms," I 65

Products, waste, 53,56

Propagation, 8I, I25, I34, I47, 154, I6I, I68, 175, 180, I9I, 195, 200, 204, 213, 224, 236, 238, 241, 246, $25 \mathrm{I}$

by seeds, 4 I

of cacao, I 13

of coffee, 92

Protoplasm, 39

Pruning, 78, 79, 80, 150, 155, I 81

cacao, I 16

coffee, IO2

rules, 79

tea, 126

Prussic acid, 275

Pulping coffee, 107

Pumpkins, 150

\section{Q}

QUARTZ, I 3 sand, 13

Queen pine-apple, 174

Quicklime, 60, I5I

Quill bark, 229

Quinine, 22I
$\mathrm{R}$

RACES, I94, 195

Radicle, 35

Rags, 53

Rain, 23, 24, 55

Rainfall, I80

Rainless tracts, 70

Rajania pleioneura, 284

Rake, 73

Raleigh, 2I I

Rat coffee, 106

Rats, 106, I7 I

Rattoons, I38

Raw lime juice, 153 sugar, I4I

Red bark, 223 loam, 179 peppers, 278

Redonda, 57

Reduced phosphates, 56, 58, 59

Remains of animals, Io in ice, 10

Réunion, 204, 244

Rhizomes, 194, 279

Rice, 265 aquatic, 270

Ballam, 269

common, 266

Carolina, 265

Moonghy, 269

mountain, 270

tabie, 269

Ricinus communis, 229

Ripley pine-apple, I 74

Rivers, 9, 24, 70 action of, 9

Robber stems, 79, 103

Robinson, Sir W., 212

Rochfort, 245

Rock-crystal, 13

Rocks expanding, 7

Rollers, 75, 77

Rolling, 127, 128

Root, 27, 37

bark, 229

fibres, 27

functions, 2 
Root hairs, 24, 28, 37, $3^{8}$

Roots in rocks, 7

Rose apple, 100

Roseau Valley, I I I

Rotation of crops, 62

Norfolk course, 63

system, 79

Roucou, 244

Royal Gardens, Kew, 90, 91, 223

Royle, Dr., 222

Rules for pruning, 79

Runners, 4I, 43

Rust on oranges, $15 \mathbf{I}$

Rye, 53

\section{S}

SACCHARUM OFFICINARUM, 132 Saddle grafting, 84

St. Kitts, 54, I33, 260, 283

St. Martin, 57

St. Vincent, 279, 282, 283

Salicylic acid, 157

Saline atmosphere, 167

Salt, 38 crude, $6 \mathrm{r}$

Saltpetre, Chili, 56

Saman trees, 116

San Domingo, IOI

Sand, II, I8

Sands, I 2

calcareous, I2

coral, 12

micaceous, 12

quartz, I3

Sandy calcareous soil, 16 deserts, 48

loams, 15,17

soils, I6, 50

Sap, 78

Sarsaparilla, 240

Savannahs, 49

Saw-dust, 53

Scale blight, I05

insect, I 5 I, 170

Schübler, 17

Scientific discoveries, 64

Scion, 82,182
Scraped ginger, 196

Scurvy, I 53

Sea, 9, 23, 47

breezes, 167

level, 47

salt, 23 water, $55,6 \mathrm{I}$

Sea-weed, 54

Seas, 24

Secondaries, 103

Sedentary soils, I I

Seed, 28, 35, 4I

cake, 52 envelopes, 30

Seeding trees, $8 \mathrm{I}$

Seeds, propagation, $4 \mathrm{I}$

Sepals, 29

Seychelles, 204

Shade, 100, I I 5, I 8 I

belts, II 4

Shaving cinchona, 227

Shell insects, 105 sands, 12

Shelled corn, 264

Shelter belts, 48, 100, 125, 154 sheds, 186

Siam, 200

Siberia, Io

Silica, I3, 21, 25, 39, 62

Silicon, 2I

Silver-skin, I08

Simmonds, Mr. P. L., 282

Slag, Thomas Gilchrist, 59

Slaked-lime, 60, I 7 I

Slopes of mountains, Io

Smilax officinalis, 240, 243

Smoke, 2 I

Smooth Cayenne pine-apple, 174

Snow, 23

Soda, 2 I, 25, 39 nitrate, 55,56

Sodium, 2I, 6I

Soft soap, I7o

Soil, I I 2, I 24, I 33, I46, I 54, I60, I67, 185, I88, 19I, 194, 197, $200,204,-223,230,236,238$, 24I, 245, 25I, 262, 265, 266, $272,275,279,286,289,292$ 
Soil exhausted, 49

fertilised by worms, 12

submarine, 9 surface, I I

Soils, 5, I7, 49

Soils, active constituents, 24

classes, 15

classification, I5, I7

clay, 15

constituents, 4, 9, 12

distribution of, Io

dormant constituents of, 24

examined, 18

ferruginous, 59

heavy, I9

how formed, 5

light, I 9

loamy, I7

local, II

lowland, io

mechanically tested, 18

mountain, IO

stiff, 19

transported, I I

vegetable, 60

Sombrero, 57

Sorghum saccharatum, 272 vulgare, 271

Sorting tea, I 30

Souchong, 130

Soudan, 271

Sour soils, 67

South America, I Io, I 88, I94, $206,236,265,288$

American Andes, 234

Southern India, 196, 200

United States, 229

Spadic, 234

Spain, 21 I, 228

Spanish Islands, 212

Spathe, 30

Special manures, 50, 54

Sphinx quinquemaculatus, 216

Spice Islands, I 84

Spices, I78, 194

Spruce, Mr. R., 223

Spurs, 34

Staking plants, 100
Stamens, 29, 33

Staminate flower, $30,32,182$, $26 \mathrm{I}$

Starch, 39

Stem, 27, 28

Stem-cut oranges, I5I

Sterile branches, 97

Stiff soils, 19

Stigma, 29, 33, 34, 208

Stocks, 8 I

Stomata, 28

Stone cisterns, 257 mullers, 260

Stones, 12 in soils, 14

Stools, 138, 163

Straits Settlements, 200

Straw, 5 I

Strawberry, 43, 47

Style, 29

Sub-soil, I I plough, 76 ploughing, 73

"Suckering" tobacco, 21 5, 216

Suckers, 41, 43, 79, I63, I75, I $8 \mathrm{I}$

Sugar, 38, 39

analysis, I 40

bounties, 132

cane, $44,47,6 \mathrm{I}, \mathrm{I} 32$

Sugar-loaf pine-apple, I 74

Sulphate of ammonia, 55 of calcium, $5^{8}$ of lime, 60

Sulphur, 21

Sulphuric acid, 22, 24, 39, 58, 60

Superphosphates, 56, 60, 263

Supplies, I 36

Surface feeders, 64 soil, I I

Surinam, I I 9

Surplus water, 67

Sweating, I 20

Sweet cassava, 572 juices, 34 potatoes, $44,63,288$

Swizzle stick, I7 I

Syria, 271 


\section{$\mathrm{T}$}

TAble Rice, 269

Tahiti, 204

Tanias, 30, 63, 64, 290

Taniers, $29 \mathrm{I}$

Tannias, 29I

Tanniers, 29I

Tapioca, 274, 277

Tap-roots, 27

Tea, I 23

Assam, 124

chests, I29, I3 I

China, I 24

"gardens," 125

Jamaica, I 24 machinery, 129

varieties, I 24

Teache, 142

Temperature, variation of, 7

Temporary shade, 99

Tennant, Emerson, I66

Theobroma Cacao, i Io

Thermometer, 46 ,

Thinning out, 78

Thomas Gilchrist Slag, 59

Threshing millet, 273

Thunder storms, 23

Tillage, 50, 63

operations, 25,72

Tobacco, 2II, 2I2, 2I3, 2I4, 220

curing, 2I6, 218

decoction, I5 I

house, II 7

Toddy, 165

Tongue grafting, 84

Topping coffee, 102 tobacco, 2I 5

Tortillas, 260

Tous-les-mois, 283,284

Transported soils, II

Trashing canes, I 37

Travancore, 200, 203

Trenching, 195

Tribasic phosphate, 58

Tricalcic phosphate, $5^{8}$
Trinidad, I21, 153, 197, 200, 212,283 cacao, IIO, III

Tropical America, 274 cereals, 260 forests, 8

Trumpet tree, I 16

Tubers, 4I, 42, 238

Turkeys, 216

Turmeric, 248 paper, 249

Turn furrow, 76

Turnips, 53, 53

Typical cacao tree, I I 7

$\mathrm{U}$

UNASSORTED TEA, I 20

"Uncoated" ginger, I96

United States, I44, I52, I53, I60, I 74, 260

Unrolled tea, 129

"Unscraped" ginger, 196

Unslaked lime, I42

Usines, I32

\section{V}

VALlEys, 47

Vanilla, 203, 205, 206 . beans, 203 curing, 209

fertilisation, 206 orchid, 206 vine, 204

Vanilla planifolia, 203

Vapour, 21, 23, 38, 60

Vapours, 47

Variation in plants, 4I

Variations of temperature, 7

Varieties, cacao, 1 I0

Vegetable blights, 64,65

matter, 12, I3

mould, I3

soil, 16, 60

tissue, 28

Vegetation, 7

Veins, 28 
Venezuela, I22

Vermin, 106

Vetches, 53

Vine, vanilla, 204

Virgin forest, I 79

Voleanic agency, 9

Volcanoes, 23

Vuelta-Abajo, 212

\section{W}

WARMTH, 36

Washing, I08

Waste products, 53,56

Wasteful cultivation, I I4

Watering plants, IOO

Watery vapour, 28

Waves, action of, 9

Waw-waw, 284, 285

Weather, 53

Weathering, 6

Wedge grafting, 84

Weeding, 192 cacao, 116 coffee, IOI

Weeds, 52, 60

Wells, 70

West India fruits, 42

Wheat, 63

Whip grafting, 84

White fly, 105 ginger, 196 pepper, 203 yam, 285

Wickerwork trays, 183

Wind, 9 action of, 9

fertilisation, 32
Wind-blown pollen, 32

Wind-carried pollen, 32

Winds, 23

Winnowing coffee, Io9

Withering, 127

Woad, 253

Woodashes, 6I, I49, 214, 263

Wool, 53

Works of irrigation, 7I

Worm burrows, 12 castings, I2

Worming, 216

Worms and tobacco, 216

Wrappers, 217

Wrapping oranges, 152

Wrightson, Mr., I 7

\section{$\mathrm{X}$}

XALAPA, 237

\section{Y}

Y AM, 284, 285, 288 tubers, 42

Yams, 63

Yellow dye, 248

Yield of arrowroot, 28I coffee, 107 mace, 184

\section{Z}

Zea Mays, 260

Zingiber officinale, I94

THE END 

Gen.Lib.

$$
\text { Ag.R.S. } 7 \text { DAY USE }
$$

RETURN TO DESK FROM WHICH BORROWED

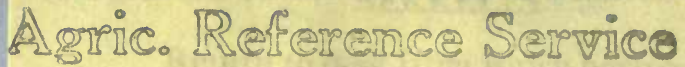

This publication is due on the LAST DATE low. stamped below.
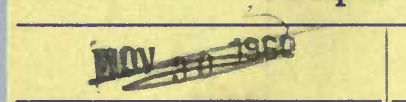

LD 2: 


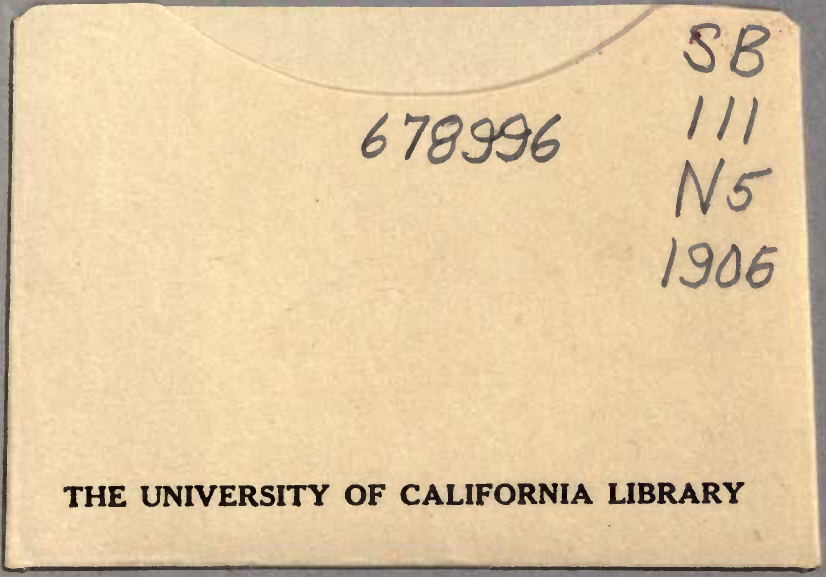


